\title{
Die vollständige Entschlüsselung der Genomsequenz des Tetanus-Erregers Clostridium tetani und die Analyse seines genetischen Potentials
}

\author{
Dissertation \\ zur Erlangung des Doktorgrades \\ der Mathematisch-Naturwissenschaftlichen Fakultäten \\ der Georg-August-Universität zu Göttingen
}

vorgelegt von

Holger Brüggemann

aus Neuenhaus

Göttingen, 2002 
D7

Referent:

Prof. Dr. G. Gottschalk

Korreferent:

Prof. Dr. B. Bowien

Tag der mündlichen Prüfung: $\quad 30.01 .2003$ 


\section{Inhaltsverzeichnis}

Abkürzungsverzeichnis $\quad$ VII

1. Einleitung 1

2. Material und Methoden

2.1 Organismen und Plasmide

2.2 Nährmedien, Puffer und Stammlösungen 6

2.2.1 Komplexmedium für C. tetani 6

2.2.2 Medien für E. coli 7

2.2.2.1 LB (Luria-Bertani)-Medium 7

2.2.2.2 TB-Medium 7

2.2.3 Medienzusätze 7

2.2.4 Stamm- und Pufferlösungen 8

$\begin{array}{lll}2.3 & \text { Zellanzucht und Stammhaltung } & 8\end{array}$

2.3.1 Zellanzucht von C. tetani 8

2.3.2 Zellanzucht von E. coli 9

2.3.3 Stammhaltung 9

$\begin{array}{lll}2.3 .4 & \text { Reinheitskontrolle } & 10\end{array}$

$2.4 \quad$ Standardtechniken für das Arbeiten mit Nukleinsäuren $\quad 10$

2.4.1 Behandlung von Geräten und Lösungen 10

2.4.2 Reinigung und Konzentrierung von Nukleinsäuren 10

2.4.2.1 Phenol/Chloroform-Extraktion 10

2.4.2.2 Fällung von Nukleinsäuren 10

2.4.2.3 Mikrodialyse von DNA 11

2.4.3 Konzentrationsbestimmung und Reinheitskontrolle von DNA 11

2.4.4 Standard-Agarose-Gelelektrophorese 12

2.4.5 Größenbestimmung von Nukleinsäuren 13 
2.5.1 Isolierung genomischer DNA aus C. tetani mit dem

AquaPure ${ }^{\circledR}$-Kit $\quad 14$

2.5.2 Isolierung genomischer DNA nach MARMUR, $1961 \quad 15$

$\begin{array}{lll}2.5 .3 & \text { Isolierung von Plasmid-DNA } & 16\end{array}$

2.5.3.1 Isolierung von Plasmiden mit sehr niedriger Kopienzahl/Zelle 16

$\begin{array}{lll}\text { 2.5.3.2 Schnellpräparation von Plasmid-DNA } & 18\end{array}$

$\begin{array}{lll}\text { 2.5.3.3 Robotgesteuerte Plasmidpräparation } & 18\end{array}$

2.5.4 Robotgesteuerte Cosmidpräparation 19

2.5.5 Isolierung von DNA-Fragmenten aus Agarosegelen 20

2.5.6 Aufreinigung von PCR-Produkten 20

2.6 Enzymatische Modifikation von DNA 20

2.6.1 Spaltung von DNA durch Restriktionsendonukleasen 20

2.6.2 Dephosphorylierung von DNA-Fragmenten 21

2.6.3 Herstellung von glatten Enden ("blunt ends") und Phosphorylierung von 5'-Hydroxyl-Enden bei DNA-Fragmenten 21

2.6.4 Ligation von DNA-Fragmenten 22

2.7 Übertragung von DNA in E. coli und Selektion rekombinanter Klone 23

2.7.1 Transformation in E. coli durch Elektroporation 23

2.7.2 Blau-Weiß-Test zur Selektion rekombinanter E. coli-Klone 24

$2.8 \quad$ Polymerase-Kettenreaktion (PCR) 25

$2.9 \quad$ Herstellung von Genbanken 26

2.9.1 Herstellung einer Plasmid-Genbank 26

2.9.2 Herstellung einer Cosmid-Genbank 28

$2.10 \quad$ Sequenzierung von DNA 31

2.10.1 Sequenzierung mit ABI DNA Sequencer 377

2.10.2 Sequenzierung mit dem MegaBACE 1000 Capillar Sequencer 34 
2.11 Die Prozessierung von Rohsequenzen

2.11.1 Einführung in die Prozessierung von Rohsequenzen mittels des STADEN-Software-Pakets $\quad 35$

2.11.1.1 Pregap4 36

$\begin{array}{lll}2.11 .1 .2 & \text { Gap4 } & 37\end{array}$

2.12 Methoden zur Überwindung von Sequenzlücken in einem Genomsequenzierungsprojekt 38

2.12.1 Identifikation von Contigüberlappe mit Gap4 oder BLASTN 38

2.12.2 Primer-Walking 38

2.12.3 PCR-basierte Methoden 39

2.12.4 Lückenschluss unter Zuhilfenahme der Genomannotation 40

$\begin{array}{lll}2.13 & \text { Sequenzanalyse } & 41\end{array}$

2.13.1 ORF-Vorhersage 41

2.13.2 Genomweite Annotation mit ERGO 42

2.14 Standardtechniken zum Arbeiten mit Proteinen 45

2.14.1 Bestimmung der Proteinkonzentration 45

2.14.2 Bestimmung der Molekularmassen von Proteinen 45

2.14.3 Polyacrylamidgelelektrophorese (PAGE) von Proteinen 46

2.14.4 Silberfärbung (BLUM et al., 1987) 48

2.15 Chemikalien, Enzyme und Gase 50

3. Experimente und Ergebnisse 52

3.1 Sequenzierung des Plasmids pE88 aus $C$. tetani E88 52

3.1.1 Isolierung des Plasmids pE88 aus C. tetani E88 52

3.1.2 Strategie der Sequenzierung von pE88

3.2 Analyse der Sequenz des Plasmids pE88 55

3.2.1 ORF-Vorhersage für pE88 55 
3.2.2 Annotation der Plasmidsequenz: genetische Karte und $\begin{array}{ll}\text { Annotationstabelle } & 57\end{array}$

3.2.3 Allgemeine Merkmale der Plasmidsequenz 61

3.2.4 Analyse zur Identifikation des Replikationsursprungs 61

3.2.5 Toxine auf pE88: Tetanus-Toxin und Collagenase 63

3.2.6 Regulatorische Funktionen 64

3.2.6.1 TetR, der Transkriptionsaktivator des Tetanus-Toxins 64

3.2.6.2 Regulatorische Proteine mit Homologien zu RNA-Polymerase$\begin{array}{ll}\text { Sigmafaktoren } & 65\end{array}$

3.2.6.3 Zwei-Komponenten-System 70

$\begin{array}{lll}3.2 .7 & \text { Transportfunktionen } & 73\end{array}$

3.2.8 Replikationsfunktionen und mobile Elemente $\quad 77$

$\begin{array}{lll}3.2 .8 .1 \quad \text { Replikationsproteine } & 77\end{array}$

3.2.8.2 Mobile Elemente 78

$\begin{array}{lll}3.2 .9 & \text { Sonstige Funktionen } & 79\end{array}$

3.2.9.1 23S rRNA(Guanin-N1)-Methyltransferase 79

3.2.9.2 Aminopeptidasen 79

3.3 Sequenzierung des Chromosoms von C. tetani E88 81

3.3.1 Sequenzierungsstrategie: Die Shotgun-Methode 81

3.3.2 Phase 1: Rohsequenzierung und Assemblierung 82

3.3.3 Phase 2: Editierung und Primer-Walking 85

3.3.3.1 Auflösung fehlerhafter Assemblierungen 86

$\begin{array}{lll}\text { 3.3.3.2 Editierung der Consensus-Sequenz } & 87\end{array}$

3.3.3.3 Primer-Walking über Sequenzlücken 88

3.3.3.4 Lückenschluss mittels Abgleich der Contigenden 88

3.3.4 Phase 3: Schließen verbleibender Sequenzlücken 88

3.3.4.1 Lückenschluss unter Zuhilfenahme einer Cosmid-Genbank 89

3.3.4.2 Lückenschluss unter Zuhilfenahme der kombinatorischen

3.3.4.3 Lückenschluss unter Zuhilfenahme der genomweiten Annotation $\quad 90$

3.3.4.4 Die letzten Sequenzlücken in Regionen repetitiver DNA-Abschnitte 91 
3.4

3.4 .5

3.4.5.1

3.4.5.2

3.4.6.1

3.4.6.2

3.4.6.3

3.4.7.1

3.4.7.2

3.4.9.1

3.4.9.2

3.4.9.3

3.4.9.4

3.4.9.5

3.4.9.6

3.4.9.7

3.4 .10

3.4.10.1

3.4.10.2

3.4.11

3.4.11.1

3.4.11.2

3.4 .12

3.4 .13

3.4.13.1

3.4.13.2
Sequenzanalyse des Chromosoms von C. tetani E88

95

Allgemeine Merkmale der Sequenz des Chromosoms 95

ORF-Vorhersage 96

Übersicht über die Annotation des Chromosoms 97

Identifizierung des Replikationsursprungs 99

Toxine und weitere Virulenzfaktoren 103

Bekannte Virulenzfaktoren 103

Zelloberflächenproteine 104

Metabolismus 1: Substratverwertung 106

Vergärung von Zuckern: Glykolyse und Pentosephosphat-Weg 107

Vergärung von Aminosäuren 107

Verwertung von Lipiden $\quad 109$

Metabolismus 2: Verstoffwechselung von Pyruvat 110

$\begin{array}{ll}\text { Pyruvat:Ferredoxin-Oxidoreduktase } & 110\end{array}$

$\begin{array}{ll}\text { Der Butyrat-Weg } & 111\end{array}$

Bioenergetik 1:Substratkettenphosphorylierung 112

Bioenergetik 2: Membrangebundene Prozesse 113

Das Nqr/Rnf-System 114

$\begin{array}{ll}\text { V-Typ-ATPasen } & 115\end{array}$

Das NatAB-System 116

V-Typ-H $\mathrm{H}^{+}$-Pyrophosphatase 117

$\mathrm{H}^{+} / \mathrm{Na}^{+}$-Antiporter 117

Das Mrp-ähnliche System 117



Weitere membranassoziierte Komplexe 119

Fumarat-Reduktasen $\quad 119$

CO-Dehydrogenase-System und Häm-Oxygenase 120

$\begin{array}{ll}\text { Transportsysteme } & 122\end{array}$

ABC-Transporter 123

Membranpotential-abhängige Transporter 124

Systeme des Proteinexports und exportierte Proteine 125

Regulatorische Funktionen $\quad 129$

$\begin{array}{ll}\text { Transkriptionsregulatoren } & 129\end{array}$

Zwei-Komponenten-Systeme 130 
$\begin{array}{lll}\text { 3.4.13.3 RNA-Polymerase-Sigmafaktoren } & 133\end{array}$

$\begin{array}{lll}\text { 3.4.14 Mobile Elemente und Prophagen } & 135\end{array}$

4. Diskussion

4.1 Vergleichende Sequenzanalyse der Genome von pathogenen und nicht-pathogenen Clostridien

4.1.1 Stand der Genomforschung von Organismen der Gattung Clostridium

4.1.2 Verwandtschaft clostridieller Genome

4.1.2.1 Phylogenetische Betrachtungen anhand von 16 S rRNA-Sequenzen

4.1.2.2 Phylogenetische Betrachtungen anhand von TriosephosphatIsomerase- und Elongationsfaktor EF-Tu-Sequenzen

4.1.3 Genomweiter Vergleich von C. acetobutylicum und C. perfringens mit C. tetani

4.1.3.1 Vergleich der Genome auf Proteinebene

4.1.3.2 Kandidaten-Gene für eine pathogene Lebensweise clostridieller Organismen

4.1.3.3 Kandidaten-Gene für Tetanus-spezifische Funktionen 148

$\begin{array}{lll}\text { 4.1.4 Natrium-abhängige Prozesse in C. tetani } & 150\end{array}$

4.1.4.1 Mögliche Involvierung des Nqr/Rnf-Systems in die $\mathrm{Na}^{+}$-Bioenergetik

4.1.4.2 $\quad \mathrm{Na}^{+}$-Bioenergetik und Virulenz

$\begin{array}{lll}\text { 4.2.1.1 Tetanus-Toxin } & 156\end{array}$

$\begin{array}{llr}\text { 4.2.1.2 Collagenase } & 159\end{array}$

$\begin{array}{lll}\text { 4.2.1.3 Tetanolysin O } & 162\end{array}$

4.2.1.4 S-Layer-Proteine als möglicher Virulenzfaktoren 166

4.2.2 Übersicht über die metabolischen Fähigkeiten sowie andere zelluläre Funktionen 
4.3

Ausblick

175

5.

Zusammenfassung

176

6. Literaturverzeichnis

180 


\section{Abkürzungsverzeichnis}

A

Abb.

$\mathrm{ABC}$

Amp

APS

ATP

As

$B$.

BD

BLAST

BLASTN

BLASTP

BoNT

bp

bzw.

${ }^{\circ} \mathrm{C}$

C.

C

ca.

$\mathrm{cm}$

$\mathrm{Cm}$

CoA

CTC

CTP

C-terminal

Da

d. h.

dest.

DNA

dNTP

E.

E-Cup
Adenin

Abbildung

ATP-bindende Kassette, ATP-binding cassette

Ampicillin

Ammoniumpersulfat

Adenosin-5'-triphosphat

Aminosäure(n)

Bacillus

Big dye ${ }^{\circledR}$

Basic Local Alignment Search Tool

BLAST auf Nukleotidebene

BLAST auf Proteinebene

Botulinus-Toxin(e)

Basenpaar(e)

beziehungsweise

Grad Celcius

Clostridium

Cytosin

circa

Zentimeter

Chloramphenicol

Coenzym A

C. tetani-Chromosom

C. tetani-Plasmid

carboxyterminal

Dalton

das heißt

destilliert

Desoxyribonukleinsäure

Desoxyribonukleotid-5'-triphosphat

Escherichia

Eppendorf-Reaktionsgefäß 


\begin{tabular}{|c|c|}
\hline EDTA & Ethylendiamintetraessigsäure \\
\hline et al. & et alteri, und andere \\
\hline Fa. & Firma \\
\hline FAD & Flavinadenindinukleotid \\
\hline FeS-Cluster & Eisen-Schwefel-Cluster \\
\hline FMN & Flavinmononucleotid \\
\hline $\mathrm{g}$ & Gramm \\
\hline $\mathrm{G}$ & Guanin \\
\hline GABA & $\gamma$-Aminobutyrat \\
\hline Gap & Genomassemblierungsprogramm, genome assembly program \\
\hline GLIMMER & Gene Locator and Interpolated Markov Modeler \\
\hline $\mathrm{GmbH}$ & Gesellschaft mit beschränkter Haftung \\
\hline $\mathrm{xg}$ & -fache Erdbeschleunigung $\left(9,81 \mathrm{~m} / \mathrm{s}^{2}\right)$ \\
\hline $\mathrm{h}$ & Stunde \\
\hline $\mathrm{H}^{+}$ & $\operatorname{Proton}(\mathrm{en})$ \\
\hline Hrsg. & Herausgeber \\
\hline HPLC & high performance liquid chromatography \\
\hline i. d. R. & in der Regel \\
\hline IPTG & Isopropyl- $\beta$-thiogalactopyranosid \\
\hline IS & Insertionssequenz(en) \\
\hline $\mathrm{k}$ & Kilo \\
\hline $\mathrm{kb}$ & Kilobasenpaare \\
\hline $\mathrm{kDa}$ & Kilodalton \\
\hline$L$. & Listeria \\
\hline 1 & Liter \\
\hline LB & Luria-Bertani \\
\hline$\mu$ & Mikro \\
\hline$M$. & Mycobacterium \\
\hline $\mathrm{M}$ & Molar (Mol pro Liter); Mega $\left(10^{6}\right)$ \\
\hline $\mathrm{m}$ & Meter; milli- $\left(10^{-3}\right)$ \\
\hline $\mathrm{MCS}$ & multiple Klonierungsstelle, multiple cloning site \\
\hline $\min$ & Minute \\
\hline mol & Mol \\
\hline $\mathrm{n}$ & Nano \\
\hline
\end{tabular}




\begin{tabular}{|c|c|}
\hline$N$. & Neisseria \\
\hline $\mathrm{Na}^{+}$ & Natrium \\
\hline $\mathrm{NAD}(\mathrm{H})$ & Nicotinamidadenindinukleotid (reduzierte Form) \\
\hline $\mathrm{NCBI}$ & National Center for Biotechnology Information \\
\hline NCTC & National Collection of Type Cultures \\
\hline Nqr & NADH-Ubichinon-Oxidoreduktase \\
\hline Nr. & Nummer \\
\hline N-terminal & aminoterminal \\
\hline OD & Optische Dichte \\
\hline ORF & offener Leserahmen, open reading frame \\
\hline PCR & Polymerasekettenreaktion, polymerase chain reaction \\
\hline PFAM & Datenbank für Protein-Familien und Hidden-Markov-Modelle \\
\hline $\mathrm{pH}$ & negativer dekadischer Logarithmus der Protonenkonzentration \\
\hline RNA & Ribonukleinsäure \\
\hline Rnf & Rhodobacter specific nitrogen fixation \\
\hline rRNA & ribosomale Ribonukleinsäure \\
\hline RT & Raumtemperatur \\
\hline $\mathrm{s}$ & Sekunde \\
\hline$S$ & Streptococcus \\
\hline Sa. & Salmonella \\
\hline S. & siehe \\
\hline S. 0 . & siehe oben \\
\hline s. u. & siehe unten \\
\hline SDS & Natriumdodecylsulfat \\
\hline $\mathrm{Sec}$ & Sekretion \\
\hline S-Layer & Zelloberfläche, Surface-Layer \\
\hline sp. & species \\
\hline$T$. & Thermoanaerobacter \\
\hline $\mathrm{T}$ & Thymin \\
\hline TEMED & N, N, N', N'-Tetramethylethylendiamid \\
\hline TeTx & Tetanus-Toxin \\
\hline $\operatorname{Tm}$ & Schmelztemperatur \\
\hline $\mathrm{TM}$ & transmembrane Helix/Helices \\
\hline Tris & Tris-(hydroxymethyl-)aminomethan \\
\hline
\end{tabular}




$\begin{array}{ll}\text { U } & \text { Unit (Einheit der Enzymaktivität) } \\ \text { ü. N. } & \text { über Nacht } \\ \text { Upm } & \text { Umdrehungen pro Minute } \\ \text { v/v } & \text { Volumen pro Volumen } \\ V . & \text { Vibrio } \\ \text { V } & \text { Volt } \\ \text { VAMP } & \text { Vesikel-assoziiertes Membranprotein } \\ \text { V-Typ } & \text { vakuolärer Typ } \\ \text { w/v } & \text { Masse pro Volumen } \\ \text { X-Gal } & \text { 5-Brom-4-Chlor-3-Indolyl-D-Galactosid } \\ Y . & \text { Yersinia } \\ \text { z. B. } & \text { zum Beispiel }\end{array}$

\section{Aminosäuren}

$\begin{array}{llllll}\text { A } & \text { Ala } & \text { Alanin } & \text { M } & \text { Met } & \text { Methionin } \\ \text { C } & \text { Cys } & \text { Cystein } & \text { N } & \text { Asn } & \text { Asparagin } \\ \text { D } & \text { Asp } & \text { Aspartat } & \text { P } & \text { Pro } & \text { Prolin } \\ \text { E } & \text { Glu } & \text { Glutamat } & \text { Q } & \text { Gln } & \text { Glutamin } \\ \text { F } & \text { Phe } & \text { Phenylalanin } & \text { R } & \text { Arg } & \text { Arginin } \\ \text { G } & \text { Gly } & \text { Glycin } & \text { S } & \text { Ser } & \text { Serin } \\ \text { H } & \text { His } & \text { Histidin } & \text { T } & \text { Thr } & \text { Threonin } \\ \text { I } & \text { Ile } & \text { Isoleucin } & \text { V } & \text { Val } & \text { Valin } \\ \text { K } & \text { Lys } & \text { Lysin } & \text { W } & \text { Trp } & \text { Tryptophan } \\ \text { L } & \text { Leu } & \text { Leucin } & \text { Y } & \text { Tyr } & \text { Tyrosin }\end{array}$




\section{$1 \quad$ Einleitung}

Die Entschlüsselung kompletter Genome ist erst seit einigen Jahren durch die Entwicklung neuer, halbautomatischer DNA-Sequenziermaschinen möglich geworden. Die Sequenzierung der Genome humanpathogener Bakterien hat dabei einen besonderen Stellenwert, da die Genomsequenz und das daraus abgeleitete genetische Potential wichtige Erkenntnisse in Bezug auf die Entstehung und Ausprägung der Pathogenität eines Erregers vermitteln. Diese Erkenntnisse können direkt zur Entwicklung effizienter Abwehrstrategien gegen Erreger genutzt werden; sie kommen letztlich über neue Therapien betroffenen Patienten zugute.

Im Rahmen dieser Arbeiten sollte das Genom des humanpathogenen Erregers Clostridium tetani vollständig sequenziert werden. C. tetani ist der Verursacher der Tetanus-Krankheit, gemeinhin auch Wundstarrkrampf genannt. Diese Erkrankung ist weltweit verbreitet und kann sowohl bei Menschen wie auch bei Wirbeltieren auftreten. Sie ist zudem schon sehr lange bekannt, die ältesten überlieferten Befunde dieser Krankheit stammen aus dem 4. Jahrhundert vor der Zeitrechnung (TIZZONI \& CATTANI, 1890). Die Manifestation der Krankheit, die spastische Paralyse, wird durch ein von C. tetani gebildetes Gift ausgelöst, dem Tetanus-Toxin, auch Tetanospasmin genannt. Dieses Neurotoxin ist nach dem Botulinus-Toxin - gebildet durch den nah verwandten Organismus C. botulinum - die zweitgiftigste aller der Menschheit bekannten Substanzen. Die letale Dosis beträgt etwa $1 \mathrm{ng} / \mathrm{kg}$ Körpergewicht (GILL, 1982). Glücklicherweise gibt es seit etwa 1940 einen hochwirksamen Impfstoff, das Tetanus-Toxoid, ein durch Formaldehyd-Behandlung inaktiviertes Tetanus-Toxin, welches in einem Fermentationsprozess aus einer C. tetani-Kultur gewonnen wird (WASSILAK et al., 1999). Nahezu jeder Mensch der industrialisierten Welt wird mehrmals in seinem Leben gegen Tetanus geimpft. So treten TetanusFälle in diesen Ländern nur sporadisch auf. In Entwicklungsländern allerdings gibt es laut einer Studie der WHO (Weltgesundheitsorganisation) über 400000 Fälle pro Jahr, in erster Linie Fälle von neonatalem Tetanus (WHO, 2000). Bei dieser Art des Tetanus infizieren sich Neugeborene von nicht geimpften Müttern aufgrund mangelnder Hygiene. Die Tetanus-Krankheit fordert jährlich nach Schätzungen etwa 280000 Todesopfer. Laut WHO ist diese Erkrankung bei Kindern die zweithäufigste 
Todesursache unter den durch Vakzination kontrollierbaren Krankheiten weltweit. Sie wird zudem in etwa 90 Entwicklungsländern als endemisch angesehen (WHO, 2000).

Der Tetanus-Erreger C. tetani ist ein Gram-positives, stäbchenförmiges Bakterium, dessen natürliche Habitate der Boden und der Intestinaltrakt vieler Tiere sind. Der Organismus gehört zur Gattung Clostridium, deren Vertreter definitionsgemäß Sporen bilden können, hauptsächlich einen anaeroben Gärungsstoffwechsel betreiben und nicht zur dissimilatorischen Sulfatreduktion befähigt sind (BERGEY et al., 1923; GOTTSCHALK et al., 1981). Die sehr heterogene Gattung besteht aus etwa 120 Arten, wobei 35 Vertreter einen pathogenen Phänotyp ausprägen können, darunter der Erreger von Gasgangrän, C. perfringens, und der Verursacher des Botulismus, eine durch C. botulinum verursachte Lebensmittelvergiftung (STACKEBRANDT \& RAINEY, 1997).

Der Kenntnisstand bezüglich C. tetani erschöpft sich im wesentlichen in der Erforschung der Tetanus-Krankheit, insbesondere im Hinblick auf den Aufbau und die Wirkungsweise des Tetanus-Toxins. Es ist bekannt, dass die Tetanus-Krankheit meistens als Folge einer Wundinfektion auftritt. Sporen gelangen in die unsaubere Wunde, keimen dort in anaeroben Zonen aus, vegetative Zellen entstehen und vermehren sich (ARNON, 1997). Schließlich wird durch bisher nicht verstandene Prozesse die Bildung des Tetanus-Toxins ausgelöst. Das Toxin bindet spezifisch an Ganglioside neuronaler Membranen, wird internalisiert und gelangt dann retrograd $\mathrm{zu}$ seinem eigentlichen Wirkungsort, den Synapsen von inhibitorischen Interneuronen des Knochenmarks sowie des Stammhirns (SCHIAVO \& MONTECUCCO, 1997). Dort verhindert das Toxin die Freisetzung von Neurotransmittern wie $\gamma$ Aminobutyrat (GABA) und Glycin von der präsynaptischen Membran. Das geschieht durch die proteolytische Spaltung von Synaptobrevin-II, einem essentiellen Protein für die Fusion von Neurotransmitter-enthaltenden Vesikeln mit der präsynaptischen Membran (SCHIAVO et al., 1992). Die daraus resultierende Ausschaltung der Nervenenden verhindert, dass sich angeschlossene Muskeln entspannen können, wodurch also eine kontinuierliche Muskelkontraktion herbeigeführt wird. Die Inkubationszeit einer Tetanus-Erkrankung beträgt in der Regel 2 bis 14 Tage, bevor die ersten Symptome, eine Muskelverhärtung im Kiefer- und im Nackenbereich, auftreten. Schließlich kontrahieren die Muskeln des gesamten Körpers. Im Endstadium verkrampft sich der Körper häufig zur Opisthotonos-Position (Abb. 1). 
Erwähnt sei an dieser Stelle, dass das dem Tetanus-Toxin in Struktur und Wirkungsweise sehr ähnliche und etwa 10 mal giftigere Botulinus-Toxin mittlerweile als Medikament $\left(\right.$ BOTOX $^{\circledR}$ bzw. Dysport ${ }^{\circledR}$ ) zum Einsatz kommt (MOORE, 1995). Da das Botulinus-Toxin auf Nervenenden an der motorischen Endplatte wirkt, wodurch die Freisetzung des Neurotransmitters Acetylcholin unterbunden wird, hat es die Verhinderung der Muskelkontraktion zur Folge und kann damit - in geringsten Mengen als muskelkrampflösende Substanz eingesetzt werden. Anwendungsgebiete sind Fälle von Muskelüberreaktionen und verschiedenste Formen der Dystonie bis hin zur kosmetischen Anwendung gegen Altersfalten (ARNON, 1997).

Genetische Informationen über C. tetani waren zu Beginn der vorliegenden Arbeit kaum vorhanden. Es war bekannt, dass das Gen des Tetanus-Toxins, tet $X$, im Stamm Massachusetts auf dem ca. 75 kb großen Plasmid pCL1 liegt (FINN et al., 1984). Im Jahre 1986 konnte schließlich die Nukleotidsequenz von tet $X$ entschlüsselt werden (EISEL et al., 1986; FAIRWEATHER \& LYNESS, 1986). 12 Jahre später wurde ein weiteres, unmittelbar stromaufwärts zum tet $X$ gelegenes Gen des Plasmids pCL1 sequenziert, genannt tetR (MARVAUD et al., 1998a). Es konnte experimentell belegt werden, dass es sich bei TetR um den Transkriptionsaktivator des Tetanus-Toxins handelt. Hinsichtlich des Chromosoms war lediglich ein Gen bekannt; es kodiert für das Cholesterol-abhängige Cytolysin Tetanolysin O, ein Protein, das in multimerer Form Poren in cholesterolhaltigen Membranen bildet und damit die Integrität der betreffenden Zelle zerstören kann (TWETEN, 1997; CERRATO et al., 2000).

Auch waren zu Beginn der Arbeiten keine clostridiellen Genomsequenzen bekannt. Das änderte sich aber: so wurde im Jahre 2001 das Genom von C. acetobutylicum veröffentlicht, einem nicht-pathogenen Organismus, der Lösungsmittel wie Aceton oder Butanol produzieren kann (NÖLLING et al., 2001). Des weiteren erschien im Jahre 2002 die Genomsequenz von C. perfringens (SHIMIZU et al., 2002). So eröffnete sich die Möglichkeit, die im Rahmen dieser Arbeit entschlüsselte Genomsequenz von $C$. tetani mit diesen beiden clostridiellen Genomen zu vergleichen. Zuvor sollten das Genom von C. tetani nach kodierender Sequenz abgesucht und die aus den Genen abgeleiteten Proteine mittels bioinformatischer Methoden charakterisiert werden. Die Analyse des genetischen Potentials von $C$. tetani sowie die vergleichende Genomanalyse hatte das Ziel, Informationen hinsichtlich der pathogenen Lebens- 
weise von Clostridien im allgemeinen und von C. tetani im speziellen zu gewinnen. Dadurch sollten Hinweise dazu erhalten werden, wie sich der Lebenswandel von einem harmlosen Bodenbakterium zu einem potentiell tödlichen Nervensystemschädigenden Organismus vollzieht. Ein besonderes Augenmerk sollte auf die Identifizierung möglicher Virulenzfaktoren sowie auf regulatorische Systeme geworfen werden, welche die Bildung des Tetanus-Toxins kontrollieren könnten.

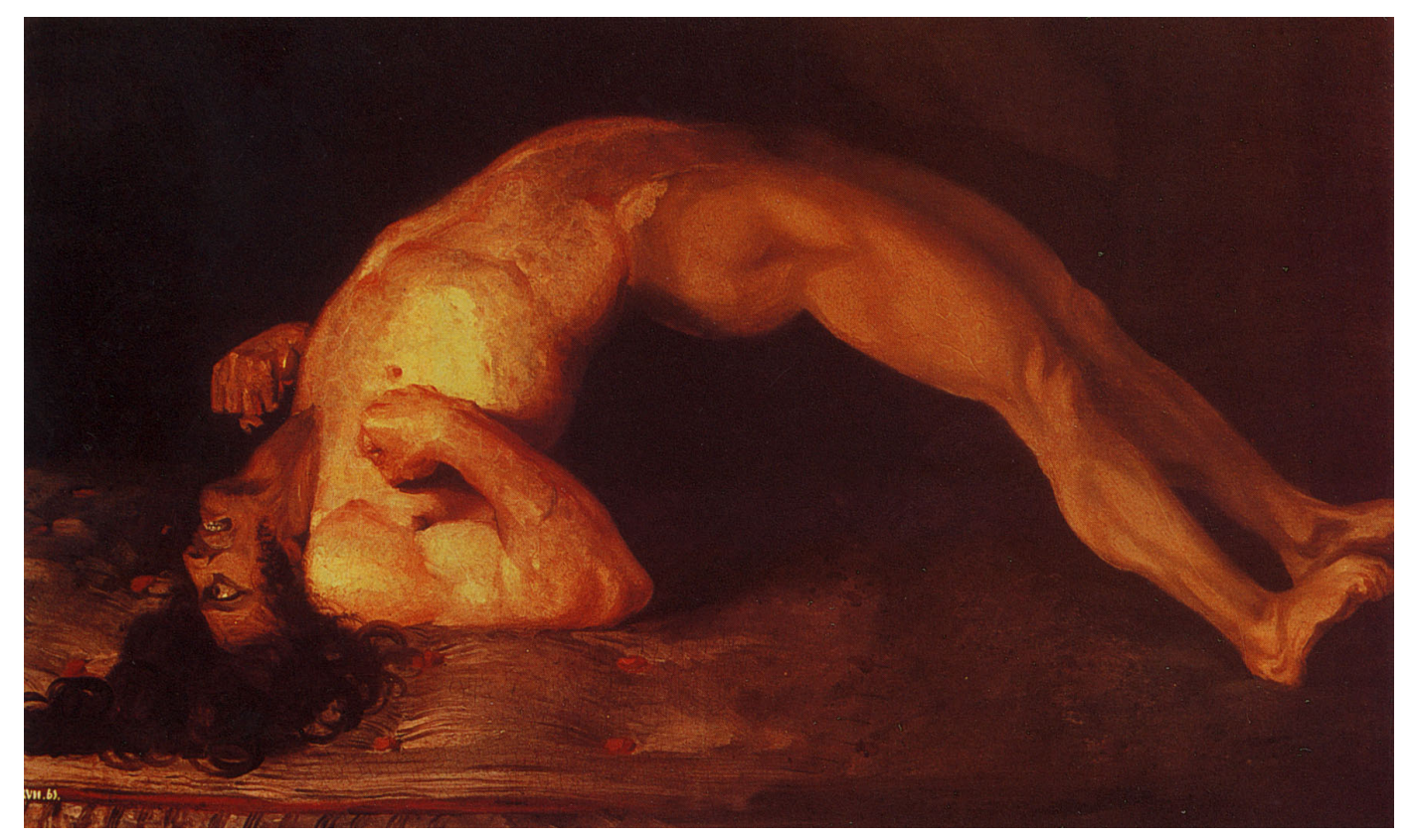

Abb. 1: Sir Charles Bells Porträt eines an Tetanus erkrankten Mannes

$\mathrm{Zu}$ sehen ist die verkrampfte Haltung des Körpers (Opisthotonos) im Endstadium der Krankheit. Das Original dieses Bildes aus dem Jahre 1821 befindet sich im ,Royal College of Surgeons' in Edinburgh, Schottland. 


\section{$2 \quad$ Material und Methoden}

\subsection{Organismen und Plasmide}

Die im Rahmen der experimentellen Arbeiten dieser Arbeit verwendeten Bakterienstämme sind in Tabelle 1 zusammengefasst. Die Tabelle 2 listet die verwendeten Klonierungsvektoren sowie die in dieser Arbeit hergestellten rekombinanten Plasmide und Cosmide auf.

\section{Tabelle 1: Verwendete Organismen}

\begin{tabular}{|c|c|c|}
\hline Stamm & $\begin{array}{l}\text { relevanter Geno-/Phänotyp } \\
\text { \& Kommentare }\end{array}$ & Referenz/Herkunft \\
\hline Clostridium tetani $\mathrm{E} 88$ & $\begin{array}{l}\text { toxisch, Derivat des Stam- } \\
\text { mes Massachusetts }\end{array}$ & $\begin{array}{l}\text { Firma Chiron Behring } \\
\text { GmbH \& Co }\end{array}$ \\
\hline $\begin{array}{l}\text { Clostridium tetani } \\
\text { E4222 }\end{array}$ & $\begin{array}{l}\text { nicht-toxisch, Krankenhaus- } \\
\text { Isolat }\end{array}$ & $\begin{array}{l}\text { isoliert von G. Schallehn; } \\
\text { WILDE et al., } 1989 \\
\text { (DSM 11745) }\end{array}$ \\
\hline $\begin{array}{l}\text { Clostridium tetani } \\
\text { NCTC } 279\end{array}$ & $\begin{array}{l}\text { NCTC } 279 \text { - USA II (ATCC } \\
\text { 19406) / Typstamm }\end{array}$ & $\begin{array}{l}\text { isoliert } 1920 \text { von G. F. } \\
\text { Petrie, Lister Institute, Paris }\end{array}$ \\
\hline Escherichia coli $\mathrm{DH} 5 \alpha$ & $\begin{array}{l}\mathrm{F}^{-}, \phi 80 \mathrm{~d}, \text { lacZ } \mathrm{M} 15, \text { endA1, } \\
\text { recA1, hsdR17, }\left(\mathrm{r}_{\mathrm{K}}-\mathrm{m}_{\mathrm{K}}+\right), \\
\text { supE44, thi-1, } \lambda^{-}, \text {gyrA96, } \\
\text { relA1, } \Delta(\text { lacZYA'argF }) U 169\end{array}$ & HANAHAN, 1983 \\
\hline $\begin{array}{l}\text { Escherichia coli BL21 } \\
\text { (DE3) }\end{array}$ & $\begin{array}{l}\text { hsdF, gal }(\lambda c I t s 857, \text { ind } 1, \\
\text { Sam7, nin5, lacUV5- } \\
\text { T7genel })\end{array}$ & $\begin{array}{l}\text { STUDIER \& MOFFAT, } \\
1986\end{array}$ \\
\hline
\end{tabular}


Tabelle 2: Vektoren und rekombinante Plasmide und Cosmide

\begin{tabular}{|c|c|c|c|}
\hline Plasmid/ & Größe des & relevante Merkmale & Referenz/ \\
\hline Cosmid & Plasmids (kb) & & Herkunft \\
\hline pTZ19R & 2,8 & lacZ, MCS, Amp ${ }^{\mathrm{r}}$ & Fa. Fermentas \\
\hline $\mathrm{pTZ19R}^{\mathrm{Cm}}$ & 3 & lacZ, $\mathrm{MCS}, \mathrm{Cm}^{\mathrm{r}}$ & $\begin{array}{l}\text { freundlicherweise zur } \\
\text { Verfügung gestellt } \\
\text { von A. Christmann }\end{array}$ \\
\hline $\begin{array}{l}\text { ctaa01- } \\
\text { ctpz96 }\end{array}$ & $4-6$ & $\begin{array}{l}\text { Shotgun-Genbänke: } \\
\text { genomische DNA aus } \\
\text { C. tetani in pTZ19R }{ }^{(\mathrm{Cm})}\end{array}$ & diese Arbeit \\
\hline $\begin{array}{l}\text { superCos } 1 \\
(\mathrm{sCos} 1)\end{array}$ & 7,9 & $\begin{array}{l}\mathrm{Amp}^{\mathrm{r}} ; \mathrm{Kan}^{\mathrm{r}} ; \\
\cos \end{array}$ & Fa. Stratagene \\
\hline $\begin{array}{l}\text { ctsa01- } \\
\text { ctsd50 }\end{array}$ & $35-48$ & $\begin{array}{l}\text { Cosmid-Genbank: } \\
\text { genomische DNA aus } \\
\text { C. tetani in sCos } 1\end{array}$ & diese Arbeit \\
\hline
\end{tabular}

\subsection{Nährmedien, Puffer und Stammlösungen}

Alle aufgeführten Medien wurden durch Autoklavieren für $30 \mathrm{~min}$ bei $121{ }^{\circ} \mathrm{C}$ sterilisiert. Die C-Quellen, i. d. R. Glucose, wurden separat autoklaviert oder sterilfiltriert und dem Medium unmittelbar vor dem Animpfen steril zugegeben. Anaerobe Medien wurden nach der von COSTILOW (1981) beschriebenen Methode unter Begasung mit sauerstofffreiem Stickstoff hergestellt. Zur Herstellung von Agarplatten wurde dem Medium vor dem Autoklavieren 1,5\% (w/v) Agar zugefügt.

\subsubsection{Komplexmedium für C. tetani}

Die C. tetani-Stämme wurden im Komplexmedium angezogen (MARVAUD et al., 1998). 


$\begin{array}{lr}\text { Trypton } & 30 \mathrm{~g} \\ \text { Hefeextrakt } & 20 \mathrm{~g} \\ \text { Cystein- } \mathrm{HCl} & 0,5 \mathrm{~g} \\ \mathrm{H}_{2} \mathrm{O}_{\text {bidest. }} & \text { ad } 1000 \mathrm{ml}\end{array}$

Dem Medium wurde Glucose in einer Endkonzentration von $5 \mathrm{~g} / 1$ zugesetzt.

\subsubsection{Medien für $E$. coli}

2.2.2.1 LB (Luria-Bertani)-Medium (SAMBROOK et al., 1989)

$\begin{array}{lr}\text { Trypton } & 10 \mathrm{~g} \\ \text { Hefeextrakt } & 5 \mathrm{~g} \\ \mathrm{NaCl} & 10 \mathrm{~g} \\ \mathrm{H}_{2} \mathrm{O}_{\text {bidest. }} & \text { ad } 1000 \mathrm{ml}\end{array}$

\subsubsection{TB-Medium}

$\begin{array}{lr}\text { Trypton } & 12 \mathrm{~g} \\ \text { Hefeextrakt } & 24 \mathrm{~g} \\ \text { Glycerin }(87 \%, \mathrm{v} / \mathrm{v}) & 4 \mathrm{ml} \\ \mathrm{H}_{2} \mathrm{O}_{\text {bidest. }} & \text { ad } 1000 \mathrm{ml}\end{array}$

\subsubsection{Medienzusätze}

Antibiotika-Stammlösungen sowie IPTG und X-Gal wurden dem autoklavierten und auf mindestens $50{ }^{\circ} \mathrm{C}$ abgekühlten Medium zur Selektion entsprechender rekombinanter E. coli-Stämme zugesetzt (Tabelle 3). 
Tabelle 3: Medienzusätze

\begin{tabular}{lll}
\hline Zusatz & Stammlösung & Endkonzentration \\
\hline Ampicillin & $100 \mathrm{mg} / \mathrm{ml}$ in $\mathrm{H}_{2} \mathrm{O}_{\text {bidest }}{ }^{\mathrm{a}}$ & $100 \mu \mathrm{g} / \mathrm{ml}$ \\
\hline Kanamycin & $100 \mathrm{mg} / \mathrm{ml} \mathrm{in} \mathrm{H}_{2} \mathrm{O}_{\text {bidest }}{ }^{\mathrm{a}}$ & $25-50 \mu \mathrm{g} / \mathrm{ml}$ \\
\hline Chloramphenicol & $100 \mathrm{mg} / \mathrm{ml} \mathrm{in} \mathrm{H}_{2} \mathrm{O}_{\text {bidest }}{ }^{\mathrm{a}}$ & $100 \mu \mathrm{g} / \mathrm{ml}$ \\
\hline IPTG & $100 \mathrm{mg} / \mathrm{ml} \mathrm{in} \mathrm{H}_{2} \mathrm{O}_{\text {bidest }}{ }^{\mathrm{b}}$ & $40 \mu \mathrm{g} / \mathrm{ml}$ \\
\hline X-Gal & $40 \mathrm{mg} / \mathrm{ml}$ in N,N-Dimethylformamid & $40 \mu \mathrm{g} / \mathrm{ml}$
\end{tabular}

${ }^{\mathrm{a}}$ Die Lösung wurde bei $4{ }^{\circ} \mathrm{C}$ gelagert.

${ }^{b}$ Die Lösung wurde direkt vor Gebrauch frisch angesetzt.

\subsubsection{Stamm- und Pufferlösungen}

Weitere Puffer und Lösungen, die im Text nicht näher erläutert werden, sind wie folgt zusammengesetzt. Zur Einstellung geringerer Konzentrationen wurde mit $\mathrm{H}_{2} \mathrm{O}_{\text {bidest. verdünnt: }}$

$20 \times$ TAE-Puffer

$10 \times$ TE-Puffer

\begin{tabular}{|c|c|c|c|}
\hline Tris & $96,9 \mathrm{~g}$ & $1 \mathrm{M}$ Tris- $\mathrm{HCl}(\mathrm{pH} 8,0)$ & $100 \mathrm{ml}$ \\
\hline Eisessig & $22,8 \mathrm{ml}$ & 0,5 M EDTA $(\mathrm{pH} 8,0)$ & $10 \mathrm{ml}$ \\
\hline EDTA & $7,5 \mathrm{~g}$ & $\mathrm{H}_{2} \mathrm{O}_{\text {bidest. }}$ & ad $1000 \mathrm{ml}$ \\
\hline
\end{tabular}

$\mathrm{H}_{2} \mathrm{O}_{\text {bidest. }} \quad$ ad $1000 \mathrm{ml}$

\subsection{Zellanzucht und Stammhaltung}

\subsubsection{Zellanzucht von $C$. tetani}

Für die Anzucht der in Tabelle 1 aufgelisteten C. tetani-Stämme mussten aufgrund ihrer nachgewiesenen oder potentiellen Toxizität besondere Vorsichtsmaßnahmen getroffen werden. Alle Arbeiten mit den Organismen fanden in einem Sicherheitslabor der Stufe 2 statt. Darüber hinaus wurde zu Beginn der Arbeiten der TetanusImpfschutz aller im Institut beschäftigten Mitarbeiter überprüft und gegebenenfalls aufgefrischt. 
Die Kultivierung der strikt anaeroben Bakterien erfolgte nach der Hungate-Technik (HUNGATE, 1969) und den modifizierten Methoden von BRYANT (1972). Als Kulturgefäß dienten $16 \mathrm{ml}$ Schraubdeckelröhrchen (Hungate-Röhrchen; Bellco Glass Inc., Vineland, New Jersey, USA) oder Müller-Krempel-Serumflaschen (Fa. Ochs Glasgerätebau, Bovenden). Als Verschluss für diese Glasgefäße dienten gasdichte Stopfen aus Butylgummi bzw. Naturkautschuk. Zur Zugabe sowie Entnahme von Flüssigkeiten wurden sterile Plastikspritzen benutzt. Als Gasatmosphäre diente bei der Anzucht ein $\mathrm{N}_{2} / \mathrm{CO}_{2}$-Gemisch im Verhältnis $80 \%$ zu 20\%.

\subsubsection{Zellanzucht von $E$. coli}

Die aerobe Anzucht von E. coli erfolgte bis zu einem Kulturvolumen von $5 \mathrm{ml}$ in Reagenzgläsern, bis $30 \mathrm{ml}$ in 100-ml-Erlenmeyerkolben und bis $300 \mathrm{ml}$ in 1 Erlenmeyerkolben (Fa. Ochs, Bovenden). Die Kulturen wurden unter Schütteln bei $30{ }^{\circ} \mathrm{C}$ oder $37^{\circ} \mathrm{C}$ inkubiert. Angeimpft wurde jeweils $1-5 \%$ ig.

\subsubsection{Stammhaltung}

Für die kurzfristige Stammhaltung wurde E. coli auf LB-Agarplatten - gegebenenfalls mit dem Zusatz eines Antibiotikums - bei $4{ }^{\circ} \mathrm{C}$ gelagert. Diese Kulturen wurden alle 4 Wochen überimpft. Zur Herstellung von Stammkulturen wurden E. coliStämme in LB-Medium bei $30{ }^{\circ} \mathrm{C}$ angezogen. In der logarithmischen Wachstumsphase wurde $0,75 \mathrm{ml}$ Zellsuspension entnommen, mit 0,25 $\mathrm{ml}$ Glycerin (87\%, v/v) versetzt und bei $-70{ }^{\circ} \mathrm{C}$ gelagert.

Die Stammhaltung von C. tetani erfolgte im Komplexmedium in Hungate-Röhrchen. Die Kulturen wurden ü. N. bei $37{ }^{\circ} \mathrm{C}$ inkubiert und anschließend bei $4{ }^{\circ} \mathrm{C}$ aufbewahrt. Im Abstand von 4 Wochen erfolgte eine erneute Anzucht. 


\subsubsection{Reinheitskontrollen}

Die Reinheit der Bakterienkulturen wurde durch Vereinzelungsausstrich auf Agarplatten mit anschließender makroskopischer Kontrolle und durch mikroskopische Kontrolle der Zellmorphologie im Phasenkontrastmikroskop (Fa. Carl Zeiss, Standard RA, Oberkochen) sichergestellt.

\subsection{Standardtechniken für das Arbeiten mit Nukleinsäuren}

\subsubsection{Behandlung von Geräten und Lösungen}

Zur Inaktivierung von Nukleasen wurden alle hitzestabilen Geräte und Lösungen durch Autoklavieren $\left(20 \mathrm{~min}\right.$ bei $\left.121^{\circ} \mathrm{C}\right)$ sterilisiert. Nicht autoklavierbare Materialien wurden mit 70\%igem Ethanol (v/v) gespült oder mit 96\%igem Ethanol (v/v) abgeflammt. Hitzelabile Substanzen (z. B. Antibiotika, Lysozym) wurden sterilen Lösungen in pulverisierter Form zugegeben, oder entsprechende Lösungen wurden sterilfiltriert.

\subsubsection{Reinigung und Konzentrierung von Nukleinsäuren \\ 2.4.2.1 Phenol/Chloroform-Extraktion}

Um Proteine aus DNA-Lösungen zu entfernen, wurden diese mit 1 Vol. PhenolLösung versetzt und kräftig gemischt. Das eingesetzte Phenol war mit 0,5 M Tris$\mathrm{HCl}(\mathrm{pH} \mathrm{8,0)}$ gesättigt. Zur Phasentrennung wurde 3 min bei 12000 Upm zentrifugiert. Danach wurde die obere, wässrige Phase mit 1 Vol. Chloroform/Isoamylalkohol (24:1) extrahiert, bis keine weiße Interphase mehr sichtbar war und anschließend erneut zentrifugiert. Die obere Phase wurde mit Isopropanol oder Ethanol gefällt.

\subsubsection{Fällung von Nukleinsäuren}

Zur Konzentrierung bzw. Entsalzung von Nukleinsäuren wurde eine Fällung mit 1/10 Vol. (v/v) Natriumacetat (2,5 M; pH 5,2) durchgeführt, um den Gehalt an monova- 
lenten Kationen zu erhöhen. Die Präzipitation erfolgte durch Zugabe von 3 Vol. eiskaltem 99\%igen Ethanol (v/v) oder 0,8 Vol. Isopropanol. Nach vorsichtigem Durchmischen wurde die DNA bei der Ethanol-Fällung $1 \mathrm{~h}$ bei $-20{ }^{\circ} \mathrm{C}$ bzw. bei der Isopropanolfällung ca. $15 \mathrm{~min}$ bei $4{ }^{\circ} \mathrm{C}$ inkubiert. Nach der Zentrifugation (15000 Upm, $4{ }^{\circ} \mathrm{C}$, $30 \mathrm{~min}$ ) wurde das DNA-Pellet zweimal mit $1 \mathrm{ml}$ eiskaltem 70\%igen Ethanol (v/v) gewaschen, getrocknet und in $\mathrm{H}_{2} \mathrm{O}_{\text {bidest. }}$ oder TE-Puffer aufgenommen.

\subsubsection{Mikrodialyse von Nukleinsäuren}

Diese Methode wurde angewandt, wenn störende niedermolekulare Substanzen wie z.B. Salze aus DNA-Lösungen entfernt werden sollten. Die Mikrodialyse erhöht z. B. die Ligationseffizienz bei Verdauansätzen. Auch wurden ganze Ligationsansätze mikrodialysiert, bevor sie zur Elektroporation eingesetzt wurden. 20-50 $\mu 1$ DNALösung wurden vorsichtig auf einen sterilen Membranfilter $(0,025 \mu \mathrm{m}$ Porengröße, Filtertyp „VS“, Millipore GmbH, Eschborn) pipettiert und gegen steriles Wasser dialysiert. Dazu wurde der Filter mit seiner glänzenden Seite nach oben auf die Wasseroberfläche gelegt. Nach 30-60 min wurde die DNA-Lösung abgenommen.

\subsubsection{Konzentrationsbestimmung und Reinheitskontrolle von DNA}

Die Konzentration von DNA-Lösungen wurde durch Absorption bei einer Wellenlänge von $260 \mathrm{~nm}$ in $1 \mathrm{ml}$ Quarzküvetten mit einer Schichtdicke von $1 \mathrm{~cm}$ mit Hilfe eines Photometers (Uvikon 810 Photometer, Kontron Instruments, Eching) ermittelt. Der Nullwert wurde mit Wasser oder TE-Puffer eingestellt, je nachdem, worin die DNA gelöst war. Für eine $\mathrm{OD}_{260}$ von 1,0 wurden folgende Konzentrationen angenommen (SAMBROOK et al., 1989):

$\begin{array}{ll}\text { doppelsträngige DNA } & 50 \mu \mathrm{g} / \mathrm{ml} \\ \text { einzelsträngige DNA/RNA } & 40 \mu \mathrm{g} / \mathrm{ml} \\ \text { Oligonukleotide } & 31 \mu \mathrm{g} / \mathrm{ml}\end{array}$

Zusätzlich konnte die Reinheit einer DNA-Lösung durch OD-Bestimmungen bei $230 \mathrm{~nm}$ und $280 \mathrm{~nm}$ überprüft werden. Für reine DNA gilt: 


$$
\begin{aligned}
\mathrm{OD}_{260}: \mathrm{OD}_{280} & =1,8 \\
\mathrm{OD}_{230}: \mathrm{OD}_{260}: \mathrm{OD}_{280} & =0,45: 1,0: 0,515
\end{aligned}
$$

Verunreinigungen durch Proteine oder Phenol sind an einer deutlichen Steigerung der Absorption bei $280 \mathrm{~nm}$ erkennbar, Polysaccharide hingegen erhöhen die Absorption bei $230 \mathrm{~nm}$. Konnte diese Methode der Konzentrationsbestimmung aufgrund der geringen Menge an vorhandener DNA nicht durchgeführt werden, wurde die Konzentration anhand der Intensität der Banden in Agarose-Minigelen abgeschätzt.

\subsubsection{Standard-Agarose-Gelelektrophorese}

Sowohl zur analytischen als auch zur präparativen Auftrennung von DNA und DNAFragmenten wurden horizontale Gelelektrophoresen in Kammern der Größe $11,0 \times 6,5 \mathrm{~cm}$ (kleine Gele) und 14 × $12 \mathrm{~cm}$ (große Gele) durchgeführt. Die Agarose wurde in Abhängigkeit der $\mathrm{zu}$ untersuchenden Fragmentgrößen in der Regel $0,8 \%$ ig (w/v) bzw. 2,0\%ig (w/v) in TAE-Puffer angesetzt, welcher gleichzeitig auch als Elektrophoresepuffer diente. Vor dem Auftragen in die Geltaschen wurden die DNA-Proben mit 0,2 Vol. Stop-Mix (= Beschwerer-Lösung) versetzt. Dadurch konnte man während der Elektrophorese die Lauffront verfolgen, und eventuell noch vorhandene Proteine wurden denaturiert. Zur späteren Auswertung und Größenbestimmung wurden zusätzlich noch $4 \mu \mathrm{l}$ (bei einem großen Gel $20 \mu \mathrm{l}$ ) DNALängenstandard aufgetragen. Nach der Elektrophorese (40-90 V, 0,5-2 h für Minigele; 40-100 V, 4-6 h für präparative Gele) wurden die Gele für 15 min im Ethidiumbromidbad ( $\left.1 \mu \mathrm{g} / \mathrm{ml} \mathrm{H}_{2} \mathrm{O}\right)$ angefärbt, dann gewässert und die Nukleinsäurebanden mittels eines UV-Transilluminators (Croma 41, Fa. Vetter, Wiesloch) bei $254 \mathrm{~nm}$ sichtbar gemacht. Bei Bedarf wurden die Gele zur Dokumentation mit einer Polaroid-Kamera (Polaroid-Corporation, Cambridge, USA) unter Verwendung eines Orangefilters fotografiert. Wahlweise war auch eine Übertragung des Bandenmusters auf Thermopapier mittels einer Videokamera möglich (Fa. Intas, Göttingen). 
50 x TAE-Puffer (SAMBROOK et al., 1989)

Tris

EDTA $(0,5 \mathrm{M} ; \mathrm{pH} 8,0)$

Essigsäure (konz.)

$\mathrm{H}_{2} \mathrm{O}_{\text {bidest. }}$

pH 8,5

$\underline{\text { Stop-Mix (SAMBROOK et al., 1989) }}$

EDTA

Harnstoff

Saccharose

Bromphenolblau

$\mathrm{H}_{2} \mathrm{O}_{\text {bidest. }}$

pH 7,0
$242 \mathrm{~g}$

$100 \mathrm{ml}$

$57 \mathrm{ml}$

ad $1000 \mathrm{ml}$
$2 \mathrm{M}$

$50 \mathrm{mM}$

$1 \mathrm{M}$

Aliquots der autoklavierten Lösung wurden bei $-20{ }^{\circ} \mathrm{C}$ gelagert.

Ethidiumbromid-Stammlösung

Die Stammlösung wurde in einer Konzentration von $10 \mathrm{mg} / \mathrm{ml}$ in Wasser angesetzt und lichtgeschützt bei $4{ }^{\circ} \mathrm{C}$ gelagert.

\subsubsection{Größenbestimmung von Nukleinsäuren}

Um die Größe gelelektrophoretisch aufgetrennter, linearer DNA-Fragmente ermitteln zu können, wurde entweder der GeneRuler ${ }^{\mathrm{TM}}$ DNA Ladder Mix (Fa. MBI Fermentas) benutzt oder mit HindIII verdaute DNA des Bakteriophagen $\lambda$ als Längenstandard parallel auf das Gel aufgetragen. Die Größe der erhaltenen Fragmente wurde durch den Vergleich der Laufstrecken mit denjenigen der bekannten $\lambda$-Fragmente bestimmt. Nachfolgend sind die zur Bestimmung herangezogenen Fragmentgrößen angegeben (SANGER et al., 1982; Fa. MBI Fermentas): 
GeneRuler ${ }^{\mathrm{TM}}$ -

DNA Ladder Mix
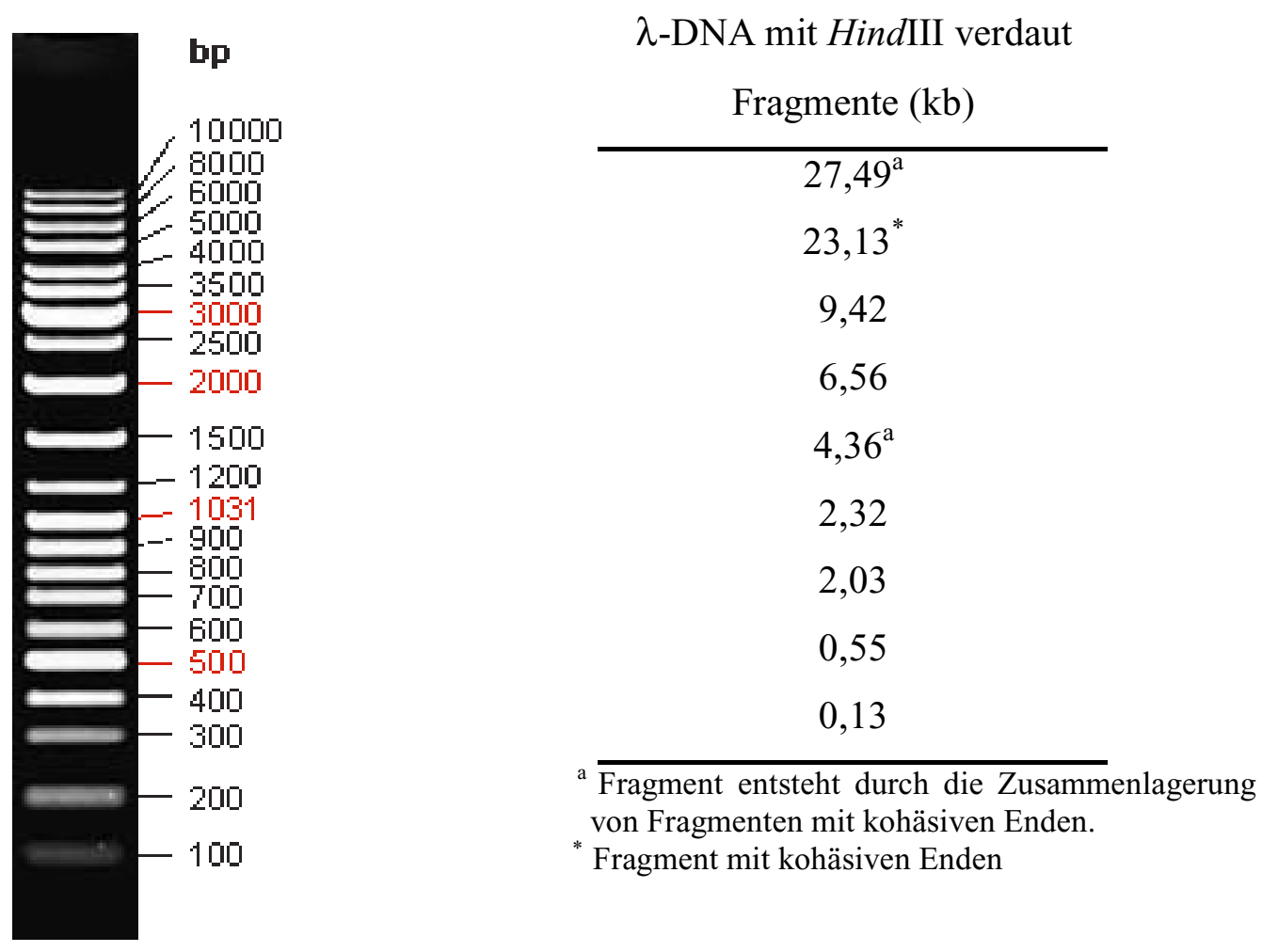

Zur Auswertung wurden die bekannten Fragmentgrößen halblogarithmisch gegen ihre Wanderungsstrecke aufgetragen. Diese Eichkurve wurde zur Größenbestimmung herangezogen.

\subsection{Isolierung von Nukleinsäuren}

\subsubsection{Isolierung genomischer DNA aus C. tetani mit dem AquaPure ${ }^{\circledR}$-Kit}

Es kamen mehrere Methoden zur Isolierung genomischer DNA aus C. tetani zur Anwendung. Ziel dabei war die Isolierung reiner und hochmolekularer DNA, die i. d. R. bessere Klonierbarkeit zeigte als stark fragmentierte DNA. Ein Hauptproblem der DNA-Isolierung lag in der hohen Nuklease-Aktivität der Clostridien; schon nach kurzer Zeit setzte die Fragmentierung der DNA aus lysierten C. tetani-Zellen ein. Die Zugabe hoher Mengen EDTA nach Zelllyse konnte diese Fragmentierung partiell stoppen.

Als geeignete Methode erwies sich das AquaPure ${ }^{\circledR}$-Genomic-DNA-Isolation-Kit (Fa. BioRad), wobei das Protokoll zur Isolierung von DNA aus Gram-negativen Bakteri- 
en leicht modifiziert verwendet wurde (für Gram-positive lag kein Protokoll vor). Wichtig war, dass die Arbeitsschritte zügig vonstatten gingen. Nach ü. N.-Anzucht von $C$. tetani wurden die Zellen durch Zentrifugation geerntet. Nach unverzüglicher Zugabe von $300 \mu \mathrm{l}$ Genomic-DNA-Lysis-Solution zum Zellpellet (aus 5-50 ml Kulturvolumen), wurde dieses vorsichtig resuspendiert. Bei $80^{\circ} \mathrm{C}$ wurden dann die Zellen für 5 min lysiert. Wichtig war, dass die Zellen komplett lysierten. Gegebenenfalls wurden weniger Zellen eingesetzt oder Proteinase K zur Auflösung von Zellklumpen verwendet. Die RNA wurde anschließend durch Zugabe einer RNase-Lösung (4 $\mathrm{mg} / \mathrm{ml}$ ) abgedaut (15-30 $\left.\mathrm{min}, 37^{\circ} \mathrm{C}\right)$. Nun erfolgte die Zugabe von $100 \mu 1$ ProteinPrecipitation-Solution und die Durchmischung des Ansatzes. Dieser wurde dann abzentrifugiert (13000 Upm, 3 min). Der Überstand wurde vorsichtig abgenommen und in ein E-Cup überführt, das $300 \mu 1$ Isopropanol enthielt. Anschließendes vorsichtiges Mischen und Abzentrifugieren (13000 Upm, 1 min) des Ansatzes ergab ein DNAPellet, das schließlich noch mit 70\%igem Ethanol gewaschen, getrocknet und in 20$100 \mu 1 \mathrm{H}_{2} \mathrm{O}_{\text {bidest }}$ aufgenommen wurde.

\subsubsection{Isolierung genomischer DNA nach MARMUR, 1961}

Als weitere Methode wurde die Isolierung genomischer DNA nach MARMUR, 1961 (modifiziert) verwendet. Diese DNA wurde vorrangig für die Herstellung von Plasmid-Genbanken (s. 2.9.1) verwendet. Es wurden i. d. R. 2 bis 3 g Zellen (Feuchtgewicht) eingesetzt. Die Zellen wurden zuvor im Komplexmedium ü. N. angezogen und durch Zentrifugation für $20 \mathrm{~min}$ bei $6000 \mathrm{x} \mathrm{g}$ und $4{ }^{\circ} \mathrm{C}$ geerntet. Nach der Suspendierung der Zellen in $10 \mathrm{ml}$ STE-Puffer erfolgte eine Inkubation unter Schütteln bei $37^{\circ} \mathrm{C}$ für $15 \mathrm{~min}$. Anschließend wurden 0,5 g Lysozym zugegeben und für weitere 45 min unter Schütteln bei $37^{\circ} \mathrm{C}$ inkubiert. Nach Zentrifugation bei $4000 \mathrm{x}$ g und $4{ }^{\circ} \mathrm{C}$ für $10 \mathrm{~min}$ wurde das Zellpellet in $7 \mathrm{ml}$ EDTA-Tris-Saccharose-Puffer suspendiert und $1 \mathrm{ml}$ SDS-Lösung $(25 \%, \mathrm{w} / \mathrm{v})$ sowie $100 \mu$ l Proteinase K-Lösung (80 $\mu \mathrm{g} / \mathrm{ml})$ zugegeben. Es folgte eine Inkubation für $30 \mathrm{~min}$ bei $65^{\circ} \mathrm{C}$. Danach wurden $12 \mathrm{ml} 6 \mathrm{M}$ Guanidiniumthiocyanat und $1 \mathrm{ml}$ Glasmilch hinzugefügt und die Lösung durch mehrmaliges Umschwenken vorsichtig gemischt. Anschließend erfolgte die Zugabe von $20 \mathrm{ml}$ Isobutanol und eine Inkubation bei RT für 10 bis $15 \mathrm{~min}$ bis sich die an die Glasmilch gebundene DNA abgesetzt hatte. Der Überstand konnte abge- 
nommen und verworfen werden. Das DNA-haltige Glasmilchpellet wurde mit $10 \mathrm{ml}$ NaJ-Lösung versetzt, vorsichtig gemischt und der Überstand nach Inkubation für 15 min bei RT verworfen. Nach Zugabe von $10 \mathrm{ml}$,new wash“-Puffer wurde die Lösung wiederum vorsichtig gemischt und für $15 \mathrm{~min}$ bei RT inkubiert, so dass sich die an die Glasmilch gebundenen DNA absetzen konnte. Die Elution der DNA erfolgte durch die Zugabe von $10 \mathrm{ml}$ TE-Puffer, vorsichtigem Mischen und einer Inkubation für $15 \mathrm{~min}$ bei $55^{\circ} \mathrm{C}$. Anschließend wurde die Glasmilch bei $4000 \mathrm{x} \mathrm{g}$ und $4{ }^{\circ} \mathrm{C}$ für 2 min zentrifugiert. Der Überstand wurde zur Fällung der DNA mit $1 \mathrm{ml}$ 7,5 M Ammoniumacetat $(\mathrm{pH} \mathrm{7,5)}$ und $30 \mathrm{ml}$ eiskaltem Ethanol $(96 \%$, v/v) versetzt und für 5 min bei $3000 \mathrm{x} \mathrm{g}$ und $4{ }^{\circ} \mathrm{C}$ zentrifugiert. Das DNA-Pellet wurde mit eiskaltem Ethanol $(70 \%, v / v)$ gewaschen und anschließend in 1 bis $2 \mathrm{ml}$ TE-Puffer oder $\mathrm{H}_{2} \mathrm{O}_{\text {bidest }}$ aufgenommen.

$\underline{\text { STE-Puffer }}$

Saccharose

Tris

EDTA

$\mathrm{pH} 8,0$

„new wash“-Puffer

Ethanol $(96 \%, \mathrm{v} / \mathrm{v})$

$\mathrm{NaCl}$

Tris

EDTA

$\mathrm{pH} \mathrm{7,5}$

Die Lösung wurde bei $-20{ }^{\circ} \mathrm{C}$ gelagert.

$$
1 \mathrm{mM}
$$

\section{EDTA-Tris-Saccharose-Puffer}

EDTA $120 \mathrm{mM}$

Tris $\quad 50 \mathrm{mM}$

Saccharose $\quad 150 \quad \mathrm{mM}$$$
150 \mathrm{mM}
$$

\section{NaJ-Lösung}

$\begin{array}{lll}\mathrm{NaJ} & 6 & \mathrm{M}\end{array}$

$\mathrm{Na}_{2} \mathrm{SO}_{3} \quad 0,12 \quad \mathrm{M}$

Die Lösung wurde lichtgeschützt bei

\section{$4{ }^{\circ} \mathrm{C}$ gelagert.}

\subsubsection{Isolierung von Plasmid-DNA}

2.5.3.1 Isolierung von Plasmiden mit sehr niedriger Kopienzahl pro Zelle

Zur Isolierung des $74 \mathrm{~kb}$ großen low-copy Plasmids aus C. tetani E88 wurden 3-6 g Zellen (Feuchtgewicht) eingesetzt. Die Isolierung erfolgte mit dem Quiagen-Midi$\mathrm{Kit}^{\circledR}$ (Fa. Qiagen), wobei die im Handbuch erwähnten Regeln zur Isolierung von 
großen low-copy Plasmiden befolgt wurden. Prinzip dieser Methode ist die alkalischer Lyse der Zellen, gefolgt von der Präzipitation der Zellproteine zusammen mit der hochmolekularen chromosomalen DNA und der anschließenden Aufreinigung der Plasmid-DNA über Anionenaustauschchromatographie. Nichtsdestotrotz war die mit dem Kit aufgereinigte Plasmid-DNA i. d. R. noch mit chromosomaler DNA verunreinigt. Bei der anschließenden Herstellung einer Genbank sowie deren Sequenzierung wurde dieses Manko in Kauf genommen.

Die Zellen wurden in $4 \mathrm{ml}$ P1-Puffer suspendiert. Es folgte die Zugabe von $4 \mathrm{ml}$ P2Puffer und eine Inkubation für 5 min bei RT. Anschließend wurden $4 \mathrm{ml} \mathrm{P3-Puffer}$ zugefügt und für $30 \mathrm{~min}$ auf Eis inkubiert. Nach Zentrifugation $(16000 \mathrm{x} \mathrm{g,} 30 \mathrm{~min}$, $4{ }^{\circ} \mathrm{C}$ ) wurde der Überstand abgenommen und zur vollständigen Aufklarung erneut für 15 min zentrifugiert. Der hierbei erhaltende Überstand wurde auf eine mit $4 \mathrm{ml}$ QBT-Puffer äquilibrierte „Qiagen-tip-100-Säule“ aufgetragen. Die Säule wurde anschließend mit $20 \mathrm{ml}$ QC-Puffer gewaschen und die Plasmid-DNA durch Zugabe von $5 \mathrm{ml} \mathrm{QF-Puffer} \mathrm{eluiert.} \mathrm{Die} \mathrm{DNA} \mathrm{wurde} \mathrm{mit} \mathrm{0,7} \mathrm{Vol.} \mathrm{Isopropanol} \mathrm{gefällt} \mathrm{und} \mathrm{durch}$ Zentrifugation (16000 x g, $30 \mathrm{~min}, 4{ }^{\circ} \mathrm{C}$ ) pelletiert. Das Sediment wurde anschließend mit eiskaltem Ethanol (70\%, v/v) gewaschen, getrocknet und in 100 bis $200 \mu \mathrm{l}$ $\mathrm{H}_{2} \mathrm{O}_{\text {dest. }}$ oder TE-Puffer aufgenommen. Für die Isolierung von Plasmid-DNA aus größeren Kulturvolumina wurde die Menge an P1, P2 und P3 erhöht. Die Anionenaustauschchromatographie erfolgte dann in mehreren Durchgängen.

\section{$\underline{\text { P1-Puffer }}$}

Tris

EDTA

RNase A

$\mathrm{pH} 8,0$

P3-Puffer

K-Acetat

$\mathrm{pH} 5,5$

( $\mathrm{pH}-$ Wert mit Eisessig einstellen)

\section{$\underline{\text { P2-Puffer }}$}

SDS $1 \quad \%$

$\mathrm{NaOH} 200 \mathrm{mM}$

\section{QBT-Puffer}

$\begin{array}{lrr}\text { NaCl } & 0,75 & \mathrm{M} \\ \text { MOPS } & 50 & \mathrm{mM} \\ \text { Ethanol }(96 \%, \mathrm{v} / \mathrm{v}) & 15 & \% \\ \text { Triton X-100 } & 0,15 & \% \\ \text { pH 7,0 } & & \end{array}$


QF-Puffer

$\mathrm{NaCl}$

MOPS

Ethanol $(96 \%, \mathrm{v} / \mathrm{v})$

pH 8,2
QC-Puffer

$\mathrm{NaCl} \quad 1 \quad \mathrm{M}$

MOPS $50 \mathrm{mM}$

Ethanol $(96 \%, \mathrm{v} / \mathrm{v}) \quad 15 \quad \%$

$\mathrm{pH} 7,0$

\subsubsection{Schnellpräparation von Plasmid-DNA (RIGGS \& MCLACHLAN, 1986)}

Zum schnellen Nachweis und Charakterisierung rekombinanter Plasmide wurden 1,5 $\mathrm{ml}$ einer über Nacht gewachsenen Kultur von E. coli pelletiert (8000 Upm, 5 min). Nach der Resuspendierung des Pellets in $350 \mu 1$ STET-Puffer und $35 \mu 1$ LysozymLösung wurde der Ansatz für $50 \mathrm{~s}$ auf $100{ }^{\circ} \mathrm{C}$ erhitzt. Zellreste und denaturiertes Protein wurden nach 10-minütiger Zentrifugation bei $14000 \mathrm{Upm}$ mit einem sterilen Zahnstocher entfernt. Die Plasmid-DNA im Überstand wurde durch Zugabe von 40 $\mu 1 \mathrm{Na}$-Acetat $(2,5 \mathrm{M}, \mathrm{pH} 5,2)$ und $420 \mu 1$ Isopropanol gefällt. Nach Zentrifugation für 10 min bei 14000 Upm wurde das erhaltene Pellet einmal mit 70\%igen (v/v) Ethanol gewaschen. Nach der Trocknung bei $37^{\circ} \mathrm{C}$ konnte es schließlich in $50 \mu 1$ TER-Puffer (20 $\mu \mathrm{g}$ RNase/ml TE-Puffer) aufgenommen werden.

\section{STET-Puffer}

$\mathrm{NaCl}$

Tris-HCl

EDTA

Triton X-100

$\mathrm{pH} 8,0$

\section{Lysozym-Lösung}

$10 \mathrm{mg} / \mathrm{ml}$ einer 10 mM Tris-HCl-Lösg., pH 8,0

Die RNase-Stammlösung ( $5 \mathrm{mg} / \mathrm{ml}$ TE-Puffer) wurde durch 10-minütige Inkubation bei $80{ }^{\circ} \mathrm{C}$ von hitzelabilen DNasen befreit.

\subsubsection{Robotgesteuerte Plasmidpräparation}

Die große Menge zu sequenzierender rekombinanter Plasmide in einem Genomsequenzierungsprojekt macht eine Automatisierung der Plasmidpräparation notwendig. 
Mittels eines robotgesteuertem Systems (Qiagen-BioRobot $9600^{\circledR}$ ) konnte die Präparation von Plasmid-DNA im 96er Maßstab durchgeführt werden (http://www.qiagen.com/literature/handbooks/qp/1019952_QPHB_prot04.pdf). Ausgangsmaterial war dabei ein 96er Flat-Bottom-Block, der pro Loch (Well) 1,3 ml TBMedium mit dem entsprechenden Antibiotikum enthielt. Der Block wurde manuell mit 96 rekombinanten Klonen der Genbank (s. 2.9.1) beimpft. Dazu wurden entsprechende einzelliegende Kolonien von einer Agarplatte mittels Zahnstocher in die einzelnen Wells überimpft. Die Anzucht des mit einem luftdurchlässigen Aerosheet abgeklebten Blocks erfolgte ü. N. (mindestens $18 \mathrm{~h}$ ) bei $37{ }^{\circ} \mathrm{C}$ im Schüttelinkubator (350 Upm). Abzentrifugiert wurde der Block für 20 min bei $3300 \mathrm{Upm}$ mit einer Plattenzentrifuge (Heraeus 2.0 Megafuge). Dieser Block wurde dann in das Robotsystem Qiagen-BioRobot $9600^{\circledR}$ eingespannt. Prinzipiell erfolgte die Aufreinigung der Plasmid-DNA, wie in Kapitel 2.5.3.1 erläutert, über Anionenaustauschchromatographie. Die Puffer P1, P2 und P3 wurden automatisch über eine Nadel in die Wells des Flat-Bottom-Blocks pipettiert. Anschließend transferierte das System das Lysat aus dem Block heraus in eine 96er TurboFilter-Platte. Automatisch wurde nun durch Anlegen eines Vakuums das gebildete Präzipitat - bestehend aus Zellproteinen und hochmolekularer DNA - aus dem Lysat herausgefiltert. Die das Präzipitat enthaltende TurboFilter-Platte wurde verworfen. Der Durchfluss landete in eine unter der TurboFilter-Platte befindlichen 96er QIAprep-Platte, welche aus 96 Anionenaustauschchromatographie-Säulchen bestand. Die im Durchfluss enthaltende Plasmid-DNA wurde durch erneutes Anlegen eines Vakuums an die 96 Säulchen der QIAprep-Platte gebunden, und anschließend mit den Puffern PB und PE gewaschen. Nach Trocknung der QIAprep-Platte erfolgte die Elution der Plasmid-DNA in eine 96er Mikrotiter-Platte mit $100 \mu 1 \mathrm{H}_{2} \mathrm{O}$ pro Well. Ausbeuten rangierten i. d. R. im Bereich von $100-300 \mathrm{ng} / \mu 1$.

\subsubsection{Robotgesteuerte Cosmidpräparation}

Die Cosmid-Präparation erfolgte ebenfalls mit dem Qiagen-BioRobot $9600^{\circledR}$ in Analogie zur in Kapitel 2.5.3.3 beschriebenen Methode. Folgende Abänderungen zum obigen Protokoll trugen der niedrigen Kopienzahl der Cosmide im Anzuchtstamm E. coli DH5 $\alpha$ Rechnung: Die rekombinanten Klone wurden nicht in einem 96er Flat- 
Bottom-Block, sondern in 96 einzelnen, $5 \mathrm{ml}$ Medium enthaltenden Röhrchen angezogen. Des weiteren erfolgte die Elution mit $120 \mu 1 \mathrm{H}_{2} \mathrm{O}$, das zur Optimierung der Elution auf $70^{\circ} \mathrm{C}$ vorgewärmt worden war.

\subsubsection{Isolierung von DNA-Fragmenten aus Agarosegelen}

Zur Extraktion von DNA aus Agarosegelen kam das QIAquick ${ }^{\circledR}$-Kit (Fa. Qiagen) zum Einsatz. Zuerst wurde die DNA enthaltende Bande mit einem Skalpell aus dem Agarosegel ausgeschnitten. Die Agarose wurde abgewogen und mit 3 Vol (w/v) QGPuffer versetzt. Nach Auflösung der Agarose bei $50^{\circ} \mathrm{C}$ für 10 min wurde die Lösung auf einen Säule gegeben und abzentrifugiert (13000 Upm, 1 min). Die Säule wurde mit 0,75 ml Puffer PE gewaschen und anschließend mittels erneuter Zentrifugation (13000 Upm, 2 min) getrocknet. Die Elution erfolgte mit 20-50 $\mu 1 \mathrm{H}_{2} \mathrm{O}_{\text {bidest. }}$.

\subsubsection{Aufreinigung von PCR-Produkten}

Die Aufreinigung von PCR-Produkten zwecks Abtrennung ungenutzter Nukleotide und Primer sowie zur Abtrennung der Taq-DNA-Polymerase (s. 2.8) wurde ebenfalls mit dem QIAquick ${ }^{\circledR}$-Kit (Fa. Qiagen) durchgeführt (s. 2.5.5). Als Abweichungen zum obigen Protokoll wurde der PCR-Ansatz zuerst mit 5 Vol PB-Puffer versetzt und die Mischung dann auf die Säule gegeben und abzentrifugiert. Alle weiteren Schritte sind identisch mit der in 2.5.5 beschriebenen Methode.

\subsection{Enzymatische Modifikation von DNA}

\subsubsection{Spaltung von DNA durch Restriktionsendonukleasen}

Die sequenzspezifische Spaltung von DNA mit Restriktionsendonukleasen liefert lineare Fragmente mit definierten Enden. Der Verdau erfolgte in den von den Herstellern der Restriktionsenzyme mitgelieferten Puffersystemen bei den empfohlenen Temperaturen. In analytischen Ansätzen betrug das Gesamtvolumen $20 \mu$, wobei ca. 
1-2 $\mu \mathrm{g}$ DNA und 3-5 U Enzym/ $\mu \mathrm{g}$ DNA $2 \mathrm{~h}$ inkubiert wurden. In präparativen Ansätzen wurden bis zu $15 \mu \mathrm{g}$ DNA über Nacht verdaut in einem Volumen von insgesamt $100 \mu \mathrm{l}$. Im Endvolumen lag das Enzym mindestens $1: 10$ verdünnt vor, um eine Gesamtkonzentration von 5\% Glycerin nicht zu überschreiten, die sich störend auf die Spaltungsreaktion hätte auswirken können. Sollten Fragmente mit zwei verschiedenen Enzymen verdaut werden, die unterschiedliche Pufferbedingungen benötigten, so wurde zuerst ein Verdau in dem System mit niedrigerer Ionenstärke durchgeführt und diese dann anschließend für das zweite Enzym erhöht. Falls eine Inaktivierung der Restriktionsenzyme erforderlich war, wurde der Verdauansatz $20 \mathrm{~min}$ bei $65^{\circ} \mathrm{C}$ inkubiert. Die Spaltprodukte wurden im Agarosegel überprüft.

\subsubsection{Dephosphorylierung von DNA-Fragmenten}

Vor der Ligation von Vektor-DNA mit den zu klonierenden DNA-Fragmenten (s. 2.6.4) wurde die 5'-Phosphatgruppe der Vektor-DNA oder der Insert-DNA mit alkalischer Phosphatase abgespalten. Dadurch sollte die Ligation von VektorFragmenten mit sich selbst oder mit anderen linearen Vektor-Fragmenten oder die Ligation von diskontinuierlichen, genomischen DNA-Fragmenten verhindert werden (SAMBROOK et al., 1989). Die Dephosphorylierung wurde direkt im Verdauansatz durchgeführt. Nach dem Verdau wurde $1 \mathrm{U}$ alkalische Phophatase pro $10 \mu \mathrm{g}$ zu dephosphorylierender DNA zugegeben und $30 \mathrm{~min}$ bei $37{ }^{\circ} \mathrm{C}$ inkubiert. Anschließend wurde erneut $1 \mathrm{U}$ Enzym zugegeben und die Inkubation wiederholt. Abgestoppt wurde die Reaktion durch Inkubation für $15 \mathrm{~min}$ bei $65^{\circ} \mathrm{C}$ und die DNA mittels Phenol-Chloroform gereinigt.

\subsubsection{Herstellung von glatten Enden (,blunt ends ${ }^{6}$ ) und Phosphorylierung von 5'-Hydroxyl-Enden bei DNA-Fragmenten}

Da thermostabile Polymerasen, die bei Amplifikationsreaktionen eingesetzt werden, als letztes Nukleotid oftmals unspezifisch ein Adenosin-Triphosphat an das amplifizierte DNA-Fragment anfügen, mussten diese Enden geglättet werden, bevor sie zur ,blunt end'-Ligation eingesetzt werden konnten. Außerdem musste sichergestellt 
sein, dass die DNA-Fragmente an den 5'-Enden phosphoryliert vorlagen, um eine Ligation über glatte Enden zu ermöglichen. Hierzu wurden die DNA-Polymerase I, die überhängende, einzelsträngige DNA abbauen kann, und die $\mathrm{T}_{4}$-PolynukleotidKinase eingesetzt, die in Anwesenheit von ATP freie 5' -Enden phosphoryliert. Beide Enzyme arbeiten gut in KGB-Puffer, so dass beide Reaktionen in einem Ansatz durchgeführt wurden. Dieser bestand aus folgenden Komponenten:

\begin{tabular}{|c|c|}
\hline DNA & $0,5-1$ \\
\hline KGB-Puffer $(10 \mathrm{x})$ & 2 \\
\hline dNTP-Gemisch ( $10 \mathrm{mM}$ ) & 2 \\
\hline ATP ( $10 \mathrm{mM})$ & 2 \\
\hline DNA-Polymerase I (5 U/ $\mu 1)$ & 1 \\
\hline $\mathrm{T}_{4}$-Polynukleotid-Kinase $(2 \mathrm{U} / \mu \mathrm{l})$ & 1 \\
\hline $\mathrm{H}_{2} \mathrm{O}_{\text {bidest. }}$ & ad 20 \\
\hline
\end{tabular}

Der Ansatz wurde 45 min bei $37^{\circ} \mathrm{C}$ inkubiert. Nach 15 min erfolgte die Zugabe der Polynukleotid-Kinase. Anschließend wurde der Ansatz mit Phenol-Chloroform gereinigt und zur Ligation eingesetzt.

\section{$\underline{\text { KGB-Puffer }(10 \mathrm{x}):}$}

$\begin{array}{ll}\text { K-Glutamat } & 1,00 \mathrm{M} \\ \text { Tris-Acetat } & 0,25 \mathrm{M} \\ \text { Mg-Acetat } & 0,10 \mathrm{M} \\ \text { Rinderserumalbumin } & 0,50 \mathrm{mg} / \mathrm{ml} \\ \beta \text {-Mercaptoethanol } & 5,00 \mathrm{mM} \\ \text { pH 7,5 } & \end{array}$

\subsubsection{Ligation von DNA-Fragmenten}

Bei der Ligation werden Phosphodiesterbindungen zwischen doppelsträngigen DNAFragmenten geknüpft, die freie 3'-Hydroxylenden und 5'-Phosphatenden aufweisen. Um die Ligationseffizienz zu erhöhen, wurde in der Regel ein Überschuss an Insert- 
DNA eingesetzt (Verhältnis Vektor:Insert-DNA von etwa $1: 3$ ). Die Ligation erfolgte i. d. R. im $20 \mu$ l Ansatz und in dem vom Hersteller mitgelieferten Puffersystem:

$\begin{array}{cr}\left.\text { Vektor-DNA (in } \mathrm{H}_{2} \mathrm{O}\right) & 0,2-2 \mu \mathrm{g} \\ \left.\text { Insert-DNA (in } \mathrm{H}_{2} \mathrm{O}\right) & 0,8-8 \mu \mathrm{g} \\ 10 \mathrm{x} \mathrm{T}_{4} \text {-Ligase-Puffer } & 2 \mu \mathrm{l} \\ \mathrm{T}_{4} \text {-DNA-Ligase }(1 \mathrm{U} / \mu \mathrm{l}) & 1-2 \mu \mathrm{l} \\ \mathrm{H}_{2} \mathrm{O}_{\text {bidest }} & \mathrm{ad} 20 \mu \mathrm{l}\end{array}$

Bei der Ligation von kohäsiven, überhängenden Enden erfolgte die Inkubation der Ansätze ü. N. bei $16^{\circ} \mathrm{C}$. Zur Ligation glatter Enden (,blunt-ends') wurden 2 U Ligase eingesetzt und die Ansätze i. d. R. über Nacht bei RT oder $2 \mathrm{~h}$ bei $37{ }^{\circ} \mathrm{C}$ inkubiert.

\section{7 Übertragung von DNA in $E$. coli und Selektion rekombinan- ter Klone}

\subsubsection{Transformation in E. coli durch Elektroporation}

Eine Möglichkeit, Plasmide oder Cosmide in E. coli zu transferieren, ist die sogenannte Elektroporation. Dabei werden durch das Anlegen einer hohen Spannung die Membranen kurzzeitig für Plasmid- oder Cosmid-DNA durchlässig gemacht (FIEDLER \& WIRTH, 1988). Für die Elektroporation von E. coli DH5 $\alpha$ wurde folgende Methode verwendet: Der Stamm wurde über Nacht in einer $3 \mathrm{ml}$ Vorkultur angezogen, die dann in $500 \mathrm{ml} \mathrm{LB}-M e d i u m$ unter starkem Schütteln bei $37{ }^{\circ} \mathrm{C}$ bis zu einer $\mathrm{OD}_{600 \mathrm{~nm}}$ von $0,7-0,8$ inkubiert wurde. Nach einer 15-minütigen Inkubation auf Eis wurden die Zellen geerntet (5000 Upm, $10 \mathrm{~min}, 4{ }^{\circ} \mathrm{C}$ ) und anschließend zweimal mit eiskaltem $\mathrm{H}_{2} \mathrm{O}_{\text {bidest }}$ gewaschen. Das Pellet wurde mit $20 \mathrm{ml}$ einer 10\%igen GlycerinLösung gewaschen und in $800 \mu 1$ derselben Lösung aufgenommen. Eine Lagerung erfolgte in Aliquots von $50-80 \mu 1$ bei $-70{ }^{\circ} \mathrm{C}$, oder die Zellen wurden sofort verwendet.

Die Elektroporation wurde an einem „Gene Pulser“ (Fa. BioRad Laboratories, München) durchgeführt. Dazu wurde 0,5-2 $\mu 1$ Plasmid/Cosmid-DNA mit ca. $50 \mu 1$ kom- 
petenter Zellen in vorgekühlten Elektroporationsküvetten gemischt. Es wurde eine Spannung von 2,5 kV, eine Kapazität von $25 \mu \mathrm{F}$ und ein Widerstand von $200 \Omega$ gewählt. Direkt nach der Elektroporation wurde $1 \mathrm{ml}$ LB-Medium hinzugefügt, gemischt, der Ansatz in ein E-Cup überführt und $1 \mathrm{~h}$ bei $37^{\circ} \mathrm{C}$ unter gelegentlichem Schwenken inkubiert. Dann wurde dieser Ansatz entweder direkt auf Selektivplatten ausplattiert (5-100 $\mu 1$ pro Platte), oder aber zuerst abzentrifugiert (4000 Upm, $5 \mathrm{~min}$ ), in $50 \mu 1 \mathrm{LB}-M e d i u m$ aufgenommen und schließlich ausplattiert.

Nach der beschriebenen Methode wurden auch ganze Ligationsansätze zur Elektroporation eingesetzt. Hierbei wurde aber zuvor der Ligationsansatz inaktiviert (20 $\min , 65^{\circ} \mathrm{C}$ ) und einer Mikrodialyse (30-45 min) unterzogen (s. 2.4.2.3).

\subsubsection{Blau-Weiß-Test zur Selektion rekombinanter E. coli-Klone}

Bei Klonierungen ist es entscheidend, Klone, die nur den Plasmid-Vektor enthalten, von denjenigen, die ein Plasmid mit Insert tragen, zu unterscheiden. Neben den Plasmid-kodierten Antibiotikaresistenzen stellt der Blau-Weiß-Test ein weiteres schnelles Selektionssystem dar. Er beruht darauf, dass Insertionen in die multiple Klonierungsstelle des entsprechenden Vektors die Bildung einer aktiven $\beta$-Galactosidase verhindern. Eine aktive $\beta$-Galactosidase ist in der Lage, neben dem eigentlichen Substrat Lactose auch 5-Brom-4-Chlor-indoyl- $\beta$-D-Galactosid (X-Gal) zu spalten. Es entsteht der Farbstoff 5-Brom-4-Chlor-Indigo, der sich in Anwesenheit von Sauerstoff spontan blau verfärbt (HOROWITZ et al., 1964). Im X-Gal-Test werden E. coli-Stämme (z. B. DH5 $\alpha$ ) eingesetzt, die durch eine Deletion im Chromosom nur eine inaktive $\beta$-Galactosidase ohne Aminoterminus bilden können. Bestimmte Vektoren (z. B. pGEM-7Zf(+)) sind nun in der Lage, diesen Effekt zu kompensieren. Sie tragen neben dem Promoter- und Operatorbereich des lac-Operons auch das $5^{6}$ Ende des lacZ-Gens, welches für das sogenannte $\alpha$-Peptid kodiert. Dies kann in vivo mit der verkürzten $\beta$-Galaktosidase zum aktiven Enzym assoziieren ( $\alpha$ Komplementation). Da die multiple Klonierungsstelle des Vektors innerhalb des lacZ-Gens liegt, wird die Bildung des $\alpha$-Peptids verhindert, wenn der Vektor ein Insert trägt. Auf Indikatorplatten, die IPTG (zur Induktion der $\beta$-Galactosidase) und X-Gal enthalten, können die Kolonien leicht an ihrer Färbung unterschieden werden. 
Blaue Kolonien enthalten nur den Plasmid-Vektor, während weiße Kolonien mit hoher Wahrscheinlichkeit ein Plasmid mit Insert tragen.

\subsection{Polymerasekettenreaktion (PCR)}

Diese Methode der in vitro-Amplifikation von DNA wurde für vielerlei Zwecke angewandt. So sollte z. B. an Hand der PCR die Richtigkeit der Assemblierung von Sequenzen überprüft oder Sequenzlücken (Gaps) innerhalb eines Genoms geschlossen werden. Näheres dazu wird in Kapitel 2.12. beschrieben. Als Enzym wurde die Taq-DNA-Polymerase eingesetzt (Fa. Eppendorf, Hamburg). Als Matrize diente genomische DNA aus C. tetani. Die verwendeten Starteroligonukleotide (Primer) waren i. d. R 17-25 Basen lang. Eine optimale Amplifikation war gewährleistet, wenn beide Primer einen ähnlichen Schmelzpunkt $\left(\mathrm{T}_{\mathrm{m}}\right)$ hatten und in gleicher Konzentration vorlagen. Die Berechnung des Schmelzpunktes erfolgte nach CHESTER \& MARSHAK (1993):

$$
\begin{aligned}
\mathrm{T}_{\mathrm{m}}=69,3+0,41 & (\% \mathrm{G}+\mathrm{C}-\mathrm{Gehalt})-650 / \mathrm{L} \\
\% \mathrm{G}+\mathrm{C}-\mathrm{Gehalt} & =\text { prozentualer } \mathrm{G}+\mathrm{C}-\text { Gehalt des Primers } \\
\mathrm{L} & =\text { Länge des Primers }
\end{aligned}
$$

Die Standard-PCR-Reaktionen fanden in $50 \mu 1$-Ansätzen statt. Folgende Komponenten wurden - bis auf das Enzym - auf Eis zusammenpipettiert:

$\begin{array}{lr}\text { Matrizen-DNA } & 1,0 \mu \mathrm{g} \\ \text { Primer } 1 & 0,5 \mu \mathrm{M} \\ \text { Primer } 2 & 0,5 \mu \mathrm{M} \\ \text { dNTP-Gemisch }(10 \mathrm{mM}) & 1 \mu \mathrm{l} \\ 10 \text { x Reaktionspuffer } & 5 \mu \mathrm{l} \\ \mathrm{MgCl}_{2}(25 \mathrm{mM}) & 5 \mu \mathrm{l} \\ \mathrm{H}_{2} \mathrm{O}_{\text {bidest. }} & \text { ad } 49,5 \mu \mathrm{l} \\ \text { DNA-Polymerase }(2 \mathrm{U} / \mu \mathrm{l}) & 0,5 \mu \mathrm{l}\end{array}$


Nach Durchmischung wurde der Ansatz in den PCR-Thermoblock (MWG-Biotech) gestellt. Das entsprechende PCR-Programm wurde entweder nach Zugabe der DNAPolymerase direkt begonnen oder aber es erfolgte vor Zugabe des Enzyms eine 5minütige Inkubation bei $95^{\circ} \mathrm{C}$ zur Denaturierung und eine 2-minütige Inkubation bei $80{ }^{\circ} \mathrm{C}$. Während des letzten Inkubationsschrittes erfolgte die Zugabe der TaqPolymerase („hot start“). Zur Amplifizierung schlossen sich folgende Temperaturzyklen in 25-35facher Wiederholung an:

PCR-Programm:

$\begin{array}{lll}\text { Denaturierung } & 95{ }^{\circ} \mathrm{C} & 30 \mathrm{~s} \\ \text { Anlagerung } & \mathrm{x}{ }^{\circ} \mathrm{C} & 30 \mathrm{~s} \\ \text { Polymerisierung } & 72{ }^{\circ} \mathrm{C} & \text { y s }\end{array}$

Die Anlagerungstemperatur war abhängig von der Schmelztemperatur der Primer und lag idealerweise $5{ }^{\circ} \mathrm{C}$ tiefer. Die Dauer y der Polymerisierung betrug 1 min pro $1 \mathrm{~kb}$ zu amplifizierender DNA. Zur Optimierung der PCR konnten einzelne Parameter variiert werden wie z.B. die Anlagerungstemperatur und die Anzahl der Zyklen oder auch die Konzentrationen der eingesetzten Primer sowie der Matrizen-DNA. Ferner konnte man die Spezifität durch Zugabe von DMSO (4\%,v/v) und Verringerung der $\mathrm{MgCl}_{2}$-Konzentration steigern. Nach Abschluss der Amplifikation wurde ein Aliquot im Agarosegel überprüft.

\subsection{Herstellung von Genbanken}

\subsubsection{Herstellung einer Plasmid-Genbank}

Im folgenden soll der Ablauf zur Herstellung von Genbanken dargelegt werden. Es wurde dabei der sogenannte Shotgun-Approach angewandt, der auf die Ermöglichung einer gleichwahrscheinlichen Klonierung aller genomischen DNA-Abschnitte abzielt. Mit anderen Worten: die Klonierung genomischer DNA sollte nach dem Zufallsprinzip ablaufen; keine Genomabschnitte sollten in der Genbank über- oder unterrepräsentiert sein. Die Sequenzierung solch einer Genbank gewährleistete eine 
Abnahme der Contig-Zahl in einem Genomsequenzierungsprojekt nach der Formel von LANDER \& WATERMAN (1988).

Die Herstellung einer optimalen Genbank war indes immens wichtig für das zügige Voranschreiten des gesamten Genomsequenzierungsprojekts. Optimal bedeutete hier ein günstiges Blau-Weiß-Verhältnis - weiße Kolonien sollten gegenüber den blauen in der Überzahl sein -, eine geringe Vektorkontamination, d. h. es durften nicht mehr als 5\% der Klone Plasmide ohne Insert tragen, und konstante Insertgrößen zwischen 2-3 kb.

Herstellung der Insert-Fragmente. Nach der Isolierung genomischer DNA (s. 2.5.1) wurde diese über mechanische Scherkräfte mit Hilfe einer umgebauten HPLCPumpe fragmentiert. Diese Methode zur Fragmentierung wurde gewählt, weil es im Gegensatz zum Verdau mit Restriktionsenzymen die Zufälligkeit der DNA-Brüche gewährleisten sollte. Die Fragmentgröße der so gescherten DNA konnte mittels Druckänderung und/oder Dauer der Zirkulation der DNA in dem HPLC-Pumpsystem variiert werden. Für die Herstellung von Fragmenten der Größe 1,5-3 kb wurde i. d. R. ein Druck von 0,5 bar und eine Zirkulationsdauer von 10 min gewählt. Allerdings konnte die gewünschte Fragmentgröße nur näherungsweise erreicht werden. Oft erhielt man einen ,DNA-Schmier', so dass eine nachfolgende Gelelution (s. 2.5.5) unumgänglich war. Die DNA-Fragmente wurden nach der Zirkulation mit $\mathrm{H}_{2} \mathrm{O}$ aus dem HPLC-System eluiert, aufgefangen und einer Ethanolfällung zur Aufkonzentrierung unterzogen (s. 2.4.2.2). Um sicherzustellen, dass die DNA-Fragmente keinen Einzelstrangüberhang aufwiesen, wurde eine Auffüllreaktion mit der T4DNA-Polymerase zur Herstellung von ,blunt-end'- Fragmenten durchgeführt (vgl. 2.6.3). Folgender Ansatz wurde pipettiert:

$14 \mu 1 \quad$ gescherte genomische Fragmente

$4 \quad \mu 1 \quad$ 5fach T4-DNA-Polymerase Puffer

$1 \mu \mathrm{dNTP}-\mathrm{Mix}(10 \mathrm{mM})$

$1 \quad \mu 1$ T4-DNA-Polymerase

Die Inkubation bei $11^{\circ} \mathrm{C}$ erfolgte für $20 \mathrm{~min}$. Anschließend wurde das Enzym bei $70{ }^{\circ} \mathrm{C}$ für 20 min inaktiviert oder aber der gesamte Ansatz wurde sofort auf ein Aga- 
rosegel aufgetragen. Nach ihrer Auftrennung wurde die gewünschte Fragmentgröße (i. d. R. 2-3 kb) aus dem Gel ausgeschnitten und eluiert (s. 2.5.5).

Behandlung des Klonierungsvektors. Zur Herstellung von Genbanken, deren rekombinante Plasmide im Rahmen der Genomsequenzierung von C. tetani sequenziert werden sollten, wurde der Plasmidvektor pTZ19R verwendet. Dieser enthielt das Gen zur Vermittlung einer Ampicillin-Resistenz, die Möglichkeit zu einem BlauWeiß-Screening (s. 2.7.2) sowie eine ,multi-cloning-site', die eine ,blunt-end' SmaISchnittstelle enthielt. Somit wurde SmaI-geschnittener und dephosporylierter Vektor (s. 2.6.1 und 2.6.2) mit den aufgefüllten, 2-3 kb großen genomischen Fragmenten ligiert (s. 2.6.4). Bei einigen Genbanken wurde ein modifizierter pTZ19R-Vektor verwendet, der anstelle der Ampicillin- eine Chloramphenicol-Resistenz vermittelt (freundlicherweise bereitgestellt von Andreas Christmann, Göttingen). Anschließend wurde der Ligationsansatz inaktiviert $\left(20 \mathrm{~min}, 65^{\circ} \mathrm{C}\right.$ ) und gegen $\mathrm{H}_{2} \mathrm{O}$ mikrodialysiert (30 min, RT). Es schloss sich eine Elektroporation (s. 2.7.1) und das Ausplattieren auf Selektivagarplatten an. Die Qualität der Genbank wurde schließlich per PlasmidSchnellpräparation (s. 2.5.3.2) getestet.

\subsubsection{Herstellung einer Cosmid-Genbank}

Die Verwendung von Cosmiden zur Erstellung von Genbanken hat gegenüber der Verwendung von Plasmiden oder Bakteriophagen als Klonierungsvektoren verschiedene Vorteile. Die erheblich höhere Klonierungskapazität der Cosmide im Vergleich zu Plasmiden ermöglicht die Klonierung von kontinuierlichen, genomischen DNAFragmenten in der Größenordnung von 30 bis $50 \mathrm{~kb}$ und vereinfacht dadurch die Erforschung von funktionell zusammengehörigen Genomabschnitten. Damit verbunden ist eine wesentlich geringere Zahl benötigter Klone, um statistisch betrachtet das ganze Genom in einer Cosmid-Genbank zu erfassen. Gegenüber Phagen haben Cosmide den Vorteil der einfacheren Handhabung: es entfällt das bei der Trennung von rekombinanten Phagen benötigte Verfahren der Plaque-Bildung auf Bakterienrasen. Stattdessen lassen sich, wie bei der Genbank-Herstellung mit Plasmiden, rekombinante Cosmide durch die Transformation in Bakterien trennen, die dadurch eine An- 
tibiotika-Resistenz erwerben und sich auf Antibiotika-haltigen Agar-Platten über das Wachstum zu getrenntliegenden Kolonien verteilen.

In dieser Arbeit wurde der Cosmid-Vektor superCos1 (Abb. 2; Fa. Stratagene; EVANS et al., 1989) verwendet, der die Gene für die Ausbildung einer zweifachen Antibiotika-Resistenz gegen Ampicillin $\left(\mathrm{Amp}^{\mathrm{R}}\right)$ und Kanamycin $\left(\mathrm{Neo}^{\mathrm{R}}\right)$ trägt, was zur Steigerung der Stabilität der Cosmid-Klone während des Koloniewachstums in Nährmedien mit beiden Antibiotika führt (WENZEL \& HERRMANN, 1996). Des weiteren besitzt der Vektor eine doppelte Kopie des Cos-Elements der DNA des Bakteriophagen Lambda. Das Cos-Element wird bei der Verpackung von concatemerer DNA in Phagenköpfe benötigt. Die doppelte Kopie des Elements bewirkt gegenüber Vektoren mit nur einer Cos-site eine Erhöhung der Klonierungseffizienz: im Zuge der Vektorpräparation entstehen zwei unterschiedliche Vektor-Arme, jedes mit einer cos-site, wodurch sich - nach erfolgter Ligation - die Anzahl an Kolonien reduziert, die sich aufgrund der Verpackung von concatemerer Vektor-DNA ohne klonierte, genomische DNA bilden (WENZEL \& HERRMANN, 1996). Die Klonierungskapazität des superCos1-Vektors liegt zwischen 31 und $48 \mathrm{~kb}$, d. h. dass ausschließlich Cosmide mit diesen Insertgrößen erfolgreich verpackt werden.

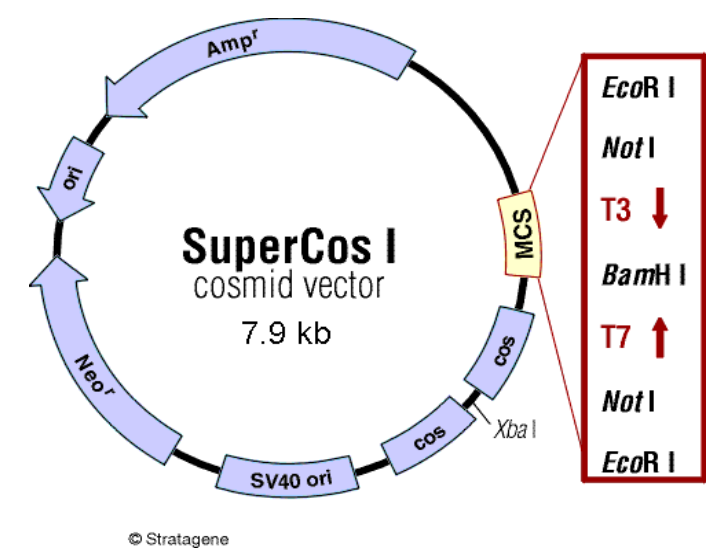

Abb. 2: Der Cosmid-Vektor SuperCos1 (Fa. Stratagene, EVANS et al., 1989)

Die Vorbereitung zum Einsatz des Vektors in der Ligation bestand in folgenden Punkten:

- Restriktionsverdau mit $X b a \mathrm{I}$

- Dephosphorylierung mit alkalischer Phosphatase

- Phenol-Chloroform-Reinigung und Ethanol-Fällung 
- Restriktionsverdau mit dem Klonierungsenzym BamHI bzw. EcoRI (je nach Enzym für den partiellen Verdau)

- Phenol-Chloroform-Reinigung und Ethanol-Fällung

Die Gewinnung hochmolekularer genomischer DNA aus C. tetani wurde wie in Kapitel 2.5.1 beschrieben durchgeführt. Insbesondere wurde auf die Vermeidung von starken Scherkräften geachtet, um DNA-Fragmente von über 200 kb Größe zu erhalten. Anschließend wurde die genomische DNA einem partiellen Verdau mit dem Enzym Sau3AI unterworfen, welches die gleichen überstehenden Enden wie BamHI und daher komplementäre Enden produziert. Später wurde zum partiellen Verdau auch das Enzym TasI benutzt, das komplementäre Enden zum alternativen Klonierungsenzym EcoRI bildet. Ziel war dabei die Gewinnung von Fragmenten mit durchschnittlichen Größen zwischen 30 und 50 kb. Die Bedingungen zur Herstellung dieser Fragmentgrößen mussten experimentell bestimmt werden. Dabei wurde zum einen die eingesetzte Enzymkonzentration und zum anderen die Inkubationszeit des Verdaus variiert. Die Überprüfung der Ansätze erfolgte über ein 0,4\%iges AgaroseGel. Geeignete Partialverdaus wurden mit Phenol-Chloroform aufgereinigt, mit Ethanol gefällt und mit alkalischer Phosphatase dephosphoryliert, um die Ligation von nicht-kontinuierlichen genomischen Fragmenten zu verhindern. Anschließend erfolgte eine erneute Phenol-Chloroform-Reinigung und Fällung mit Ethanol.

Die Ligation wurde mit unterschiedlichen Konzentrationsverhältnissen der beiden Vektorarme zu den genomischen Sau3AI- bzw. TasI-Fragmenten durchgeführt. Die anschließende Verpackung des Ligationsansatzes wurde mit dem in vitroVerpackungsextrakt Gigapack $^{\circledR}$ III XL (Fa. Stratagene) durchgeführt, welches die einzelnen Strukturelemente eines Phagenpartikels enthält. Dazu wurden 2-4 $\mu 1$ der ligierten DNA zu dem unmittelbar zuvor aufgetauten Verpackungsextrakt gegeben und kurz durchmischt. Nach 2-stündiger Inkubation bei RT wurden $500 \mu 1$ SMPuffer und $20 \mu \mathrm{l}$ Chloroform hinzugefügt. Nach einer kurzen Zentrifugation wurde der Überstand, welcher die rekombinanten Phagen enthielt, abgenommen und wie nachfolgend beschrieben zur Transduktion weiterverwendet. Als Rezipient der in den Phagenköpfen verpackten, rekombinanten DNA wurde der E. coli Stamm DH5 $\alpha$ verwendet, der in einem LB-Medium angezogen wurde, welches mit $10 \mathrm{mM} \mathrm{MgSO}_{4}$ und 0,2\% (w/v) Maltose komplementiert wurde. Nach 4-6-stündigem Wachstum bis $\mathrm{zu}$ einer $\mathrm{OD}_{600 \mathrm{~nm}}$ von maximal 1,0 wurden die Zellen geerntet (4000 Upm, $10 \mathrm{~min}$ ) 
und in $1 / 2$ Vol. sterilem $10 \mathrm{mM} \mathrm{MgSO}_{4}$ aufgenommen. Diese Suspension wurde dann bis zu einer OD von 0,5 mit $10 \mathrm{mM} \mathrm{MgSO}_{4}$ weiterverdünnt. $25 \mu 1$ dieser Zellsuspension wurden anschließend zu $25 \mu 1$ des vorher mit SM-Puffer 1:5 bis 1:40 verdünnten Phagen-enthaltenden Überstandes gegeben und für 30 min bei RT inkubiert. Dann erfolgte die Zugabe von $200 \mu 1$ LB-Medium zum E-Cup und die Inkubation für $1 \mathrm{~h}$ bei $37^{\circ} \mathrm{C}$, dabei das E-Cup jede 15 min kurz schüttelnd. Nach dem Abzentrifugieren der Zellen und der Aufnahme des Pellets in frischem LB-Medium wurden die Zellen auf Selektiv-Platten mit Ampicillin und/oder Kanamycin ausplattiert. Die Klone, die auf Platten mit beiden Antibiotika wuchsen, wurden wie in Kapitel 2.5.4 beschrieben für die robotgesteuerte Cosmid-Präparation eingesetzt.

\section{$\underline{\text { SM-Puffer }}$}

$\mathrm{NaCl}$

$\mathrm{MgSO}_{4} \times 7 \mathrm{H}_{2} \mathrm{O}$

$1 \mathrm{M}$ Tris- $\mathrm{HCl}(\mathrm{pH} 7,5)$

$2 \%(\mathrm{w} / \mathrm{v})$ Gelatine

$\mathrm{H}_{2} \mathrm{O}_{\text {bidest. }}$
$5,8 \mathrm{~g}$

$2,0 \mathrm{~g}$

$50 \mathrm{ml}$

$5 \mathrm{ml}$

ad $1000 \mathrm{ml}$

\subsection{0 \\ Sequenzierung von DNA}

Die Sequenzierung von DNA, sei es die Sequenzierung von rekombinanten Plasmiden/Cosmiden oder die Sequenzierung von PCR-Produkten, wurde an ABI PRISM 337 Geräten (Applied Biosystems, Weiterstadt) oder am MegaBACE 1000 System (Amersham Bioscience, Molecular Dynamics) durchgeführt. Beide Gerätearten sollen im folgenden kurz vorgestellt werden. Allerdings würde es den Rahmen dieser Arbeit sprengen, auf genauere Details einzugehen oder die komplette Prozedur der Sequenzierung zu beschreiben. Für Interessierte verweise ich auf die Internetseiten der beiden Firmen (http://www.appliedbiosystems.com und http://www5.amersham biosciences.com/aptrix/upp01077.nsf/content/na_homepage). 


\subsubsection{Sequenzierung mit ABI DNA Sequencer 377}

Der ABI PRISM ${ }^{\circledR} 377$ DNA Sequencer (Fa. Perkin-Elmer/Applied Biosystems) analysiert automatisch DNA-Moleküle, die mit multiplen Fluoreszenzfarbstoffen (Big Dye ${ }^{\circledR}$ Terminatoren) markiert sind, wobei für jede DNA-Base ein anderer Farbstoff gewählt wird. Die Markierung der DNA erfolgt dabei nach dem Prinzip der von SANGER et al. (1977) entwickelten Didesoxy- oder Kettenabbruch-Methode. Die zu sequenzierenden markierten Proben werden auf ein vertikal verlaufendes Polyacrylamid-Gel aufgetragen und durch Anlegen einer Spannung elektrophoretisch aufgetrennt. 96 Proben können dabei gleichzeitig sequenziert werden. Die Farbstoffe werden beim Durchlaufen des unteren Endes des Gels mittels eines Lasers detektiert und die Signale anschließend einer Computeranalyse unterzogen. Die Fluoreszenzsignale werden dabei über das sogenannte Base calling (s. 2.11) automatisch in Sequenzdaten umgewandelt. Zur Markierung der DNA wurde das Big Dye ${ }^{\circledR}$ Terminator Cycle Sequencing Kit benutzt, das eine spezielle DNA-Polymerase enthielt (Ampli-Taq ${ }^{\mathrm{R}}$ DNA-Polymerase). Ein optimal hergestellter Sequenzieransatz (s. u.) konnte so in einem ü. N.-Lauf zu einer auflösbaren DNA-Leseweite von ca. 800 Basen führen. Die Sequenzierungsprozedur mit dem ABI PRISM ${ }^{\circledR} 377$ umfasste folgende Schritte:

- Reinigung der Glasplatten

- Gießen des Polyacrylamid-Gels zwischen die Glasplatten

- Einbau des Gels in das Gerät

- Plattencheck und Vorlauf

- Beladen des Gels mit 96 Proben

- Starten der Elektrophorese

Tabelle 4 gibt einen Einblick in die Zusammensetzung eines Sequenziergels und in die einzustellenden Parameter am ABI PRISM ${ }^{\circledR} 377$ zur Durchführung eines Sequenzierlaufes. 
Tabelle 4: Parameter zur Beschaffenheit eines Sequenziergels $(4,25 \%$ ig) sowie zur Bedienung eines ABI PRISM ${ }^{\circledR} 377$ bei einem ü. N.-Lauf

\begin{tabular}{cc}
\hline Geldicke & $0,2 \mathrm{~mm}$ \\
\hline Gellänge & $48 \mathrm{~cm}$ \\
\hline Harnstoff $7 \mathrm{M}$ & $18 \mathrm{~g}$ \\
\hline Acrylamid $(30 \%, 29: 1)$ & $5,3 \mathrm{ml}$ \\
\hline $10 \mathrm{x}$ TBE ${ }_{\text {long run }}$ & $6 \mathrm{ml}$ \\
\hline $\mathrm{H}_{2} \mathrm{O}_{\text {bidest }}$ & $21,5 \mathrm{ml}$ \\
\hline $10 \%$ APS & $250 \mu 1$ \\
\hline TEMED & $25 \mu 1$ \\
\hline Spannung & $3500 \mathrm{~V}$ \\
\hline Stromstärke & $60 \mathrm{~mA}$ \\
\hline Leistung & $40 \mathrm{~W}$ \\
\hline Temperatur & $45{ }^{\circ} \mathrm{C}$ \\
\hline CCD Offset & 0 \\
\hline CCD Gain & 4 \\
\hline Vorlaufzeit & $90 \mathrm{sec}$ \\
\hline Laufzeit & $1,5 \mathrm{~h}+14,5 \mathrm{~h}$ \\
\hline Laufpuffer & 22000 \\
\hline Minimale Anzahl der Scans & TTE oben, $1 \mathrm{x} \mathrm{TTE} \mathrm{unten}$ \\
\hline
\end{tabular}

Probenbereitung. Die Zusammensetzung eines Sequenzieransatzes variierte je nach Art der DNA (Plasmid, Cosmid oder PCR) sowie nach dessen G+C-Gehalt. Der Ansatz erfolgte normalerweise im 96er Maßstab. Typischerweise wurde zur Sequenzierung von Templates (d. h. Inserts von Plasmiden einer C. tetani-Genbank), die aus dem Genom von C. tetani stammten, folgender Ansatz pipettiert (im ,Premix' sind dabei die ABI Big Dye ${ }^{\circledR}$ Terminatoren enthalten): 
"1/2-half BD-Ansatz"

Premix

$$
2 \mu 1
$$

half BD

Betain (5 M)

$2 \mu 1$

$\operatorname{Primer}(5 \mathrm{pmol} / \mu \mathrm{l})$

$1 \mu 1$

$\mathrm{H}_{2} \mathrm{O}$

$1 \mu 1$

DNA-Template $(\max .13 \mu 1)$

$$
\mathrm{x} \mu 1
$$

$\underline{\mathrm{x} \mu \mathrm{l}}=400 \mathrm{ng}$

$20 \mu 1$

Dieser Ansatz wurde dann in einen 96er PCR-Thermoblock (MWG-Primus 96 plus) gegeben und dort 2 min bei $98{ }^{\circ} \mathrm{C}$ denaturiert. Folgendes Programm wurde anschließend gestartet, wobei sich die Anlagerungstemperatur nach den Schmelztemperaturen der verwendeten Primer richtete, die meistens um die $50^{\circ} \mathrm{C}$ lag:

$\begin{array}{lll}\text { Denaturierung } & 96{ }^{\circ} \mathrm{C} & 20 \mathrm{~s} \\ \text { Anlagerung } & \text { i.d. R. } 45^{\circ} \mathrm{C} & 15 \mathrm{~s} \\ \text { Polymerisierung } & 60{ }^{\circ} \mathrm{C} & 4 \mathrm{~min}\end{array}$

Es schloss sich eine Fällung mit Ethanol (99\%) und 3 M Natriumacetat (pH 4,6) an, um überschüssige, nicht eingebaute farbstoffmarkierte Terminatoren zu entfernen, da diese sonst als „Dye-Blobs“ in den ersten 100 Basen der Sequenz erscheinen würden. Vor dem Auftragen auf das Sequenziergel wurde die gefällte DNA mit $1 \mu 1$ StopMix (Formamid zu Loading Puffer (50 mg Blue Dextran/ml 25mM EDTA, pH 8,0) im Verhältnis 5:1) versetzt.

\subsubsection{Sequenzierung mit dem MegaBACE 1000 Capillar Sequencer}

Das MegaBACE 1000 System analysiert wie das ABI PRISM ${ }^{\circledR} 377$ Gerät automatisch DNA-Moleküle, die mit multiplen Fluoreszenzfarbstoffen (DYEnamic ET Dye $^{\circledR}$ Terminatoren) markiert sind. Ein Lasersystem übernimmt die Detektion der Fluoreszenzsignale. Im Gegensatz zum ABI Gerät aber benutzt der MegaBACE 1000 die Kapillar-Technik: es muss nicht mehr ein Polyacrylamid-Gel gegossen werden; stattdessen findet die Elektrophorese in winzig kleinen (ca. $100 \mu \mathrm{m}$ im Durchmesser) 
Kapillaren statt, die Polyacrylamid-Matrix enthalten, welches das System über Hochdruck aus 6 Matrix-Tubes in die Kapillaren hineinschießen kann. Diese Kapillaren sind in 6 Arrays mit jeweils 16 Einzelkapillaren angeordnet. Zum Beladen des Systems wird lediglich eine 96er Platte mit den enthaltenden Proben in die Maschine gestellt; mittels des Anlegens einer Spannung gelangt die Probe dann in die Kapillaren, in denen dann die elektrophoretische Auftrennung stattfindet. Die Bedienung des Gerätes folgte dann den auf dem Display erscheinenden Anweisungen. Das System kann im Hochdurchsatz arbeiten und dabei 96 Proben in 2-4 Stunden mit einer Leseweite von ca. 600 Basen sequenzieren. Im Gegensatz zum ABI PRISM ${ }^{\circledR} 377$ zeigt der MegaBACE 1000 eine höhere Empfindlichkeit bei schwankenden DNAKonzentrationen, so dass diese nach Möglichkeit im Vorfeld angeglichen werden sollten. Alle gewonnenen Rohdaten werden nach Ende eines Laufes automatisch mittels Base calling ausgewertet. Die Probenbereitung entsprach weitestgehend der bereits beschriebenen Methode für den ABI PRISM ${ }^{\circledR} 377$ (s. 2.10.1). Abweichend davon wurde das Amersham-DYEnamic-ET-Dye-Terminator-Cycle-Sequencing Kit benutzt.

\subsection{Die Prozessierung von Rohsequenzen}

Nach einem Sequenzierlauf werden die Rohdaten, die Fluoreszenzsignale und intensitäten, automatisch analysiert und in DNA-Sequenzen umgerechnet, was als Base calling bezeichnet wird. Benutzt wurde der Basecaller Phred (EWING et al., 1998). Dieser liest die Rohdaten von den DNA Sequenziermaschinen (trace files), rechnet sie in DNA-Basen um und teilt diesen zusätzlich einen Qualitätswert zu. Phred kann sowohl die Rohdaten vom ABI 377 DNA Gerät als auch vom Megabace 1000 lesen. Die Sequenzen und die dazugehörigen Qualitätswerte können dann zur Assemblierung mit Hilfe von Sequenzassemblierungsprogrammen benutzt werden (BONFIELD \& STADEN, 1996). 


\subsubsection{Einführung in die Prozessierung von DNA-Sequenzen mittels des STADEN-Software-Packets}

Das STADEN-Software-Packet beinhaltet verschiedene Programme zum Selektieren, Aufbereiten, Assemblieren und Editieren von DNA-Sequenzen (STADEN et al., 2000). Es würde den Rahmen dieser Arbeit sprengen, auf die Struktur und Funktionsweise der einzelnen Programme einzugehen. Hier soll nur ein Überblick über die Anwendung des Software-Packetes im Rahmen des Genomsequenzierungsprojektes C. tetani gegeben werden. Eine ausführliche Dokumentation kann unter http://www.mrc-lmb.cam.ac.uk/pubseq/staden_home.html abgerufen werden. Im wesentlichen sind es zwei Programme, die zur Prozessierung der DNA-Sequenzen benutzt wurden: Pregap4 und Gap4.

\subsubsection{Pregap4}

Bevor DNA-Sequenzen in das Genomassemblierungsprogramm Gap4 eingespeist werden können, müssen diese durch diverse Prozesse geleitet werden, welche das Programm Pregap4 leistet (BONFIELD \& STADEN, 1996):

- Screening auf Vektor-Kontaminationen: Sequenzen, die den Vektor-Sequenzen (pTZ19R oder superCos1) entsprechen, fallen aus der Datenbank heraus.

- Screening auf Kontamination mit E. coli DNA: bei der Herstellung der Genbank kann es zu Kontaminationen mit der DNA des Wirtsstammes (E. coli DH5 $\alpha$ ) kommen. Diese Daten müssen ebenfalls entfernt werden.

- Qualitätskontrolle: Sequenzen mit einer geringen Qualität fallen aus der Datenbank heraus.

- Vektor-Clipping: Es werden die Basen einer Sequenz maskiert, die im Übergang zum Insert der Vektor-Sequenz entsprechen.

- Umformatierung in ein neues Dateiformat: Zur Assemblierung benötigt Gap4 ein anderes Dateiformat (experiment files).

Zur Erleichterung der Prozessierung der Rohdaten wurden im Göttinger Genomanalyselabor Computerskripte entwickelt, die hier nicht näher erläutert werden sollen. Prinzipiell bewerkstelligten solche Skripte das Umbenennen von Dateinamen, das 
Einleiten der Rohsequenzen in Pregap4 und das Sortieren der Ausgabe von Pregap4 in mehrere Listen (Failed, Passed, ScreenVector, etc.).

\subsubsection{Gap4}

Gap4 ist ein Genomassemblierungsprogramm; es kann aber auch für kleinere DNAAbschnitte wie Cosmide oder große Plasmide verwendet werden (BONFIELD et al., 1995). Neben der Assemblierung kann das Programm auch zur Editierung der Sequenzen benutzt werden. Gap4 ist des weiteren unerlässlich beim sogenannten Finishing, dem Schließen von Sequenzlücken in einem Genomsequenzierungsprojekt.

Assemblierung. Mit Hilfe von Algorithmen (PHRAP, http://bozeman.mbt.washington.edu/phrap.docs/phrap.html) werden Sequenzüberlappe ausfindig gemacht. Sequenzläufe (readings) die solche Sequenzüberlappe aufweisen, werden dann passend zueinander ausgerichtet (Alignment) und zu zusammenhängenden DNA-Abschnitten, den sogenannten Contigs zusammengefasst. Aus den , alignten’ Sequenzen innerhalb eines Contigs bildet das Programm dann eine Consensus-Sequenz.

Editierung. Ziel ist es hierbei, die Qualität der Consensus-Sequenz eines Contigs zu verbessern und Fehler in der Assemblierung zu detektieren und aufzulösen. Dabei wurden entsprechende Einzelsequenzen markiert, aus dem Contig extrahiert und dann manuell in den Datensatz zu passenden Contigs zurücktransferiert. Assemblierungsfehler (Misassemblies) treten vor allem in repetitiven Bereichen einer Genomsequenz auf, wie z. B. IS-Elemente oder rRNA-Cluster. Zur Anwendung kommt dabei die Funktion Contig Editor, mit dessen Hilfe man u. a. Sequenzschwächen und fehler finden und reparieren kann. Als Anhaltswert für die Sequenzqualität soll die Fehlerrate nicht höher als 1 in 10000 Basen betragen. Dabei lässt sich die Qualität jeder einzelnen Base in der Consensus-Sequenz über deren Base Confidence-Wert überprüfen.

Finishing. In Gap4 können zwei (oder mehrere) Contigs anhand der Lage und Orientierung der enthaltenden readings zueinander geordnet werden (s. 2.12.2), was eine Hilfe zur Überwindung von Sequenzlücken zwischen Contigs ist (s. 2.12). Gegebenenfalls können Contigs dann semi-manuell mit Hilfe der Funktion Join Contigs miteinander verbunden werden. 


\subsection{Methoden zur Überwindung von Sequenzlücken in ei- nem Genomsequenzierungsprojekt}

\subsection{1}

Identifikation von Contigüberlappe mit Gap4 oder BLASTN

Nach erfolgter Assemblierung, deren Überprüfung und der ersten Editierung sämtlicher Contigs wurde versucht, überlappende Contigs zu identifizieren. Dies geschah zum einen automatisch über die Funktion Find Internal Joins in Gap4. Jeder gefundene potentielle Contigüberlapp bedurfte im Join Contigs Editor einer genauen Überprüfung. Zum anderen wurde ,extern' nach überlappenden Contigs gesucht, indem die Enden sämtlicher Contigs gegen den gesamten Datensatz - bestehend aus allen Contig-Consensus-Sequenzen - mit dem BLAST-Algorithmus abgeglichen wurden (ALTSCHUL et al., 1990). Die letztere Methode zeigte eine bessere Trefferquote. Mit dieser Methode wurden auch alle repetitiven Sequenzen im Genom identifiziert, die Kopienzahl bestimmt und jede Kopie im Gap4-Datensatz markiert, da diese die größten Probleme im letzten Stadium eines Genomsequenzierungsprojektes bereiteten. Contigs, die potentiell überlappen sollten, wurden dann in Gap4 manuell über Join Contigs zueinander ausgerichtet und gegebenenfalls miteinander verbunden.

\subsection{2}

\section{Primer-Walking}

Mit Hilfe der Gap4-Funktion Template Display können einzelne Contigs visuell dargestellt werden: dort sind alle im Contig enthaltenden Readings und deren Templates aufgeführt. Ein Template entspricht dabei einem Insert eines rekombinanten Plasmids der C. tetani-Genbank. Anzumerken ist, dass die Inserts der Plasmide von beiden Seiten her ansequenziert wurden (forward und reverse). Da die durchschnittliche Insertgröße bei etwa $2 \mathrm{~kb}$ lag und ein typischer Sequenzierlauf etwa 600-700 Basen lang war, bedeutete dies, dass ein Insert (= Template) nicht vollständig sequenziert wurde. Im Template Display nun sind die beiden readings desselben Templates zueinander angeordnet. Mit Hilfe der Funktion Order Contigs ließen sich dann solche Contigs aneinander reihen, die an den Rändern readings beinhalteten, die zu demselben Template gehörten: 
beispielsweise begann oder endete der Contig A mit dem forward reading des Templates $\mathrm{X}$, während Contig $\mathrm{B}$ nun mit dem reverse reading des Templates $\mathrm{X}$ endete oder begann. Damit war es nun möglich, durch ein sogenanntes Primer-Walking die Lücke zwischen diesen beiden Contigs zu schließen: es wurde ein Sequenzierprimer vom Ende eines der beiden readings abgeleitet (mit der Orientierung zum Insertinneren), der dann zur Sequenzierung des entsprechenden Templates eingesetzt wurde. So konnte man die überbrückende Sequenz zwischen den Contigs ermitteln, woraufhin die beiden Contigs i. d. R. geschlossen werden konnten.

\subsubsection{PCR-basierte Methoden}

Der folgende Abschnitt soll kurz aufzeigen, wie PCR-basierte Methoden zur Überwindung von Sequenzlücken in einem Genomsequenzierungsprojekt beitragen können.

War kein Plasmid-Template vorhanden, dass eine Sequenzlücke zwischen zwei Contigs überspannte, mussten weitere Daten herangezogen werden, um Contigs aneinander zu reihen. Wichtig war dabei u. a. eine Cosmid-Genbank. Die Größe des Inserts zwischen 30-40 kb eines rekombinanten Cosmids erhöhte im Vergleich zu rekombinanten Plasmiden die Möglichkeit, dass ein solches Cosmid eine Lücke zwischen zwei Contigs überspannte. Wurden solche Cosmide in Gap4 identifiziert, konnten die dazugehörigen Contigs zueinander geordnet werden. Daraufhin wurden Primer von den beiden entsprechenden Contigenden her abgeleitet - mit der Orientierung zur Lücke - und eine PCR entweder mit genomischer DNA oder mit dem die Lücke überspannenden Cosmid durchgeführt.

Des weiteren wurde die Methode der kombinatorischen PCR eingesetzt. Hierbei wurden zuerst Primer von allen Contigrändern abgleitet, mit der Orientierung zum Contigende hin. Nun wurden diese in allen denkbaren Kombinationen miteinander eingesetzt, wobei eine durchschnittliche Lückengröße von nicht mehr als $2 \mathrm{~kb}$ angenommen wurde. Da die Anzahl an möglichen Kombinationen entsprechend groß war (z. B. bei 100 Contigs 19900 mögliche Kombinationen), wurden in der Praxis zur Erleichterung der Arbeit nur Subsätze von Primerkombinationen angesetzt. Jedes erhaltende PCR-Produkt wurde sofort sequenziert und die Sequenz zum Lückenschluss eingesetzt. 
Als sehr effektiv zur Überwindung von Sequenzlücken in einem Genomprojekt hat sich die Hinzunahme von Annotationsdaten erwiesen. Allerdings bedurfte es dazu einer Voraussetzung: es musste ein oder mehrere Genome von (nah) verwandten Organismen bereits - zumindest teilweise - bekannt sein. Für das C. tetani Projekt bot sich die Verwendung der Genomdaten von C. acetobutylicum, C. perfringens, $C$. difficile und C. botulinum an. Dabei machte man sich den Umstand zunutze, dass nah verwandte Organismen i. d. R. einen hohen Konservierungsgrad in der genetischen Organisation haben. So ist bei Prokaryonten die genetische Nachbarschaft eines bestimmten ORFs (open reading frame) innerhalb einer Gattungen oft ähnlich oder sogar identisch. Für alle Enden der Contigs im C. tetani-Projekt wurde folgendermaßen vorgegangen:

- Die DNA-Sequenz des Endes eines Contigs (1-4 kb) wurde einer ORFIdentifikation (s. 2.13.1) unterworfen.

- Die Proteinsequenz(en) des/der gefundenen ORFs (z. B. ORF X) wurde(n) mittels des BLASTP-Algorithmus gegen die Proteinsequenzen der verwandten Organismen abgeglichen (ALTSCHUL et al., 1990). Dazu wurde i. d. R. ERGO verwendet (OVERBEEK et al., 2000; s. 2.13.2).

- Sollte ein hoch homologes Protein, ORF X', in einem verwandten Organismus gefunden worden sein, wurde mit Hilfe von ERGO die genetische Nachbarschaft dieses ORFs angezeigt.

- Die Proteinsequenz eines direkt benachbarten ORFs, ORF Y', in diesem verwandten Organismus wurde dann mittels tBLASTN (Proteinsequenz-BLAST gegen alle 6 translatierten Leserahmen) gegen das Genom von C. tetani abgeglichen.

- Wurde ein BLAST-Treffer mit hoher Homologie, d. h. der ORF Y, in dem Genom von C. tetani gefunden und bezog sich dieser auf ein Protein, das in der DNA-Sequenz des Endes eines anderen Contigs kodiert vorlag, wurden die beiden Contigs - also das ORF X und das ORF Y kodierende - als potentiell zusammengehörig eingestuft.

- Nun wurde eine PCR mit Primern durchgeführt, die von den entsprechenden Enden dieser beiden Contigs abgeleitet wurden. Die Elongationszeit konnte 
aus der Größe der ORFs X' und Y' sowie deren Abstand im Genom des verwandten Vergleichsorganismus annäherungsweise abgeleitet werden.

- Zeigte sich ein PCR-Produkt (in der zu erwartenden Größe), wurde dieses sequenziert und die DNA-Sequenz zum Contigschluss verwendet.

\section{$2.13 \quad$ Sequenzanalyse}

Nach Beendigung der Sequenzierungsphase und dem Schluss der letzten Lücken in der Genomsequenz wurde versucht, alle in der Sequenz vorkommenden Gene zu identifizieren. Das Vorhersagen von allen potentiellen Genen wird als ORFVorhersage bezeichnet, welche mit entsprechenden Computer-Algorithmen durchgeführt wurde. Danach schloss sich die eigentliche Annotation an, welches die Zuweisung von Funktionen zu den abgeleiteten Proteinsequenzen der ORFs meint.

\subsubsection{ORF-Vorhersage}

Alle ORF-Vorhersageprogramme für Prokaryonten basieren auf das Auffinden von Start (ATG, GTG, TTG)- und Stopcodons (TAA, TGA, TAG) auf allen sechs möglichen Leserahmen. Danach werden solche Sequenzbereiche festgelegt, die zwischen dem Start- und Stopcodon auf demselben Leserahmen eine bestimmte Cutoff-Größe erreichen (oft 30 Codons). Dieser Bereich wird als ORF bezeichnet, stellt also ein potentielles Gen dar.

Im C. tetani-Genomprojekt kamen unterschiedliche ORF-Vorhersage-Programme zum Einsatz. Bei der Plasmidsequenz (pE88) wurde das Programm Frameplot (ISHIKAWA \& HOTTA, 1999) angewandt, das besonders für Organismen mit extremen G+C-Gehalt geeignet ist (http://watson.nih.go.jp/ jun/cgi-bin/frameplot3.0b.pl). Mit Frameplot ist es möglich, sich die abgeleiteten Proteinsequenzen der einzelnen vorhergesagten ORFs anzeigen zu lassen und diese direkt mit der NCBISequenz-Datenbank (http://www.ncbi.nlm.nih.gov) abzugleichen. Dadurch können homologe Proteine aus andern Organismen identifiziert werden, und somit dem betrachteten ORF gegebenenfalls eine Funktion zugewiesen werden. 
Für die ORF-Vorhersage auf der chromosomalen DNA-Sequenz wurde das Programm GLIMMER (Gene Locator and Interpolated Markov Modeler; DELCHER et al., 1999) verwendet. Dieses Programm benutzt interpolierende Markov-Modelle (IMM), um kodierende Regionen zu identifizieren und sie von nicht-kodierenden Bereichen zu unterscheiden. Zuerst entwickelt GLIMMER anhand einer Trainingsmenge ein IMM. Typischerweise sollte die Testmenge aus bereits bekannten Genen des Organismus' und - sollten solche nicht vorliegen - aus solchen ORFs bestehen, die sehr lang sind und daher mit hoher Wahrscheinlichkeit Gene darstellen. Im eigentlichen ORF-Vorhersageprogramm wendet nun GLIMMER dieses IMM an, um alle potentiellen Gene zu identifizieren. GLIMMER löst i. d. R. auch Probleme bei Überlappungen von ORFs, wobei es sich für einen der beiden überlappenden ORFs entscheidet.

Abschließend sei gesagt, dass es bisher kein ORF-Vorhersage-Programm gibt, welches alle Gene richtig vorhersagt. Manuelle Verbesserungen der Gen-Vorhersage sind daher unumgänglich.

\subsubsection{Genomweite Annotation mit ERGO}

Zur Erleichterung der genomweiten Annotation, d. h. der Zuordnung von Funktionen $\mathrm{zu}$ allen potentiellen Genen - sprich ORFs - eines Genoms, gibt es verschiedene Computerprogramme wie PEDANT, MAGPIE oder ERGO. Im Göttinger Genomanalyselabor wird das ERGO Programm benutzt (Fa. Integrated Genomics; http://www.integratedGenomics.com; OVERBEEK et al., 2000), genauer gesagt, eine lokal installierte Version, das ERGO Göttingen. Es soll an dieser Stelle nicht der Versuch unternommen werden, die Vielzahl der Möglichkeiten diese Programms vorzustellen, was den Rahmen dieser Arbeit sprengen würde. Vielmehr soll konkret erläutert werden, wie bei der genomweiten Annotation von C. tetani vorgegangen wurde.

Die von GLIMMER vorhergesagten ORFs wurden in das ERGO-Programm eingespeist. Dieses berechnet nun mittels des FASTA-Algorithmus' die Ähnlichkeiten aller C. tetani-ORFs - auf Nukleotid- wie auf Proteinebene - zu Sequenzen der internen ERGO-Datenbank. Die nicht-redundante interne ERGO-Datenbank umfasst zur Zeit (Oktober 2002) Sequenzen - i. d. R. vollständige Genome - aus 394 Organis- 
men: 25 Archaeen, 81 Eukaryoten, 88 Viren und 200 Prokaryoten. Eine neuere Version des ERGO-Programms, die zum Zeitpunkt der Annotation des C. tetani-Genoms noch nicht vorlag, ist auch in der Lage, eine Ähnlichkeitssuche aller ORFs mit der externen NCBI-Datenbank durchzuführen. Der externe NCBI-Sequenzabgleich umfasst eine Vielzahl von Nukleotid- und Proteinsequenz-Datenbanken wie die PDB-, SwissProt-, Pir-, DDBJ-, EMBL- und die GenBank-Datenbank.

Das ERGO-Programm wies also allen C.tetani-ORFs automatisch eine Funktion zu, die aus dem Ähnlichkeitsvergleich mit der internen ERGO-Datenbank abgeleitet wurde. Wenn keine Ähnlichkeiten in der Datenbank gefunden wurden, bezeichnete das Programm den entsprechenden ORF als hypothetisch. Diese automatische Annotation musste nun - ORF für ORF - überprüft werden, da sich der interne DatenbankAbgleich oftmals als ungenügend herausstellte. So z. B. konnte vielen der von ERGO als hypothetisch bezeichneten ORFs durch einen zusätzlichen externen NCBISequenzabgleich eine Funktion zugewiesen werden. Ein externer Sequenzabgleich erwies sich gegenüber dem internen Abgleich i. d. R. als umfassender, aktueller und genauer in der Funktionszuordnung. Als weitere Fehlermöglichkeit der automatischen ERGO-Annotation wurde erkannt, dass ERGO dem betrachteten ORF die Funktion desjenigen Proteins zuwies, das den höchsten Ähnlichkeitswert (SmithWaterman-Score) zum betrachteten ORF aufwies. Gerade bei geringer Homologie, also einem niedrigen Smith-Waterman-Score, zeigte sich aber oftmals, dass die dem ORF zugewiesene Funktion zu ungenau oder aber auch zu speziell war (WATERMAN, 1984).

Folgende Vorgehensweise wurde bei der Überprüfung der automatischen Annotation eines ORFs angewandt:

- Vergleich der dem ORF zugewiesenen Funktion mit den Funktionen der homologen Proteine; Überprüfung der Ähnlichkeitswerte (eine signifikante Homologie zwischen zwei Proteinsequenzen wird im allgemeinen definiert als eine Proteinidentität größer als $30 \%$ bei einer Überlappung (Alignment) von mehr als 60\% der Eingabe (query)- und der Vergleichssequenz). Insbesondere wurde darauf geachtet, ob sich unter den homologen Proteinen eines betrachteten $C$. tetani-ORFs auch eines (oder mehrere) befand, das bereits biochemisch charakterisiert ist; dessen Funktion wurde - bei entsprechend hoher Homologie - dem ORF vorrangig zugewiesen. 
- Durchführung eines externen Sequenzabgleichs mit der NCBI-Datenbank; Vergleich des Ergebnisses und gegebenenfalls manuelle Änderung der ORFAnnotation.

- Überprüfung des Startcodons des ORFs: gibt es 6-12 Nukleotide stromaufwärts eine Ribosomen-Bindestelle?

- Vergleich der genetischen Umgebung des betrachteten ORFs mit der Umgebung homologer ORFs aus (nah) verwandten Organismen mittels der ERGOFunktionen Pinned Regions oder Contig Regions. Durch solch eine Vergleich konnte ermittelt werden, wie homolog die genomische Organisation zwischen verwandten Organismen ist und ob ein ORF in C. tetani fehlte oder zusätzlich nur in C. tetani vorlag, was oft auf einen Fehler der ORF-Vorhersage hinwies.

- Identifizierung und Entfernung hypothetischer ORFs, die mit solchen ORFs überlappen, welche mit hoher Wahrscheinlichkeit Gene darstellen.

- bei hypothetischen und konservierten ORFs: kann das abgeleitete Protein mittels Abgleich mit der COG-Datenbank (COG: clusters of orthologous genes) einer Proteinfamilie zugeordnet werden ? Können durch Abgleich mit Domänen-Datenbanken (PFAM, ProSite, PROFILE, ProDom) konservierte Domänen identifiziert werden ? Weist das Protein transmembrane Helices auf (TMPred; http://www.ch.embnet.org/software/TMPRED_form.html)?

Durch die beschriebene Vorgehensweise wurde die Annotation des C. tetani-Genoms entscheidend verbessert. Erwähnt werden soll an dieser Stelle auch das Dilemma eines ,Annotators': die Mehrzahl der C. tetani-ORFs zeigt die höchsten Homologien zu Proteinen, die biochemisch nicht charakterisiert sind. Diese haben ihre Funktionen nur über Sequenzhomologien zu Proteinen, die ihrerseits oftmals nicht biochemisch charakterisiert sind, zugeordnet bekommen. So können sich Fehler, die an anderer Stelle bei der Annotation von Genen anderer Organismen gemacht wurden, in Datenbanken fortpflanzen und ausbreiten. Deshalb war es dem C. tetani-AnnotationsTeam wichtig, wie bereits oben erwähnt, Homologien zu biochemisch charakterisierten Proteinen besonders anzuerkennen und in die Annotation des C. tetani-Genoms einfließen zu lassen.

Das ERGO-Programm hat darüber hinaus noch eine Vielzahl weiterer Funktionen, die hier nur am Rande erwähnt seien, wie etwa der ,Genome-Walk', das genomweite 
Abgleichen aller ORFs von ausgewählten Organismen zum Vergleich der genetischen Organisation, oder die Rekonstruktion von Stoffwechsel-Wegen basierend auf dem genetischen Potential eines Organismus'.

\subsection{Standardtechniken zum Arbeiten mit Proteinen}

\subsubsection{Bestimmung der Proteinkonzentration}

Die Konzentrationsbestimmung von Proteinlösungen erfolgte nach BRADFORD (1976, mod.). Diese Methode beruht auf der Bindung des Farbstoffes „CoomassieBrilliant-Blue“ an Proteine. $20 \mu \mathrm{l}$ Probe wurden mit $1 \mathrm{ml}$ Bradford-Reagenz vermischt und 5 min bei RT inkubiert. Die Extinktionsmessung erfolgte in $1 \mathrm{ml}$ Plastikküvetten mit einer Schichtdicke von $1 \mathrm{~cm}$ bei $584 \mathrm{~nm}$ gegen $\mathrm{H}_{2} \mathrm{O}$ als Leerwert (Spektralphotometer Uvikon 810, Kontron Instruments, Eching). Bei der Proteinbestimmung von ganzen Zellen wurden dem Ansatz vor der Inkubation noch $50 \mu 11 \mathrm{M}$ $\mathrm{NaOH}$ zugefügt. Die Eichgerade wurde mit Rinderserumalbumin im Bereich von 0$20 \mu \mathrm{g}$ Protein aufgenommen.

\section{Bradford-Reagenz:}

Serva Blau G-250

$70 \mathrm{mg}$

Ethanol $(96 \%[\mathrm{v} / \mathrm{v}])$

$50 \mathrm{ml}$

$\mathrm{H}_{3} \mathrm{PO}_{4}(85 \%[\mathrm{v} / \mathrm{v}])$

$100 \mathrm{ml}$

$\mathrm{H}_{2} \mathrm{O}_{\text {bidest. }}$

ad $1000 \mathrm{ml}$

Der Farbstoff wurde in Ethanol gelöst, erst mit Phosphorsäure, dann mit Wasser aufgefüllt und filtriert. Das Reagenz hatte eine bräunliche Farbe und wurde lichtgeschützt bei RT aufbewahrt.

\subsubsection{Bestimmung der Molekularmassen von Proteinen}

Zur Bestimmung des Molekulargewichts von Proteinen in SDS-Gelen wurden gleichzeitig entsprechende Standardproteine mitaufgetrennt: 


\begin{tabular}{ll} 
Standardproteine & LMW-Marker $[\mathrm{kDa}]^{\mathrm{a}}$ \\
\hline Phosphorylase b & 94,0 \\
Rinderserumalbumin & 67,0 \\
Ovalbumin & 43,0 \\
Carboanhydrase & 30,0 \\
Trypsin-Inhibitor & 20,1 \\
Lactalbumin & 14,4
\end{tabular}

${ }^{\mathrm{a}}$ Fa. Pharmacia GmbH, Freiburg

Nach Anfärbung der Gele konnte die Molekularmasse von Proteinen berechnet werden, indem die Wanderungsstrecke im Gel mit der von den Markerproteinen verglichen wurde. Die Auftragung des Logarithmus der Molekularmassen der Standardproteine gegen deren Rf-Wert ergab eine Eichgerade, aus der die Molekularmasse der unbekannten Proteine abgelesen werden konnten.

$$
\text { Rf-Wert }=\frac{\text { Wanderungsstrecke des Proteins }}{\text { Wanderungsstrecke des Farbstoffes }}
$$

\subsubsection{Polyacrylamidgelelektrophorese (PAGE) von Proteinen}

Zur Reinheitskontrolle und Molekularmassenbestimmung wurde das Protein unter denaturierenden Bedingungen gelelektrophoretisch aufgetrennt (SDS-PAGE). Das anionische Detergenz SDS zerstört die Quartärstruktur von Proteinen und lagert sich an die hydrophoben Regionen des Proteins an. Dadurch wird die Eigenladung des Proteins überdeckt, und es findet nur noch eine Auftrennung nach der Masse und nicht nach der Ladung statt. Zur besseren Trennungsleistung arbeitet man zusätzlich mit diskontinuierlichen Gelen (Sammel- und Trenngel). Die Elektrophorese wurde in einer vertikalen Minigelkammer (Fa. Biometra, Göttingen) mit 10 x $10 \mathrm{~cm}$ Glasplatten und $1 \mathrm{~mm}$ Spacern durchgeführt. 
Die Lösungen setzten sich folgendermaßen zusammen:

Acrylamid-Lösung

$\underline{\text { Trenngelpuffer }}$

$\underline{\text { Sammelgelpuffer }}$

$\underline{\text { SDS-Lösung }}$

Ammoniumpersulfat-

Lösung

Elektrodenpuffer

$\underline{\text { Probenauftragspuffer }}$
Acrylamid

$30,0 \mathrm{~g}$

Bisacrylamid

$\mathrm{H}_{2} \mathrm{O}_{\text {bidest. }}$

$0,8 \mathrm{~g}$

ad $100 \mathrm{ml}$

Anschließend erfolgte eine Filtration.

Tris/HCl

$\mathrm{H}_{2} \mathrm{O}_{\text {bidest. }}$

$22,77 \mathrm{~g}$

pH 8,8 (mit $\mathrm{HCl}$ )

Tris/HCl

$7,57 \mathrm{~g}$

$\mathrm{H}_{2} \mathrm{O}_{\text {bidest. }}$

ad $100 \mathrm{ml}$

pH 6,8 (mit HCl)

SDS

$0,5 \mathrm{~g}$

$\mathrm{H}_{2} \mathrm{O}_{\text {bidest. }}$

ad $100 \mathrm{ml}$

APS

$0,1 \mathrm{~g}$

$\mathrm{H}_{2} \mathrm{O}_{\text {bidest. }}$

$940 \mu 1$

Tris

$3,0 \mathrm{~g}$

Glycin

$14,4 \mathrm{~g}$

SDS

$1,0 \mathrm{~g}$

$\mathrm{H}_{2} \mathrm{O}_{\text {bidest. }}$

ad $1000 \mathrm{ml}$

pH 8,3 mit Glycin einstellen

Sammelgelpuffer

2,0 ml

SDS

$0,2 \mathrm{~g}$

Bromphenolblau (1\% in Ethanol)

$0,1 \mathrm{ml}$

Mercaptoethanol

$0,5 \mathrm{ml}$

Glycerin

$5,0 \mathrm{ml}$

$\mathrm{H}_{2} \mathrm{O}_{\text {bidest. }}$ ad 10,0 ml 
Die Lösungen wurden je nach gewünschter Acrylamidkonzentration folgendermaßen gemischt:

\begin{tabular}{lcccc}
\hline Lösung & \multicolumn{3}{c}{ Trenngel } & Sammelgel \\
& $14 \%$ & $10 \%$ & $8 \%$ & $5 \%$ \\
\hline Acrylamid-Lösung & $2,8 \mathrm{ml}$ & $2 \mathrm{ml}$ & $1,6 \mathrm{ml}$ & $0,33 \mathrm{ml}$ \\
Trenngelpuffer & $1,2 \mathrm{ml}$ & $1,2 \mathrm{ml}$ & $1,2 \mathrm{ml}$ & - \\
Sammelgelpuffer & - & - & - & $0,4 \mathrm{ml}$ \\
SDS-Lösung & $1,2 \mathrm{ml}$ & $1,2 \mathrm{ml}$ & $1,2 \mathrm{ml}$ & $0,4 \mathrm{ml}$ \\
$\mathrm{H}_{2} \mathrm{O}_{\text {bidest. }}$ & $0,8 \mathrm{ml}$ & $1,6 \mathrm{ml}$ & $2,0 \mathrm{ml}$ & $0,87 \mathrm{ml}$ \\
TEMED & $5 \mu 1$ & $5 \mu 1$ & $5 \mu 1$ & $5 \mu 1$ \\
APS & $30 \mu l$ & $30 \mu l$ & $30 \mu l$ & $30 \mu l$
\end{tabular}

Die einzelnen Komponenten des Trenngels wurden gemischt, zwischen die mit $\mathrm{H}_{2} \mathrm{O}_{\text {bidest. }}$ und Ethanol (70 \% [v/v]) gesäuberten Glasplatten gegossen und mit $\mathrm{H}_{2} \mathrm{O}_{\text {bidest. }}$ überschichtet, damit eine ebene Geloberfläche entstand. Nach dem Polymerisieren wurde das Wasser mit Filterpapier entfernt, die frisch angesetzte Sammelgellösung über das Trenngel geschichtet und der Kamm zur Taschenformung luftblasenfrei eingesetzt. Vor dem Auftragen der Proben wurden die Dichtung und der Kamm entfernt und das Gel in die mit Elektrodenpuffer gefüllte Kammer gespannt. $25 \mu 1$ Probe (Proteingehalt 8-20 $\mu \mathrm{g}$ ) wurden mit dem gleichen Volumen Probenauftragspuffer vermischt und für $15 \mathrm{~min}$ bei $95^{\circ} \mathrm{C}$ inkubiert. Aufgetragen wurden jeweils 20 $\mu 1$ mit einer Hamiltonspritze. Die Auftrennung der Proteine erfolgte bei RT und konstanter Stromstärke von $25 \mathrm{~mA}$ und war beendet, wenn die blaue Lauffront das Gelende erreicht hatte.

\subsubsection{Silberfärbung (BLUM et al., 1987)}

Die Silberfärbung ist eine sehr empfindliche Färbemethode, da selbst geringe Mengen an Protein nachgewiesen werden können. Folgende Schritte wurden durchgeführt:

- mindestens $1 \mathrm{~h}$ Inkubation in Fixiererlösung

- 3 x 1 min waschen in $50 \%$ Ethanol (v/v) 
- 1 min Inkubation in Thiosulfatlösung

- 3 x $10 \mathrm{sec}$ waschen mit $\mathrm{H}_{2} \mathrm{O}_{\text {bidest. }}$

- 20 min Inkubation in Imprägnierlösung

- 2 x $10 \mathrm{sec}$ waschen mit $\mathrm{H}_{2} \mathrm{O}_{\text {bidest }}$

- Behandlung mit Entwicklerlösung, bis die Banden im Gel deutlich sichtbar sind

$-2 \times 10 \mathrm{sec}$ mit $\mathrm{H}_{2} \mathrm{O}_{\text {bidest. }}$ waschen

- Inkubation in Stopplösung, bis eine leichte Trübung sichtbar wird

- mindestens 15 min in $\mathrm{H}_{2} \mathrm{O}_{\text {bidest. waschen }}$

Die Gele wurden in Plastikfolie eingeschweißt und sofort mit Hilfe eines Scanners dokumentiert, da die Gefahr des Nachdunkelns bestand. Die Lagerung erfolgte bei $4{ }^{\circ} \mathrm{C}$.

Fixiererlösung:

Methanol

Eisessig

Formaldehyd (37 \% [v/v])

$\mathrm{H}_{2} \mathrm{O}_{\text {bidest. }}$

Thiosulfatlösung:

$\mathrm{Na}_{2} \mathrm{~S}_{2} \mathrm{O}_{3} \times 5 \mathrm{H}_{2} \mathrm{O}$

$\mathrm{H}_{2} \mathrm{O}_{\text {bidest. }}$

Lagerung bei $4{ }^{\circ} \mathrm{C}$

Imprägnierlösung:

$\mathrm{AgNO}_{3}$

Formaldehyd (37 \% [v/v])

$\mathrm{H}_{2} \mathrm{O}_{\text {bidest. }}$

Lagerung bei $4{ }^{\circ} \mathrm{C}$
$500 \mathrm{ml}$

$120 \mathrm{ml}$

$0,5 \mathrm{ml}$

ad $1000 \mathrm{ml}$

$0,2 \mathrm{~g}$

ad $1000 \mathrm{ml}$

$$
\begin{array}{r}
2 \mathrm{~g} \\
0,75 \mathrm{ml} \\
\text { ad } 1000 \mathrm{ml}
\end{array}
$$


Entwicklerlösung:

$\mathrm{Na}_{2} \mathrm{CO}_{3}$

$60 \mathrm{~g}$

Formaldehyd $(37 \%[\mathrm{v} / \mathrm{v}])$

$0,5 \mathrm{ml}$

$\mathrm{Na}_{2} \mathrm{~S}_{2} \mathrm{O}_{3} \times 5 \mathrm{H}_{2} \mathrm{O}$

$4 \mathrm{mg}$

$\mathrm{H}_{2} \mathrm{O}_{\text {bidest. }}$

ad $1000 \mathrm{ml}$

Lagerung bei $4{ }^{\circ} \mathrm{C}$

Stopplösung:

EDTA

$18,6 \mathrm{~g}$

$\mathrm{H}_{2} \mathrm{O}_{\text {bidest. }}$

ad $1000 \mathrm{ml}$

pH 7 - 8 mit $\mathrm{NaOH}$ eingestellt

\subsection{Chemikalien, Biochemikalien und Gase}

Es wurden z. T. Chemikalien der Fa. Merck, Darmstadt, des höchsten handelsüblichen Reinheitsgrades verwendet. Die Restriktionsendonukleasen stammten von den Firmen New England Biolabs (Schwalmbach) und MBI Fermentas GmbH (St. Leon Rot). Die Bezugsquellen weiterer Chemikalien, Enzyme, Verbrauchsmaterialien und Kits sind an den entsprechenden Stellen im Text angegeben. Nicht explizit erwähnte Firmen sind nachfolgend aufgeführt:

Biomol, Hamburg

IPTG, Lysozym, Phenol (äquilibriert mit Tris-Puffer), TEMED, X-Gal, DTE

Biozym GmbH, Hessisch Oldendorf:

Agarose

Boehringer Mannheim GmbH, Mannheim

Alkalische Phosphatase, Proteinase K, RNase, T4-DNA-Ligase, ATP, DNase

$\underline{\text { Canberra Packard GmbH, Frankfurt }}$

Vials 
Difco Laboratories, Detroit, USA

Bacto-Agar, Bacto-Pepton

Gerbu Traiding GmbH, Gaiberg

Ampicillin, Acrylamid

Gibco-BRL, Eggenstein

Agarose, Hefeextrakt, Primer

$\underline{\text { KODAK AG, Stuttgart }}$

Röntgenfilmentwickler LX 24, Röntgenfilmfixierer AL4, Röntgenfilme (X-OMAT)

Pharmacia LKB, Freiburg

LMW-Markerproteine

Qiagen, Hilden

BioRobots, low-copy-Plasmid-Präparationskit (Mini- und Midi-Kit)

Serva, Heidelberg

APS, Acrylamid, Bisacrylamid, BSA, EDTA, Glycin

Sigma Chemie GmbH, Deisenhofen

Ethidiumbromid, u.a.

Alle Gase, sowie flüssiger Stickstoff wurden von der Fa. Messer Griesheim, Kassel, bezogen. Die Gase waren von folgender Reinheit:

$\mathrm{N}_{2}: 99,99 \%$

$\mathrm{N}_{2}-\mathrm{CO}_{2}-\mathrm{Gemisch}(80 \% / 20 \%)$, Reinheit nicht angegeben

$\mathrm{H}_{2}: 99,9 \%$ 
Ziel der Arbeit war die vollständige Entschlüsselung des Genoms von C. tetani sowie die Analyse seines genetischen Potentials. Als Sequenzierungsstamm wurde dafür C. tetani E88 gewählt, der freundlicherweise von der Firma Behring Chiron GmbH \& Co (Marburg, Deutschland) zur Verfügung gestellt wurde. Dort wird dieser Stamm zur Produktion großer Mengen des Tetanus-Toxins genutzt, das in inaktiver Form (Tetanus-Toxoid) als Tetanus-Impfstoff eingesetzt wird.

In diesem Teil der Arbeit sollen der Ablauf des Genomsequenzierungsprojektes und dessen Ergebnisse im Detail beschrieben werden. Weiterhin werden allgemeine Sequenzmerkmale des Genoms von C. tetani vorgestellt, und es wird ein Einstieg in die Analyse der Sequenz unternommen. Aufgrund der Menge der gewonnenen Sequenzdaten kann sich diese Analyse nur auf ausgewählte Eigenschaften beziehen.

\subsection{Sequenzierung des Plasmids pE88 aus C. tetani E88}

\subsubsection{Isolierung des Plasmids pE88 aus C. tetani E88}

Die Existenz eines extrachromosomalen Elements in C. tetani wurde erstmals 1984 beschrieben (FINN et al., 1984): dort konnte für den Stamm Massachusetts gezeigt werden, dass dieser ein etwa $75 \mathrm{~kb}$ großes Plasmid - genannt pCL1 - besitzt, welches für das Tetanus-Toxin kodiert. Die enge Verwandtschaft der C. tetani-Stämme Massachusetts und E88, welches als Derivat des Stammes Massachusetts bezeichnet wird (Behring Chiron $\mathrm{GmbH} \& \mathrm{Co}$, persönliche Mitteilung), sowie die Tatsache, dass der Stamm E88 zur Tetanus-Toxin-Produktion genutzt wird, ließ vermuten, dass auch C. tetani E88 ein solches Plasmid besitze. Um dies zu überprüfen, wurde eine Plasmidpräparation durchgeführt, wie sie unter Kapitel 2.5.3.1 für Plasmide mit sehr niedriger Kopienzahl pro Zelle beschrieben ist. Das Eluat der Plasmidpräparation wurde auf ein 0,5\%iges Agarose-Gel aufgetragen: es konnten mehrere hochmolekulare DNA-Banden ausgemacht werden (Abb. 3A). Da das 
Auflösungsvermögen eines Agarose-Gels in diesem Größenbereich an seine Grenzen stößt und das Laufverhalten intakter chromosomaler DNA in einem Agarose-Gel i. d. R. in derselben Größenordnung liegt wie die untere der beiden beobachteten DNA-Banden, ließen sich zwei vorläufige Schlüsse ziehen: 1. Es konnte mit einiger Sicherheit von der Existenz eines extrachromosomalen Plasmids in C. tetani E88 ausgegangen werden. 2. Eine chromosomale Verunreinigung dieser PlasmidPräparation konnte nicht ausgeschlossen werden.

A)

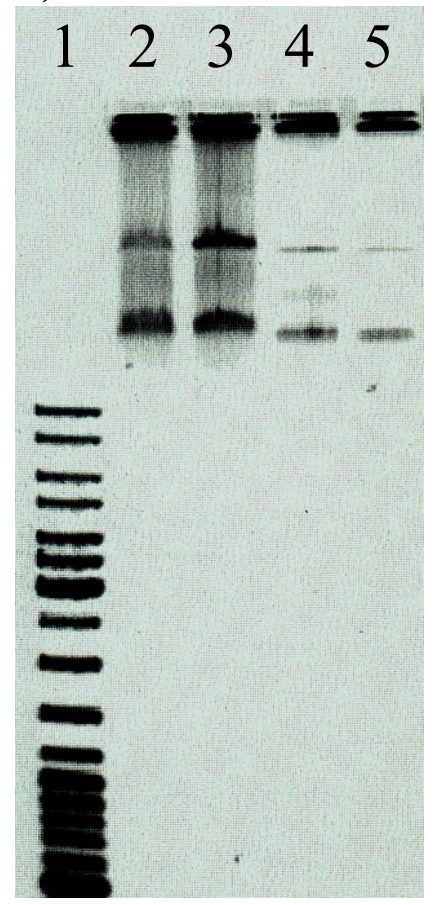

B)

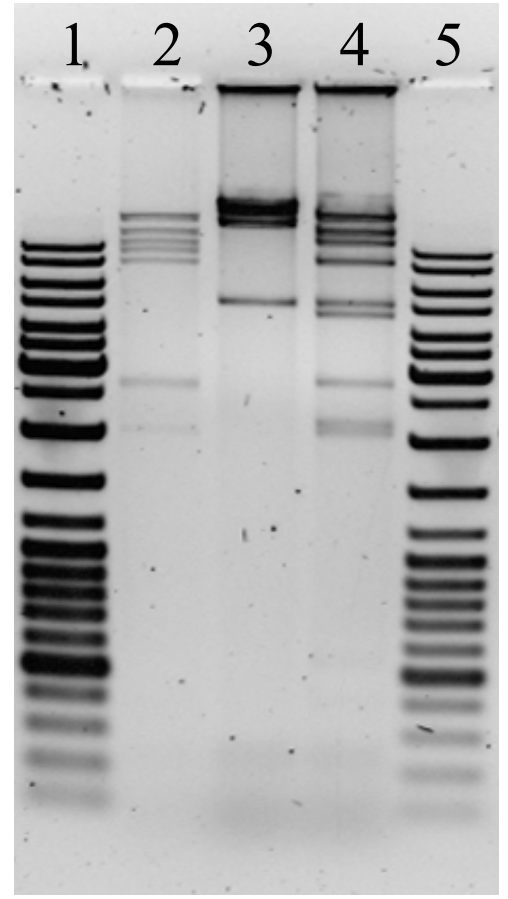

Abb. 3: Erste Charakterisierung des Plasmids pE88 aus $C$. tetani E88

A) Proben aus der Plasmidpräparation, unverdaut

Spur 1: $\quad$ Längenstandard

Spur 2+3: $\quad$ Probe nach der 1. Fällung der Plasmidpräparation

Spur 4+5: $\quad$ Eluat nach der 2. Fällung der Plasmidpräparation

B) Restriktionsverdaue

Spur 1+5: Längenstandard

Spur 2: $\quad$ EcoRI-Verdau

Spur 3: $\quad$ PstI-Verdau

Spur 4: $\quad$ EcoRI/PstI-Doppelverdau

In einer weitergehenden Untersuchung wurde die DNA des Eluats mit den Restriktionsendonukleasen EcoRI und PstI verdaut. Hintergrund dieses Experiments war die Überlegung, dass sich bei einer mit EcoRI und/oder PstI-verdauten PlasmidDNA distinkte DNA-Banden im Agarose-Gel erkennen lassen sollten - im Gegensatz 
zu verdauter genomischer DNA, die aufgrund der hohen Anzahl an EcoRI/PstISchnittstellen lediglich ein DNA-Schmier im Agarose-Gel zeigen sollte. Abbildung 3B zeigt, dass klare DNA-Banden ausgemacht werden konnten, deren Größen aufaddiert zwischen 70 und $80 \mathrm{~kb}$ lagen. Dieses Bandenmuster entsprach zudem dem, welches für EcoRI/PstI-verdaute pCL1-Plasmid-DNA beobachtet worden war (FINN et al., 1984). Damit konnte die Existenz eines Plasmids - gemäß den Konventionen als pE88 bezeichnet - in C. tetani E88 nachgewiesen werden, das dem pCL1-Plasmid des Stammes Massachusetts sehr ähnlich oder sogar identisch ist.

\subsubsection{Strategie der Sequenzierung von pE88}

Das Plasmid pE88 wurde nach dem sogenannten Shotgun-Prinzip sequenziert (s. 2.92.12). Zunächst musste eine Genbank hergestellt werden. Dazu wurde die isolierte Plasmid-DNA (Abb. 3A) mittels einer umgebauten HPLC-Pumpe fragmentiert. DNA-Fragmente aus pE88 in der Größenordnung von 1-3 kb wurden dann in den Vektor pTZ19R kloniert. Damit sollte prinzipiell die Voraussetzung einer ShotgunSequenzierung gewährleistet sein, nämlich dass jedes pE88-Fragment statistisch gesehen mit gleicher Häufigkeit in der Genbank repräsentiert ist, um dem Entstehen großer Sequenzlücken im spätern Prozess der Assemblierung der Sequenzen vorzubeugen.

Etwa 1700 rekombinante Klone der hergestellten Genbank wurden einer robotgesteuerten Plasmidpräparation unterworfen. Die Inserts der gereinigten rekombinanten Plasmide wurden dann mit Hilfe zweier Primer von beiden Seiten her, jeweils in 5'-3'-Richtung, ansequenziert. Die Sequenzierungsprimer waren dabei von der pTZ19R-Vektorsequenz im Bereich der multiplen Klonierungsstelle abgeleitet. Die eigentliche Sequenzierung erfolgte mit ABI377 ${ }^{\circledR}$-DNASequenziermaschinen. Anschließend wurden die Sequenzen, insgesamt ca. 2900, prozessiert und mit Hilfe des Genomassemblierungsprogramms Gap4 assembliert (s. 2.11). Es bildeten sich mehrere größere Contigs in der Größenordnung von 10-25 kb, die in Gap4 editiert wurden. Etwa 36\% aller Einzelsequenzen assemblierten jedoch nicht. Es wurde angenommen, dass diese chromosomalen Ursprungs seien, was auch später - im Rahmen der Sequenzierung des gesamten Genoms - bestätigt werden konnte. Somit war die Plasmidpräparation noch mit chromosomaler DNA 
kontaminiert. Um die noch verbliebenen Lücken zwischen den Contigs zu schließen, wurden die Methode des Primer-Walkings und PCR-basierte Methoden herangezogen (s. 2.12). Schließlich konnte so ein einziger Contig - bestehend aus insgesamt 1850 assemblierten Einzelsequenzen - gebildet werden, dessen ConsensusSequenz der kompletten Sequenz des Plasmids pE88 entsprach. Zur Berechnung der durchschnittlichen Abdeckungsrate jeder Base im Consensus wurde folgende Formel benutzt:

$$
\frac{N * w}{L}
$$

wobei $\mathrm{N}$ die Anzahl der Einzelsequenzen, w die durchschnittliche Länge einer Einzelsequenz ( 600 Basen guter Qualität, d. h. guter Auflösung) und L die Größe des Genoms (hier: 74082 Basenpaare) ist. Es ließ sich so eine etwa 15 fache Abdeckung der Plasmidsequenz berechnen.

\subsection{Analyse der Sequenz des Plasmids pE88}

\subsubsection{ORF-Vorhersage für pE88}

Nach Abschluss der Sequenzierung sollten alle möglichen Gene auf pE88 identifiziert werden. Die Vorhersage aller offenen Leserahmen (ORFs, open reading frames) erfolgte dabei mit Hilfe des Programms FRAMEPLOT (ISHIKAWA \& HOTTA, 1999; s. 2.13.1). Durch Hinzufügen weiterer durch FRAMEPLOT analysierbarer Kriterien wie das Vorkommen einer Ribosomen-Bindestelle in unmittelbare Nähe stromaufwärts des Startcodons eines ORFs sowie eine Häufigkeitsanalyse der benutzten Codone (Codon-Usage-Analyse) wurde versucht, die Charakterisierung der ORFs zu verbessern. Ziel war dabei, die Entscheidung zu erleichtern, welche ORFs tatsächlich Gene darstellen könnten. Alle überlappenden ORFs wurden nach den oben genannten Kriterien überprüft und jeweils der ORF gewählt, welcher ausgeprägtere Merkmale eines Gens trägt. Dazu wurde auch die Annotation aller möglichen ORFs dahingehend herangezogen, dass solche ORFs, die für bekannte, d. h. in Datenbanken abgelegte Proteine kodieren aller Wahrscheinlichkeit nach Gene darstellen. So konnten insgesamt 61 ORFs auf pE88 identifiziert werden, die gemäß ihrer Position als CTP01 bis CTP61 (CTP: C. tetani 
Plasmid) bezeichnet wurden. Diese Bezeichnung soll im folgenden sowohl für das entsprechende Gen als auch für die abgeleitete Proteinsequenz gelten.

Interessant war die Beobachtung, das kodierende Sequenz i. d. R. eine andere G+CVerteilung als nicht-kodierende Sequenz zeigte. So liegt der G+C-Gehalt der dritten Base eines Codons innerhalb kodierender Sequenz auf pE88 im Durchschnitt bei nur 15\%, also 10 Prozentpunkte niedriger als der durchschnittliche $\mathrm{G}+\mathrm{C}-\mathrm{Gehalt}$ der gesamten Plasmidsequenz. Abbildung 4 soll diese Beobachtung anhand zweier ORFs auf pE88 veranschaulichen: so hat der erste ORF (CTP60, tet X) in der dritten Base eines Codons einen durchschnittlichen $\mathrm{G}+\mathrm{C}-\mathrm{Gehalt}$ von nur 16,3\%. Beim zweiten ORF (CTP61, tetR) beträgt dieser Wert sogar lediglich 12,3\%.



\section{Abb. 4: Die ORF-Vorhersage mit Frameplot}

Im oberen Teil der Abbildung sind alle Start- (als Pfeile) und Stopcodone (als senkrechte Striche) in allen sechs Leserahmen gezeigt sowie die ORFs CTP61 und CTP60 als durchgezogene grüne bzw. rote Linie gekennzeichnet. Der untere Teil der Abbildung gibt die Verteilung des G+C-Gehalts der dritten Base eine (potentiellen) Codons wieder - mit der gleichen Farbgebung wie die drei jeweiligen Leserahmen. Die gestrichelte Linie kennzeichnet den durchschnittlichen G+C-Gehalt der betrachteten Sequenz (hier 27,5\%). 


\subsubsection{Annotation der Plasmidsequenz: genetische Karte und Annotationstabelle}

Die 61 potentiellen Gene auf pE88 wurden in Proteinsequenzen übersetzt und gegen die NCBI- und die ERGO-Datenbank abgeglichen (s. 2.13), um homologe Proteine $\mathrm{zu}$ identifizieren und eine daraus resultierende theoretische Funktionszuordnung machen zu können. In Abbildung 5 sind alle 61 ORFs wiedergegeben und gemäß der gefundenen Homologien in Funktionsklassen eingeordnet. Etwa 41\% (25) aller abgeleiteten Proteine haben keine Ähnlichkeiten $\mathrm{zu}$ in Datenbanken abgelegten Proteinen; sie werden nachfolgend als hypothetische Proteine bezeichnet. 6 Proteine zeigen Ähnlichkeiten lediglich zu Proteinen unbekannter Funktion; sie werden nachfolgend als konservierte Proteine bezeichnet. 30 Proteinen konnte eine Funktion aufgrund signifikanter Homologien zu Proteinen aus Datenbanken, für die eine Funktion angegeben ist, zugeordnet werden. Eine signifikante Homologie zwischen zwei Proteinsequenzen wurde hierbei definiert als eine Proteinidentität größer als $30 \%$ bei einer Überlappung (Alignment) von mehr als 60\% der Eingabe- und der Vergleichssequenz (s. 2.13.2). 

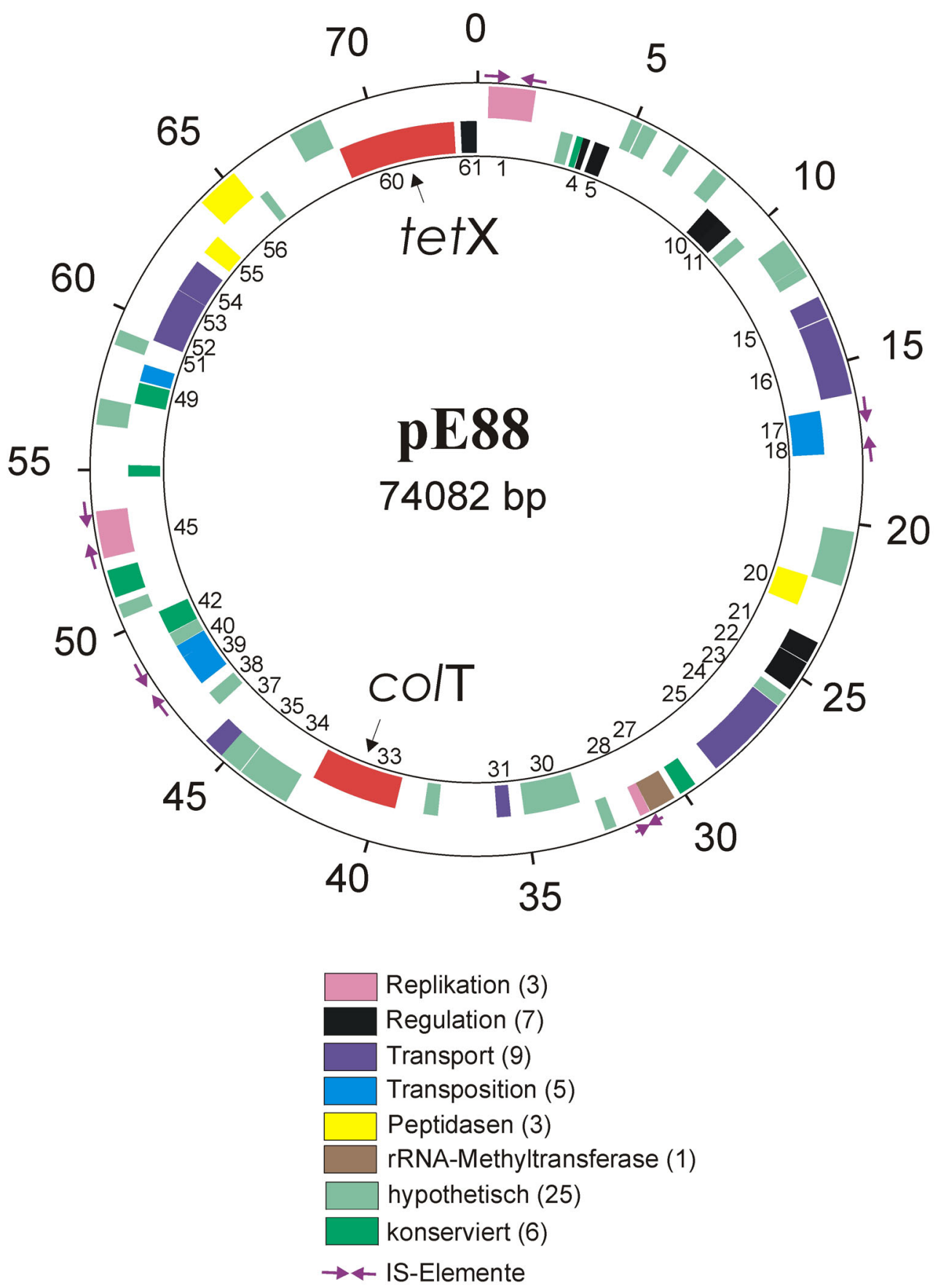

\section{Abb. 5: Zirkuläre Genkarte des Plasmids pE88 aus $C$. tetani}

Die Zahlen auf der Außenseite des Ringes geben die Größe in kb an. Der Hauptring zeigt die ORFs - gemäß ihrer DNA-Strang-Orientierung - mit einer Farbgebung, die sich auf die Funktionsklassen der abgeleiteten Proteine bezieht (s. Legende). Die Zahlen auf der Innenseite des Ringes geben die Namen der ORFs an, die in den nachfolgenden Kapiteln näher erläutert werden. Das Gen für das Tetanus-Toxin, tet $X$, und das Gen für die Collagenase, colT, sind in rot gekennzeichnet. 
In den folgenden Kapiteln sollen interessante ORFs vorgestellt und mit Hilfe bioinformatischer Methoden untersucht werden. Zuvor soll aber eine Gesamtübersicht über alle gefundenen ORFs des Plasmids gegeben werden: Tabelle 5 gibt Auskunft über die Lage der ORFs auf pE88, deren Größen und potentielle Funktionen. Zudem sind $\mathrm{zu}$ jedem ORF mit zugewiesener Funktion diejenigen Organismen angegeben, welche die Proteine mit der höchsten Homologie enthalten.

Tabelle 5: Gesamtübersicht aller ORFs auf pE88 und ihre möglichen Funktionen

\begin{tabular}{|c|c|c|c|c|c|c|}
\hline $\begin{array}{l}\text { ORF- } \\
\text { Name }\end{array}$ & Start & Stop & $\begin{array}{l}\text { Länge } \\
\text { in bp }\end{array}$ & $\begin{array}{c}\text { Höchste } \\
\text { Homologien zu } \\
\text { Proteinen aus } \\
\end{array}$ & Annotation & $\begin{array}{l}\text { G+C- } \\
\text { Gehalt } \\
\text { in \% * }\end{array}$ \\
\hline СТР01 & 378 & 1826 & 1448 & $\begin{array}{l}\text { Bacillus sp., } \\
\text { C. perfringens }\end{array}$ & Replikationsprotein & 24,4 \\
\hline СТР02 & 3286 & 2876 & 410 & - & hypothetisches Protein & 15,3 \\
\hline СТР03 & 3646 & 3428 & 219 & Listeria ivanovii & $\begin{array}{l}\text { konserviertes Protein mit } \\
\text { LysM-Domäne }\end{array}$ & 15,1 \\
\hline СТР04 & 3886 & 3671 & 216 & C. perfringens & UviB-Homologon & 11,1 \\
\hline СТР05 & 4582 & 4065 & 517 & $\begin{array}{l}\text { C. perfringens, } \\
\text { C. diificile }\end{array}$ & $\begin{array}{c}\text { Frameshift: } \\
\text { UviA/TxeR-Homologon }\end{array}$ & 14,3 \\
\hline СТР06 & 4870 & 5223 & 354 & - & hypothetisches Protein & 13,6 \\
\hline СТР07 & 5274 & 5738 & 464 & - & hypothetisches Protein & 12,9 \\
\hline СТР08 & 6510 & 6860 & 350 & - & hypothetisches Protein & 14,5 \\
\hline СТР09 & 7792 & 8292 & 500 & - & hypothetisches Protein & 21,6 \\
\hline CTP10 & 9008 & 8469 & 539 & C. botulinum & $\begin{array}{c}\text { möglicher RNA } \\
\text { Polymerase-Sigmafaktor }\end{array}$ & 16,7 \\
\hline СТP11 & 9564 & 9010 & 554 & $\begin{array}{l}\text { C. aceto- } \\
\text { butylicum, } \\
\text { C. botulinum }\end{array}$ & $\begin{array}{c}\text { möglicher RNA } \\
\text { Polymerase-Sigmafaktor }\end{array}$ & 15,1 \\
\hline СТP12 & 10255 & 9833 & 422 & - & hypothetisches Protein & 10,6 \\
\hline CТP13 & 10855 & 11817 & 962 & - & hypothetisches Protein & 15,0 \\
\hline СТР14 & 11832 & 12173 & 341 & - & hypothetisches Protein & 14,0 \\
\hline СТР15 & 12879 & 13541 & 662 & viele & $\begin{array}{c}\text { ABC Transporter, ATP- } \\
\text { bindendes Protein }\end{array}$ & 14,9 \\
\hline CTP16 & 13588 & 16011 & 2423 & $\begin{array}{l}\text { C. botulinum, } \\
\text { C. difficile }\end{array}$ & $\begin{array}{c}\text { ABC-Transporter } \\
\text { assoziierte Permease }\end{array}$ & 13,1 \\
\hline СТР17 & 17430 & 16369 & 1061 & B. cereus & Transposase & 13,5 \\
\hline CTP18 & 17836 & 17429 & 407 & viele & Transposase & 20,6 \\
\hline СТР19 & 20256 & 21941 & 1685 & - & hypothetisches Protein & 23,3 \\
\hline СТР20 & 22989 & 21961 & 1028 & $\begin{array}{l}\text { C. aceto- } \\
\text { butylicum }\end{array}$ & Aminopeptidase & 12,5 \\
\hline СТР21 & 23821 & 24495 & 674 & viele & $\begin{array}{l}\text { Zwei-Komponenten- } \\
\text { System } \\
\text { Response-Regulator }\end{array}$ & 20,4 \\
\hline
\end{tabular}




\begin{tabular}{|c|c|c|c|c|c|c|}
\hline СТP22 & 24529 & 25473 & 944 & viele & $\begin{array}{l}\text { Zwei-Komponenten- } \\
\text { System } \\
\text { Sensor-Histidin-Kinase }\end{array}$ & 17,1 \\
\hline СТP23 & 25671 & 26078 & 407 & - & hypothetisches Protein & 11,8 \\
\hline СТР24 & 26108 & 26866 & 758 & $\begin{array}{l}\text { B. halodurans, } \\
\text { B. anthracis }\end{array}$ & $\begin{array}{l}\text { ABC Transporter, ATP- } \\
\text { bindendes Protein }\end{array}$ & 18,6 \\
\hline СТР25 & 26853 & 28781 & 1928 & B. halodurans & $\begin{array}{c}\text { ABC-Transporter } \\
\text { assoziierte Permease }\end{array}$ & 19,3 \\
\hline СТР26 & 29575 & 30111 & 536 & $\begin{array}{l}\text { C. botulinum, } \\
\text { C. difficile }\end{array}$ & konserviertes Protein & 20,1 \\
\hline СТР27 & 30338 & 31174 & 836 & $\begin{array}{c}\text { Streptococcus } \\
\text { pneumoniae }\end{array}$ & $\begin{array}{l}\text { rRNA(Guanin-N1)- } \\
\text { Methyltransferase } \\
\text { (Antibiotika-Resistenz- } \\
\text { Protein) }\end{array}$ & 18,6 \\
\hline СТР28 & 31193 & 31504 & 311 & C. perfringens & $\begin{array}{c}\text { Replikations- } \\
\text { proteinfragment }\end{array}$ & 29,8 \\
\hline СТР29 & 32303 & 32668 & 365 & - & hypothetisches Protein & 13,1 \\
\hline СТP30 & 35057 & 33162 & 1895 & - & $\begin{array}{c}\text { hypothetisches } \\
\text { Membranprotein } \\
\text { (schwache Homologie zu } \\
\text { Hämolysin) }\end{array}$ & 14,1 \\
\hline CTP31 & 35994 & 35521 & 473 & viele & $\begin{array}{c}\text { ABC Transporter, ATP- } \\
\text { bindendes Protein }\end{array}$ & 14,6 \\
\hline CTP32 & 38466 & 37990 & 476 & - & hypothetisches Protein & 15,7 \\
\hline $\begin{array}{l}\text { CTP33, } \\
\text { ColT }\end{array}$ & 42365 & 39438 & 2927 & $\begin{array}{l}\text { C. perfringens, } \\
\text { C. histolyticum, } \\
\text { C. botulinum }\end{array}$ & mikrobielle Collagenase & 14,0 \\
\hline СТP34 & 42761 & 43603 & 842 & - & $\begin{array}{l}\text { hypothetisches } \\
\text { Membranprotein }\end{array}$ & 14,6 \\
\hline CTP35 & 43596 & 44405 & 809 & - & $\begin{array}{l}\text { hypothetisches } \\
\text { Membranprotein }\end{array}$ & 15,2 \\
\hline СТР36 & 44443 & 45192 & 749 & - & $\begin{array}{l}\text { hypothetisches } \\
\text { Membranprotein }\end{array}$ & 11,6 \\
\hline CTP37 & 45189 & 45830 & 641 & $\begin{array}{c}\text { B. stearo- } \\
\text { thermophilus }\end{array}$ & $\begin{array}{l}\text { ABC Transporter, ATP- } \\
\text { bindendes Protein }\end{array}$ & 16,8 \\
\hline СТР38 & 46895 & 46386 & 509 & - & $\begin{array}{l}\text { hypothetisches } \\
\text { Membranprotein }\end{array}$ & 14,1 \\
\hline СТР39 & 48362 & 47307 & 1055 & viele & Transposase & 13,4 \\
\hline СТР40 & 48801 & 48367 & 434 & viele & Transposase & 22,8 \\
\hline СТР41 & 49281 & 48826 & 455 & - & hypothetisches Protein & 19,1 \\
\hline СТР42 & 50104 & 49310 & 794 & S. pneumoniae & $\begin{array}{c}\text { konserviertes } \\
\text { Membranprotein }\end{array}$ & 12,5 \\
\hline СТР43 & 50368 & 50796 & 428 & - & hypothetisches Protein & 21,0 \\
\hline СТР44 & 51041 & 51895 & 854 & C. botulinum & konserviertes Protein & 14,4 \\
\hline СТР45 & 52281 & 53732 & 1451 & $\begin{array}{l}\text { Bacillus sp., } \\
\text { C. perfingens }\end{array}$ & Replikationsprotein & 20,9 \\
\hline СТР46 & 55150 & 54773 & 377 & C. botulinum & konserviertes Protein & 11,1 \\
\hline СТР47 & 56391 & 56750 & 359 & - & hypothetisches Protein & 15,0 \\
\hline СТР48 & 56701 & 57186 & 485 & - & hypothetisches Protein & 17,9 \\
\hline СТР49 & 57954 & 57241 & 713 & $\begin{array}{l}\text { B. anthracis, } \\
\text { C. perfringens, } \\
\text { B. cereus }\end{array}$ & $\begin{array}{l}\text { konserviertes } \\
\text { Membranprotein }\end{array}$ & 17,2 \\
\hline СТP50 & 58588 & 58025 & 563 & viele & Integrase/Rekombinase & 18,1 \\
\hline CTP51 & 58890 & 59366 & 476 & - & $\begin{array}{l}\text { hypothetisches } \\
\text { Membranprotein }\end{array}$ & 15,1 \\
\hline
\end{tabular}




\begin{tabular}{|c|c|c|c|c|c|c|}
\hline СТР52 & 60158 & 59451 & 707 & viele & $\begin{array}{c}\text { ABC Transporter, ATP- } \\
\text { bindendes Protein }\end{array}$ & 15,7 \\
\hline СТP53 & 61336 & 60161 & 1175 & $\begin{array}{l}\text { C. aceto- } \\
\text { butylicum }\end{array}$ & $\begin{array}{l}\text { Membranprotein, } \\
\text { mögliche Permease }\end{array}$ & 15,3 \\
\hline СТP54 & 62486 & 61356 & 1130 & $\begin{array}{l}\text { Desulfitobac- } \\
\text { terium sp. }\end{array}$ & $\begin{array}{l}\text { Membranprotein, mögliche } \\
\text { Permease }\end{array}$ & 11,9 \\
\hline СТP55 & 63565 & 62882 & 683 & C. botulinum & $\begin{array}{c}\text { mögliche N-Acetyl- } \\
\text { muramoyl-L-Alanin } \\
\text { Amidase }\end{array}$ & 16,7 \\
\hline СТР56 & 64009 & 65337 & 1328 & Bacillus sp. & Aminopeptidase & 15,8 \\
\hline CTP57 & 65829 & 65527 & 302 & - & hypothetisches Protein & 11,9 \\
\hline CTP58 & 67415 & 68161 & 746 & - & hypothetisches Protein & 12,4 \\
\hline СТР59 & 68165 & 68461 & 296 & - & hypothetisches Protein & 12,1 \\
\hline $\begin{array}{l}\text { СТР60, } \\
\text { TeTx }\end{array}$ & 72587 & 68640 & 3947 & C. botulinum & Tetanus-Toxin & 16,3 \\
\hline $\begin{array}{l}\text { CTP61, } \\
\text { TetR }\end{array}$ & 73354 & 72818 & 536 & C. botulinum & $\begin{array}{c}\text { Transkriptionsaktivator } \\
\text { TetR }\end{array}$ & 12,3 \\
\hline
\end{tabular}

\subsubsection{Allgemeine Merkmale der Plasmidsequenz}

Das Plasmid pE88 aus C. tetani E88 besteht aus 74082 Basenpaaren. Der $\mathrm{G}+\mathrm{C}-$ Gehalt ist mit 24,5\% sehr niedrig und gehört bei den Prokaryoten zu den niedrigsten Werten überhaupt. Die insgesamt identifizierten 61 ORFs auf pE88 machen 67,1\% der gesamten Plasmidsequenz aus, was relativ niedrig im Vergleich $\mathrm{zu}$ anderen prokaryotischen Genomen ist. Allerdings sind intergene Regionen auf extrachromosomalen Elementen im allgemeinen größer als auf Chromosomen, wo kodierende Sequenz etwa 80-90\% der Gesamtsequenz ausmacht.

\subsubsection{Analyse zur Identifizierung des Replikationsursprungs}

Um erste Hinweise bezüglich der Lokalisation des Replikationsursprungs auf pE88 zu gewinnen, wurde eine sogenannte kumulative GC-Skew-Analyse durchgeführt (Abb. 6). Dabei handelt es sich um die kumutative Berechung der GC-Verteilung nach der Formel $(\mathrm{C}-\mathrm{G} / \mathrm{C}+\mathrm{G})$ in einer definierten Fenstergröße und einer definierten Schrittzahl (GRIGORIEV, 1998). Diese Berechnung macht sich das Phänomen bei prokaryotischen Genomen zunutze, dass sich die Nukleotidzusammensetzung zwischen dem leading- und dem lagging-Strang der Replikation unterscheidet: i. d. $\mathrm{R}$. ist der leading-Strang mit den Basen $\mathrm{G}$ und $\mathrm{T}$ angereichert, wohingegen der 
lagging-Strang überwiegend A und C enthält (LOBRY, 1996). Biologisch erklärt man sich dieses Phänomen mit der Annahme, dass der leading- und der laggingStrang unterschiedlichen Mutationsdrücken ausgesetzt sind, da die Stränge während der Replikation unterschiedlich lang einzelsträngig vorliegen und so einer DNASchädigung unterschiedlich lang ausgesetzt sind (TILLIER \& COLLINS, 2000).

Nun lässt sich anhand der Formel $(\mathrm{C}-\mathrm{G} / \mathrm{C}+\mathrm{G})$ der Überschuss von $\mathrm{C}$ über $\mathrm{G}$ berechnen, welcher im lagging- positiv und im leading-Strang negativ ist. Die Genompositionen, an denen nach der obigen Formel ein Vorzeichenwechsel stattfindet, entsprechen dem Replikationsursprung und dem Replikationsterminus, welche i. d. R. eine halbe Genomlänge auseinanderliegen. Genau diesen empirisch ermittelten Umstand macht man sich zur Identifizierung möglicher Replikationsursprünge auf Chromosomen mittels der kumulativen GC-SkewAnalyse zunutze (GRIGORIEV, 1998).

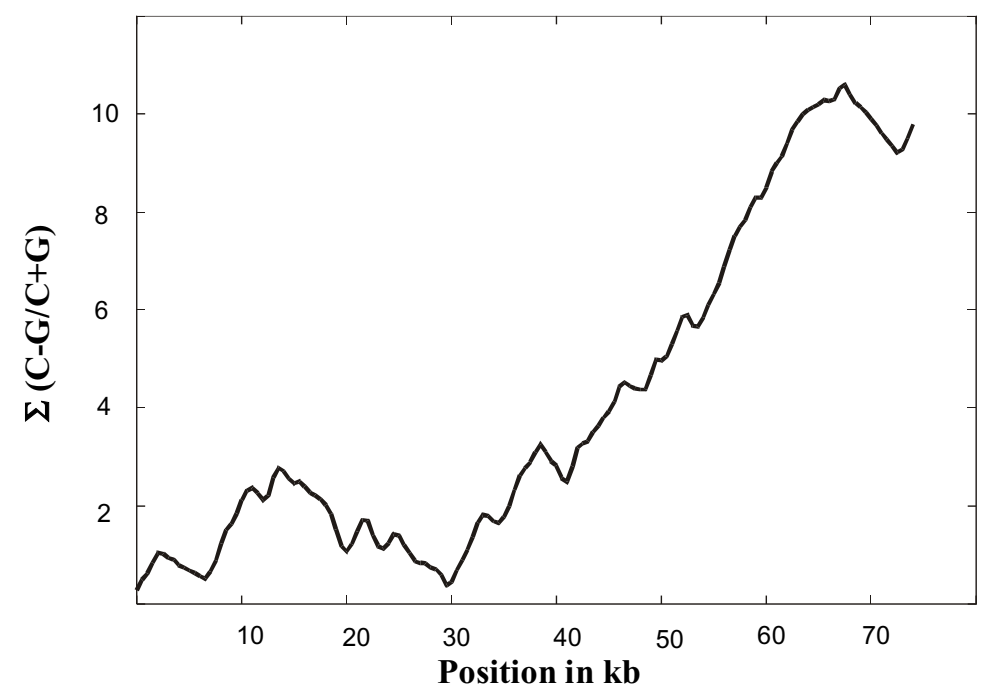

Abb. 6: Kumulative GC-Skew-Analyse des Plasmids pE88

Berechnet wurde die Summe von $(\mathrm{C}-\mathrm{G} / \mathrm{C}+\mathrm{G})$ in Fenstern von jeweils 100 bp. Zur besseren Visualisierung eines möglichen Replikationsursprungs wurde die Sequenz so umgestellt, dass sie mit CTP35 begann und mit CTP34 endete. Das lokale Minimum bei etwa $30 \mathrm{~kb}$ befand sich demzufolge in der Region der ORFs CTP61 und CTP01.

Allerdings kann man dieses Verfahren nur bedingt auf Plasmidsequenzen anwenden, die i. d. R. keinen ausgeprägten Unterschied in der GC-Verteilung zeigen. Das ist auch bei dem Plasmid pE88 der Fall (Abb. 6), wobei aber dennoch ein lokales 
Minimum in der Region stromaufwärts von CTP01, einem Replikationsprotein, auszumachen ist. Dieser Befund und andere Gründe (s. 3.2.8) lassen die Vermutung zu, dass der Replikationsursprung des Plamsids in der Nähe von CTP01 liegt, also in direkter Nachbarschaft zum Tetanus-Toxin und dessen Transkriptionsaktivator TetR.

\subsubsection{Toxine auf pE88: Tetanus-Toxin und Collagenase}

Bevor die Sequenzierung von pE88 im Rahmen der vorliegenden Arbeit begann, war bekannt, dass das Tetanus-Toxin (TeTx) - zumindest im C. tetani-Stamm Massachusetts - Plasmid-kodiert ist (FINN et al., 1984). Des weiteren bestand Zugang zu der bereits bekannten Nukleotidsequenz des Toxins, welche aus drei verschiedenen $C$. tetani-Stämmen bestimmt wurde: aus dem auch in dieser Arbeit verwendeten Stamm E88 (EISEL et al., 1986), aus dem Stamm CN3911, einem Derivat des Stammes Harvard (FAIRWEATHER \& LYNESS, 1986) und aus einem nicht näher charakterisierten C. tetani-Stamm (SHUMIN \& DIANLIANG, 2001).

Die im Rahmen der Sequenzierung von pE88 erhaltende TeTx-Nukleotidsequenz (CTP60) stimmt vollständig mit den bereits bekannten Sequenzen aus E88 und CN3911 überein. Im Gegensatz dazu existieren zur TeTx-Nukleotidsequenz, die von SHUMIN \& DIANLIANG (2001) bestimmt wurde, Unterschiede in 26 Basen, die 18 Aminosäure-Austausche zur Folge haben. Ob diese von biologischer Bedeutung sind, kann aufgrund der fehlenden Information zum von SHUMIN \& DIANLIANG (2001) verwendeten Stamm nicht geklärt werden. Der derzeitige Wissensstand über die Funktion des Tetanus-Toxins und seines immensen neurotoxischen Potentials im Verlauf einer Tetanus-Erkrankung wird in Kapitel 4.2.1.1 beschrieben.

Bisher war nichts über weitere Plasmid-kodierte Toxine bei C. tetani bekannt. Die Sequenzanalyse von pE88 ergab nun, dass das Plasmid auch das Gen (CTP33) einer $114 \mathrm{kDa}$ großen Collagenase trägt, nachfolgend als ColT bezeichnet. Die Proteinsequenz von ColT zeigte hohe Ähnlichkeiten zu den charakterisierten Collagenasen ColH und ColG aus C. histolyticum (MATSUSHITA et al., 1999) und ColA aus C. perfringens (MATSUSHITA et al., 1994). ColA wird auch als $\kappa$-Toxin bezeichnet. Es ist wie das Tetanus-Toxin eine Zink-abhängige Protease, welche die Degradation von Collagen katalysiert, das am häufigsten vorkommende Matrix- 
Protein in Vertebraten. ColA wird für die durch $C$. perfringens verursachte Myonekrose mitverantwortlich gemacht (ROOD, 1998).

Eine detaillierte Beschreibung der Collagenase in C. tetani sowie deren möglicher Beitrag zur Pathogenität des Organismus wird in Kapitel 4.2.1.2 gegeben.

\subsubsection{Regulatorische Funktionen}

Die Regulation des Tetanus-Toxins in C. tetani sowie der homologen BotulinusToxine in C. botulinum ist bisher nur ansatzweise verstanden. In Untersuchungen von MARVAUD et al. (1998a/1998b) konnte eine Regulation dieser Toxine auf der Ebene der Transkription festgestellt werden: über ein DNA-bindendes Protein (TetR bzw. BotR) kann die Expression des Toxin-Gens direkt aktiviert werden. Unbekannt ist, ob das Tetanus-Toxin auch auf anderen Ebenen z. B. posttranslational reguliert wird. Des weiteren wurde vermutet, dass es dem Transkriptionsaktivator übergeordnete Regulationssysteme gibt (MARVAUD et al., 2000). Allerdings konnten bisher keine identifiziert werden. So bleibt die wichtigste Frage bis heute unbeantwortet: wie gelingt es einem harmlosen Bodenbakterium, bei Eintritt in den Säugetierwirt sich in einen (zumindest potentiell) tödlichen Organismus zu verwandeln, der eines der stärksten der Menschheit bekannten Nervengifte produziert ? Sind es Faktoren des Wirts, die C. tetani zur Produktion des TetanusToxins veranlassen, und wenn ja, welche sind diese ?

\subsubsection{TetR, der Transkriptionsaktivator des Tetanus-Toxins}

Erste Untersuchungen zur Regulation des Tetanus-Toxins konzentrierten sich auf die genetische Umgebung von TeTx. Unmittelbar stromaufwärts wurde von MARVAUD et al. (1998a) ein ORF identifiziert und sequenziert, der für ein 21,6 $\mathrm{kDa}$ großes Protein kodiert, genannt TetR, welches typische Merkmale eines DNAbindenden Proteins aufweist. In weiteren Studien konnte gezeigt werden, dass TetR die Transkription von tet $X$ positiv reguliert (MARVAUD et al., 1998a). Parallel dazu wurde in C. botulinum stromaufwärts vom Botulinus-Toxin A-Gen ein ORF identifiziert, genannt botR, dessen Proteinsequenz zu TetR eine 67\%ige Identität zeigt (MARVAUD et al., 1998b). Gelretardationsexperimente und weitere Versuche 
ergaben, dass BotR an die Promoterregion des Botulinus-Toxin-Gens binden und dessen Transkription positiv regulieren kann. Erst kürzlich wurde die Vermutung aufgestellt, dass TetR und BotR als alternative RNA-Polymerase-Sigmafaktoren und nicht als typische Transkriptionsaktivatoren anzusehen sind (MANI \& DUPUY, 2001). Dies wurde aus der Sequenzhomologie des TetR bzw. des BotR zum TxeR aus C. difficile abgeleitet (s. Tabelle 6). Die Autoren konnten experimentell nachweisen, dass TxeR als alternativer RNA-Polymerase-Sigmafaktor bei der Regulation der Toxinsynthese von ToxA und ToxB in C. difficile wirkt.

Die Sequenzanalyse von pE88 hat nun ergeben, dass TetR (CTP60) auch auf pE88 stromaufwärts von tet $X$ kodiert ist. Der Vergleich zur bereits bekannten tetR-Sequenz (MARVAUD et al., 1998a), welche aus dem C. tetani-Stamm CN655 stammt, offenbarte Unterschiede in 4 Basen, die 2 Aminosäure-Austausche im C-Terminus des Proteins zur Folge haben.

\subsubsection{Regulatorische Proteine mit Homologien zu RNA-Polymerase- Sigmafaktoren}

Neben TetR lassen sich auf pE88 weitere bisher unbekannte regulatorische Elemente ausmachen (Tabelle 6). Besonders interessant ist die Region 4-10 kb stromaufwärts vom tetX Gen. Dort sind zum einen zwei Proteine kodiert, CTP10 und CTP11, die signifikante Ähnlichkeiten zu RNA-Polymerase-Sigmafaktoren aufweisen. Beide zeigen schwache Homologien zur Sigma-70-Faktor-Domäne PF00140; für CTP10 ergab der Sequenzvergleich mit dem BLASTP-Programm einen E-Wert* von 0.00016, für CTP11 von 5.1e-05.

\footnotetext{
* Der E (Erwartungs)-Wert in der Ausgabe des BLAST-Programms gibt die Signifikanz des Ergebnisses einer Ähnlichkeitssuche wieder. Z. B. ist ein E-Wert von 1 folgendermaßen zu interpretieren: man kann erwarten, dass der Vergleich der Eingabesequenz mit den DatenbankSequenzen einen Treffer mit gleichem Ähnlichkeitswert lediglich durch Zufall liefert.
} 
Tabelle 6: Ähnlichkeiten einiger regulatorischer Elemente von pE88 zu charakterisierten clostridiellen Toxinsynthese-Regulatoren (A) und untereinander (B)

A)

\begin{tabular}{|c|c|c|c|c|}
\hline pE88 & Annotation & $\begin{array}{c}\text { UviA* } \\
(185 \mathrm{As})\end{array}$ & $\begin{array}{c}\text { TxeR* } \\
(184 \mathrm{As})\end{array}$ & $\begin{array}{c}\text { BotR* } \\
(178 \mathrm{As})\end{array}$ \\
\hline $\begin{array}{c}\text { CTP05 } \\
(172 \mathrm{As})\end{array}$ & $\begin{array}{c}\text { Frameshift; UviA/TxeR- } \\
\text { Homologon }\end{array}$ & $\begin{array}{c}32 \%(48 \%) \\
\text { über } 188 \mathrm{As}\end{array}$ & $\begin{array}{c}31 \%(49 \%) \\
\text { über } 170 \mathrm{As}\end{array}$ & $\begin{array}{c}26 \%(43 \%) \\
\text { über } 178 \mathrm{As}\end{array}$ \\
\hline $\begin{array}{c}\text { CTP10 } \\
(179 \mathrm{As})\end{array}$ & $\begin{array}{c}\text { DNA-bindendes Protein, } \\
\text { möglicher RNA } \\
\text { Polymerase-Sigmafaktor }\end{array}$ & $\begin{array}{c}24 \%(43 \%) \\
\text { über } 184 \mathrm{As}\end{array}$ & $\begin{array}{c}28 \%(47 \%) \\
\text { über } 82 \mathrm{As}\end{array}$ & $\begin{array}{c}\text { nicht } \\
\text { signifikant }\end{array}$ \\
\hline $\begin{array}{c}\text { CTP11 } \\
(184 \mathrm{As})\end{array}$ & $\begin{array}{c}\text { DNA-bindendes Protein, } \\
\text { möglicher RNA }\end{array}$ & $\begin{array}{c}25 \%(44 \%) \\
\text { Polymerase-Sigmafaktor }\end{array}$ & $\begin{array}{c}24 \%(44 \%) \\
\text { über } 179 \mathrm{As}\end{array}$ & $\begin{array}{c}\text { nicht } \\
\text { signifikant }\end{array}$ \\
\hline $\begin{array}{c}\text { CTP61 } \\
(177 \mathrm{As})\end{array}$ & $\begin{array}{c}\text { Transkriptionsaktivator } \\
\text { von tetX }\end{array}$ & $\begin{array}{c}27 \%(49 \%) \\
\text { über } 183 \mathrm{As}\end{array}$ & $\begin{array}{c}26 \%(47 \%) \\
\text { über } 184 \mathrm{As}\end{array}$ & $\begin{array}{c}67 \%(85 \%) \\
\text { über } 177 \mathrm{As}\end{array}$ \\
\hline
\end{tabular}

* UviA stammt aus C. perfringens (GARNIER \& COLE, 1988a), TxeR aus C. difficile

(MANI \& DUPUY, 2001) und BotR aus C. botulinum (MARVAUD et al., 1998b).

B)

\begin{tabular}{|c|c|c|c|c|}
\hline pE88 & CTP05 & CTP10 & CTP11 & CTP61 \\
\hline CTP05 & $/$ & $\begin{array}{c}24 \%(45 \%) \\
\text { über 178 As }\end{array}$ & $\begin{array}{c}27 \%(43 \%) \\
\text { über 180 As }\end{array}$ & $\begin{array}{c}25 \%(46 \%) \\
\text { über 162 As }\end{array}$ \\
\hline CTP10 & & $/$ & $\begin{array}{c}30 \%(48 \%) \\
\text { über 176 As }\end{array}$ & $\begin{array}{c}\text { nicht } \\
\text { signifikant }\end{array}$ \\
\hline CTP11 & & & $/$ & $\begin{array}{c}25 \%(41 \%) \\
\text { über 193 As }\end{array}$ \\
\hline CTP61 & & & & $/$ \\
\hline
\end{tabular}

Die Prozentzahlen in A und B geben Aminosäureidentitäten (in Klammern: -ähnlichkeiten) wieder. Hier nicht aufgeführt ist CTP04 (71 As), welches eine Homologie zu UviB (64 As) aus C. perfringens (40\% Identität über 67 As) zeigt.

CTP10 kodiert für ein 179 As großes Protein. Eine potentielle Shine-Dalgarno (SD)Sequenz (AGGGTGG) findet man 6 bp stromaufwärts vom ATG-Startcodon. Der Sequenzvergleich mit der NCBI-Datenbank ergab Ähnlichkeiten zu folgenden Proteinen: der als hypothetisch annotierte ORF CPE0507 (24\% Proteinidentität über 184 As) aus $C$. perfringens (SHIMIZU et al., 2002) sowie CAP0167 (25\% Identität über $175 \mathrm{As}$ ) aus C. acetobutylicum, der als spezialisierter Sigmafaktor annotiert wurde (NÖLLING et al., 2001). Tabelle 6 listet zudem die Ähnlichkeiten zu charakterisierten regulatorischen Proteinen auf: zu TxeR aus C. difficile (MANI \& DUPUY, 2001) und zu UviA, einem möglichen positiven Regulator des Bacteriocin- 
Gens aus $C$. perfringens (GARNIER \& COLE, 1988a). UviA sowie das Bacteriocin sind in C. perfringens auf dem 10 kb-Plasmid pIP404 kodiert. Durch den Vergleich von CTP10 mit der $C$. botulinum-Sequenzdatenbank des Sanger-Zentrums (ftp://ftp.sanger.ac.uk/pub/pathogens/cb) wurden zusätzlich zwei hoch homologe Proteine in diesem Organismus identifiziert (ORF A und ORF B, Abb. 7). Interessanterweise befindet sich ORF A auf dem Chromosom von C. botulinum unmittelbar stromabwärts, in umgekehrter Orientierung, vor $c o l B$, dem Gen für eine Collagenase, die starke Ähnlichkeiten zu ColT aus $C$. tetani zeigt. ORF B in $C$. botulinum ist Teil eines möglichen IS (Insertionssequenz)-Elements und befindet sich in einer genetischen Umgebung, die viele Phagen-verwandte Gene enthält.

$\begin{array}{lrll}\text { ORF A } & 1 & \text { GEESKFVPYCINAIKTNYKALLKGEIKHHREI PDENILNKGNEYMFTIED } \\ \text { ORF B } & 1 & \text { GEENKFIPYCIKTIKTNYKALLKGEIKHHREIPDENISDKGNEYFFTIED } \\ \text { CTP10 } & 1 & \text { GNGDNFIPYCINAIKNNYTALLKGEIKHHREIPDEFILNKAKDYMFTLED } \\ \text { ORF A } & 51 & \text { EIIAYEKTKEIYEALDKLTQEEKOVINDFYIKNNSLNKIAEDTNKTYNSV } \\ \text { ORF B } & 51 & \text { EIIAYENIKELYKALDKLTPEEKEVIDSFYIKNNSLQEIANYTNKSYNSV } \\ \text { CTP10 } & 51 & \text { EVIAYEKIEELYKALDKLSSSERYIIGSFYIGNKAMGEIACTTNKSYNEV } \\ \text { ORF A } & 101 & \text { RYTKDKAIKKLQKILEEH- } \\ \text { ORF B } & 101 & \text { RYTKEKAIKKLQNMLEH- } \\ \text { CTP10 } & 101 & \text { RYAKDKAIKNLQRILKKHI }\end{array}$

\section{Abb. 7: Partielles multiples Alignment der Proteinsequenzen von CTP10 aus} C. tetani mit ORF A und ORF B aus $C$. botulinum ORF A zeigt eine 67\%ige Proteinidentität über 179 As zu CTP10, ORF B eine 65\% Identität über 175 As. In schwarz, identische As; in grau, ähnliche As. Die C. botulinum-Daten entstammen dem Sequenzierungsprojekt des Sanger-Zentrums (ftp://ftp.sanger.ac.uk/pub/pathogens/cb).

CTP11 kodiert für ein Protein aus 184 As. Stromaufwärts vom TTG-Startcodon befindet sich eine mögliche SD-Sequenz (AGGAGG). Die Proteinsequenz zeigt höhere Ähnlichkeitswerte zu möglichen Sigmafaktoren als CTP10, z. B. eine 35\%ige Identität über 175 As zum oben erwähnten ORF CAP0167 aus C. acetobutylicum. Ähnlichkeiten zu TxeR, UviA und TetR sind in Tabelle 6 aufgeführt. Im Genom von C. botulinum ließen sich keine zum CTP11 homologen Proteine identifizieren.

Zwei weitere ORFs mit möglicher regulatorischer Bedeutung lassen sich etwa $4 \mathrm{~kb}$ stromaufwärts vom tet $X$-Gen ausmachen (CTP04 und CTP05). Die 71 As große Proteinsequenz von CTP04 zeigt eine Homologie (40\% Identität über 67 As) zu 
UviB aus C. perfringens, einem 64 As großen Protein, welches auf pIP404 in unmittelbarer Nachbarschaft zum uviA kodiert ist (GARNIER \& COLE, 1988a). UviB soll zusätzlich zum UviA an der Regulation der Bacteriocin-Synthese beteiligt sein. Stromaufwärts von CTP04 befindet sich ein durch eine Leserastermutation (Frameshift) unterbrochener ORF (CTP05). Die entsprechende Stelle der Nukleotidsequenz wurde in Gap4 dahingehend überprüft, ob diese Leserasterverschiebung auch durch einen Sequenzierfehler entstanden sein könnte. Die Korrektheit der Basenfolge an dieser Stelle konnte aber zweifelsfrei festgestellt werden, so dass davon auszugehen ist, dass CTP05 ein Pseudogen darstellt. Die Proteinsequenz des Pseudogens zeigt Ähnlichkeiten zu UviA, TxeR und BotR sowie zu TetR und CTP10 (Tabelle 6). Abbildung 8 zeigt ein Sequenzalignment von CTP05 mit UviA, wobei das Alignment eine Lücke stromaufwärts der möglichen Leseraster-Mutation aufweist. Es bleibt zu klären, ob diese Leserastermutation in CTP05 spezifisch für den C. tetani-Stamm E88 ist.

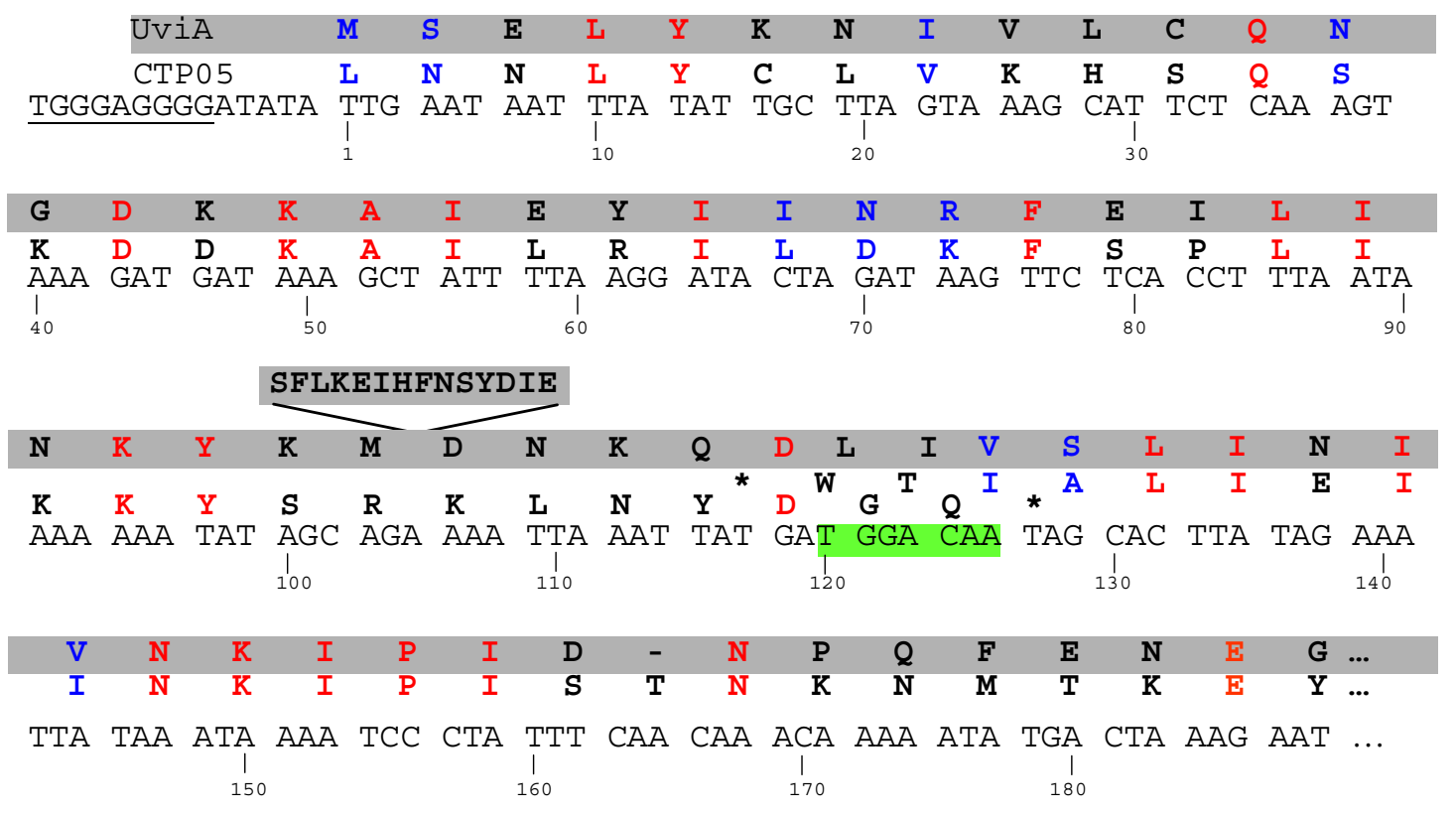

\section{Abb. 8: Darstellung der Leserasterverschiebung in CTP05 und dessen Sequenz- alignment mit UviA aus $C$. perfringens}

CTP05 ist durch einen authentischen Frameshift unterbrochen, möglicherweise entstanden durch eine Nukleotid-Deletion zwischen den Positionen 120 bis 126 (in grün). Eine Lücke im Alignment zu UviA (grau hinterlegt) befindet sich stromaufwärts zu der potentiellen Position der Leserasterverschiebung. Identische Aminosäuren im Alignment sind rot, ähnliche blau dargestellt. Unterstrichen ist die mögliche SD-Sequenz. * : Stopcodon. 
Um die in Tabelle 6 aufgeführten Sequenzähnlichkeiten der beschriebenen regulatorischen Elemente von pE88 untereinander und $\mathrm{zu}$ den homologen charakterisierten Proteinen aus anderen Clostridien besser veranschaulichen $\mathrm{zu}$ können, wurden deren phylogenetische Beziehungen mit dem Neighbour-JoiningAlgorithmus berechnet (Abb. 9). Dabei sind zwei getrennte Cluster auszumachen: CTP10 und CTP11 sind deutlich abgesetzt von dem Cluster der anderen regulatorischen Proteine. Darin bilden TetR und BotR eine Untergruppe.

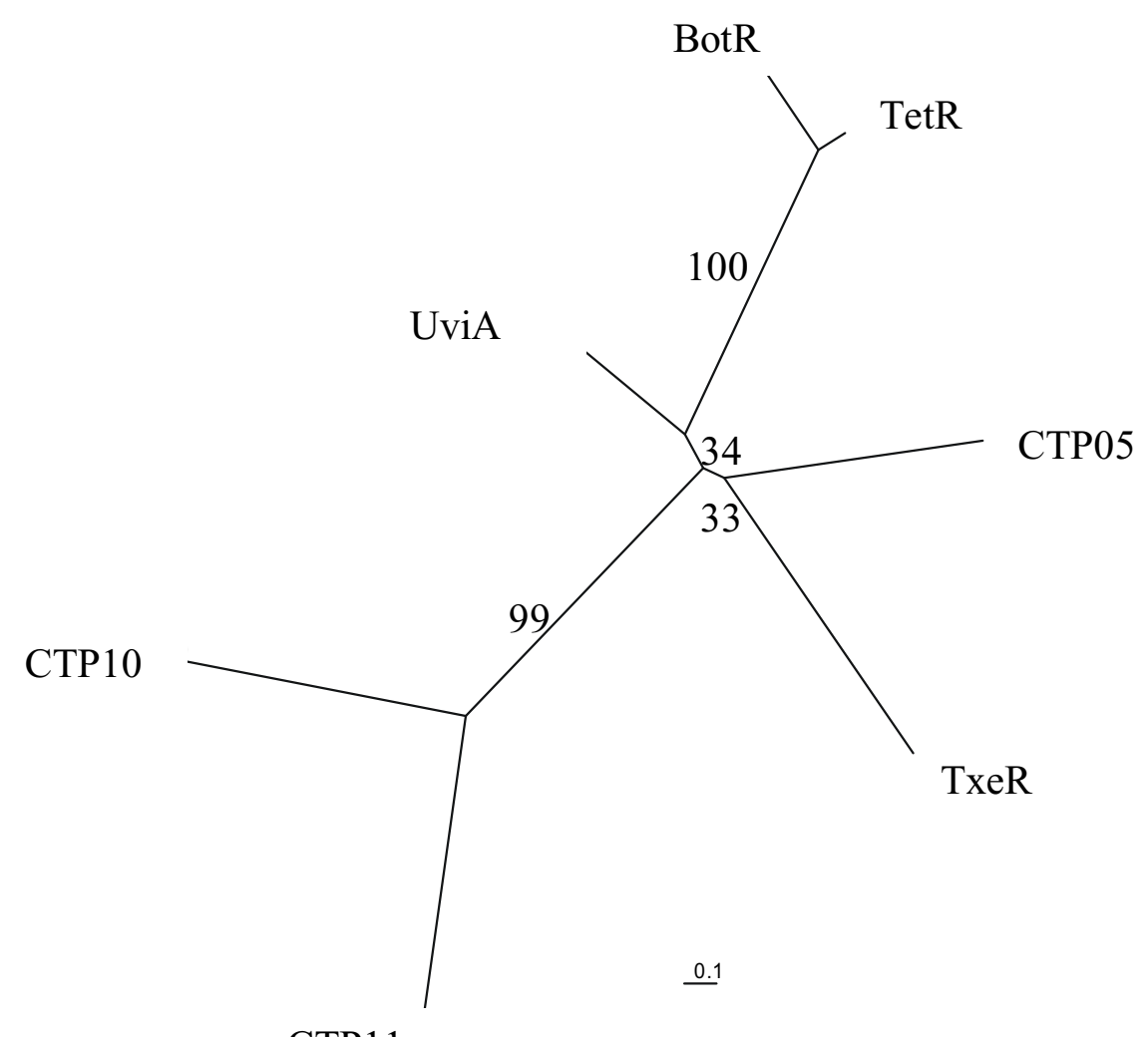

CTP11

\begin{abstract}
Abb. 9: Phylogenetische Beziehung der regulatorischen Elemente von pE88 untereinander sowie zu TxeR aus $C$. difficile, UviA aus $C$. perfringens und BotR aus $C$. botulinum

Der Neighbour-Joining (NJ)-Algorithmus wurde auf genetische Distanzen zwischen Paaren von Proteinsequenzen angewandt (1000 bootstrapIterationen). Die Distanzen wurden mit der Dayhoff PAM Matrix-Methode berechnet. Das darauf basierende multiple Sequenzalignment wurde mit dem ClustalW-Algorithmus erstellt. Als Computerprogramm kam dabei das Phylip (Phylogeny Inference Package) 3.5c-Softwarepacket zur Anwendung (SAITOU \& NEI, 1987).
\end{abstract}




\subsubsection{Zwei-Komponenten-System}

Auf pE88 befinden sich auch die Gene für ein Zwei-Komponenten-System, bestehend aus einem Response-Regulator (CTP21) und einer Sensor-Histidin-Kinase (CTP22). Der Sequenzabgleich dieses Systems mit externen Datenbanken offenbarte starke Ähnlichkeiten zu Zwei-Komponenten-Systemen aus u. a. B. cereus, B. halodurans, C. botulinum und C. acetobutylicum. Das 228 As umfassende ResponseRegulator-Protein besteht aus einer N-terminalen Empfänger (Receiver)- und einer C-terminalen Transkriptionsregulator-Domäne. Die Sensor-Histidin-Kinase enthält eine den Histidin-Kinasen typische ATPase-Domäne sowie eine Dimerisations- und Phosphatgruppenakzeptor-Domäne. Für einige charakterisierte Zwei-KomponentenSysteme ist bekannt, dass sie die Transkription des oder der Gene regulieren, die in unmittelbarer genetischer Nachbarschaft auf dem Genom lokalisiert sind (KORETKE et al., 2000). So wurde auch die genetische Umgebung von CTP21/CTP22 betrachtet und mit der von homologen Systemen anderer Organismen verglichen (Abb. 10).

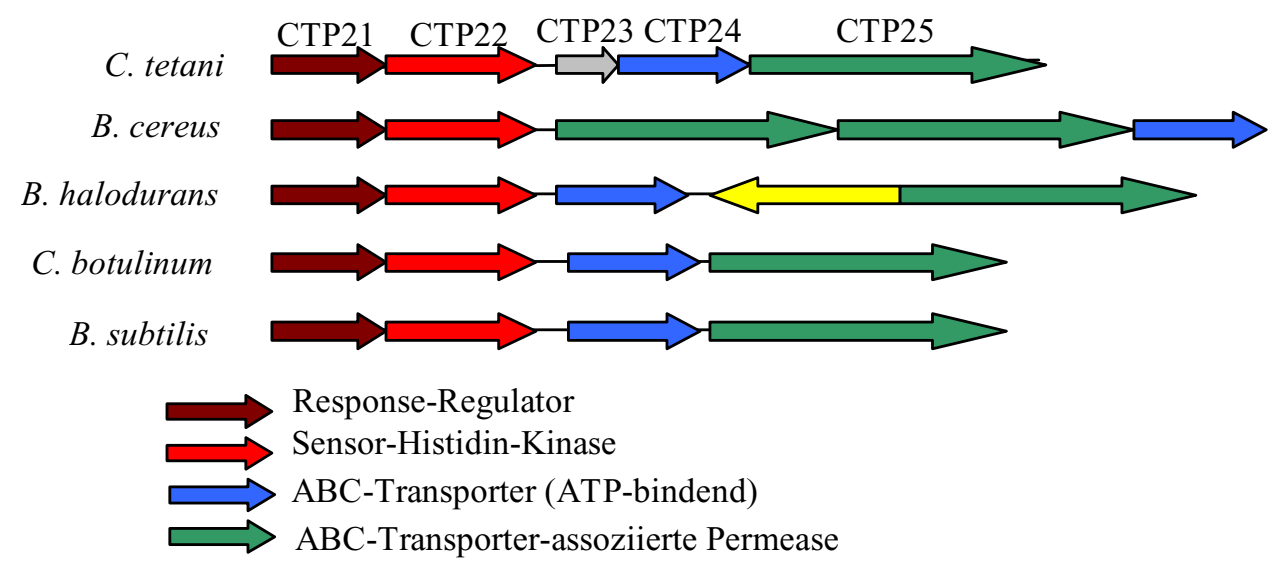

\footnotetext{
Abb. 10: Genetische Organisation der Region stromabwärts der Gene des Zwei-Komponenten-Systems CTP21/CTP22 sowie homologer Systeme Auf pE88 befindet sich ein zusätzlicher hypothetischer ORF (CTP23). Ein Transposase-Gen (in gelb) ist innerhalb des Transport-Genclusters in $B$. halodurans lokalisiert.
}

Es stellte sich heraus, dass die genetische Umgebung der Zwei-KomponentenSysteme in verschiedenen Organismen konserviert ist. Dabei kodiert das an den Systemen angrenzende genetische Cluster für Proteine mit Transport-Funktionen. 
Auf pE88 beispielsweise kodiert CTP24 für ein ABC (ATP-bindende Kassette)Transportprotein mit einer ATP-bindenden Domäne (Abb. 10). CTP25 kodiert für eine ABC-Transporter-assoziierte Permease mit 10 transmembranen Helices (s. 3.2.7). Zu CTP21/CTP22 homologe Zwei-Komponenten-Systeme, an deren Gene solche angrenzen, die für ähnliche ABC-Transporter und Permeasen kodieren, konnten in B. anthracis, B. cereus, B. halodurans, C. acetobutylicum, C. botulinum, C. difficile, B. subtilis, S. aureus, St. epidermidis und C.perfringens gefunden werden. Es kann vermutet werden, dass das CTP21/CTP22-System die Transkription der stromabwärts lokalisierten Transport-Gene reguliert.

Allerdings wäre auch denkbar, dass das System die Transkription anderer auf dem Plasmid oder Chromosom liegende Gene reguliert, wie das z. B. beim VirR/VirSSystem in C. perfringens der Fall ist (ROOD, 1998). Daher sollte überprüft werden, ob das Zwei-Komponenten-System möglicherweise in der Regulation des TetanusToxins involviert ist. Hierzu wurde das Gen CTP21, welches für den ResponseRegulator kodiert, über PCR amplifiziert und über Eco31I-Schnittstellen in den Vektor IBA3 (pASK) kloniert. Nach Identifikation und Sequenzierung eines positiven Klons wurde das rekombinante Plasmid, genannt pHBRR2, in E. coli XL1 transformiert. Schließlich erfolgte das Expressionsexperiment, indem ein transformierter Klon bis $\mathrm{zu}$ einer $\mathrm{OD}$ von 0,8 angezogen und anschließend Anhydrotetracyclin zugegeben wurde, was die Expression des unter der Kontrolle eines tetA-Promoters stehenden klonierten Gens induzierte. Zusätzlich wurde dem exprimierten Protein C-terminal ein ,Strep-Tag' angehängt, was die chromatographische Aufreinigung des heterolog exprimierten Proteins über eine ,Strep-Tactin ${ }^{\circledR}$-Säule ermöglichte. Nach erfolgter Inkubation ( $3 \mathrm{~h}$ ) wurden dazu die Zellen geerntet und über Ultraschall-Behandlung aufgeschlossen. Der gewonnene Rohextrakt wurde dann auf die ,Strep-Tactin ${ }^{\circledR}$--Säule gegeben. Die Elution erfolgte durch Zugabe des spezifischen Kompetitors Desthiobiotin.

Abbildung 11 zeigt, dass schon im Rohextrakt des rekombinanten Klons eine zusätzliche Bande bei $29 \mathrm{kDa}$ erschien, was der theoretisch zu erwartenden Größe des Response-Regulators entsprach. Des weiteren ist ersichtlich, dass durch die Benutzung der Affinitätssäule das heterolog in E. coli XL1 produzierte Protein aufgereinigt werden konnte. Die Konzentration des Proteins war allerdings aufgrund des Vorhandenseins von Einschlusskörpern (,Inclusion bodies') nach der Expression 
sehr gering und konnte durch Änderung der Induktionsparameter (Dauer, Temperatur) nur geringfügig verbessert werden. Trotzdem wurde der so gereinigte Response-Regulator in Gelretardationsexperimenten eingesetzt, um zu prüfen, ob dieses heterolog produzierte Protein DNA-bindende Eigenschaften zeigte. Als mögliche Ziele einer Bindung wurden DNA-Bereiche von 150-400 bp gewählt, die den Promotorregionen der Gene tetX, tetR, colT, CTP23 und CTP24 entsprachen. In ersten Versuchen konnte keine Bindung des Proteins an die gewählten DNABereiche festgestellt werden. Da Interaktionen zwischen Proteinen und DNA von vielen Faktoren abhängen können, was i. d. R. langwierige Untersuchungen mit sich bringt, wurde entschieden, die begonnenen Arbeiten im Rahmen der Diplomarbeit von Elke Raade fortzusetzen und zu intensivieren.

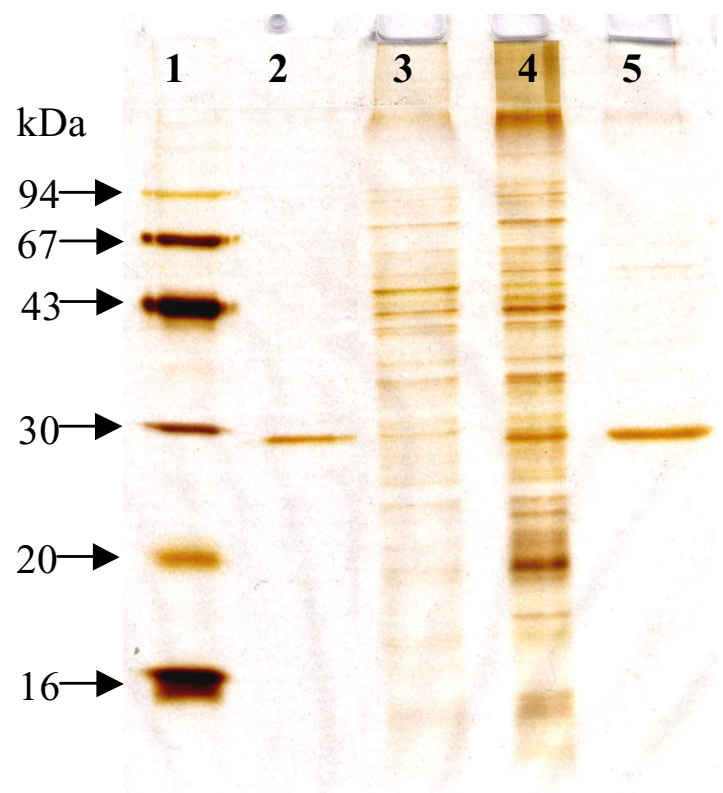

\footnotetext{
Abb. 11: Heterologe Expression des Response-Regulators CTP21 aus C. tetani in $E$. coli XL1 (10\%iges SDS-PAGE-Gel)

Spur 1: Proteinstandard

Spur 2: gereinigtes Protein aus dem Eluat (3. Stufe)

Spur 3: Rohextrakt aus E. coli XL1 + Plasmid IBA3 (Leervektor)

Spur 4: Rohextrakt aus E. coli XL1 + Plasmid pHBRR2

Spur 5: gereinigtes Protein aus dem Eluat (4. Stufe)
} 
Die Annotation von pE88 hatte ergeben, dass fast ein Drittel aller auf pE88 kodierten Proteine offensichtlich an Transportprozessen beteiligt sind: 10 Proteine zeigten Homologien zu Transportern aus verwandten Organismen und weitere sieben Proteine schienen aufgrund der Präsenz multipler transmembraner Helices in der Membran verankert zu sein, und somit ebenfalls potentiell Transportfunktionen $\mathrm{zu}$ haben.

Bei näherer Betrachtung kann man fünf Transportsysteme identifizieren, die aus jeweils mehreren Proteinen bestehen und dem ABC(ATP-bindende Kassette)-Typ von Transportern zuzuordnen sind: CTP15/CTP16, CTP24/CTP25, CTP30/CTP31, CTP34/CTP35/CTP36/CTP37 und CTP52/CTP53/CTP54. Jedes dieser Systeme besteht aus einem Protein (CTP15, CTP24, CTP31, CTP37 und CTP52), das jeweils mindestens eine ABC-Transporter-Domäne und eine ATP-bindende Domäne beinhaltet, sowie einem oder mehrerer Proteine mit multiplen transmembranen Helices. Offenbar existieren hier Transportsysteme, die jeweils aus einer ATPhydrolysierenden Untereinheit, welche die benötigte Energie für den Transportprozess liefert, und einer oder mehrerer membranintegraler Untereinheiten aufgebaut sind, welche das Substrat im Periplasma oder Cytoplasma - je nachdem, $\mathrm{ob}$ es sich um ein Aufnahme- oder Efflux-System handelt - binden und durch die Membran hindurchschleusen. Das in Abbildung 12 gezeigte Hydrophobizitätsdiagramm von CTP25 veranschaulicht dessen mögliche Proteinstruktur und -lokalisation: das Protein besteht aus einem hydrophilen Bereich im mittleren Teil (etwa zwischen den Aminosäureresten 320-500), der möglicherweise ins Periplasma oder Cytoplasma gerichtet ist und die Substrat-Bindestelle beinhalten könnte, und aus zwei hydrophoben transmembranen Bereichen am N- und C-Terminus, mit deren Hilfe das Substrat durch die Membran transportiert werden könnte. 
CTP16: 8 transmembrane Helices

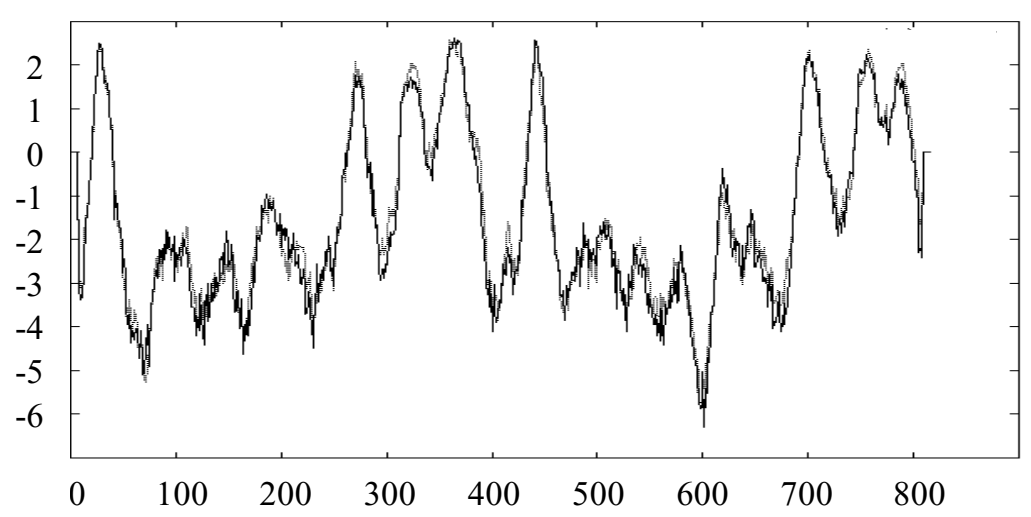

CTP25: 10 transmembrane Helices

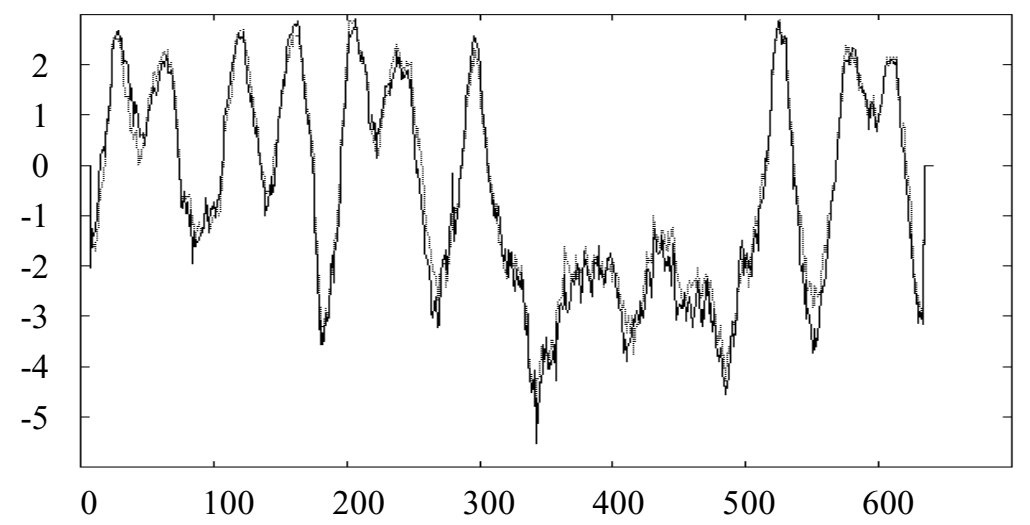

CTP30: 7 transmembrane Helices



Abb. 12: Hydrophobizitätsdiagramme einiger potentieller, auf pE88 kodierten ABC-Transporter-assoziierten Permeasen

Die Zahlen an der Ordinate geben die relative Hydrophobizität an; ein Kurvenverlauf oberhalb der Nullpunktlinie gibt hydrophobe, einer unterhalb der Linie hydrophile Bereiche des Proteins an. Die Zahlen an der Abzisse zeigen die Positionen der Aminosäurenreste im Protein an. 
Die Zusammensetzung der einzelnen Transportsysteme, die auf pE88 kodiert sind, unterscheidet sich leicht von ,typischen' ABC-Transportern der ABC-Superfamilie. Ein solcher ABC-Transporter besteht i. d. R. aus vier Domänen bzw. Untereinheiten: zwei Kopien der ABC-Transporter-Domäne (Pfam00005), welche die ATPBindestelle (Walker A und B-Motive) beinhaltet, und zwei Kopien der transmembranen Domäne, welche die Membran mehrere Male in $\alpha$-helicaler Konformation durchspannt (SAIER, 1999; DAVIDSON, 2002). Diese vier Domänen können in einem Protein vereinigt oder aber auf mehrere Proteine eines Komplexes aufgeteilt sein. Eine Vielzahl von Variationen dieses Typs sind in letzter Zeit insbesondere durch Genomsequenzierungsprojekte identifiziert worden (DASSA et al., 1999). Generell unterscheidet man in der aus derzeit 48 Familien bestehenden ABC-Transporter-Superfamilie folgende zwei Funktionen: solche Komplexe, welche die Aufnahme von Substraten wie z. B. Aminosäuren oder Peptiden katalysieren (hauptsächlich Transportsysteme mit periplasmatischen Bindeproteinen) und solche, die für den Export von z. B. Peptiden, Proteinen, antimikrobiellen Agenzien oder Toxinen verantwortlich sind (i. d. R. Transporter ohne Bindeproteine).

Zur genaueren Charakterisierung der Transportsysteme auf pE88 wurden weitere Vergleiche herangezogen, welche in Tabelle 7 wiedergegeben sind. Beispielsweise offenbarte dabei ein Abgleich der Proteinsequenz des Transportsystems CTP24/CTP25 mit einer speziellen von SAIER entwickelten und gepflegten Datenbank (http://www-biology.ucsd.edu/ msaier/transport/), die nur Transportproteine enthält, welche biochemisch oder zumindest bioinformatisch charakterisiert sind, eine in den anderen Datenbanken bisher nicht erkannte hohe Homologie zu einem System bestehend aus zwei Proteinen aus Streptococcus mutans, die bei der Bacitracin-Resistenz eine Rolle spielen (TSUDA et al., 2002). Da es sich bei Bacitracin um ein Peptid-Antibiotikum handelt, ist es möglich, dass das System CTP24/CTP25 als Peptid-Transporter fungiert. 
Tabelle 7: Bioinformatische Charakterisierung einiger auf pE88 kodierter Transportfunktionen

\begin{tabular}{|c|c|c|c|c|c|}
\hline $\begin{array}{l}\text { ORF- } \\
\text { Name }\end{array}$ & Domänen & $\begin{array}{c}\text { Hydro } \\
\text { pho- } \\
\text { bizität }\end{array}$ & Homologes Protein* & Herkunft & $\begin{array}{c}\text { - BLAST-E-Wert } \\
\text { - identische } \\
\text { (ähnliche) As }\end{array}$ \\
\hline \multirow[t]{2}{*}{ CTP15 } & \multirow{2}{*}{$\begin{array}{c}1 \text { ABC-Transporter- } \\
\text { Domäne; } \\
1 \text { ATP- } \\
\text { Bindedomäne }\end{array}$} & \multirow[t]{2}{*}{-} & $\begin{array}{c}\text { Lipoprotein } \\
\text { freisetzendes System - } \\
\text { ATP-bindendes } \\
\text { Protein LolD }\end{array}$ & $\begin{array}{c}\text { E. coli } \\
(233 \mathrm{As})\end{array}$ & $\begin{array}{c}3 \mathrm{e}-45 ; \\
41 \%(64 \%) \text { über } 215 \\
\text { As }\end{array}$ \\
\hline & & & $\begin{array}{l}\text { Mutans Bacitracin- } \\
\text { Resistenz Protein A }\end{array}$ & $\begin{array}{l}\text { St. mutans } \\
(250 \mathrm{As})\end{array}$ & $3 e-45$ \\
\hline \multirow{2}{*}{ СТР24 } & \multirow{2}{*}{$\begin{array}{c}1 \text { ABC-Transporter- } \\
\text { Domäne; } \\
1 \text { ATP- } \\
\text { Bindedomäne }\end{array}$} & \multirow[t]{2}{*}{-} & $\begin{array}{l}\text { Mutans Bacitracin- } \\
\text { Resistenz-Protein A }\end{array}$ & $\begin{array}{l}\text { St. mutans } \\
(250 \mathrm{As})\end{array}$ & $\begin{array}{c}8 \mathrm{e}-60 ; \\
48 \%(69 \%) \text { über } 248 \\
\text { As } \\
\end{array}$ \\
\hline & & & SalX & $\begin{array}{c}\text { St. } \\
\text { salivarius } \\
(245 \text { As }) \\
\end{array}$ & $\begin{array}{c}3 \mathrm{e}-53 ; \\
44 \%(61 \%) \text { über } 245 \\
\text { As } \\
\end{array}$ \\
\hline \multirow{2}{*}{ СТР25 } & \multirow{2}{*}{1 DUF214-Domäne } & \multirow[t]{2}{*}{$10 \mathrm{TM}$} & $\begin{array}{l}\text { Mutans Bacitracin- } \\
\text { Resistenz Protein B }\end{array}$ & $\begin{array}{l}\text { St. mutans } \\
\text { (667 As) }\end{array}$ & $\begin{array}{c}2 \mathrm{e}-09 ; \\
17 \%(36 \%) \text { über } 289 \\
\text { As }\end{array}$ \\
\hline & & & SalY & $\begin{array}{c}\text { St. } \\
\text { salivarius } \\
(635 \text { As }) \\
\end{array}$ & $\begin{array}{c}2 \mathrm{e}-08 ; \\
19 \%(40 \%) \text { über } \\
361 \mathrm{As} \\
\end{array}$ \\
\hline CTP31 & $\begin{array}{c}1 \text { ABC-Transporter- } \\
\text { Domäne }\end{array}$ & - & $\begin{array}{l}\text { Nodulation ATP- } \\
\text { Bindeprotein I }\end{array}$ & $\begin{array}{l}\text { Rhizobium } \\
\text { galegae } \\
\text { (347 As) } \\
\end{array}$ & $\begin{array}{c}6 \mathrm{e}-17 ; \\
38 \%(66 \%) \text { über } 100 \\
\text { As } \\
\end{array}$ \\
\hline СТP37 & $\begin{array}{c}1 \text { ABC-Transporter- } \\
\text { Domäne + ATP- } \\
\text { Bindedomäne }\end{array}$ & - & SpaF & $\begin{array}{l}\text { B. subtilis } \\
\text { (247 As) }\end{array}$ & $\begin{array}{c}5 \mathrm{e}-25 ; \\
30 \%(52 \%) \text { über } 211 \\
\text { As }\end{array}$ \\
\hline CTP38 & $\begin{array}{l}\text { Zink-Transporter- } \\
\text { Domäne }\end{array}$ & $2 \mathrm{TM}$ & - & - & - \\
\hline СТP49 & $\begin{array}{l}\text { Metall-abhängige } \\
\text { Hydrolase }\end{array}$ & 4-7 TM & - & - & - \\
\hline CTP52 & $\begin{array}{c}1 \text { ABC-Transporter- } \\
\text { Domäne; } \\
2 \text { ATP- } \\
\text { Bindedomäne }\end{array}$ & - & $\begin{array}{c}\text { Lipoprotein } \\
\text { freisetzendes System - } \\
\text { ATP-bindendes } \\
\text { Protein LolD }\end{array}$ & $\begin{array}{c}\text { E. coli } \\
(233 \mathrm{As})\end{array}$ & $\begin{array}{c}3 \mathrm{e}-38 ; \\
39 \%(60 \%) \text { über } 213 \\
\text { As }\end{array}$ \\
\hline
\end{tabular}

* Die Proteinsequenzen wurden gegen die Transportprotein-Datenbank von SAIER abgeglichen (http://www-biology.ucsd.edu/ msaier/transport/).

Letztendlich können die Substratspezifitäten der auf pE88 kodierten Transportsysteme nicht allein über bioinformatische Methoden geklärt werden. Vieles deutet aber darauf hin, dass es sich bei den meisten der Transportsysteme um solche handelt, die Peptide oder sogar ganze Proteine transportieren. Diese Annahme stellt auch die mögliche Bedeutung der Transportsysteme im Hinblick auf den Export des Tetanus-Toxins und die Regulation der TeTx-Synthese in ein neues Licht. Es wäre durchaus denkbar, dass bestimmte Signalmoleküle des Wirts (z. B. Peptidhormone) über auf pE88 kodierte Systeme in die C. tetani-Zelle gelangen und dort die Expression von tet $X$ beeinflussen. 


\subsubsection{Replikationsfunktionen und mobile Elemente}

3.2.8.1 Replikationsproteine

Die Suche nach möglichen Replikationsproteinen führte zur Identifikation zweier Proteine, CTP01 (422 As) und СТP45 (423 As), die zueinander eine 93\%ige DNAHomologie bzw. eine 89\%ige Proteinidentität besitzen, wobei sich deren Alignment im wesentlichen nur innerhalb der letzten 60 C-terminalen Aminosäureresten unterscheidet. Ein Abgleich dieser Proteinsequenzen mit der NCBI-Datenbank ergab eine hohe Ähnlichkeit (41\% Identität über 382 As) zu dem charakterisierten Replikationsprotein des Virulenz-Plasmids pIP404 aus C. perfringens, welches u. a. für die Bacteriocin-Synthese und für dessen Regulationssystem UviA/UviB kodiert (GARNIER \& COLE, 1998b). Dieses Replikationsprotein wird in einem ShuttleVektor genutzt, der sowohl in $E$. coli als auch in $C$. perfringens replizierbar ist (SLOAN et al., 1992). Eine weitere Ähnlichkeit (44\% Identität über 384 As) zeigt CTP01/CTP45 zu dem Replikationsprotein eines Plasmids, welches aus dem nicht näher charakterisierten alkaliphilen Bacillus-Stamm KSM-KP43 isoliert wurde (HATADA \& ITO, 1999). Daneben gibt es zusätzlich zur Duplikation von CTP01/CTP45 ein weiteres Protein auf pE88, CTP28, welches aus nur 103 As besteht, die eine 90\%ige Proteinidentität (über $72 \mathrm{As}$ ) zu dem mittleren Proteinabschnitt von CTP01 bzw. CTP45 zeigen (Aminosäurereste 220-290). Bei CTP28 handelt es sich offenbar um ein Fragment des Replikationsproteins. Interessant ist der Umstand, dass diese drei Gene (СTP01, СТP28, CTP45) andere Codone benutzen. Der G+C-Gehalt der dritten Base eines Codons dieser Gene liegt im Durchschnitt bei $25 \%$ und ist damit weitaus höher als bei den anderen Genen auf pE88 (15\%). Das deutet darauf hin, dass das Replikationsprotein über lateralen Gentransfer aus einem Organismus der Bacillus/Clostridium-Gruppe akquiriert wurde. Eine weiteres Indiz für diese Hypothese ist die offenbar vorliegende Mobilität dieses Gens ähnlich der eines IS-Elementes: Abbildung 13 zeigt die Abundanz von direkten Sequenzwiederholungen (direct repeats) stromaufwärts des Startcodons von CTP45. Direkte Sequenzwiederholungen entstehen bei der Insertion von DNAFragmenten (IS-Elementen) in die Empfänger-DNA über die durch den Insertionsmechanismus bedingte Zielstellenverdopplung. Vermutlich hat sich also das Replikationsprotein auf pE88 dupliziert. Da um CTP01 keine direkten Sequenzwiederholungen identifiziert werden konnten, ist davon auszugehen, dass 
CTP01 das ursprünglichere Replikationsprotein darstellt und die eigentliche Replikationsfunktion übernimmt. Diese Vermutung korreliert mit der vom GC-Skew abgeleiteten Annahme, dass der Replikationsursprung (ori) des Plasmids in der Nähe von CTP01 liegt. Allerdings gibt es auch eine gegensätzliche Erklärung dieser multiplen Sequenzwiederholungen vor CTP45: viele ori enthalten Sequenzwiederholungen (z. B. DnaA-Boxen), die Bindestellen für das Replikationsprotein darstellen (KNIPPERS, 1995). Nach dieser Erklärung wäre der ori also eher in der Umgebung stromaufwärts von CTP45 lokalisiert.

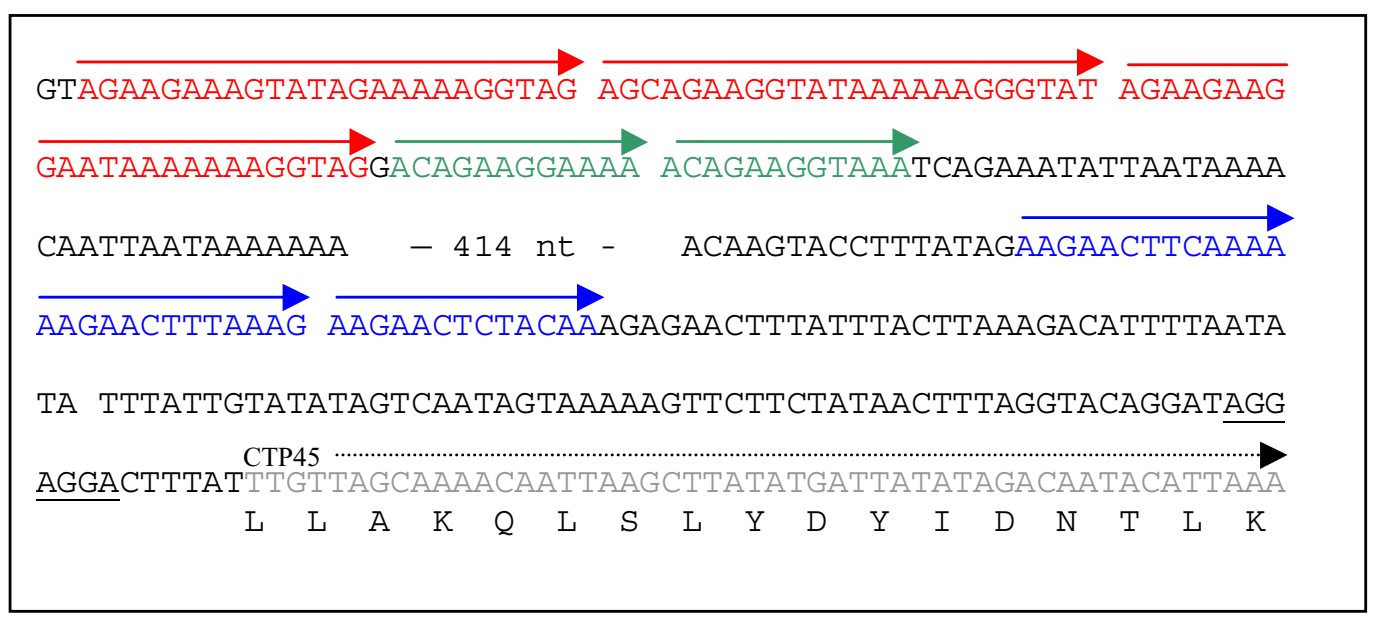

Abb. 13: Direkte Sequenzwiederholungen stromaufwärts von CTP45.

Drei unterschiedliche Sequenzabschnitte (rot, grün, blau) werden in 2-3 direkt benachbarten Kopien (dargestellt als durchgezogene Pfeile) mit leichter Variation der Basenfolge wiederholt. Folgende ConsensusSequenzen liegen vor: 23 bp (rot), AGAAGAAGGTATAAAAAAGGT AG; 12 bp (grün), ACAGAAGG $/{ }_{A}$ AAA; 13 bp (blau), AAGAACTTTA AAA.

\subsubsection{Mobile Elemente}

Zusätzlich zu dem eben beschriebenen potentiellen mobilen Element lässt sich ein weiteres IS-Element auf pE88 ausmachen, welches in zweifacher Kopie vorkommt und keine Ähnlichkeit zu bekannten IS-Elementen zeigt (BLAST gegen Datenbank aus IS-Elementen: http://www-is.biotoul.fr/is.html). Dieses Element besteht aus jeweils zwei ORFs, einer vollständigen Transposase (CTP17 und CTP39 - 98\%ige DNA-Homologie) und einem möglichen Transposase-Fragment (CTP18 und CTP40). CTP17 bzw. CTP39 zeigen hohe Homologien zu einer möglichen Transposase aus B. cereus (60\% Identität über 355 As), welche genomweit in fünf 
Kopien vorkommt, und zu einer möglichen Transposase aus B. stearothermophilus (40\% Identität über 295 As), die 9fach im Genom vorliegt (unveröffentlichte Daten aus ERGO Göttingen, s. 2.13.2). Der zweite ORF des IS-Elements (CTP18 und CTP40 - 99\%ige DNA-Homologie) zeigt starke Ähnlichkeiten zu ORFs in Anabaena sp. Stamm PCC 7120 (73\% Identität über 132 As) und Thermomonospora fusca (60\% Identität über 125 As).

\subsection{9}

Sonstige Funktionen

3.2.9.1

23S rRNA(Guanin-N1)-Methyltransferase

CTP27 kodiert für eine 23S rRNA(Guanin-N1)-Methyltransferase. Das Protein zeigt Ähnlichkeiten (46\% Identität über 276 As) zu einer rRNA-Methyltransferase aus St. pneumoniae R6 (AAL00715) sowie zu Enzymen aus $V$. cholerae, P. aeruginosa (HOSKINS et al., 2001). Für Methyltransferasen diesen Typs wird angenommen, dass sie Resistenzen vermitteln können und zwar zu den Antibiotika der MakrolidLincosamid-Streptogramin B-Gruppe wie z. B. Erythromycin oder Mycinamicin (GUSTAFSSON \& PERSSON, 1998). Die Methylierung der 23S rRNA durch diese Methyltransferasen hat zur Folge, dass das Antibiotikum eine schwächere Affinität zum Ribosomen hat und dadurch seine Wirkung als Proteinsynthesehemmer nicht mehr entfalten kann.

\subsubsection{Aminopeptidasen}

CTP20 und CTP56 kodieren für Aminopeptidasen mit N-terminalen Signalpeptiden, was den Export dieser Enzyme ins Periplasma ermöglicht. Dabei zeigt CPT20 schwache Homologien zur Aminopeptidase-Domäne von Proteinen aus $C$. acetobuylicum (AAK80787, 32\% Identität über 197 As; NÖLLING et al., 2001) und C. perfringens (AP003193, 33\% Identität über 190 As; SHIMIZU et al., 2002). CTP56 enthält eine Peptidase-Domäne der M20/M25/M40-Peptidase-Familie (Pfam01546, 29\% Identität über 179 As). Dieses Protein zeigt außerdem Ähnlichkeiten zu Aminopeptidasen aus B. halodurans, B. subtilis und $B$. licheniformis (TAKAMI et al., 2000; KUNST et al., 1997). 
Es ist denkbar, dass die beiden Peptidasen von pE88 an der Aktivierung des TetanusToxins durch proteolytische Spaltung des Toxins beteiligt sind (s. 4.2.1.1). 


\subsection{Sequenzierung und Sequenzanalyse des Chromosoms von C. tetani $\mathbf{E 8 8}$}

\subsubsection{Sequenzierungsstrategie: Die Shotgun-Methode}

Die Sequenzierung eines gesamten Bakterienchromosoms stellte weitaus höhere Ansprüche an die Methodik und deren Qualitätskontrolle als die eines $74 \mathrm{~kb}$ großen Plasmids. Prinzipiell sollte das gleiche Verfahren zur Anwendung kommen, das auch für die Plasmidsequenzierung genutzt wurde: Die Shotgun-Methode (2.9-2.12). Abbildung 14 gibt einen Überblick über die Strategie und den Ablauf der Genomsequenzierung von C. tetani.

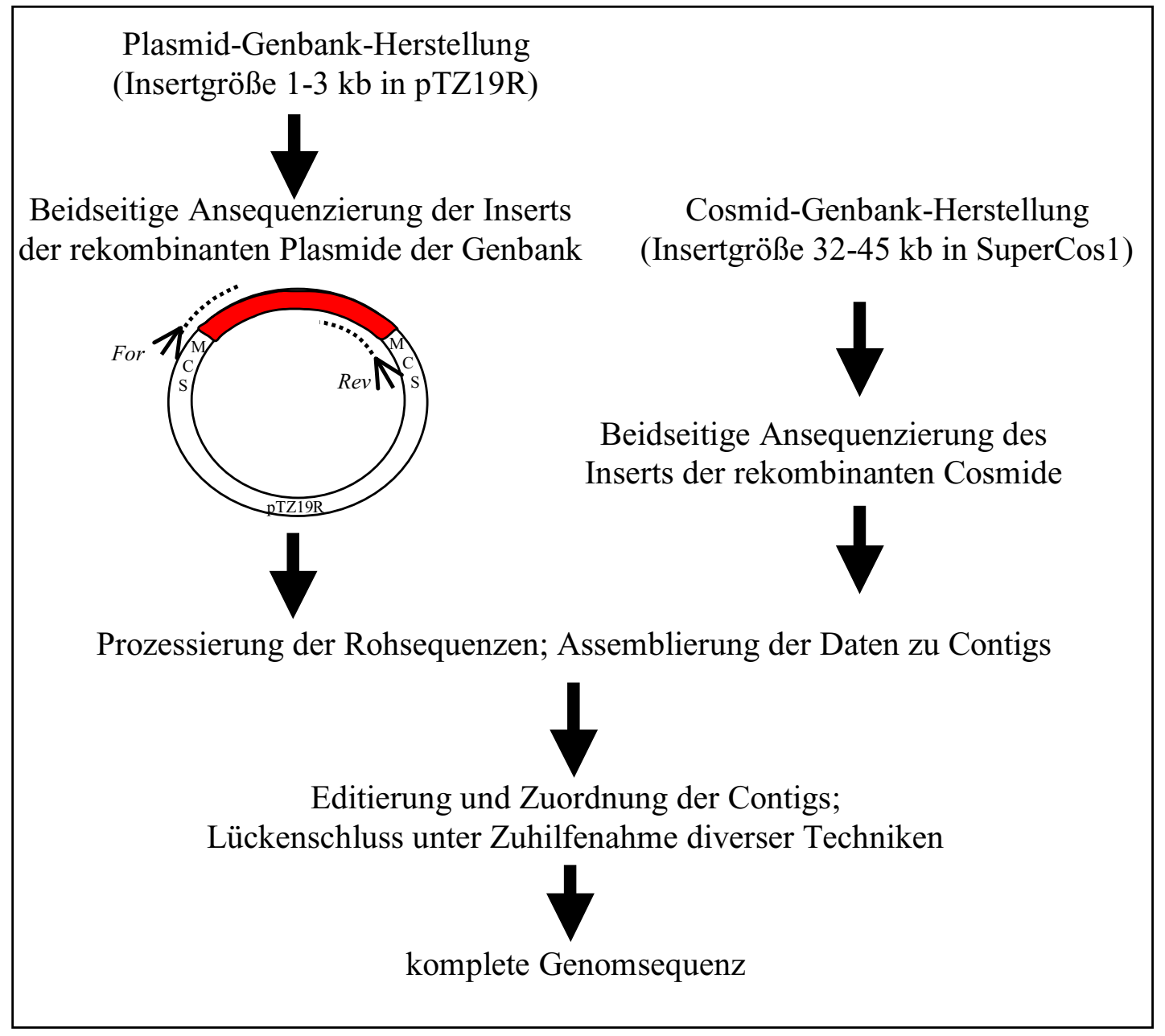

Abb. 14: Fließschema zur Strategie und zum Verlauf der Sequenzierung des Gesamtgenoms von $C$. tetani.

Abkürzungen: MCS, multiple Klonierungsstelle; Rev, Reverse-Primer; For, Forward-Primer; in rot, C. tetani-DNA-Fragment (Insert). 
Als erstes wurden Genbanken erstellt. Dazu wurde genomische DNA aus C. tetani E88 isoliert, aufgereinigt und mittels einer umgebauten HPLC-Pumpe mechanisch geschert. Die entstandenen Fragmente wurden wie in Kapitel 2.9 beschrieben weiterverarbeitet und solche der Größen 1-3 kb in den Vektor pTZ19R kloniert. Genbanken wurden strengstens auf ihre Qualität überprüft, da die Sequenzierung von Banken mit hohem Anteil ,leerer' Vektoren, d. h. Banken, die über 5\% Vektoren ohne C. tetani-Inserts enthielten, immense Mehrkosten verursacht hätte und somit inakzeptabel war. Wichtig war bei der Herstellung der Genbanken auch die Verwendung von genomischer DNA aus unterschiedlichen DNA-Präparationen, da sich im Laufe des Sequenzierungsprojektes herausstellte, dass die meisten Genbanken nicht das statistisch zu erwartende gleichwahrscheinliche Vorkommen jedes denkbaren DNA-Abschnitts des C. tetani-Genoms gewährleisteten. Nach der Sequenzierung der rekombinanten Plasmide einer Genbank wurden die Einzelsequenzen prozessiert und mittels des Programms Gap4 assembliert (s. 2.11). Die darauffolgenden Schritte sind in den nächsten Kapiteln ausführlich erläutert.

\subsection{2}

Phase 1: Rohsequenzierung und Assemblierung

Unter Rohsequenzierung versteht man die Sequenzierung möglichst vieler klonierter DNA-Fragmente (Inserts) der rekombinanten Plamide einer Genbank. Diese wurden von beiden Seiten her mit Hilfe zweier von der Vektorsequenz abgeleiteten Primern ansequenziert (s. Abb. 14). Die Aufgabe des Projektbetreuers in dieser Phase der Genomsequenzierung bestand vor allem in der Kontrolle der Daten. Insbesondere musste die Qualität und Länge der Sequenzläufe und deren C. tetani-Spezifität überprüft werden. Es wurden zudem Testassemblierungen nach jeweils etwa 1000 neu hinzugekommenen Einzelsequenzen durchgeführt. Unter Assemblierung versteht man dabei die Suche nach identischen Sequenzabschnitten unter allen Einzelsequenzen und deren Ausrichtungen (Alignment) zueinander (s. 2.11). Dabei kam das Assemblierungsprogramm Phrap zum Einsatz, welches in dem Programm Gap4 implementiert ist.

Um die Anzahl benötigter Einzelsequenzen bzw. benötigter rekombinanter Plasmide zur Abdeckung einer Genomsequenz abzuschätzen, kann man sich folgender Formel bedienen: 


$$
N=\frac{A * L}{w},
$$

wobei $\mathrm{N}$ die Anzahl der Einzelsequenzen, w die Leseweite, d. h. die durchschnittliche Länge einer Einzelsequenz ( 600 Basen), A die Abdeckungsrate (i. d. R. wird eine 6-9fache Abdeckung der Genomsequenz angestrebt) und L die Größe des Genoms ist. Wird das Genom von C. tetani auf eine Größe von $3 \mathrm{Mb}$ geschätzt, dessen Sequenz man 8fach abzudecken wünscht, werden nach dieser Formel theoretisch 40000 Einzelsequenzen bzw. mindestens 20000 rekombinante Plasmide benötigt.

LANDER \& WATERMAN haben eine weiterführende Formel zur Überprüfung der Assemblierung der Einzelsequenzen einer Genomsequenzierung nach dem ShotgunPrinzip entwickelt (WATERMAN, 1984). Diese berechnet die Anzahl der Contigs, die im Idealfall - gute Qualität der Sequenzen, stabile Leseweiten - bei der Assemblierung einer gegebenen Anzahl an Einzelsequenzen entsteht. Anders ausgedrückt wird die Wahrscheinlichkeit $\mathrm{P}$ berechnet, mit der eine beliebige Base des Genoms - bei einer gegebenen Anzahl an Einzelsequenzen - bisher noch nicht sequenziert worden ist:

$$
P=e^{\frac{-N * w}{L}},
$$

wobei N, w und L den Symbolen aus der obigen Formel entsprechen. Als Beispiel sei die prozentuale Wahrscheinlichkeit $\mathrm{P}$ ermittelt, mit der eine Base des Genoms nach der Assemblierung von 40000 Einzelsequenzen noch nicht sequenziert worden ist (Genomgröße $3 \mathrm{Mb}$, Leseweite $600 \mathrm{bp}$ ): sie beträgt 0,03\%, mit anderen Worten sind statistisch gesehen 1006 Basen $(=\mathrm{L} * \mathrm{P})$ des Genoms noch nicht sequenziert, was mit einer 8 fachen $(=\mathrm{N} * \mathrm{w} / \mathrm{L})$ Abdeckung der Genomsequenz und einer Contiganzahl von etwa $13(=\mathrm{N} * \mathrm{P})$ korreliert, wobei die durchschnittliche Lückengröße 75 Basen (=Anzahl der noch nicht sequenzierten Basen/Contiganzahl) beträgt.

Mit diese Formel wurde nun der Verlauf der Rohsequenzierungsphase überprüft, indem die theoretisch zu erwartende Contiganzahl (=Lückenanzahl) mit der tatsächlich nach der Assemblierung der Einzelsequenzen erhaltenen Contiganzahl verglichen wurde (Abb. 15). 


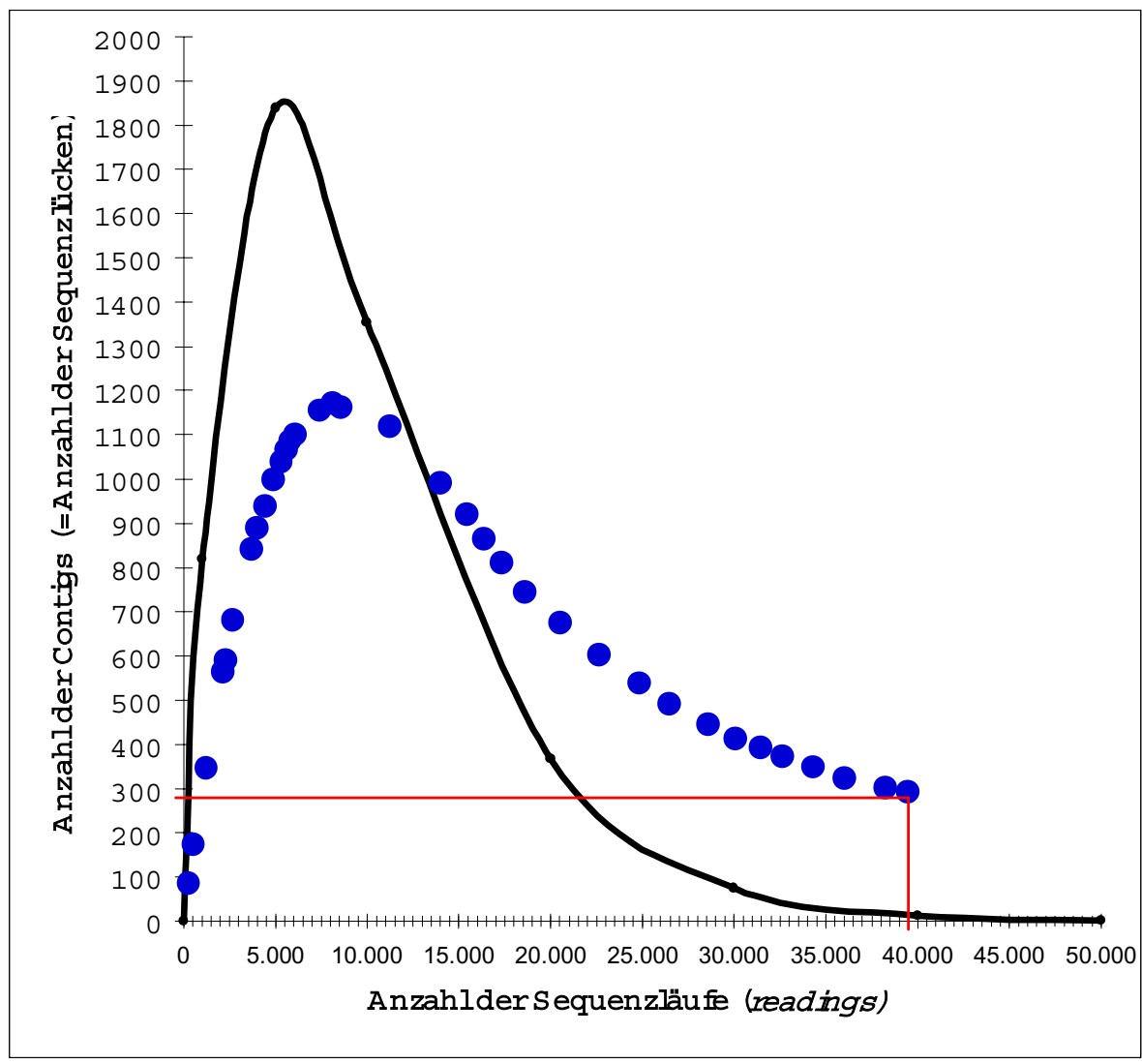

Abb. 15: Der Verlauf der Rohsequenzierung des $\boldsymbol{C}$. tetani-Genoms

Mittels der LANDER \& WATERMAN-Formel wurde der zu erwartende Verlauf unter Idealbedingungen $(\mathrm{f}(\mathrm{N})=\mathrm{N} * \exp (-\mathrm{N} * \mathrm{w} / \mathrm{L})$, schwarze Kurve) Leseweite 600 Basen, Genomgröße $3 \mathrm{Mb}$ - mit dem tatsächlichen Verlauf des Projektes (blaue Punkte) verglichen. Die Messpunkte (Contiganzahl) wurden dabei jeweils durch Neuassemblierung der Einzelsequenzen ermittelt. In rot ist das Ende der Rohsequenzierungsphase eingezeichnet: 39500 Einzelsequenzen assemblierten dabei zu 290 Contigs.

Mehrere Schlüsse konnten aus den Kurvenverläufen gezogen werden: 1. Im Anfangsstadium der Rohsequenzierung steigt die Contiganzahl annähernd proportional an, bis sie schließlich ihr Maximum erreicht (im Idealfall assemblieren 5500 Einzelsequenzen zu 1850 Contigs); danach nähert sich die Contiganzahl mit Zunahme der Menge der Einzelsequenzen asymptotisch dem Nullwert. 2. Der Vergleich der Kurven aus Abbildung 15 zeigt, dass der tatsächlich beobachtete Verlauf nicht dem theoretischen Idealfall entsprach. Hauptsächlich sind dafür drei Gründe zu nennen:

- Qualität der Genbanken: die Banken gewährleisteten nicht das gleichwahrscheinliche Vorkommen eines beliebigen genomischen 
Abschnitts. Dadurch waren bestimmte Bereiche des Genoms in einer Genbank über- andere dagegen unterrepräsentiert.

- Qualität der Einzelsequenzen: durch eine schwankende Qualität bei der Sequenzierung assemblierten Einzelsequenzen fehlerhaft.

- repetitive Sequenzen: diese in jedem Genom vorkommenden Bereiche verursachen aufgrund der Gleichartigkeit der DNA-Sequenz fehlerhafte Assemblierungen.

Das Ende der Rohsequenzierungsphase wurde bei einer 8fachen Abdeckung der Genomsequenz festgesetzt. Zu diesem Zeitpunkt sollten zudem durch die Zugabe von 1000 neuen Einzelsequenzen und deren Assemblierung nicht mehr als 5 Lücken zwischen den Contigs geschlossen werden. Im C. tetani-Projekt war dieser Zeitpunkt bei 39500 Einzelsequenzen erreicht, die zu 290 Contigs assemblierten. Das entsprach einer theoretischen Abdeckung von 7,9fach. Trotz der hohen Zahl verbliebener Contigs hätte eine Fortführung der Rohsequenzierung nur wenig zur Reduzierung der Contiganzahl beigetragen und wurde daher allein schon aus ökonomischen Gründen nicht in Erwägung gezogen.

\subsubsection{Phase 2: Editierung und Primer-Walking}

Im Anschluss an die Rohsequenzierung und die Assemblierung aller Einzelsequenzen wurden die entstandenen 290 Contigs überprüft. Wie auch schon zur Assemblierung wurde dazu das Programm Gap4 benutzt (s. 2.11), mit welchem man jeden Contig in zwei unterschiedlichen Darstellungen aufrufen kann: das sogennannte Template-Display und der Contig-Editor. Abbildung 16 gibt das Template-Display eines typischen Contigs wieder. In diesem sind schematisch alle Einzelsequenzen eines Contigs sowie die dazugehörigen Templates (= Plasmidinserts) dargestellt. 


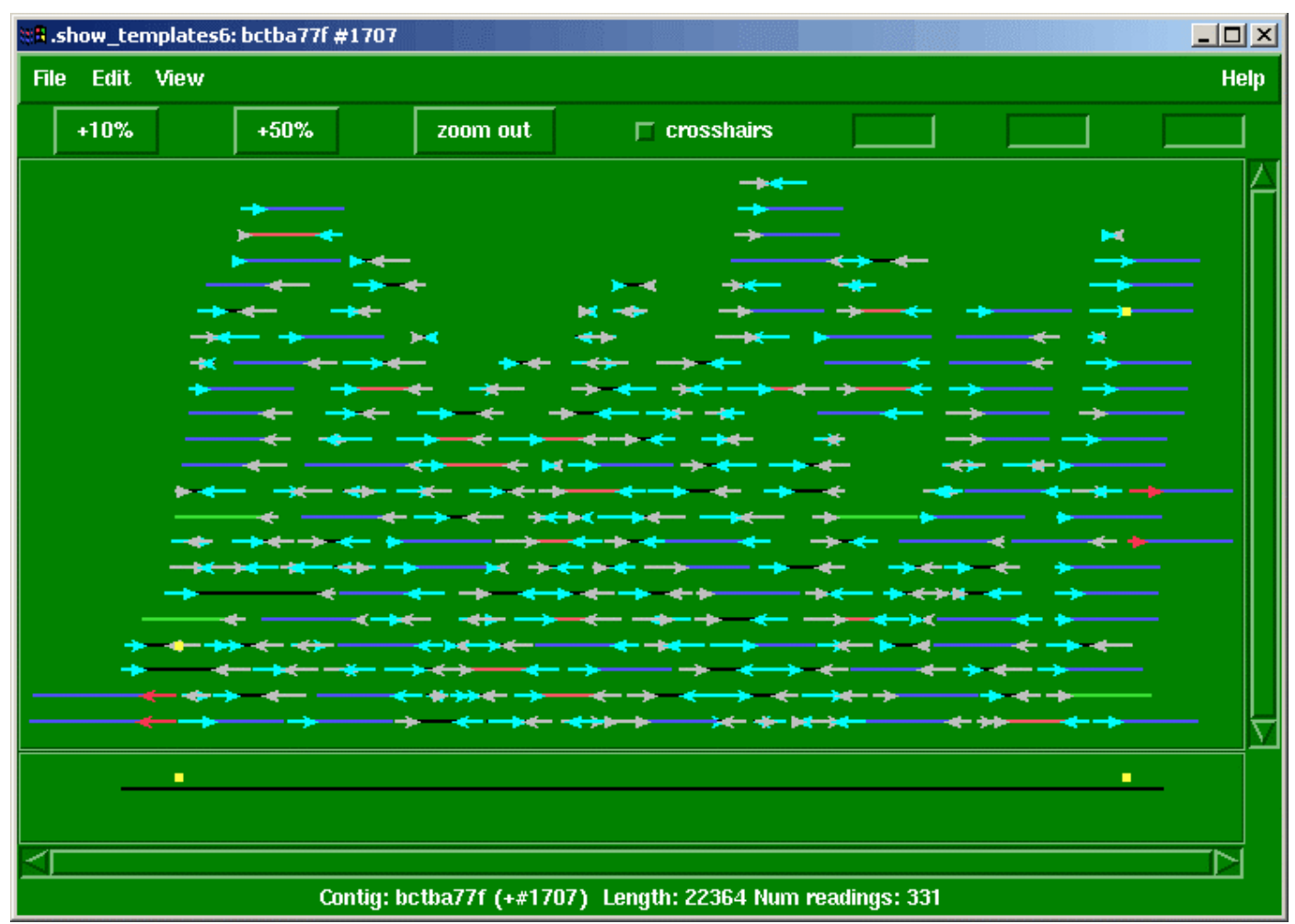

\section{Abb. 16: Die Darstellung eines Contigs im Template-Display-Modus des Programms Gap4}

Gezeigt ist der Contig bctba77f, welcher eine Länge von 22364 bp aufweist und aus 331 Einzelsequenzen besteht. Die Farben bedeuten im einzelnen: blaugrüne Pfeile, Vorwärts (forward)-Lauf auf dem entsprechenden Template (=Plasmidinsert); hellrosa Pfeile, Rückwärts (reverse)-Lauf; rote Striche (zwischen den Pfeilen), Template, das der erwarteten Größe (2-3 kb) entspricht; schwarze Striche (zwischen den Pfeilen), Template, das von der erwarteten Größe abweicht; violette Striche, der Gegenlauf dieses Templates fehlt im Gesamtdatensatz; hellgrüne Striche, der Gegenlauf dieses Templates befindet sich in einem anderen Contig des Gesamtdatensatzes; gelbe Kästchen, an dieser Stelle wurde ein Primer abgeleitet (zwecks Primer-Walking); rote Pfeile, Sequenzlauf, der durch Primer-Walking auf einem Template (oder der durch die Sequenzierung eines PCR-Produktes) erhalten wurde.

\subsubsection{Auflösung fehlerhafter Assemblierungen}

Die Überprüfung der Contigs erfolgte zum einen im Hinblick auf das Vorhandensein von fehlerhaften Assemblierungen, die wie in Kapitel 2.11.1.2 beschrieben aufgelöst wurden. Solche fehlerhaften Assemblierungen entstehen i. d. R. durch repetitive Sequenzen im Genom, wie z. B IS (Insertionssequenz)-Elemente oder rRNAClustern, die in multiplen Kopien im Genom existieren, die entweder identisch oder 
ähnlich sein können. Abbildung 17 gibt ein Beispiel für eine offensichtlich fehlerhafte Assemblierung einzelner Sequenzläufe innerhalb eines Contigs.

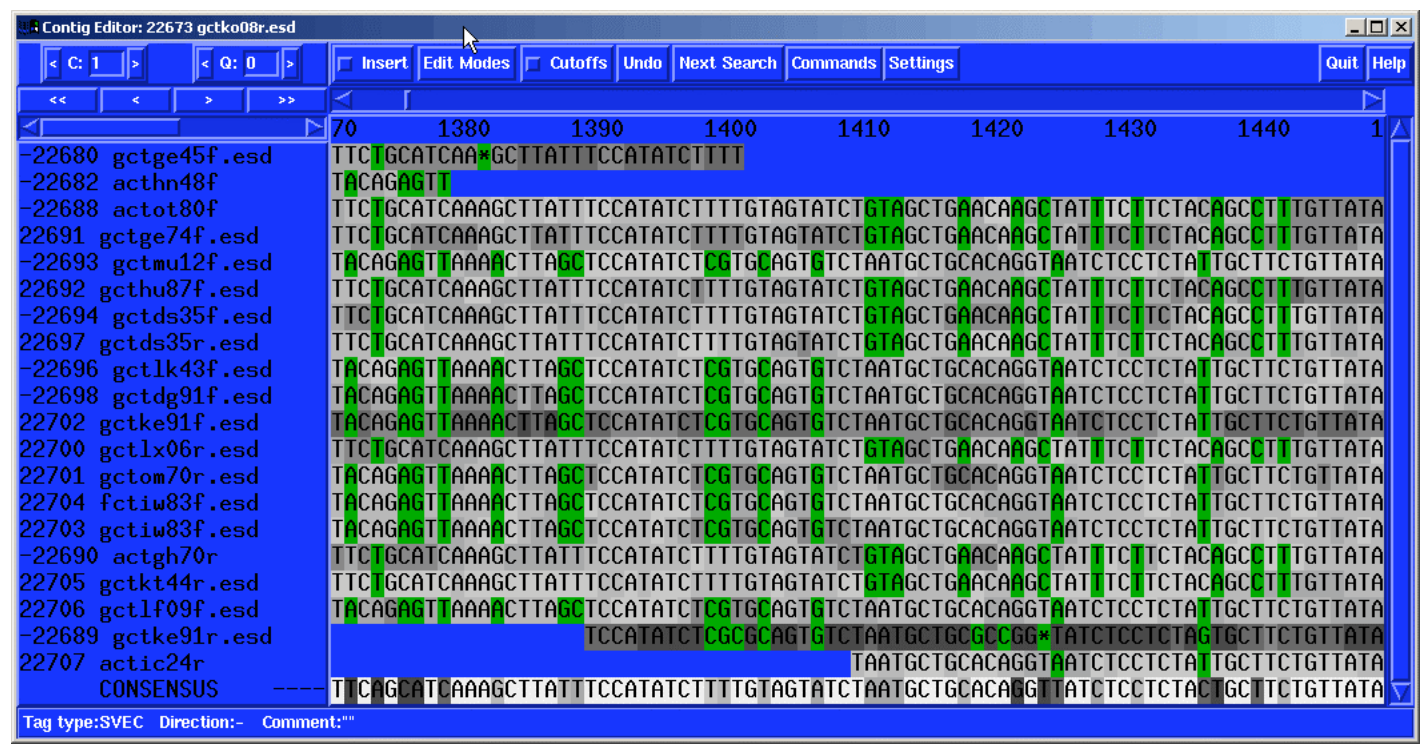

Abb. 17: Beispiel einer fehlerhaften Assemblierung im Contig gctko08r.esd

Gezeigt ist der Ausschnitt des Contigs zwischen der Nukleotidposition 1370-1450. In dieser Region assemblierten 20 Einzelsequenzläufe. In grün hervorgehoben sind die Unterschiede zum Consensus der 20 Läufe (unterste Sequenz). Betrachtet man diese genauer, so lassen sich bezüglich der Sequenz zwei Gruppen von Einzelsequenzen bilden, die aus 9 bzw. 11 Läufen bestehen. Die hinterlegten Grautöne entsprechen den Qualitätswerten der einzelnen Basen: je dunkler der Grauton, desto unwahrscheinlicher ist die Korrektheit des Nukleotids an dieser Position.

\subsubsection{Editierung der Consensus-Sequenz}

Zum anderen wurde die Consensus-Sequenz aller Contigs auf ihre Korrektheit und Qualität überprüft. Regionen innerhalb der Contigs, die nur durch eine oder wenige Einzelsequenzen abgedeckt waren oder die eine unsichere Consensus-Sequenz aufwiesen (als Indikator dafür diente der sogenannte Base Confidence Value; dieser durfte i. d. R. nicht unter 30 fallen), wurden genauer editiert. Zur Verbesserung der Qualität der Consensus-Sequenz wurden entweder Einzelsequenzläufe aus diesen Regionen wiederholt, oder aber solche Plasmidinserts mittels Insert-spezifischen Primern sequenziert, die diese Regionen überspannten. In manchen Fällen, falls keine die Region überspannenden Plasmide vorlagen, wurde der unsichere Contigabschnitt per PCR - mit genomischer DNA als Template - amplifiziert und das entstandene PCR-Produkt von beiden Seiten her (an)sequenziert (s. 2.12.3). Solche 
PCR-Amplifikationen dienten auch der Überprüfung der Korrektheit der Assemblierung in unsicheren Bereichen.

\subsubsection{Primer-Walking über Sequenzlücken}

Parallel dazu wurde damit begonnen, erste Schritte im Hinblick auf die Überwindung von Sequenzlücken zwischen den Contigs zu unternehmen: Contigs wurden anhand endständiger Sequenzläufe der beiden Ränder wie in Kapitel 2.12 .2 beschrieben einander zugeordnet, um dann über das sogenannte Primer-Walking lückenüberspannende Plasmidinserts $\mathrm{zu}$ sequenzieren und mit den gewonnenen Sequenzen die Lücken zwischen den jeweiligen Contigs zu schließen.

\subsubsection{Lückenschluss mittels Abgleich der Contigenden}

Nachdem alle diese Techniken durchgeführt worden waren und keine weiteren lückenüberspannenden Plasmide vorhanden waren, wurden alle Enden $(0,2-1 \mathrm{~kb})$ der verbliebenden Contigs wie in Kapitel 2.12.1 beschrieben gegeneinander abgeglichen, um endständig überlappende Contigs zu identifizieren. Das wurde zum einen mit der Funktion Find Internal Joints des Assemblierungsprogramms Gap4 und zum anderen mit dem BLAST-Algorithmus unternommen. Die letztere Methode stellte sich als die effektivere heraus. Mittels dieser konnte man auch leicht zwischen solchen Contigenden differenzieren, die nur einmal in der Genomsequenz vorkommen und solchen, die repetitive Sequenzen darstellen und daher mehrmals im Genom auftreten.

Zwischenbilanz. Durch die in diesem Kapitel beschriebenen Schritte der Editierung des assemblierten Sequenzdatensatzes und des Lückenschließens konnte die Contiganzahl von 290 auf 120 reduziert werden.

Phase 3: Schließen verbleibender Sequenzlücken (Gap closure)

Nun mussten weitere Strategien rekrutiert werden, um die noch verbliebenden 120 Sequenzlücken zu schließen. Dabei kamen im wesentlichen drei Methoden zur 
Anwendung: die Herstellung einer Cosmid-Genbank (2.9.2), PCR-basierte Methoden, insbesondere die kombinatorische PCR-Technik (2.12.3) sowie der Lückenschluss unter Zuhilfenahme der Annotationsdaten (2.12.4).

\subsubsection{Lückenschluss unter Zuhilfenahme einer Cosmid-Genbank}

Als erstes wurde in dieser Phase des Projektes versucht, eine Cosmid-Genbank herzustellen, indem $C$. tetani-Fragmente der Größen 30-45 kb, die durch partiellen Restriktionsverdau mit dem Enzym Sau3AI erhalten worden waren, mit dem BamHIgeschnittenen Cosmid-Vektor SuperCos1 ligiert wurden. Damit konnten aber keine rekombinanten Cosmide erhalten werden. Als mögliche Ursache wurde der schwierige partielle Verdau der genomischen DNA mit Sau3AI vermutet. Die G+Creiche Erkennungssequenz von Sau3AI ( $\downarrow$ GATC) ist im C. tetani-Genom, welches einen sehr niedrigen $\mathrm{G}+\mathrm{C}$-Gehalt von etwa $25 \%$ besitzt, nicht so häufig und regelmäßig vorhanden wie in Genomen mit höherem $\mathrm{G}+\mathrm{C}-\mathrm{Gehalt}$. Daher wurde eine neue Strategie zur Herstellung einer Cosmid-Genbank verfolgt. Der SuperCos1Vektor enthält in seiner multiplen Klonierungsstelle zwei EcoRI-


partiellen Verdau der genomischen DNA dazu komplementäre Enden bildete: das Enzym TasI ( $\downarrow$ AATT) erwies sich dafür als geeignet. So konnten schließlich rekombinante Klone gewonnen werden. Allerdings war der Erfolg bescheiden: insgesamt ließen sich lediglich etwa 150 rekombinante Klone herstellen, die eine vektorvermittelte Kanamycin- und Ampicillin-Resistenz aufwiesen. Die Cosmide dieser Klone wurden umgehend isoliert und das C. tetani-Insert der Vektoren von beiden Seiten her ansequenziert. Die erhaltenen Sequenzen wurden zum Gesamtdatensatz, bestehend aus 190 Contigs, hinzugeladen und assembliert. Ziel dabei war die Identifizierung solcher Cosmidinserts, die eine Lücke zwischen zwei Contigs überspannten. Solche Contigs konnten dann zueinander angeordnet werden, wobei die Größe der Sequenzlücke mittels des Vergleichs mit dem überspannenden Cosmidinsert abgeschätzt wurde. Schließlich wurde die Sequenzlücke über PCR mit endständig abgeleiteten Primern der entsprechenden Contigs amplifiziert, anschließend sequenziert und die erhaltene Sequenz zum Lückenschluss eingesetzt. So konnten weitere 15 Lücken geschlossen werden. Auffällig war, dass die Inserts der Cosmide - entgegen der statistischen Erwartung - keineswegs eine zufällige 
Auswahl genomischer Abschnitte darstellten. Einige Bereiche des Genoms waren mit mehreren Cosmiden abgedeckt, wohingegen weite Bereiche des Genoms nicht in den Cosmid-Vektor SuperCos1 zu klonieren waren.

\subsubsection{Lückenschluss unter Zuhilfenahme der kombinatorischen PCR-Technik}

Als weitaus effektiver erwies sich die Methode der kombinatorischen PCR. Hierbei wurden zuerst Primer von allen verbliebenen Contigrändern abgleitet - mit der Orientierung zum Contigende hin. Wichtig war dabei, dass die Primer spezifisch waren, was hier das einmalige Vorkommen jeder Primersequenz im Gesamtdatensatz meint. Nun wurden diese paarweise in allen denkbaren Kombinationen in einer PCR - mit genomischer DNA als Template - eingesetzt, wobei aufgrund der LANDER \& WATERMAN-Berechnung eine durchschnittliche Lückengröße von nicht mehr als 2 $\mathrm{kb}$ angenommen wurde. Die Anzahl an Kombinationsmöglichkeiten beschreibt die Formel

$$
\frac{n !}{k ! *(n-k) !}
$$

wobei hier $\mathrm{k}=2$ und $\mathrm{n}$ die Anzahl der Primer ist. Das bedeutete, dass bei 105 verbliebenden Contigs 21945 Kombinationsmöglichkeiten existierten. Das überstieg naturgemäß die Möglichkeiten eines kleinen Laborteams. So wurden in der Praxis nur Subsätze von Primerkombinationen genutzt, die zum Teil willkürlich gewählt wurden. Unter Zuhilfenahme der genomweiten Annotation wurden aber auch gewisse Primerkombinationen vorrangig verwendet (s. nächster Abschnitt). Jedes erhaltene PCR-Produkt wurde sofort sequenziert und die Sequenz zum Lückenschluss eingesetzt.

\subsubsection{Lückenschluss unter Zuhilfenahme der genomweiten Annotation}

Parallel dazu wurde eine weitere Methode zur Überwindung von Sequenzlücken entwickelt, die sich als sehr hilfreich herausstellte und Daten lieferte, die zur Identifikation von Contig-Paaren führte, welche direkt benachbarte DNA-Abschnitte des C. tetani-Genoms darstellten. Anschließend konnten diese Daten mit Hilfe der kombinatorischen PCR-Technik überprüft und gegebenenfalls zum Sequenzschluss 
genutzt werden. Die Methode, die in Kapitel 2.12.4 beschrieben ist, macht sich die Annotation der Contigenden zunutze, was die Identifikation von kodierender Sequenz innerhalb dieser Enden (1-3 kb) meint. Zusätzlich benötigte man die vollständig oder partiell annotierten Genomsequenzen solcher Organismen, die zu $C$. tetani möglichst nah verwandt sind. Zum Zeitpunkt der vorliegenden Arbeit lagen die Genomsequenzen von C. acetobutylicum, C. perfringens und B. subtilis sowie die unvollständigen Genomsequenzen von $C$. difficile und $C$. botulinum vor. Mit diesen Daten konnte die Tatsache genutzt werden, dass Genome nah verwandter Organismen eine ähnliche genetische Organisation besitzen. So konnten nun also die in den endständigen Sequenzen aller $C$. tetani-Contigs gefundenen offenen Leserahmen (ORFs) mit den anderen Genomsequenzen mittels des BLASTPAlgorithmus abgeglichen werden, um nach Homologien zu suchen (ALTSCHUL et al., 1990). Bei erfolgreicher Identifikation von Homologons, was die Regel war, wurde die genetische Umgebung des Homologons im entsprechenden Organismus betrachtet. Direkt benachbarte ORFs wurden anschließend vice versa mit dem Gesamtdatensatz von $C$. tetani abgeglichen. Oftmals befand sich das gesuchte Homologon im C. tetani-Datensatz am Ende eines anderen Contigs, was die Vermutung nahe legte, dass das ursprünglich betrachtete Contigende und das nun gefundene Contigende direkt benachbarte DNA-Abschnitte des C. tetani-Genoms darstellten. Durch eine anschließende PCR-Reaktion mit den entsprechenden endständig abgeleiteten Primern dieser Contigs konnte die Vermutung überprüft und gegebenenfalls zum Lückenschluss eingesetzt werden.

\subsubsection{Die letzten Sequenzlücken in Regionen repetitiver DNA-Abschnitte}

Mittels der besprochenen Techniken konnten viele weitere Contigpaare gebildet und Sequenzlücken geschlossen werden. Am Ende dieser Projektphase existierten noch 12 Contigs, wobei diese an den Enden ausnahmslos repetitive Sequenzen aufwiesen. Dabei konnte man zwei Arten von repetitiven Sequenzen unterscheiden: solche, die Kopien eines IS-Elements darstellten, welches für eine Transposase kodierte, und solche, in denen ribosomale RNA-Gene identifiziert werden konnten. Die Größe der Sequenzwiederholungen konnte bei dem IS-Element auf $3 \mathrm{~kb}$ und bei den rRNAGenregionen auf 4,9 kb festgelegt werden. Alle repetitiven Contigenden wurden 
markiert und die Übergänge zu weiter im Contiginnern liegenden Bereiche identifiziert, die ,spezifische' Sequenz darstellten, d. h. solche Sequenz, die nur einmal im Genom von C. tetani vorkommt. Dabei kam der BLASTN-Algorithmus zum Einsatz. Von diesen spezifischen Sequenzbereichen wurden Primer abgleitet, die wie nachfolgend beschrieben zum Einsatz kamen.

1. Die IS-Element-enthaltenden Regionen. Ein kombinatorischer Ansatz mit den wie eben beschrieben abgeleiteten Primern führte bei Contigenden, die Kopien eines IS-Elementes beinhalteten, nicht weiter: es konnten keine PCR-Produkte gewonnen werden. Aber folgende Strategie führte schließlich zum Erfolg: zuerst wurden alle 10 im Gesamtdatensatz gefundenen Kopien des IS-Elements untersucht, welche eine 100\%ige DNA-Homologie zueinander aufwiesen. Diese befanden sich nicht nur an den Contigenden, sondern einige auch im Contiginneren. Nun wurde die Korrektheit der Assemblierung der IS-Element-enthaltenden Contigbereiche mittels PCR überprüft. Konnte kein PCR-Produkt gewonnen werden, was in mehreren Regionen trotz augenscheinlicher Fehlerfreiheit der Assemblierung im Contig-Editor-Modus der Fall war, musste der Contig an der entsprechenden Stelle aufgebrochen werden. Dadurch entstanden neue Contigenden, von denen ,spezifische' Primersequenzen abgeleitet wurden. Benutzte man nun diese zusätzlich im kombinatorischen Ansatz, konnten PCR-Produkte gewonnen, d. h. Contigpaare gebildet und diese verbunden werden.

2. Die rRNA-Operon-enthaltenden Regionen. Anfänglich bestand hier eine große Problematik: auffällig war, dass von vielen Templates, die aus Regionen stammten, welche rDNA-Sequenzen enthielten, nur jeweils ein Sequenzlauf im Datensatz existierte, der dazugehörige Gegenlauf aber fehlte. Schnell stellte sich heraus, dass dieser Umstand auf das Prozessierungsprotokoll zurückzuführen war: die Einstellung des Programms Pregap4 war so konfiguriert, dass die Rohsequenzen u. a. gegen das Gesamtgenom von E. coli abgeglichen wurden (2.11.1.1). Alle diejenigen Einzelsequenzen, die eine 90\%ige oder höhere Homologie zur E. coli-DNA zeigten, wurden nicht in den Gesamtdatensatz geladen, sondern als E. coli-Kontaminationen bezeichnet und verworfen. Dabei wurde übersehen, dass die rRNA-Operone verschiedener Genome nahezu identisch sind, auch die von E. coli und C. tetani. Zur Behebung dieses Fehlers wurden alle entsprechend gekennzeichneten verworfenen Sequenzläufe manuell in den Gesamtdatensatz transferiert. Es zeigte sich tatsächlich, dass diese aus rDNA-Sequenzbereichen stammten. Mittels dieser zusätzlichen 
Sequenzen konnte nun ein vollständigeres Bild der rRNA-Operone gewonnen werden, wobei zwischen 6 nahezu identischen Kopien unterschieden werden konnte. Die Zusammensetzung eines typisches rRNA-Operons ist in Abbildung 18 gezeigt. Ein Operon besteht dabei aus einem 16S, einem 23S und einem 5S rRNA-Gen, wobei zwischen den ersten beiden Genen eine variable Spacer-Region existiert, in der in manchen rRNA-Operonen ein tRNA-Gen liegt.

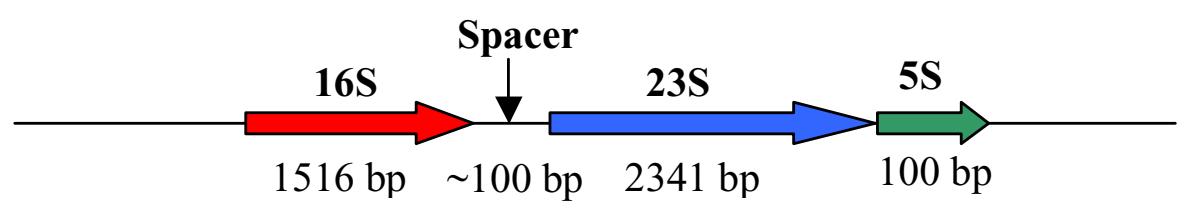

\section{Abb. 18: Aufbau eines typischen rRNA-Operons in C. tetani.}

Mit sequenzspezifischen Primern wurde nun im kombinatorischen PCR-Ansatz versucht, komplette ribosomale Operone $(\sim 6 \mathrm{~kb}) \mathrm{zu}$ amplifizieren. Das war in vielen Fällen erfolgreich. Eine Sequenzlücke verblieb aber. Der Grund dafür wurde durch einen Vergleich mit den rRNA-Operonen aus C. perfringens deutlich: das Genom dieses Organismus enthält neben isoliert liegenden rRNA-Operonen auch solche, die direkt benachbart sind, die somit repetitive Bereiche von über $10 \mathrm{~kb}$ ergeben. Anschließend durchgeführte Versuche zur Amplifikation von PCR-Produkten über $10 \mathrm{~kb}$ blieben auch mit long-PCR-DNA-Polymerasen erfolglos. Diese schwierige Situation wurde dann mit anderen Mitteln gelöst. Ins Blickfeld gerieten wieder die rekombinanten Cosmide, welche bei genauerer Analyse der Lokalisation der Cosmidinserts eine interessante Besonderheit zeigten: es stellte sich heraus, dass die genomische Herkunft der Cosmidinserts - entgegen der statistischen Erwartung nicht dem Zufallsprinzip unterlag. Vielmehr enthielten die meisten Cosmide der Genbank solche Inserts, welche rRNA-Gene enthaltende Bereiche umfassten. Möglicherweise hing dieses Phänomen mit dem in diesen Bereichen im Vergleich zur Gesamtgenomsequenz fast doppelt so hohen $\mathrm{G}+\mathrm{C}-\mathrm{Gehalt}$ zusammen, welcher zu einer besseren Klonierbarkeit solcher DNA-Abschnitte beitragen könnte. Denkbar wäre auch, dass diese DNA-Abschnitte leichter klonierbar waren, weil sie vergleichsweise wenig für Proteine kodierende Sequenz beinhalteten. Das könnte mögliche toxische Effekte durch heterologe Genexpression im Wirtsbakterium $E$. coli DH5 $\alpha$ vorgebeugt haben. Durch den Vergleich mit den Insertgößen der 
Cosmide, welche die letzte Sequenzlücke überspannten, konnte vermutet werden, dass diese letzte Lücke nicht ein rRNA-Operon, sondern zwei direkt hintereinander liegende rRNA-Operone umfassen müsste. Dieses konnte dann mit PCR-Methoden, wobei die DNA der entsprechenden Cosmide als Template verwendet wurde, und anschließender Sequenzierung der PCR-Produkte bestätigt werden.

Abschließend wurde noch einmal die Qualität des Consensus der Gesamtsequenz überprüft und gegebenenfalls Sequenzläufe wiederholt. Dadurch sollte gewährleistet werden, dass die durchschnittliche Fehlerrate kleiner als 1 in 10000 Basen war, was allgemein als ausreichend zur Veröffentlichung der Sequenz angesehen wird. Das Gap4-Programm berechnete anhand des sogenannten Base Confidence Values die Fehlerrate der Chromosomensequenz auf 1 in 147615 Basen.

Damit war ca. zwei Jahre nach Beginn der Arbeiten die Genomsequenzierungsphase des Projektes abgeschlossen: im Datensatz assemblierten nun 44455 Sequenzläufe (aus 24495 rekombinanten Plasmiden) zu zwei Contigs, welche das C. tetani-Genom bestehend aus einem 74082 bp großen Plasmid und einem zirkulären 2799251 bp großen Chromosom darstellten. Die letztendlich erhaltene Abdeckung der Sequenz betrug 9,5fach. Nun folgten die Arbeiten zur Analyse der Sequenz, was vor allem die Identifizierung aller Gene des Genoms von C. tetani bedeutet. 


\subsection{Sequenzanalyse des Chromosoms von C. tetani E88}

\subsubsection{Allgemeine Merkmale der Sequenz des Chromosoms}

Im folgenden sollen einige Merkmale der Sequenz des Chromosoms von C. tetani vorgestellt und mit den zwei bisher einzigen komplett sequenzierten Genomen von Organismen der Gattung Clostridium, C. perfringens und C. acetobutylicum, verglichen werden (Tabelle 8; SHIMIZU et al., 2002; NÖLLING et al., 2001). Das Chromosom von C. tetani besteht aus 2799251 bp. Es ist damit etwas kleiner als das Chromosom von $C$. perfringens $(3,03 \mathrm{Mb})$ und erheblich kleiner als das von $C$. acetobutylicum, welches $3,94 \mathrm{Mb}$ groß ist. Alle drei Organismen enthalten neben dem Chromosom zusätzlich ein Plasmid, welche aber in der Größe und in der kodierenden Sequenz stark variieren. Der durchschnittliche $\mathrm{G}+\mathrm{C}-\mathrm{Gehalt}$ des $C$. tetani-Chromosoms beträgt 28,6\%, ist also etwas höher als der des Plasmids pE88 (24,5\%). Der G+C-Gehalt des Genoms von C. tetani gehört $\mathrm{zu}$ den niedrigsten Werten, die bisher von kompletten Genomsequenzen ermittelt wurden. Um erste Hinweise bezüglich einer möglichen evolutiven Akquirierung von Genen anderer Genome mittels lateralem Gentransfer zu erhalten, wurde die $\mathrm{G}+\mathrm{C}$-Variation des $C$. tetani-Genoms in DNA-Abschnitten von 1000 bp untersucht (s. Abb. 19). Es zeigte sich genomweit eine geringe Abweichung vom durchschnittlichen G+C-Gehalt. Lediglich sechs Bereiche fielen durch einen $\mathrm{G}+\mathrm{C}-\mathrm{Gehalt}$ von ca. 50\% auf, die Mehrheit davon in der Nähe des potentiellen Replikationsursprungs (s. 3.4.4). Diese Bereiche entsprachen DNA-Abschnitten, welche die sechs rRNA-Operone sowie ein Operon für ribosomale Proteine enthielten.

Tabelle 8 gibt weitere Merkmale der Genomsequenz an, die in nachfolgenden Kapiteln im Detail besprochen werden sollen. Auffällig ist, dass das C. tetani-Genom im Vergleich zu den anderen Clostridien-Genomen sowohl weniger rRNA-Gene als auch weniger tRNAs enthält. Es konnten lediglich 54 tRNAs mit dem tRNAscan-SEProgramm (LOWE \& EDDY, 1997) identifiziert werden: je fünf für Met und Leu; je vier für Arg, Thr, Ser und Gly; je drei für Ala, Asn, Ile und Lys; je zwei für Glu, Cys, Phe, Gln, Tyr und Pro sowie je eine für Asp, Val, Trp und His. 
Tabelle 8: Einige Merkmale der Genomsequenzen von $C$. tetani, $C$. perfringens und $C$. acetobutylicum

\begin{tabular}{c|ccc} 
Merkmale & C. tetani E88 & C. perfringens 13 & $\begin{array}{c}\text { C. acetobutylicum } \\
\text { ATCC 824 }\end{array}$ \\
\hline Größe des Chromosoms & $2799251 \mathrm{bp}$ & $3031430 \mathrm{bp}$ & $3940880 \mathrm{bp}$ \\
\hline Größe des Plasmids (bp) & $74082(\mathrm{pE} 88)$ & $54310(\mathrm{pCP} 13)$ & $192000(\mathrm{pSOL})$ \\
\hline G+C-Gehalt (\%) & $28,6(24,5)^{\mathrm{a}}$ & $28,6(25,5)^{\mathrm{a}}$ & $30,9(30,9)^{\mathrm{a}}$ \\
\hline kodierende Sequenz $^{\mathrm{a}}$ & $86 \%$ & $83,1 \%$ & $88 \%$ \\
\hline $\begin{array}{c}\text { Anzahl der } \\
\text { identifizierten ORFs }\end{array}$ & $2373(61)$ & $2660(63)$ & $3740(178)$ \\
\hline $\begin{array}{c}\text { ORFs (\%) auf leading- } \\
\text { Strang }\end{array}$ & 81,1 & 83 & 79 \\
\hline $\begin{array}{c}\text { RNA-Gene } \\
\text { rRNA-Operone } \\
\text { tRNAs }\end{array}$ & 72 & 125 & 107 \\
\hline \begin{tabular}{c} 
(cryptische) Prophagen \\
\hline
\end{tabular} & 54 & 10 & 73 \\
\hline
\end{tabular}

${ }^{a}$ In Klammern, G+C-Gehalt der Plasmide.

${ }^{\mathrm{b}}$ In allen drei Genomprojekten wurde eine unterschiedliche Strategie bezüglich der ORF-Vorhersage gewählt. In C. perfringens wurden die Programme GAMBLER und GENEHACKER PLUS, in C. acetobutylicum UNIORF benutzt.

\subsubsection{ORF-Vorhersage}

Die Identifizierung kodierender Sequenz wurde wie in Kapitel 2.13.1 beschrieben mit Computerprogrammen durchgeführt. Bei der Genomsequenz von C. tetani wurde das Programm GLIMMER (Gene Locator and Interpolated Markov Modeler; DELCHER et al., 1999) ausgewählt, welches mit interpolierenden Markov-Modellen arbeitet. Hiermit wurden 2641 ORFs identifiziert. Allerdings waren darunter etliche ( 200), die mit anderen ORFs überlappten. Durch Vergleich mit der Annotation verwandter Genome konnte außerdem festgestellt werden, dass einige ORFs durch GLIMMER nicht erkannt worden waren. Es wurde daher entschieden, die ORFVorhersage parallel zur Annotation manuell ORF um ORF zu überprüfen. Dabei wurde bei überlappenden ORFs die Entscheidung für einen der beiden ORFs davon abhängig gemacht, ob und welche dieser ORFs Homologien zu ORFs aus anderen Organismen zeigten und ob eine Ribosomen-Bindestelle unmittelbar stromaufwärts des Startcodons ausgemacht werden konnte. Wesentlich schwieriger als das Löschen war das Hinzufügen von ORFs, was aufgrund des in diesem Punkt unflexiblen Annotationsprogramms ERGO nur auf komplizierte und zeitaufwendige Weise möglich war. Die manuelle Identifizierung aller fehlenden ORFs war zudem nicht in 
vollständiger Weise möglich, weil es dazu der Überprüfung der Genom-Annotation der verwandten Organismen bedurft hätte, was aber den Zeitrahmen dieser Arbeit gesprengt hätte.

Der momentane Stand (November 2002) der gefundenen und verifizierten ORFs im C. tetani-Chromosom beläuft sich auf 2373.

\subsection{3 Übersicht über die Annotation des Chromosoms}

Die mit GLIMMER vorhergesagten ORFs wurden dann in das Annotationsprogramm ERGO (OVERBEEK et al., 2000; Integrated Genomics, Inc.) eingespeist. Dieses Programm gleicht die Sequenzen aller ORFs mittels des FASTAAlgorithmus mit der internen ERGO-Datenbank ${ }^{*}$ ab und weist ihnen gegebenenfalls eine Funktion zu. Dieser Prozess und die anschließende manuelle Überprüfung der automatischen Annotation sind in Kapitel 2.13.2 geschildert. Im folgenden werden die Ergebnisse der Annotation des C. tetani-Chromosoms ausführlich präsentiert.

Die aus 2373 ORFs bestehende kodierende Sequenz stellt 86\% des Chromosoms dar. Diese sind - aufgeteilt nach ihrer DNA-Strang-Lokalisation - in Abbildung 19 dargestellt. Etwa 13\% aller ORFs zeigten Homologien zu Proteinen aus anderen Organismen, denen keine Funktionen zugeordnet sind. Diese werden im folgenden

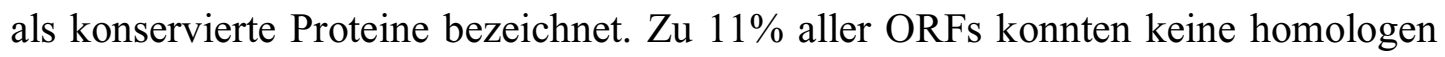
Proteine gefunden werden. Diese werden nachfolgend hypothetische Proteine genannt. $76 \%$ aller ORFs konnte eine Funktion zugewiesen werden. $\mathrm{Zu}$ dieser Gruppe gehörten solche ORFs, deren Proteinsequenzen signifikante Ähnlichkeiten zu Proteinen bekannter Funktion zeigten (s. 2.13.2). Zusätzlich wurden auch solche ORFs zu dieser Kategorie gerechnet, die eine Proteindomäne mit bekannter Funktion aufwiesen, dabei aber nicht notwendigerweise signifikante Homologien über die ganze Proteinsequenz zeigten. Streng genommen könnte man solche ORFs auch als konserviert bezeichnen, allerdings hat das ERGO-Programm solchen ORFs i. d. R. die Funktion der Domäne zugewiesen.

Eine Tabelle der Annotation aller 2373 ORFs soll in dieser Arbeit wegen ihres Umfangs nicht erscheinen. Es soll aber an dieser Stelle auf die Veröffentlichung der

\footnotetext{
* Die nicht-redundante interne ERGO-Datenbank umfasst Sequenzen - i. d. R. vollständige Genome aus 394 Organismen: 25 Archaeen, 81 Eukaryoten, 88 Viren und 200 Prokaryoten (Stand: Oktober 2002).
} 
Sequenz in der GenBank-Datenbank (http://www.ncbi.nlm.nih.gov/) hingewiesen werden, wobei sie unter den Zugangsnummern AE015927 (Chromosom) und AF528097 (pE88) abrufbar ist (BRÜGGEMANN et al., 2003).



Abb. 19: Zirkuläre ORF-Karte des Chromosoms von $C$. tetani.

Alle gefundenen ORFs sind in blau bzw. grün eingezeichnet - abhängig davon, auf welchem DNA-Strang sie kodiert sind. Der äußere Ring ist eine Größenskala. Der Nullpunkt entspricht dabei dem potentiellen Replikationsursprung (s. 3.4.4). In orange sind die C. tetani-ORFs gekennzeichnet, die Homologons im Genom von $C$. perfringens aber nicht in dem von $C$. acetobutylicum haben (s. 4.1.3.2). In pink sind solche ORFs von C. tetani angegeben, die nicht in den beiden anderen Clostridien-Genomen vorkommen (s. 4.1.3.3). Der innere Kreis gibt die lokalen Abweichungen vom durchschnittlichen $\mathrm{G}+\mathrm{C}-$ Gehalt $(28,6 \%)$ an. 


\subsubsection{Identifizierung des Replikationsursprungs}

Unter Ausnutzung bioinformatischer Methoden lassen sich Hinweise auf die Lokalisation des Replikationsursprungs eines Chromosoms sammeln. Im folgenden werden drei Hinweise genannt.

1. Die kumulative GC-Skew-Analyse wurde bereits in Kapitel 3.2.4 vorgestellt (GRIGORIEV, 1998). Im Fall des Chromosoms wurde die Sequenz als linear vorliegender Contig in ein entsprechendes GC-Skew-Analyseprogramm eingespeist. Abbildung 20 zeigt, dass es in der Genomsequenz bezüglich der GC-Verteilung nach der Formel $(\mathrm{C}-\mathrm{G} / \mathrm{C}+\mathrm{G})$ einen Vorzeichenwechsel in der Kurvensteigung gibt. Der Wechsel ist mit der unterschiedlichen GC-Verteilung im leading- und im laggingStrang der Replikation zu erklären (s. 3.2.4; LOBRY, 1996).

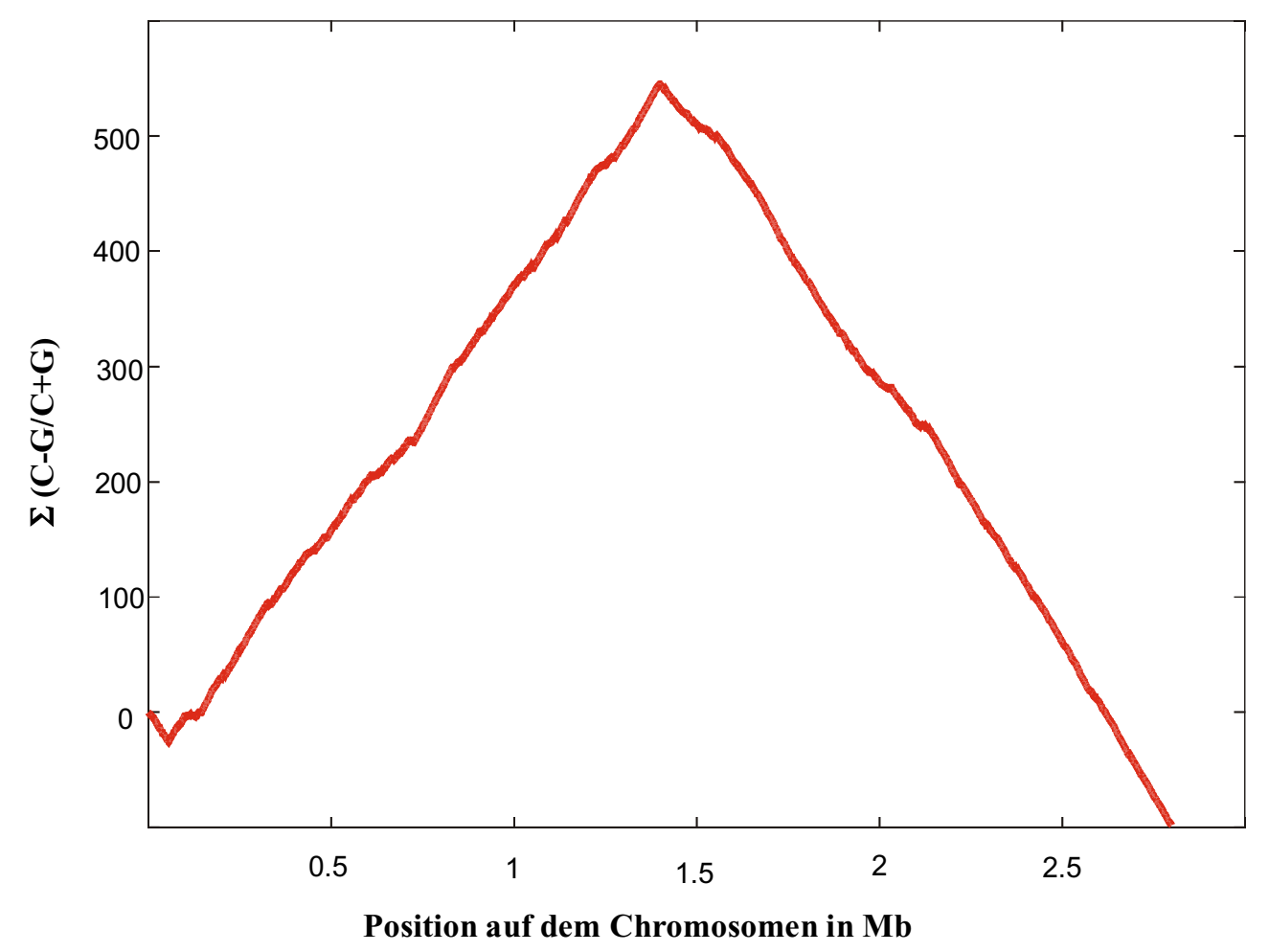

Abb. 20: Kumulativer GC-Skew des Chromosoms von $C$. tetani

Berechnet wurde die Summe von $(\mathrm{C}-\mathrm{G} / \mathrm{C}+\mathrm{G})$ in gleitenden Fenstern von 1000 bp mit einer definierten Schrittzahl. Eingabesequenz war der das gesamte Chromosom umfassende Contig, welcher an der Stelle der letzten Lücke (das zweifache rRNA-Operon) linearisiert vorlag. 
Im Bereich des Maximums des Graphen bei etwa 1,4 $\mathrm{Mb}$ befindet sich aller Wahrscheinlichkeit nach der Replikationsterminus; etwa eine halbe Genomlänge davon entfernt kann der Replikationsursprung vermutet werden (Kurvenminimum), was durch die Analyse der genetischen Umgebung bestätigt werden konnte (s. u.). Dabei war es Zufall, dass sich der Replikationsursprung des Chromosoms offenbar ziemlich genau im Bereich eines der Contigenden befand.

2. Das Ergebnis der GC-Skew-Analyse wurde mit der Verteilung der kodierenden Sequenz auf den beiden DNA-Strängen verglichen, wie sie in Abbildung 19 zu sehen ist: dabei fallen zwei starke Inflexionspunkte bezüglich des kodierenden Stranges auf, die etwa eine halbe Genomlänge voneinander entfernt sind. Die Lokalisation dieser Punkte stimmt mit den oben erwähnten Genomregionen überein, an denen im kumulativen GC-Skew ein Minimum bzw. Maximum auftritt. Diese Inflexionspunkte sind also offensichtlich der Replikationsursprung und der Replikationsterminus. Mit anderen Worten bedeuten dies, dass Transkription und Replikation codirektional verlaufen: 81,1\% der 2373 ORFs werden in der gleichen Richtung transkribiert, in der auch die Replikation verläuft $(83,4 \%$ der 1256 ORFs des -Stranges und 78,6\% der 1117 ORFs des +Stranges). Diese starke Tendenz der Codirektionalität von Transkription und Translation lässt sich auch in den Genomen von C. perfringens (83\%) und C. acetobutylicum (79\%) sowie einigen wenigen anderen Gram-positiven Organismen wie Lactococcus lactis (81\%), Streptococcus pyogenes (79,5\%), Bacillus subtilis (74,1\%) und Staphylococcus aureus $(74,6 \%)$ erkennen (SHIMIZU et al., 2002). Im Gegensatz dazu ist diese Tendenz nur sehr schwach in Genomen vieler Gram-negativer Organismen wie E. coli $(55,1 \%)$, Vibrio cholerae (52\%), Neisseria meningitidis $(53,7 \%)$ oder Yersinia pestis sowie bei archeaellen Organismen wie Methanosarcina mazei ausgeprägt (MCLEAN et al., 1998; DEPPENMEIER et al., 2002). Der bisher einzige bekannte und sequenzierte Gram-negative Organismus, der ebenfalls diese Codirektionalität zeigt, ist Thermoanaerobacter tengcongensis (86,7\%; BAO et al., 2002).

3. Als nächstes wurde das Genom nach Proteinen mit Replikationsfunktionen durchsucht. Dabei zeigt sich eine Abundanz solcher ORFs im Bereich des mit den eben vorgestellten Strategien gefundenen potentiellen Replikationsursprungs. Abbildung 21 zeigt das genetische Repertoire dieses Bereichs, der einen Inflexionspunkt bezüglich des kodierenden Stranges beinhaltet. 


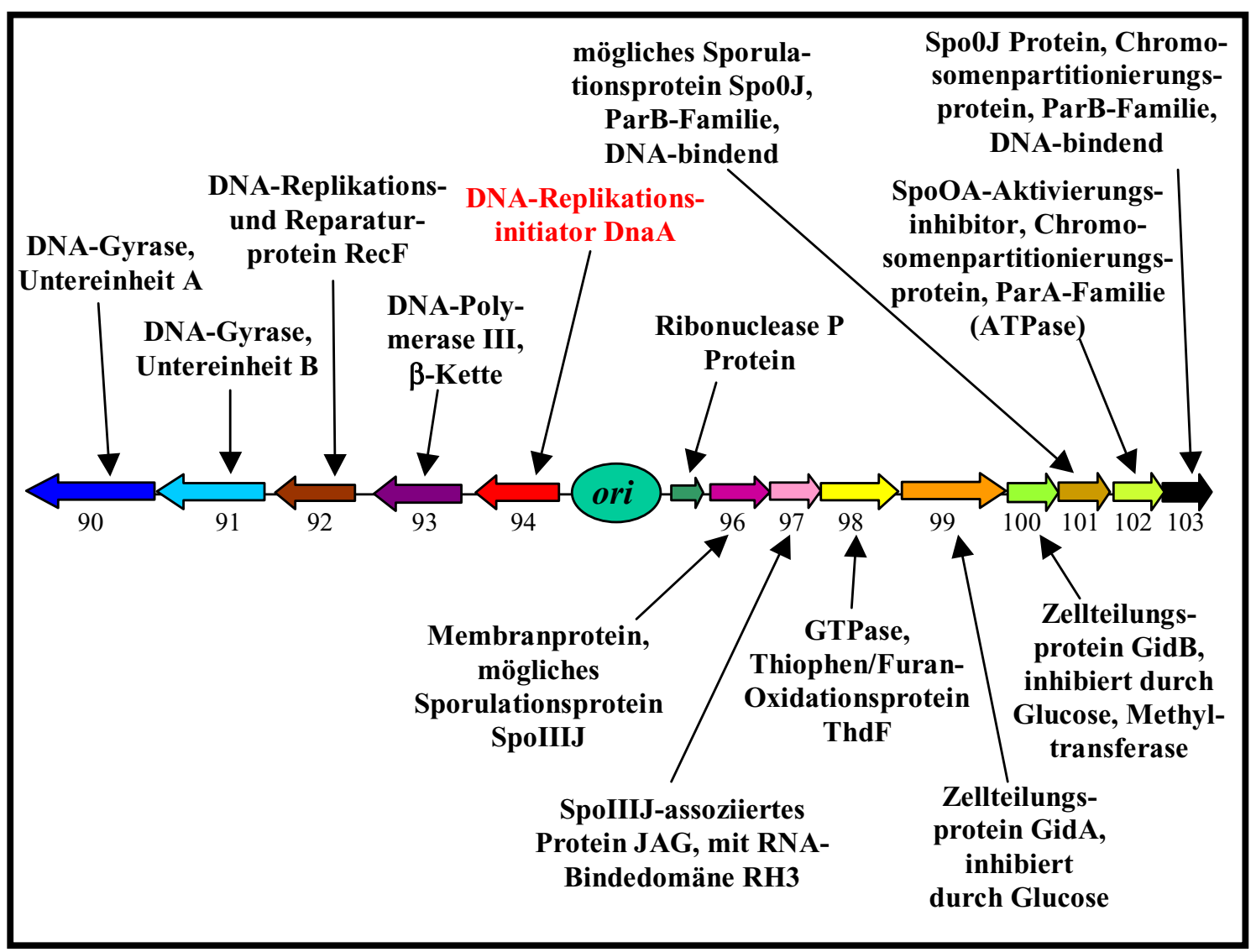

Abb. 21: Genetische Umgebung des potentiellen Replikationsursprungs des

\section{C. tetani-Chromosoms}

Gezeigt ist der Bereich $8 \mathrm{~kb}$ stromabwärts - beginnend mit CTC0090 (gyrA) - bis $9 \mathrm{~kb}$ stromaufwärts - endend mit CTC0103 - vom potentiellen ori. Nicht aufgeführt sind die etwas weiter stromaufwärts vom ori liegenden Replikationsgene dnaC (CTC0123) und dnaD (CTC0124). CTC101 und CTC103 zeigen eine hohe Homologie zueinander.

Dieser DNA-Abschnitt wurde mit der potentiellen ori-Region anderer Genome wie C. perfringens und C. acetobutylicum verglichen (Abb. 22). Es wird deutlich, dass diese Genregion in vielen Organismen hoch konserviert ist. Es soll an dieser Stelle erwähnt werden, dass die Lokalisation des ori bisher in nur wenigen der in Abbildung 22 aufgeführten Organismen, u. a. in B. subtilis, experimentell bestätigt werden konnte. Auffällig ist das Vorkommen einiger sporulationsassoziierter Gene in diesem Bereich. Es gibt experimentelle Hinweise dafür, dass die Initiation der Sporen-Bildung in B. subtilis von der Initiation der DNA-Replikation abhängig ist: es konnte nachgewiesen werden, dass Mutationen in DnaA und DnaD die Sporulationsfähigkeit inhibieren (LEMON et al., 2000). 


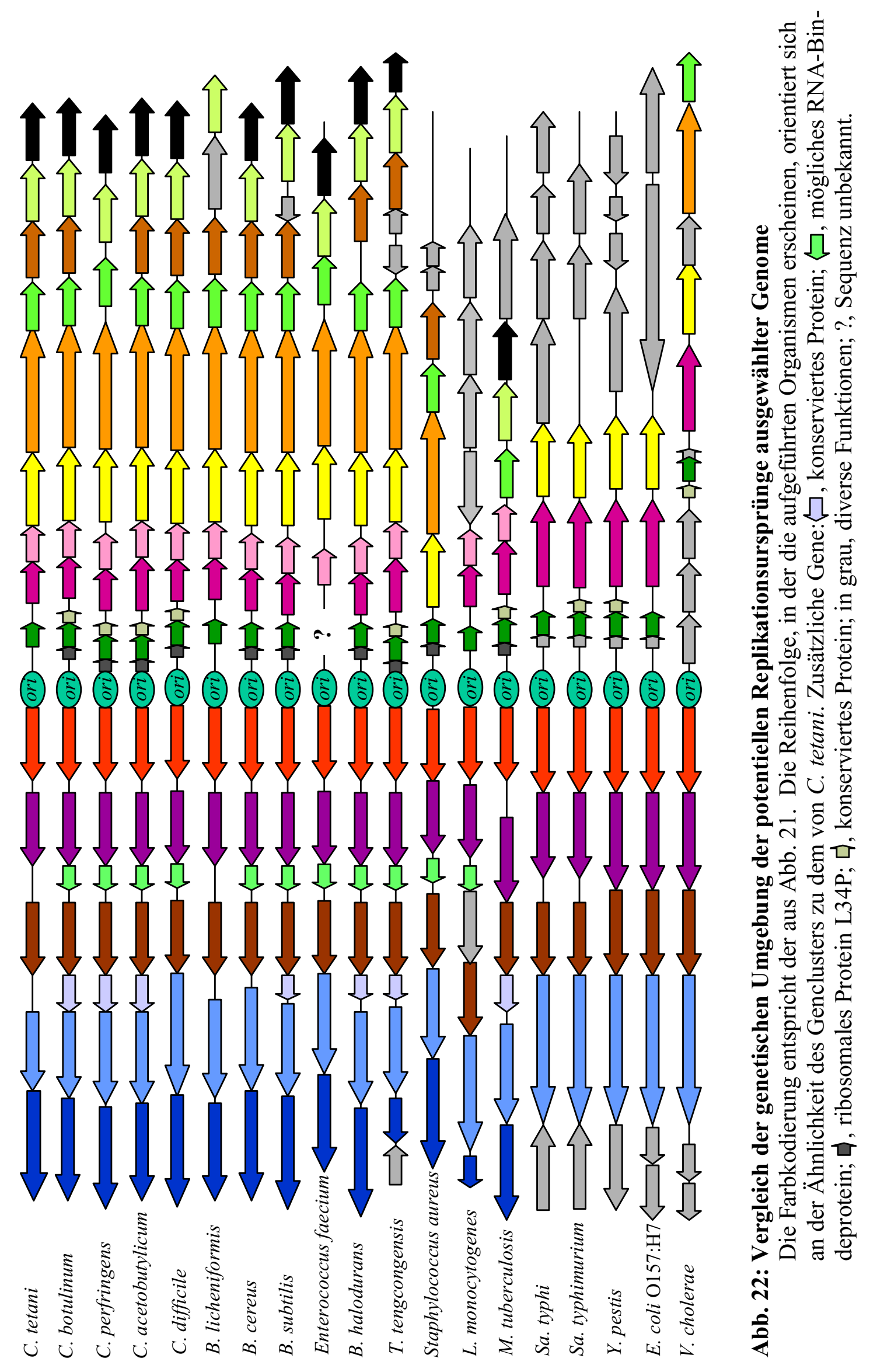




\subsubsection{Toxine und weitere Virulenzfaktoren}

3.4.5.1 Bekannte Virulenzfaktoren

Es wurde vermutet, dass C. tetani neben den Virulenzfaktoren, welche auf pE88 kodiert sind, weitere, chromosomal-kodierte Virulenz-relevante Proteine besitzt. So wurde das Chromosom systematisch nach solchen Genen durchsucht. Das Ergebnis dieser Suche ist in Tabelle 9 zusammengefasst. Viele der gefundenen Proteine, wie z. B. Hämolysine, Tetanolysin O und Fibronectin-Bindeproteine, zeigen die stärksten Ähnlichkeiten zu Proteinen aus C. perfringens.

Tabelle 9: Chromosomal-kodierte Virulenzfaktoren von $C$. tetani

\begin{tabular}{|c|c|c|c|}
\hline $\begin{array}{l}\text { ORF-Name und } \\
\text {-Größe (in As) }\end{array}$ & Produkt & $\begin{array}{c}\text { homologe } \\
\text { Sequenz in }\end{array}$ & Kommentar \\
\hline $\begin{array}{l}\text { CTC164 (224) } \\
\text { CTC471 (642) } \\
\text { CTC1606 (577) } \\
\end{array}$ & $\begin{array}{l}\text { Fibronectin- } \\
\text { Bindeprotein }\end{array}$ & $\begin{array}{c}C p, C b, C d \\
B a, L m, L i\end{array}$ & $\begin{array}{c}\text { ermöglicht die Anheftung an } \\
\text { Wund-Gewebe; COG1293; } \\
\text { GILOT et al., } 2000\end{array}$ \\
\hline CTC440 (391) & $\begin{array}{l}\alpha \text {-Clostripain- } \\
\text { Homologon }\end{array}$ & $C p, C h$ & $\begin{array}{c}\text { Cystein-Proteinase } \\
\text { (Clostripain-Familie); } \\
\text { DARGATZ et al., } 1993\end{array}$ \\
\hline CTC586 (211) & Hämolysin III & $\begin{array}{c}C p, C b, C a, \\
\text { B. cereus }\end{array}$ & $\begin{array}{c}\text { COG1272 } \\
\text { (Membranproteine); } \\
\text { BAIDA \& KUZMIN, } 1995\end{array}$ \\
\hline $\begin{array}{l}\text { CTC594 (291), } \\
\text { CTC1503 (317) }\end{array}$ & $\begin{array}{l}\text { mögliche PAF- } \\
\text { Acetyl- } \\
\text { hydrolase }\end{array}$ & $S m, S p, S p n$ & $\begin{array}{c}\text { Phospholipase, inaktiviert den } \\
\text { Thrombocyten-aktivierenden } \\
\text { Faktor (PAF); } \\
\text { KARASAWA et al., } 1994\end{array}$ \\
\hline CTC1574 (272) & Hämolysin & $\begin{array}{c}C p, C b, C a, \\
C d\end{array}$ & $\begin{array}{l}\text { COG1189 (rRNA- } \\
\text { Methylasen) }\end{array}$ \\
\hline CTC1814 (216) & $\begin{array}{l}\text { periplasm. } \\
\text { immunogenes } \\
\text { Protein } \\
\end{array}$ & $\begin{array}{c}\text { Ba, } \\
\text { Brucella } \\
\text { melitensis }\end{array}$ & $\begin{array}{l}\text { Omp (outer membrane } \\
\text { protein); } \\
\text { LINDLER et al., } 1996\end{array}$ \\
\hline CTC1855 (533) & $\begin{array}{l}\text { Myosin- } \\
\text { crossreaktives } \\
\text { Antigen }\end{array}$ & $\begin{array}{l}C p, L m, L i \\
\quad S m, C b\end{array}$ & $\begin{array}{c}\text { homolog zu MHC (major } \\
\text { histocompatibility complex)- } \\
\text { Klasse II-Antigenen; } \\
\text { AJDIC et al., } 2002\end{array}$ \\
\hline CTC1888 (527) & Tetanolysin $\mathrm{O}$ & $\begin{array}{c}C p, S p, L m, \\
\text { u. a. }\end{array}$ & Thiol-aktiviertes Cytolysin \\
\hline $\begin{array}{l}\text { CTC2255 (518) } \\
\text { CTC2261 (514) }\end{array}$ & $\begin{array}{l}\text { Virulenzfaktor } \\
\text { MviN }\end{array}$ & $\mathrm{Cb}, \mathrm{Ca}, \mathrm{Cd}$ & Membranprotein \\
\hline
\end{tabular}

Abkürzungen: $C a, C$. acetobutylicum; $C b, C$. botulinum; $C d, C$. difficile; $C h, C$. histolyticum; Cp, C. perfringens; Ba, B. anthracis; Lm, Listeria monocytogenes; Li, Listeria innocua; Sm, Streptococcus mutans; Sp, Streptococcus pyogenes; Spn, Streptococcus pneumoniae. COG, Cluster of orthologous Groups of proteins (http://www.ncbi.nlm.nih.gov/COG/). 
Von den aufgeführten Faktoren aus $C$. tetani ist bisher lediglich das Tetanolysin O untersucht worden (TWETEN, 1997); der derzeitige Wissensstand wird ausführlich in Kapitel 4.2.1.3 wiedergegeben. Die in Tabelle 9 angegebenen Funktionen der übrigen Virulenzfaktoren leiten sich aus den z. T. vorliegenden Charakterisierungen der homologen Proteine ab; für einige der aufgeführten Proteine, wie z. B. Myosincrossreaktives Antigen und Virulenzfaktor MviN, wird eine Beteiligung an der Pathogenitätsausbildung lediglich vermutet.

Die Gene der in Tabelle 9 aufgeführten Virulenzfaktoren liegen auf dem Chromosom nicht benachbart vor, bilden also keine Pathogenitätsinseln. Der $\mathrm{G}+\mathrm{C}-\mathrm{Gehalt}$ dieser Gene weicht nicht signifikant vom durchschnittlichen $\mathrm{G}+\mathrm{C}-$ Gehalt des Chromosoms ab. Auch konnten keine mobilen genetischen Elemente in den sie flankierenden DNA-Regionen ausgemacht werden, was bezüglich der evolutiven Pathogenitätsausbildung darauf hinweist, dass diese Gene nicht über lateralen Gentransfer akquiriert wurden, oder zumindest fand diese Akquirierung nicht erst kürzlich statt.

\subsubsection{Zelloberflächenproteine}

Weitere Gene konnten im Genom von C. tetani identifiziert werden, deren Proteine möglicherweise bei der Ausbildung der Pathogenität des Organismus' eine Rolle spielen: so wurden 32 Gene ausgemacht, die Zelloberflächen-Proteine kodieren und zwar solche, die möglicherweise in der sogenannten S-Layer (Surface-Layer) angeordnet sind. Der Begriff S-Layer beschreibt eine prokaryotische Zelloberflächen-assoziierte Struktur aus Proteinen, die i. d. R. in parakristalliner einschichtiger Anordnung vorkommt und die Oberfläche der Bakterienzelle umhüllt. Sie ist leicht unter dem Elektronenmikroskop sichtbar (CALABI et al., 2001).

Tabelle 10 stellt die im Genom identifizierten Gene dieser Zelloberflächen- bzw. SLayer- oder S-Layer-assoziierten Proteine zusammen. Sie sind nach ihren stärksten Homologien in drei Gruppen eingeteilt, wobei aber eine schwache Homologie zwischen den meisten der aufgeführten Proteine festzustellen ist. Die erste Gruppe beinhaltet 19 Proteine, die homolog zum Cwp66-Protein aus C. difficile sind. Dieses ist ein charakterisiertes Zelladhäsionsprotein und wird für die Adhäsion von $C$. difficile-Zellen an Zellen des Intestinaltraktes verantwortlich gemacht (s. 4.2.1.4; WALIGORA et al., 2001). 
Die zweite Gruppe von Proteinen zeigt Ähnlichkeiten zu Internalin A aus Listeria monocytogenes und andern Internalinen aus Listerien. Internaline sind verantwortlich für die Herstellung eines Zellkontaktes zwischen der Listeria-Zelle und bestimmten Epithelzellen des Säugetierwirts (CABANES et al., 2002).

Die dritte Gruppe beinhaltet 10 Proteine, die zwar konservierte ZelloberflächenDomänen aufweisen, ansonsten aber keine signifikanten Ähnlichkeiten zu Proteinen aus Datenbanken zeigen. Auffällig ist die z. T. hohe Ähnlichkeit der Proteine untereinander sowie ein herausragendes Molekulargewicht von bis $\mathrm{zu} 220 \mathrm{kDa}$ einiger dieser Proteine.

Auf interessante Details der Proteine dieser drei Gruppen wird in Kapitel 4.2.1.4 eingegangen.

Tabelle 10: Mögliche S-Layer und Zelloberflächen-assoziierte Proteine von C. tetani und anderen Clostridien

\begin{tabular}{|c|c|c|c|}
\hline & $\begin{array}{c}\text { homolog zum } \\
\text { Cwp66/SlpA } \\
\text { von C. difficile }\end{array}$ & $\begin{array}{c}\text { homolog zum } \\
\text { Internalin A aus } \\
\text { L. monocytogenes }\end{array}$ & $\begin{array}{c}\text { weitere } \\
\text { Zelloberflächen- } \\
\text { proteine }\end{array}$ \\
\hline C. tetani & $\begin{array}{c}\text { CTC462 (1080), CTC491 (508), } \\
\text { CTC504 (592), CTC515 (584), } \\
\text { CTC518 (585), CTC520 (871), } \\
\text { CTC521 (487), CTC523 (354), } \\
\text { CTC691 (505), CTC696 (518), } \\
\text { CTC748 (462), CTC774 (667), } \\
\text { CTC775 (353), CTC1202 (492), } \\
\text { CTC1364 (648), CTC1872 (471), } \\
\text { CTC1980 (722), CTC2092 (508), } \\
\text { CTC2093 (708) }\end{array}$ & $\begin{array}{l}\text { CTC494 (706), } \\
\text { CTC495 (695) }\end{array}$ & $\begin{array}{l}\text { CTC465 (1334), } \\
\text { CTC747 (1416), } \\
\text { CTC749 (1900), } \\
\text { CTC750 (1511), } \\
\text { CTC767 (528), } \\
\text { CTC769 (568), } \\
\text { CTC770 (603), } \\
\text { CTC771 (374), } \\
\text { CTC772 (360), } \\
\text { CTC776 (355), } \\
\text { CTC777 (1880) }\end{array}$ \\
\hline C. difficile & 29 (u. a. Cwp66 und SlpA) & 0 & n. b. \\
\hline C. botulinum & 8 & 4 & n. b. \\
\hline $\begin{array}{l}\text { C.per- } \\
\text { fringens }\end{array}$ & 0 & 0 & n. b. \\
\hline $\begin{array}{l}\text { C. aceto- } \\
\text { butylicum }\end{array}$ & 0 & 1 & n. b. \\
\hline
\end{tabular}

n. b., nicht bekannt

Alle in Tabelle 10 aufgeführten Proteine besitzen eine typische Signalpeptidsequenz, was den Export dieser Proteine durch die Cytoplasmamembran ermöglicht. Interessanterweise zeigt das Genom von $C$. perfringens keinerlei Homologien zu SLayer- oder S-Layer-assoziierten Proteinen, was einen anderen Mechanismus 
bezüglich der Zelladhäsion an das Gewebe des Wirts vermuten lässt - wenn ein solcher denn überhaupt vorhanden sein sollte.

Auffallend viele Gene der besprochenen Oberflächenproteine kommen im Genom von C. tetani geclustert vor. Es können zwei Bereiche ausgemacht werden, die besonders viele solcher Gene beinhalten: 1. Die Region CTC491 bis CTC523 beinhaltet mindestens $10 \mathrm{ORFs}$ für Oberflächenproteine, zusammen mit drei weiteren hypothetischen ORFs, die eine Signalpeptid-Sequenz aufweisen, sieben ORFs für den Katabolismus von Myo-Inositol und einem ORF für eine ZinkCarboxypeptidase (CTC519). 2. Die Region CTC747 bis CTC778 beinhaltet 13 Oberflächenproteine, vor allem solche aus der dritten Gruppe, zusammen mit vier weiteren Signalpeptid-tragenden ORFs und einer Reihe von hydrophoben Proteinen unbekannter Funktion.

\subsubsection{Metabolismus 1: Substratverwertung}

Die Rekonstruktion metabolischer Wege basierend auf der Genomannotation ist eine sehr umfangreiche Aufgabe. Es soll an dieser Stelle nicht der Versuch unternommen werden, alle stoffwechselrelevanten Gene von C. tetani wiederzugeben und daraus ein vollständiges Bild seiner metabolischen Fähigkeiten zu entwerfen. Zum einen bedeutet die Abwesenheit bestimmter Gene für eine metabolische Leistung nicht zwangsläufig, dass diese Leistung nicht vollzogen werden kann; viele Proteine haben neben einer Hauptaktivität häufig auch eine oder mehrerer Nebenaktivitäten, die durch die Genomannotation nicht erkannt werden können. Andererseits sollte berücksichtigt werden, dass die genetische Präsenz nicht zwangsläufig bedeutet, dass die entsprechende Stoffwechselleistung auch tatsächlich ausgeübt wird. Damit zusammenhängend ist es in einigen Fällen aufgrund von $\mathrm{zu}$ schwachen oder mehrdeutigen Homologien auch nicht eindeutig ersichtlich, ob für einen bestimmten Stoffwechselweg tatsächlich alle notwendigen Gene vorliegen.

Es soll deshalb im folgenden versucht werden, einen Überblick über die metabolischen Fähigkeiten von C. tetani zu gewinnen und insbesondere auf bisher unbekannte Besonderheiten hinzuweisen. 
C. tetani gehört zur Gattung Clostridium, welche Organismen umfasst, die nur anaerob wachsen können und einen ausgeprägten Gärungsstoffwechsel aufweisen. Je nach der Art der Substrate, welche bevorzugt fermentiert werden, unterscheidet man saccharolytische und peptolytische Clostridien, wobei C. tetani zur zweiten Gruppe zugehörig eingeordnet wurde (BERGEY et al., 1923). Als Fermentationsprodukte werden Gase wie $\mathrm{NH}_{3}, \mathrm{CO}_{2}$ und $\mathrm{H}_{2}$, Säuren wie Butyrat, Acetat, Formiat und Lactat und Alkohole wie Butanol und Ethanol gebildet.

\subsubsection{Vergärung von Zuckern: Glykolyse und Pentosephosphat-Weg}

Die Genomsequenz lässt nun ein genaueres Bild der stoffwechselphysiologischen Leistungen von C. tetani erkennen. Auffällig ist, dass vermutlich lediglich Glucose, Galactose und Ribose als Zucker-Substrate abgebaut werden können. Das unterscheidet $C$. tetani deutlich von $C$. perfringens und $C$. acetobutylicum, die zusätzlich Polysacharide wie Fructose, Maltose, Stärke und Glycogen verwerten können. C. tetani besitzt sämtliche Gene für die Glykolyse (CTC378-382, CTC2404, CTC2489, CTC2490). Neben den Genen für die Glykolyse lassen sich die Gene des Pentose-Phosphat-Weges finden. Bemerkenswert dabei ist, dass die Enzyme Glucose-6-Phosphat-1-Dehydrogenase (CTC1864) und 6-PhosphogluconatDehydrogenase (CTC1865) nicht in den Genomen anderer Clostridien kodiert sind.

\subsubsection{Vergärung von Aminosäuren}

In der Hauptsache scheint $C$. tetani Aminosäuren zu vergären: viele Aminosäureabbauende Proteine liegen in der Genomsequenz kodiert vor, die nachfolgend vorgestellt werden. Um diese Aminosäuren für die Fermentation bereit zu stellen, gibt es eine ganze Bandbreite von extrazellulären und intrazellulären Proteasen, und viele membranständige Peptid- und Aminosäuretransporter, mehrere davon sind Natrium-abhängige Symporter (s. 4.1.4).

In Tabelle 11 sind solche Aminosäure-abbauenden Proteine genannt, die den ersten Schritt des jeweiligen katabolischen Weges katalysieren. Aus der Genomsequenz lässt sich ableiten, dass C. tetani wahrscheinlich folgende Aminosäuren fermentieren kann: Alanin, Arginin, Asparagin, Aspartat, Glutamin, Glutamat, Histidin, Isoleucin, Leucin, Serin, Threonin, Tryptophan und Tyrosin. Überraschenderweise fehlt in $C$. 
tetani - anders als in $C$. difficile und $C$. botulinum - die für die Stickland-Reaktion typische Glycin-Reduktase, welche in Clostridien wie $C$. sticklandii oder $C$. sporogenes identifiziert und untersucht wurde (TURNER \& STADTMAN, 1973). So bleibt unklar, ob $C$. tetani eine paarweise Vergärung von Aminosäuren durchzuführen vermag. Bei Betrachtung der Aminosäure-abbauenden Enzyme aus Tabelle 11 fällt auf, dass viele dieser Enzyme nicht in $C$. perfringens und $C$. acetobutylicum sowie anderen Clostridien vorkommen. C. tetani scheint also gegenüber diesen Clostridien erweiterte Fähigkeiten bezüglich der Vergärung von Aminosäuren zu besitzen. So z. B. lassen sich die Gene (mutE, mutL, mutS; CTC2565-2568) des Coenzym B12-abhängigen Enzyms Glutamat-Mutase nicht in den Genomen von $C$. perfringens, $C$. botulinum, $C$. difficile und C. acetobutylicum finden. Sie existieren aber z. B. in den Genomen von C. cochlearium und C. tetanomorphum - mit einer 92-94\%igen Identität der katalytischen Untereinheit MutE zum Protein aus C. tetani (LEUTBECHER et al., 1992).

Erwähnt werden sollte an dieser Stelle auch, dass $C$. tetani weit weniger anabolische Wege der Aminosäure-Biosynthese als C. acetobutylicum zur Verfügung stehen.

Tabelle 11: In C. tetani identifizierte Enzyme zur Einleitung des Aminosäureabbaus

\begin{tabular}{|c|c|c|c|}
\hline $\begin{array}{l}\text { Amino- } \\
\text { säure }\end{array}$ & Enzym (ORF-Name) & Reaktion & Kommentar * \\
\hline Alanin & $\begin{array}{c}\text { Alanin-Aminotransferase } \\
\text { (CTC1359, CTC1738) } \\
\text { Alanin-Dehydrogenase } \\
\text { (CTC892) }\end{array}$ & $\begin{array}{c}\text { D-Alanin + 2-Oxoglutarat } \\
=\text { Pyruvat }+ \text { D-Glutamat } \\
\\
\text { L-Alanin }+\mathrm{H}_{2} \mathrm{O}+\mathrm{NAD}^{+}= \\
\text {Pyruvat }+\mathrm{NH}_{3}+ \\
\mathrm{NADH}+\mathrm{H}^{+}\end{array}$ & $\begin{array}{c}\text { katalysiert auch die } \\
\text { Umsetzung der D-Isomere } \\
\text { von Asparagin, Aspartat, } \\
\text { Glutamat, Leucin, } \\
\text { Aminobutyrat und Norvalin }\end{array}$ \\
\hline Arginin & $\begin{array}{c}\text { Arginase } \\
\text { (CTC1763) } \\
\text { Arginin-Decarboxylase } \\
\text { (CTC219, CTC2271) }\end{array}$ & $\begin{array}{c}\text { L-Arginin }+\mathrm{H}_{2} \mathrm{O}=\mathrm{L}- \\
\text { Ornithin }+ \text { Harnstoff } \\
\text { L-Arginin }=\text { Agmatin }+ \\
\mathrm{CO}_{2}\end{array}$ & $\begin{array}{l}\text { Wichtiges Enzym des } \\
\text { Harnstoffzyklus; nicht in } C b \text {, } \\
C d \text { und } C p \text {, aber in } C a\end{array}$ \\
\hline $\begin{array}{l}\text { Aspara- } \\
\text { gin }\end{array}$ & $\begin{array}{l}\text { Asparaginase } \\
\text { (CTC1877) }\end{array}$ & $\begin{array}{c}\mathrm{L} \text {-Asparagin }+\mathrm{H}_{2} \mathrm{O}=\mathrm{L}- \\
\text { Aspartat }+\mathrm{NH}_{3}\end{array}$ & $\begin{array}{c}\text { nicht in } C a, C b \text { und } C d \text {, } \\
\text { aber in } C p\end{array}$ \\
\hline Aspartat & $\begin{array}{l}\text { Aspartase (CTC824) } \\
\text { Aspartat-Aminotransferase } \\
\text { (CTC825/CTC1294/ } \\
\text { CTC1309) }\end{array}$ & $\begin{array}{c}\text { L-Aspartat = Fumarat }+ \\
\mathrm{NH}_{3} \\
\begin{array}{l}\text { L-Aspartat }+ \text { 2-Oxoglutarat } \\
=\text { Oxaloacetat }+ \text { L- } \\
\text { Glutamat }\end{array}\end{array}$ & nicht in $C p$, aber in $C a$ \\
\hline Cystein & $\begin{array}{l}\text { Cystathionin- } \beta \text {-Lyase } \\
\text { (CTC2530) }\end{array}$ & $\begin{array}{c}\text { Cystathionin }+\mathrm{H}_{2} \mathrm{O}=\mathrm{L}- \\
\text { Homocystein }+\mathrm{NH}_{3}+ \\
\text { Pyruvat }\end{array}$ & \\
\hline
\end{tabular}




\begin{tabular}{|c|c|c|c|}
\hline Glutamin & $\begin{array}{l}\text { Glutaminase } \\
\text { (CTC566) }\end{array}$ & $\begin{array}{l}\text { L-Glutamin }+\mathrm{H}_{2} \mathrm{O}=\mathrm{L}- \\
\text { Glutamat }+\mathrm{NH}_{3}\end{array}$ & in $C p$, aber nicht in $C a$ \\
\hline Glutamat & $\begin{array}{c}\text { Glutamat-Mutase } \\
\text { (CTC2565-2568) } \\
\text { Glutamat-Dehydrogenase } \\
\text { (CTC1295) }\end{array}$ & $\begin{array}{c}\text { L-Glutamat }=\text { Threo-3- } \\
\text { Methylaspartat } \\
\text { L-Glutamat }+\mathrm{H}_{2} \mathrm{O}+\mathrm{NAD}^{+} \\
=2-\mathrm{Oxoglutarat}+\mathrm{NH}_{3}+ \\
\mathrm{NADH}\end{array}$ & $\begin{array}{c}\text { B12-abhängig; nicht in } C a \text {, } \\
C b, C d \text { und } C p\end{array}$ \\
\hline Histidin & $\begin{array}{l}\text { Histidin-Decarboxylase } \\
\text { (CTC1478) } \\
\text { Histidin-Ammonium-Lyase } \\
\text { (Histidase) (CTC2318) }\end{array}$ & $\begin{array}{l}\text { L-Histidin }=\text { Histamin }+ \\
\qquad \mathrm{CO}_{2} \\
\text { L-Histidin }=\text { Urocanat }+ \\
\mathrm{NH}_{3}\end{array}$ & $\begin{array}{c}\text { nicht in } C a, C b, C d \text { und } C p \\
\text { nicht in } C a \text { und } C p\end{array}$ \\
\hline Ile, Leu & diverse Aminotransferasen & & \\
\hline Lysin & $\begin{array}{l}\text { L-Lysin-2,3-Aminomutase } \\
\text { (CTC890) } \\
\text { Lysin-Decarboxylase } \\
\text { (CTC219, CTC2271) }\end{array}$ & $\begin{array}{c}\text { L-Lysin }=3,6- \\
\text { Diaminohexanoat }(\beta- \\
\text { Lysin }) \\
\text { L-Lysin }=\text { Cadaverin }+ \\
\mathrm{CO}_{2}\end{array}$ & $\begin{array}{c}\text { nicht in } C a \text { und } C p \\
\text { die weiteren Enzyme dieses } \\
\text { Abbauweges scheinen zu } \\
\text { fehlen }\end{array}$ \\
\hline Serin & $\begin{array}{c}\text { Serin-Pyruvat- } \\
\text { Aminotransferase } \\
(\text { CTC695) } \\
\text { Serin/Threonin-Dehydratase } \\
\text { (CTC1981-1982) }\end{array}$ & $\begin{array}{c}\text { L-Serin }+ \text { Pyruvat }=3- \\
\text { Hydroxypyruvat }+\mathrm{L}- \\
\text { Alanin } \\
\text { L-Serin }+\mathrm{H}_{2} \mathrm{O}=\text { Pyruvat }+ \\
\mathrm{NH}_{3}+\mathrm{H}_{2} \mathrm{O}\end{array}$ & $\begin{array}{l}\text { katalysiert wahrscheinlich } \\
\text { auch: L-Alanin + Glyoxylat } \\
\quad=\text { Pyruvat + Glycin } \\
\text { nicht in } \mathrm{Ca} \text {, aber in } \mathrm{Cp} ; \\
\text { deaminiert auch Threonin }\end{array}$ \\
\hline Threonin & $\begin{array}{c}\text { L-allo-Threonin-Aldolase } \\
\text { (CTC1037) } \\
\text { Serin/Threonin-Dehydratase } \\
\text { (CTC1981-1982, CTC71, } \\
\text { CTC2624) }\end{array}$ & $\begin{array}{c}\text { L-allo-Threonin }=\text { Glycin }+ \\
\text { Acetaldehyd } \\
\text { L-Threonin }=2- \\
\text { Oxobutanoat }+\mathrm{NH}_{3}\end{array}$ & nicht in $C a$ und $C p$ \\
\hline $\begin{array}{l}\text { Trypto- } \\
\text { phan }\end{array}$ & $\begin{array}{c}\text { Trytophanase (=L- } \\
\text { Tryptophan:Indol-Lyase) } \\
\text { (CTC1509) }\end{array}$ & $\begin{array}{l}\text { L-Tryptophan }+\mathrm{H}_{2} \mathrm{O}= \\
\text { Indol }+ \text { Pyruvat }+\mathrm{NH}_{3}\end{array}$ & nicht in $C a$ und $C p$ \\
\hline Tyrosin & $\begin{array}{c}\text { Tyrosin:Phenol-Lyase } \\
\text { (CTC818) }\end{array}$ & $\begin{array}{c}\text { L-Tyrosin }+\mathrm{H}_{2} \mathrm{O}=\text { Phenol } \\
+ \text { Pyruvat }+\mathrm{NH}_{3}\end{array}$ & nicht in $C a$ und $C p$ \\
\hline
\end{tabular}

* Aufgrund der Homologien einiger dieser Proteine sind multiple Spezifitäten möglich. Auch können einige Enzyme im entsprechenden Biosysnthese-Weg eine Rolle spielen. Abkürzungen: $C a$, C. acetobutylicum; $\mathrm{Cb}, \mathrm{C}$. botulinum; $C d, C$. difficile; $C p, C$. perfringens.

\subsubsection{Verwertung von Lipiden}

Zusätzlich können vermutlich weitere Substrate umgesetzt werden. Der Abbau von Lipiden und Phospolipiden wird durch (Phospho-)Lipasen eingeleitet; mehrere Gene für solche Enzyme sind im Genom von C. tetani vorhanden: CTC812, CTC947, CTC990, CTC1503 und CTC1505. Dabei entstehen zum einen Fettsäuren. Diese können über die $\beta$-Oxidation abgebaut werden, wobei letztendlich Acetyl-CoA entsteht. Enzyme der $\beta$-Oxidation wie Acyl-CoA-Dehydrogenase, Enoyl-CoAHydratase (synonym: Crotonase, 3-Hydroxyacyl-CoA-Hydrolyase), L-3- 
Hydroxyacyl-CoA-Dehydrogen-ase und $\beta$-Ketothiolase sind offensichtlich in $C$. tetani vorhanden (s. 3.4.7.2). Zum anderen entsteht ein Alkohol, i. d. R. Glycerol. Dieses kann über die Glycerol-Kinase (CTC1758, CTC2462) und die Glycerol-3Phosphat-Dehydrogenase (CTC1034, CTC1139, CTC1808, CTC2436) in Dihydroxyacetonphosphat umgesetzt werden, welches dann mit Enzymen der Glykolyse weiterverwertet wird. Das letztere Enzym, die Glycerol-3-PhosphatDehydrogenase, kann auch für die Verwertung des beim Abbau bestimmter Phospholipide anfallenden Glycerol-3-Phosphats eingesetzt werden. Neben Glycerin sind auch andere Alkohole wie Ethanolamin, Inositol oder Serin in Phospholipiden vorhanden. Auch diese kann $C$. tetani offensichtlich als Substrate nutzen. So findet man einen Cluster aus 17 Genen, deren Proteine den Cobalamin-abhängigen Abbau von Ethanolamin katalysieren (CTC2163-CTC2181). Dieses System gibt es z. B. auch in pathogenen Organismen der Gattung Salmonella (KOFOID et al., 1999). Des weiteren gibt es sieben Gene (CTC508-514), die für die Aufnahme und den Abbau des Alkohols (Myo-)Inositol kodieren, einem Bestandteil der Inositolphosphatide, die sowohl in eukaryotischen Zellmembranen vorkommen als auch als intrazelluläre Signalmoleküle (Inositoltriphosphat) eine Rolle spielen.

\subsubsection{Metabolismus 2: Verstoffwechselung von Pyruvat}

\subsubsection{Pyruvat:Ferredoxin-Oxidoreduktase}

Die Glykolyse wie der Abbau vieler Aminosäuren (s. Tabelle 11) führt zur Bildung von Pyruvat. Dieses kann mit der Pyruvat:Ferredoxin-Oxidoreduktase (CTC25252528) zum Acetyl-CoA umgesetzt werden. Die dabei entstehenden Reduktionsäquivalente können auf Ferredoxin übertragen und anschließend mittels einer Hydrogenase-katalysierten Reaktion (CTC184, CTC2417) als $\mathrm{H}_{2}$ freigesetzt werden. Daneben kann Pyruvat mittels der Pyruvat:Formiat-Lyase (CTC936) zu Formiat und Acetyl-CoA und mittels der Lactat-Dehydrogenase (CTC1998) zu Lactat umgesetzt werden. 
Acetyl-CoA kann nicht mittels des Tricarbonsäurezyklus (TCC) $\mathrm{zu} \mathrm{CO}_{2}$ oxidiert werden; sämtliche Gene des TCC fehlen in C. tetani. Stattdessen wird Acetyl-CoA auf mehreren Wegen metabolisiert. Es kann mittels der Phosphotransacetylase (CTC1239) und der Acetat-Kinase (CTC1240) zu Acetat umgesetzt oder über die Enzyme des Butyrat-Weges zu Butyrat oder Butanol reduziert werden. Dazu werden einleitend mittels einer Thiolase (CTC312) zwei Moleküle Acetyl-CoA zu Acetoacetyl-CoA kondensiert. Anschließend erfolgt die Umsetzung zu Butyryl-CoA über Reaktionen, die von einer $\beta$-Hydroxybutyryl-CoA-Dehydrogenase, einer Crotonase und einer Butyryl-CoA-Dehydrogenase katalysiert werden. Das letztere benötigt die Elektronentransfer-Flavoproteine EtfA und EtfB, welche die zur Reduktion von Crotonyl-CoA benötigten Elektronen bereitstellen (BOYNTON et al., 1996). Das Gencluster des Butyrat-Weges ist in Abbildung 23 gezeigt; eine identische Genordnung kann auch in C. acetobutylicum und C. perfringens gefunden werden, wobei sich allerdings die Gene unterscheiden, die benachbart zu dem Cluster liegen. In $C$. botulinum und $C$. difficile existiert eine leicht abweichende Genordnung. Zusätzlich zu dem Cluster des Butyrat-Weges gibt es in C. tetani offenbar drei partielle Kopien. Wahrscheinlich ist, dass die Gene von einer oder mehrerer dieser partiellen Kopien in der $\beta$-Oxidation von Fettsäuren involviert sind (s. 3.4.6.4). So sind die Enzyme Acyl-CoA-Dehydrogenase, Enoyl-CoA-Hydratase, L-3-Hydroxyacyl-CoA-Dehydrogenase und $\beta$-Ketothiolase homolog $\mathrm{zu}$ den Proteinen des Butyrat-Weges (YOUNGLESON et al., 1989). Benachbart zu diesen drei Clustern in $C$. tetani finden sich sowohl Gene, deren Funktionen in einem stoffwechselphysiologischen Zusammenhang zum Butyrat-Weg bzw. zur $\beta$ Oxidation von Fettsäuren stehen (CTC478, CTC482, CTC708, CTC2085, CTC2086 CTC2422) als auch Gene für mögliche Elektronentransferproteine (CTC2424, CTC2425, CTC2421, CTC2079). Analog zum Butyrat-Weg sind auch bei der $\beta$ Oxidation von Fettsäuren Elektronentransferproteine involviert: in vielen Organismen werden die bei der Reduktion der FAD-Gruppe der Acyl-CoADehydrogenase anfallenden Elektronen über Etf-Proteine auf Ubichinon übertragen (LEHMAN \& THORPE, 1992). Es bleibt zu klären, welchen Akzeptor C. tetani, der offensichtlich nicht über Ubichinon verfügt, für die anfallenden Reduktionsäquivalente nutzt. 


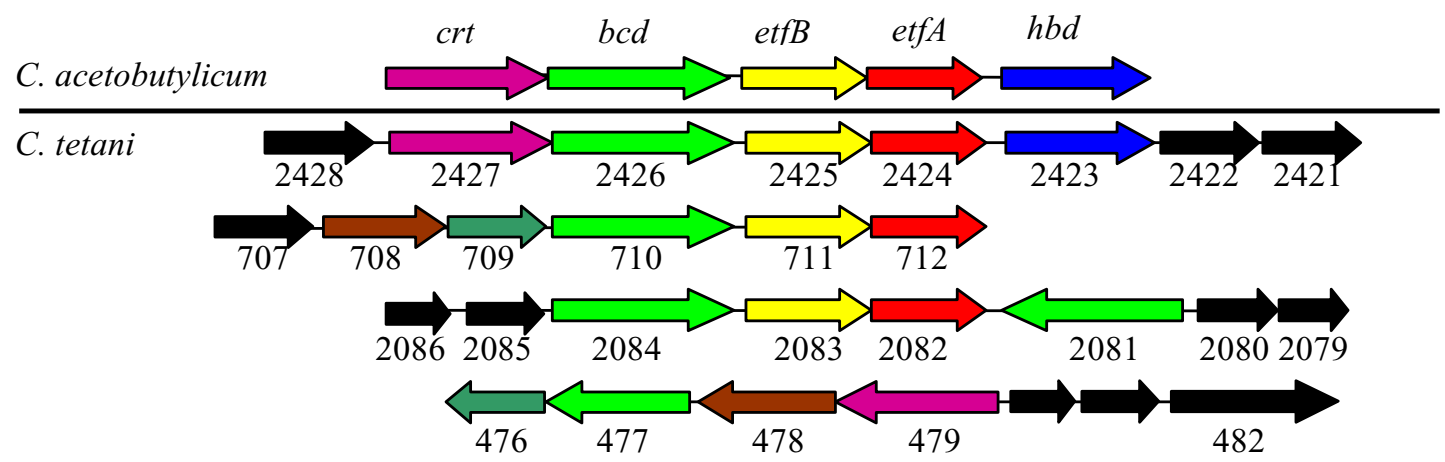

CTC482: 4-Hydroxybutyrat-Coenzym A-Transferase;

CTC707: Transkriptionsregulator;

CTC708/CTC478: Acetyl-CoA:Acetoacetyl-CoA-Transferase oder Propionat-CoA-Transferase;

CTC709/CTC476: Permease (Butyrat oder Propionat);

CTC2079: hypothetisches Elektronentransferprotein;

CTC2080: N-Acetyltransferase;

CTC2085/CTC2086: Acyl-CoA-Hydrolase;

CTC2421: mögliches Elektronentransfer-Protein;

CTC2422: Butanol-Dehydrogenase (NADPH-abhängig);

CTC2428: DNA-bindendes Protein

Abb. 23: Gencluster des Butyrat-Weges in C. tetani und C. acetobutylicum

Zusätzlich sind ähnliche Cluster in C. tetani und interessante ORFs gezeigt, die direkt benachbart zu den Genclustern liegen. crt: Crotonase bzw. Enoyl-CoA- Hydratase (lila); bcd: Butyryl-CoA-Dehydrogenase bzw. Acyl-CoA-Dehydrogenase (grün); $\quad h b d$ : $\beta$-Hydroxybutyryl-CoADehydrogenase bzw. 3-Hydroxyacyl-CoA-Dehydrogenase (blau); etf, Elektronentransfer-Flavoprotein (gelb/rot); schwarz: diverse Funktionen.

\subsubsection{Bioenergetik 1: Substratkettenphosphorylierung}

Zur Energiegewinnung nutzt $C$. tetani die Substratkettenphosphorylierung. Das geschieht zum einen in zwei glykolytischen Reaktionen, die durch die Enzyme Phosphoglycerat-Kinase und Pyruvat-Kinase katalysiert werden (Tabelle 12). Des weiteren wird ATP bei der Umsetzung des aus der Glykolyse oder aus der Verstoffwechselung von Aminosäuren entstehenden Pyruvats zum Acetat oder Butyrat mittels der Acetat-Kinase- bzw. der Butyrat-Kinase-Reaktion gebildet. Die in Tabelle 12 erwähnte Pyruvat-Phosphat-Dikinase - ein hoch konserviertes Protein, das sogar zu homologen Proteinen aus Eukaryonten wie Zea mays eine Identität von 56\% zeigt - ist in C. symbiosum gut untersucht (MCGUIRE et al., 1998). Es stellte sich heraus, dass das Enzym unter normalen Bedingungen in Richtung der ATP-Synthese arbeitet. 
Tabelle 12: Enzyme der Substratkettenphosphorylierung in C. tetani

\begin{tabular}{|c|c|c|}
\hline $\begin{array}{c}\text { ORF- } \\
\text { Name }\end{array}$ & Enzym & Reaktion \\
\hline CTC0379 & Phosphoglycerat-Kinase & $\begin{array}{c}\text { 1,3-Bisphosphoglycerat } \rightarrow \text { 3- } \\
\text { Phosphoglycerat }\end{array}$ \\
\hline CTC2489 & Pyruvat-Kinase & Phosphoenolpyruvat $\rightarrow$ Pyruvat \\
\hline CTC1240 & Acetat-Kinase & Acetylphosphat $\rightarrow$ Acetat \\
\hline CTC2545 & Butyrat-Kinase & Butyrylphosphat $\rightarrow$ Butyrat \\
\hline $\begin{array}{l}\text { CTC1761, } \\
\text { CTC1762 }\end{array}$ & Dihydroxyaceton-Kinase & $\begin{array}{c}\text { Dihydroxyacetonphosphat } \rightarrow \\
\text { Dihydroxyaceton }\end{array}$ \\
\hline CTC2524 & Carbamat-Kinase & Carbamoyl-Phosphat $=\mathrm{CO}_{2}+\mathrm{NH}_{3}$ \\
\hline CTC2014 & Pyruvat-Phosphat- & $\begin{array}{c}\text { Phosphoenolpyruvat }+ \text { Diphosphat }= \\
\text { Pyruvat }+ \text { Phosphat }\end{array}$ \\
\hline
\end{tabular}

\subsubsection{Bioenergetik 2: Membrangebundene Prozesse}

Energiekonservierende membrangebundene Elektronentransportsysteme sind in C. tetani und anderen Clostridien bisher kaum untersucht. Da der Organismus nur anaerob wächst, ist die Verwendung einer typischen aeroben Atmungskette und die damit gekoppelte ATP-Synthese mittels oxidativer Phosphorylierung nicht möglich. Entsprechende Gene sind nicht vorhanden. Auch gibt die Genomsequenz wenig Hinweise auf das Vorhandensein von Cytochromen oder Chinonen. Es konnten lediglich eine periplasmatische Flavocytochrom-haltige Fumarat-Reduktase und eine Cytochrom-haltige Häm-Oxygenase ausgemacht werden (s. 3.4.10). Es wurde auch nach charakteristischen Motiven für Elektronentransportproteine gesucht, vor allem nach Eisen-Schwefel-Clustern (FeS-Cluster) sowie nach FMN- und FADBindemotiven. So konnten 21 Proteine identifiziert werden, die das charakteristische Motiv für das [4Fe4S]-Cluster tragen (CXXCXXCXXXC). Zusätzlich konnten durch einen BLAST-Abgleich mit einer typischen Flavodoxin-Domäne (PFAM00258) mindestens 26 Flavoproteine identifiziert werden. Nachfolgend werden solche in C. tetani gefundenen Systeme vorgestellt, die über diese für Elektronentransportprozesse typischen Motive verfügen. Insbesondere soll dabei auf eine mögliche bioenergetische Involvierung dieser Systeme eingegangen werden. 
Bei näherer Betrachtung fiel die Abundanz von FeS-Zentren und FlavodoxinDomänen in den Proteinen CTC1019 und CTC1024 auf. Die entsprechenden Gene scheinen einem möglichen Operon aus sechs Genen anzugehören (Abb. 24), deren Proteine nicht nur FeS-Cluster und FMN-Bindestellen beinhalten, sondern auch multiple transmembrane Helices ausbilden, was auf ihre Lokalisation in der Cytoplasmamembran hinweist. Das System zeigt zudem starke Ähnlichkeiten zu Nqr (NADH:ubiquinone oxidoreductase)-Systemen aus aeroben pathogenen Bakterien wie $V$. cholerae, S. typhimurium, Y. pestis und Haemophilus influenzae (HAYASHI et al., 1996; HÄSE et al., 2001). Es konnte auch in den Genomsequenzen von $C$. perfringens, C. botulinum und C. difficile, nicht aber in der von C. acetobutylicum identifiziert werden. In einigen der genannten aeroben Organismen konnte gezeigt werden, dass das System als Natriumionen $\left(\mathrm{Na}^{+}\right)$-translozierende NADHDehydrogenase fungiert, welche also die membranintegrale Übertragung der Elektronen vom $\mathrm{NADH}+\mathrm{H}^{+}$auf Ubichinon mit der Ausschleusung von $\mathrm{Na}^{+}$-Ionen koppelt (STEUBER, 2001; BARQUERA et al., 2002). Zusätzlich liegt eine Homologie zum Rnf (Rhodobacter specific nitrogen fixation)-System aus Rhodobacter capsulatus vor. In diesem Organismus ist das System an der Übertragung der Elektronen von einen unbekannten Donor über Ferredoxin I auf die Nitrogenase beteiligt (SCHMEHL et al., 1993; JOUANNEAU et al., 1998).

Wie kann nun diese System im Metabolismus von C. tetani eingebunden sein - unter Berücksichtigung, dass in C. tetani weder Ubichinon noch Nitrogenase-Gene vorkommen ? In Kapitel 4.1.4.1 soll ein Modell entwickelt werden, das dem Umstand Rechnung trägt, dass C. tetani seine Energie vor allem durch die Vergärung von Aminosäuren gewinnt. 


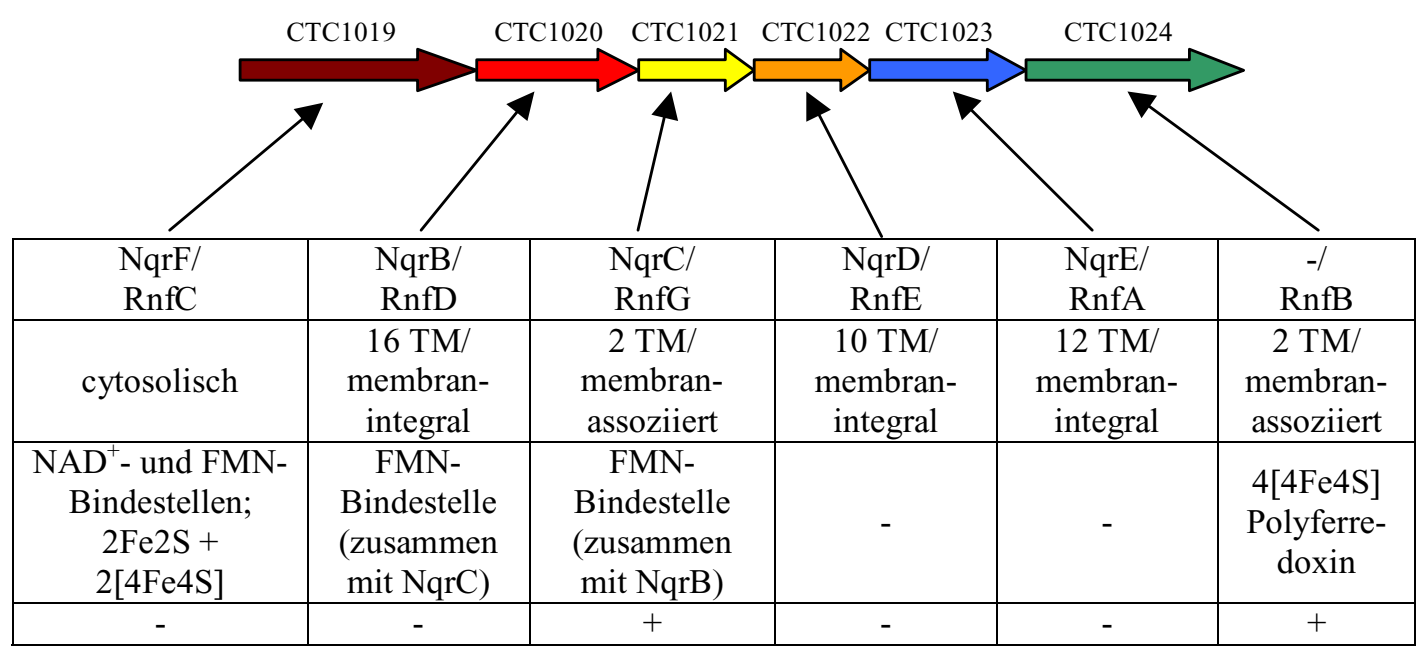

Abb. 24: Charakteristika der Untereinheiten des membrangebundenen Elektronentransportsystems Nqr/Rnf aus $C$. tetani

Die erste Zeile der Tabelle gibt die Proteinnamen an, die zweite Zeile gibt Informationen über die Hydrophobizität bzw. die mögliche Lokalisation der Proteine, die dritte Zeile listet prosthetische Gruppen der Proteine auf und die vierte Zeile gibt Auskunft darüber, ob die Proteine N-terminal ein Signalpeptid tragen. Abkürzung: TM, transmembrane Helices.

\subsubsection{V-Typ-ATPasen}

Neben dem Nqr/Rnf-System, dass die Möglichkeit eröffnet, einen eingeschränkten membrangebundenen Elektronentransport durchzuführen, der mit der Ausbildung eines $\mathrm{Na}^{+}$-Gradienten über der Cytoplasmamembran gekoppelt ist, gibt es weitere Systeme in $C$. tetani, die an der Errichtung eines Ionen-Gradienten über der Membran beteiligt sind. Das Genom beinhaltet die Gene einer V(vakuolär)-Typ ATPase, die neun Proteine umfasst (CTC0993-CTC1001; Abb. 25). Diese ATPase zeigt starke Ähnlichkeiten zu gut untersuchten Systemen aus C. fervidus und Enterococcus hirae, welche primäre $\mathrm{Na}^{+}$-Pumpen darstellen: unter ATP-Hydrolyse werden $\mathrm{Na}^{+}$-Ionen ins Periplasma befördert (HÖNER ZU BENTRUP et al., 1997, MURATA et al., 1997). Da dieser Prozess sehr energieaufwendig ist, wird das System in E. hirae stark reguliert. Die Expression des entsprechenden Operons findet nur bei extremen Bedingungen wie hoher $\mathrm{pH}-$ Wert oder hohe intrazelluläre $\mathrm{Na}^{+}-$ Konzentration statt (IKEGAMI et al., 1999). Interessanterweise fehlen im C. tetaniGenom im Gegensatz zu den Genomen von C. perfringens und C. acetobutylicum die Gene für eine $\mathrm{F}_{0} \mathrm{~F}_{1}$-Typ-ATPase. C. perfringens hat beide ATPase-Systeme, während C. acetobutylicum nur die $\mathrm{F}_{0} \mathrm{~F}_{1}$-Typ-ATPase besitzt. 
Im Gegensatz zu allen anderen bisher sequenzierten Clostridien (C. acetobutylicum, C. perfringens, $C$. difficile und $C$. botulinum) besitzt $C$. tetani noch ein zusätzliches Gencluster (CTC2326-2332), das Ähnlichkeiten zum V-Typ-ATPase-Gencluster zeigt. Dieses Cluster ist allerdings anders zusammengesetzt, wie aus Abbildung 25 ersichtlich wird. Auch zeigt es andere Homologien: die höchsten Treffer wurden zu Proteinen aus Petrotoga miotherma und aus Archaeen wie Pyrococcus furiosus und Methanobacterium thermoautotrophicum erhalten. Die in diesen Organismen vorhandenen ähnlichen Systemen stimmen auch in der Genordnung mit dem unbekannten System aus C. tetani überein. Es bleibt zu ermitteln, welche Funktion diese alternative V-Typ-ATPase in $C$. tetani ausübt.



\begin{abstract}
Abb. 25: Die Gencluster der V-Typ-ATPasen aus $C$. tetani im Vergleich zum Cluster aus Enterococcus hirae

Zwischen CTC2329 und CTC2330 ist ,manuell' ein weiterer ORF identifiziert worden, der Homologien sowohl zur F- als auch zur GUntereinheit der V-Typ-ATPase aus Enterococcus hirae zeigt.
\end{abstract}

\title{
3.4.9.3 Das NatAB-System
}

Es gibt noch ein weiteres $\mathrm{Na}^{+}$-Ionen-translozierendes System in C. tetani: das NatAB-System (CTC1485/1486), welches einen ABC-Transporter darstellt (CHENG et al., 1997). Dieses System hat wahrscheinlich vorwiegend - oder sogar ausschließlich - die Funktion, eine $\mathrm{zu}$ hohe intrazelluläre $\mathrm{Na}^{+}-$Konzentration, die toxisch wirken könnte, zu verhindern. 
C. tetani besitzt auch die Möglichkeit der Errichtung eines Protonengradienten über der Cytoplasmamembran: das Genom enthält das Gen (CTC383) einer stark hydrophoben V(vakuolär)-Typ- $\mathrm{H}^{+}$-Pyrophosphatase, ein membrangebundenes Protein, welches die Spaltung von anorganischem Diphosphat zu Monophosphat mit der Translokation von Protonen koppelt. Ähnlichkeiten - eine ca. 45\%ige Identität bestehen in erster Linie zu Systemen aus Archaeen der Gattung Methanosarcina. Andere Clostridien-Genome besitzen dieses Gen nicht. Zusätzlich existiert auch eine lösliche anorganische Pyrophosphatase (CTC1649), die Mangan-abhängig ist.

\subsubsection{5 $\quad \mathrm{H}^{+} / \mathrm{Na}^{+}$-Antiporter}

$\mathrm{Da}$ es also sowohl primäre Natriumionen- wie Protonen-Pumpen gibt, ist das Vorkommen von $\mathrm{H}^{+} / \mathrm{Na}^{+}$-Antiportern in C. tetani nicht verwunderlich: mindestens acht aus einer Untereinheit bestehende Antiporter konnten identifiziert werden, die Ähnlichkeiten zur Nha-Antiporter-Familie aus E. coli zeigten, welche einen sekundären Antiport durchführen, also einer, der durch einen elektrochemischen Protonengradienten energetisiert wird (CTC567, CTC901, CTC1183, CTC1423, CTC1853, CTC2161, CTC2520, CTC2529).

\subsubsection{Das Mrp-ähnliche System}

Zusätzlich kann ein 7,2 kb großes Gencluster aus 10 Genen identifiziert werden (CTC1337-1342), das nicht in anderen Clostridien auftritt. Einige daraus abgeleitete Proteine zeigen Homologien $\mathrm{zu} \mathrm{H}^{+} / \mathrm{Na}^{+}$-Antiportern. Bei näherer Betrachtung fällt die deutliche Ähnlichkeit - sowohl der einzelnen Proteine als auch der Genordnung des Clusters - zu bisher nicht charakterisierten Systemen aus Archaeen wie Halobaceterium sp. und Pyrococcus abyssii auf (Abb. 26). Eine gewisse Ähnlichkeit - trotz unterschiedlicher Genordnung - besteht auch zum Mrp (multiple Resistenz und pH-Adaption)-System aus B. subtilis sowie zu ähnlichen Systemen in den Organismen Sinorhizobium meliloti und Staphylococcus aureus (ITO et al., 2001; HIRAMATSU et al., 1998). Dieses besteht aus sieben stark hydrophoben Untereinheiten, welche für die Resistenzausbildung gegenüber hohen $\mathrm{Na}^{+}$- und $\mathrm{K}^{+}$- 
Konzentrationen sowie für eine $\mathrm{pH}$-Regulation verantwortlich sein sollen (ITO et al., 1999). Es konnte gezeigt werden, dass der Mrp-Komplex als $\mathrm{H}^{+} / \mathrm{Na}^{+}$-Antiporter arbeitet, der aber möglicherweise nicht nur einen sekundären Antiport katalysieren sondern auch als primäre $\mathrm{Na}^{+}$-Pumpe fungieren kann, wobei die Hypothese aufgestellt wurde, dass womöglich ein durch den Komplex katalysierter Elektronentransport mit der $\mathrm{Na}^{+}$-Translokation gekoppelt ist (ITO et al., 2001). Die 10 Proteine von C. tetani zeigen alle eine starke Hydrophobizität (Abb. 26). Auffällig ist die Homologie mehrerer Untereinheiten des potentiellen $\mathrm{H}^{+} / \mathrm{Na}^{+}$-Antiporters $\mathrm{zu}$ den hydrophoben Komponenten NuoL und NuoN des Komplex I der Atmungskette aus E. coli. Diese könnten bei der $\mathrm{Na}^{+}$-Translokation oder beim $\mathrm{H}^{+}$-Einstrom eine Rolle spielen. $\mathrm{Ob}$ sie darüber hinaus auch in membrangebundene Transportprozesse involviert sind, bleibt zu ermitteln, ist aber aufgrund des Fehlens von FeS-Clustern eher unwahrscheinlich.

\section{B. subtilis}

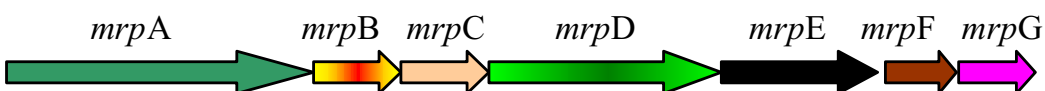



\section{Abb. 26: Das Mrp-Operon aus B. subtilis und verwandte Gencluster in Halobacterium sp. und $C$. tetani}

Die untere Tabelle gibt die Homologons der Genprodukte aus C. tetani zum Mrp-System an (erste Zeile), listet die Anzahl der transmembranen Helices (TM) der C. tetani-Proteine auf (zweite Zeile) und gibt über Proteingröße und weitere auffällige Homologien Auskunft (dritte Zeile). Einige Gene in C. tetani wurden durch GLIMMER nicht identifiziert und sind ,manuell' zugefügt worden. Abkürzungen: Nuo, NADH:UbichinonOxidoreduktase; FHL3, Formiat-Hydrogenlyase-Untereinheit 3. 
Das Genom von $C$. tetani kodiert sicherlich noch weitere (membrangebundene) Systeme, die von metabolischem und bioenergetischem Interesse sind. Leider ist wenig über Gärungsbilanzen bestimmter Substrate und daraus resultierende Energieausbeuten bekannt. Sicher scheint, dass $C$. tetani einen ausgeprägten Gärungsstoffwechsel betreibt. Allerdings schließt das nicht - wie in den vorangegangenen Abschnitten gezeigt - das Vorkommen membrangebundener Prozesse mit bioenergetischer Relevanz aus. Im nachfolgenden Kapitel sollen abschließend zwei weitere Systeme vorgestellt werden, die in anderen sequenzierten Clostridien nicht vorhanden sind.

\subsubsection{Weitere membranassoziierte Komplexe}

3.4.10.1 Fumarat-Reduktasen

Bei der Suche nach membrangebundenen Systemen, die eventuell einen Elektronentransport katalysieren können, wurde auch nach solchen Enzymen in $C$. tetani Ausschau gehalten, die im Rahmen der von vielen Anaerobiern ausgeübten „anaeroben Atmung“ eine Rolle spielen, was die Verwendung von terminalen Elektronenakzeptoren wie z. B. Nitrat, Sulfat oder Fumarat im Zuge eines membrangebundenen Elektronentransports meint. Erwartungsgemäß war diese Suche im Genom von C. tetani wenig erfolgreich. Stattdessen konnten einige Enzyme des assimilatorischen Metabolismus' gefunden werden wie eine Nitrit-Reduktase (CTC2521) oder eine aus drei Proteinen bestehende anaerobe Sulfit-Reduktase (CTC2484-2486). Interessant ist aber das Auftreten einer Fumarat-Reduktase in vier unterschiedlichen Kopien (CTC811, CTC1488, CTC1522 und CTC1847), wobei die Kopien untereinander eine 45\%ige (CTC1522 mit CTC1847 über 468 As) bis 58\%ige (CTC811 mit CTC1488 über 578 As) Proteinidentität aufweisen. In allen anderen bisher sequenzierten Clostridien und Bakterien der Gattung Bacillus sind Gene für solch eine Fumarat-Reduktase nicht vorhanden. Alle vier Genprodukte aus C. tetani zeigen schwache Homologien zur katalytischen Untereinheit der membrangebundenen Fumarat-Reduktase aus E. coli und anderen Organismen. Demgegenüber weisen die vier C. tetani-Proteine aber starke Ähnlichkeiten (42-47\% 
Proteinidentität über $\sim 510 \mathrm{As}$ ) zu einem löslichen Cytochrom c-haltigen Protein auf, welches in Organismen der Gattung Shewanella vorkommt. Es konnte in Shewanella putrefaciens gezeigt werden, dass es sich dabei um ein periplasmatisch lokalisiertes Flavocytochrom-Protein handelt, das eine Fumarat-Reduktase-Aktivität aufweist und deshalb auch Flavocytochrom c-Fumarat-Reduktase gennant wird (PEALING et al., 1992). Das Protein ist in Shewanella putrefaciens unerläßlich für die Verwendung von Fumarat als terminalen Elektronenakzeptor (GORDON et al., 1998; LEYS et al., 1999). Wie das Protein aus Shewanella tragen auch alle vier C. tetani-Proteine eine Signalpetidsequenz, wohingegen die Proteine nur eine kleine schwach hydrophobe Region enthalten. Deshalb kann man davon ausgehen, dass auch C. tetani über eine bzw. mehrere periplasmatische Fumarat-Reduktasen verfügt, wodurch Fumarat als terminaler Elektronenakzeptor genutzt werden kann. In C. formicoaceticum wurde zudem eine hohe Fumarat-Reduktase-Aktivität nachgewiesen, die auf ein membranperipheres Enzym zurückzuführen sein soll (DORN et al., 1978). Unbekannt bleibt die Natur des direkten Elektronendonors sowie der Weg, über den die Elektronen an die Außenseite der Cytoplasmamembran gelangen. In Shewanella oneidensis wurde CymA, ein membranassozziertes c-Typ-Cytochrom, als Elektronendonor der Fumarat-Redukatse identifiziert (SCHWALB et al., 2002). Ein CymA-Homologon ist im Genom von $C$. tetani nicht auffindbar, so dass es hier einen anderen Elektronendonor geben muss. Die mögliche Einbindung der FumaratReduktasen in den Stoffwechsel von C. tetani wird in Kapitel 4.2.2 diskutiert.

\subsubsection{CO-Dehydrogenase-System und Häm-Oxygenase}

Als letztes soll ein weiteres System beschrieben werden, das lediglich in C. tetani und $C$. botulinum nicht aber in anderen sequenzierten Clostridien identifiziert werden konnte. Es handelt sich dabei um ein Gencluster aus drei ORFs (CTC2474CTC2477), deren Proteine zwei [2Fe2S]-Cluster, ein FAD, sowie eine MolybdänBindestelle beinhalten. Diese Proteine zeigen hohe Homologien zu Untereinheiten einer Molybdän-abhängigen CO-Dehydrogenase. Dieser membranassoziierte Enzymkomplex, in Oligotropha carboxidovorans ein Selenocystein-haltiges Molybdo-Eisen-Schwefel-Flavoproteinkomplex, katalysiert die Oxidation von $\mathrm{CO} z \mathrm{zu}$ $\mathrm{CO}_{2}$, wobei ein Elektronenakzeptor reduziert wird (SCHUBEL et al., 1995; 
DOBBEK et al., 1999). Die Proteinsequenz der drei ORFs in C. tetani zeigt aber auch hohe Homologien zu anderen Molybdän-abhängigen Hydroxylasen wie zur 4Hydroxybenzoyl-CoA-Reduktase, welche ebenfalls aus drei Untereinheiten besteht und die irreversible Dehydroxylierung von 4-Hydroxybenzoyl-CoA zu Benzoyl-CoA durchführt, ein wichtiger Schritt in der anaeroben Degradation von 4Hydroxybenzoat. Um erste Hinweise bezüglich der Funktion dieses Komplexes in $C$. tetani zu gewinnen, wurde die genetische Umgebung betrachtet. Direkt stromaufwärts zu dem Gencluster befindet sich ein ORF, der für eine Cytochromhaltige Häm-Oxygenase kodiert. Solch ein Enzym kommt in einigen aeroben pathogenen Organismen wie Neisseria meningitidis, Pseudomonas aeruginosa oder Corynebacterium diphtheriae vor und katalysiert den ersten Schritt des Abbaus der Häm-Gruppe nach folgender Gleichung (RATLIFF et al., 2001; CHU et al., 1999):

$$
\mathrm{Häm}+\mathrm{O}_{2}+\mathrm{NADPH} \rightarrow \text { Biliverdin }+\mathrm{CO}+\mathrm{Fe}^{3+}+\mathrm{H}_{2} \mathrm{O}+\mathrm{NADP}^{+} \text {. }
$$

In dieser Reaktion entsteht also neben dem für die C. tetani-Zelle wichtigen $\mathrm{Fe}^{3+}$ auch Kohlenmonoxid. Dieses könnte nun direkt anschließend durch die CODehydrogenase zu $\mathrm{CO}_{2}$ oxidiert werden, wobei die anfallenden Elektronen auf einen Akzeptor übertragen werden. Ob die Häm-Oxygenase-Reaktion nach obiger Formel in C. tetani ablaufen kann, ist allerdings fraglich. Schließlich wird dazu Sauerstoff benötigt, was sich mit dem anaeroben Metabolismus von C. tetani nicht vereinbaren lässt. Vorstellbar wäre aber, dass die Häm-Oxygenase-Reaktion als eine Art Sauerstoff-Fänger dient. $\mathrm{Zu}$ bedenken ist, dass $C$. tetani zur erfolgreichen Kolonisierung der Wunde eines Säugetieres wahrscheinlich geringe SauerstoffKonzentrationen tolerieren muss.

Die genauere Betrachtung des Ergebnisses des BLAST-Abgleichs der HämOxygenase-Sequenz aus C. tetani lässt aber noch eine andere Vermutung zu. Neben der höchsten Ähnlichkeit zu einer möglichen Häm-Oxygenase aus C. perfringens - in C. botulinum, C. difficile und C. acetobutylicum kommt sie nicht vor - zeigt die Sequenz vorwiegend Ähnlichkeiten zu Häm-Oxygenasen aus Eukaryoten, vor allem aus Algen wie Porphyra purpurea oder Rhodella violacea. Dort ist das Enzym im Chloroplasten-Genom kodiert und katalysiert eine Reaktion nach obiger Formel (RICHAUD \& ZABULON, 1997). Es stellt ein Schlüssel-Enzym in der Synthese der Antennenpigmente des Photosynthese-Apparates dar, welche aus Biliverdin gebildet werden. Interessant ist nun das Vorkommen von blauen Gallenpigmenten (Bactobilinen) in C. tetanomorphum (BRUMM et al., 1983). Diese Bactobiline sind 
Chromophore des Biliverdin-Typs, welche unter anaeroben Bedingungen produziert werden, wenn dem Medium die Tetrapyrrol-Vorstufe $\delta$-Aminolevulinat oder Uroporphyrin I bzw. III zugesetzt wurde (CHEN \& FRIEDMANN, 1993). Es wurde in C. tetanomorphum weiter beobachtet, dass das (damals unbekannte) Enzym, welches an der Bildung solcher Bactobiline beteiligt ist, obligat anaerobe Bedingungen benötigt - im Gegensatz zu den eukaryotischen Häm-Oxygenasen, welche zur Produktion von Gallenpigmenten Sauerstoff benötigen (CHEN \& FRIEDMANN, 1993). Der Reaktionsmechanismus einer , anaeroben' HämOxygenase kann durch die Verfügbarkeit seiner Sequenz in C. tetani nun im Detail untersucht werden. Unklar bleibt, welchen Nutzen $C$. tetani aus der Bildung solcher Pigmente ziehen könnte. Möglicherweise stellen diese lediglich ein Abfallprodukt bei der Verwertung von Häm dar. Es soll aber erwähnt werden, dass ähnliche Pigmente wie z. B. Bilirubin, welches aus Biliverdin gebildet wird, in Eukaryoten als Antioxidanzien wirken können. In der Abwehr schädigender Sauerstoffverbindungen (Peroxide, Radikale) hätte $C$. tetani sicherlich einen Nutzen, zumal solche Sauerstoffverbindungen auch als Teil der Immunantwort des Säugetierwirtes in entzündeten Regionen gebildet werden.

C. tetani scheint im übrigen alle Enzyme zu besitzen, welche die Umsetzung von $\delta$ Aminolevulinat in Uroporphyrinogen III katalysieren können, einem VorläuferMolekül des Häms und Schlüssel-Molekül bei der Synthese des Cofaktors B12, dessen Synthese C. tetani offensichtlich betreiben kann (CTC726-CTC746): die $\delta$ Aminolevulinat-Dehydrase (CTC729) kondensiert zwei Moleküle $\delta$-Aminolevulinat zu Porphobilinogen, die Porphobilinogen-Deaminase kondensiert vier Moleküle Porphobilinogen zu einen linearen Tetrapyrrol-Molekül und die Uroporphyrinogen III-Synthase katalysiert die Cyclisierung des linearen Tetrapyrrol-Moleküls zum Uroporphyrinogen I oder III (CTC728).

\subsubsection{Transportsysteme}

Die Annotation ergab, dass auf dem Chromosom von C. tetani mindestens 167 Gene liegen, die für Transportproteine kodieren. 


\subsubsection{ABC-Transporter}

Zuerst sollten daraus solche selektiert und analysiert werden, die zur ABC (ATPbindende Cassette)-Transporter-Familie zu rechnen sind. Diese Familie und deren Eigenschaften sind bereits in Kapitel 3.2.7 vorgestellt worden. Um den Anteil von ABC-Transportern zu ermitteln, wurde ein BLAST-Abgleich mit der ConsensusSequenz der ABC-Transporter-Domäne PFAM00005 sowie der ATPase-Domäne SMART00382 unternommen, welche Domänen eines typischen ABC-Transporters sind: 64 Proteine des Genoms zeigten signifikante Homologien zu der ABCTransporter-Domäne und 77 Proteine beinhalteten eine ATPase-Domäne. Es zeigte sich bei fast allen der 64 potentiellen ABC-Transporter, dass das entsprechende Gen direkt benachbart zu einem oder mehreren Genen liegt, welche für stark hydrophobe Proteine kodieren; diese stellen ABC-Transporter-assoziierte Permeasen dar. Auch konnten in vielen Fällen unmittelbar benachbarte Gene für DNA-bindende Proteine entdeckt werden, die wahrscheinlich die Transkription der ABC-Transporter-Gene regulieren (vgl. 3.4.13). Nur in einigen Fällen war eine Charakterisierung der Substratspezifität auf der Grundlage der gefundenen Homologien möglich. So konnten ABC-Transporter für Eisen (CTC276-274, CTC1702-1701), Siderophore (CTC783-785, CTC962-960, CTC1197-1195, CTC1370-1372), Natrium (NatA), Kobalt (CTC751-754, CTC2574-2576), Zink (CTC2360-2362), Phosphat (CTC1132-1134), Glycin/Betain (CTC374-373, CTC2342-2340), Glutamin (CTC560-557), Ribose (CTC905-907, CTC2351-2347), Di- und Oligopeptide (CTC1400-1404, CTC1374-1380, CTC1900-1904) und für diverse Antibiotika (CTC625-627 für Subtilin, CTC1357-1358 und CTC1803-1802 für Bacitracin) identifiziert werden. Zusätzlich befanden sich unter den ABC-Transportern mehrere sogenannte Multidrug-Efflux-Systeme (CTC162, CTC425/426, CTC1199/1201, CTC1408/1410, CTC1811), die mehrere Antibiotika aus der Zelle transportieren können. Zur Analyse der restlichen Systeme mit unbekannter Substratspezifität wurden die entsprechenden Proteinsequenzen mit der Transporter-Datenbank von SAIER (http://www-biology.ucsd.edu/ msaier/transport/) abgeglichen (vgl. 3.2.7; SAIER, 1999). Es stellte sich dabei heraus, dass eine erstaunliche Anzahl der unbekannten Systeme aller Wahrscheinlichkeit nach Peptid- oder Protein-Transporter sind: mindestens zehn Transporter-Systeme (CTC394-397, CTC803-800, CTC920918, CTC1419-1418, CTC1493-1492, CTC1821-1820, CTC1985-1986, CTC1987- 
1988, CTC1916-1915 und CTC2098-2097) zeigten hohe Homologien zu Peptidtransportern wie dem Bacitracin-Exportsystem aus Streptococcus mutans oder dem Subtilin-Exportsystem aus B. subtilis (KLEIN \& ENTIAN, 1994; TSUDA et al., 2002). Bestimmte Peptidtransporter können aber auch in Quorum-Sensing-Prozessen involviert sein. Posttranslational produzierte Peptid-Pheromone werden dabei durch solche ABC-Transporter exportiert. Die Peptide fungieren dann als Inputsignale für spezifische Sensor-Elemente von Zwei-Komponentensystemen (KLEEREBEZEM et al., 1997).

Mindestens sechs weitere Transporter (CTC240-241, CTC580, CTC588, CTC633635, CTC1163, CTC2429-2430) wiesen Ähnlichkeiten zu Streptogramin-Exportern auf, welche Macrolide wie Erythromycin oder Pristinamycin aus der Zelle schleusen. Die Analyse der Transporter ohne ABC-Domäne ergab, dass viele dieser Proteine, wie oben erwähnt, hydrophobe ABC-Transporter-assoziierte Permeasen darstellen, die in direkter genetischer Nachbarschaft zu den entsprechenden ABC-Transportern lokalisiert sind.

\subsubsection{Membranpotential-abhängige Transporter}

Zusätzlich konnten eine Vielzahl Membranpotential-abhängiger Transporter erkannt werden, die meisten davon mit hohen Homologien $\mathrm{zu} \mathrm{Na}^{+}$-abhängigen AminosäureSymportern: so kann C. tetani mindestens die folgenden Aminosäuren in die Zelle aufnehmen: Alanin, Glutamin, Glutamat, Histidin, Prolin, Threonin, Tryptophan, Tyrosin und Serin. Auch wurden $\mathrm{Na}^{+}$-abhängige Symporter zur Aufnahme von Glucose und/oder Galactose (CTC1237) sowie zur Aufnahme von Myo-Inositol (CTC514) und Pantothenat (CTC928) gefunden. Zusätzlich ließen sich mindestens sechs $\mathrm{Na}^{+}$-abhängige Multidrug-Efflux-Pumpen (CTC419, CTC443, CTC603, CTC1362, CTC1799, CTC2405) identifizieren. Diese Vielzahl an $\mathrm{Na}^{+}$-abhängigen Systemen ist sehr auffällig und soll in Kapitel 4.1.4 diskutiert werden. 


\subsubsection{Systeme des Proteinexports und exportierte Proteine}

Nur wenig ist über die Mechanismen der Proteinsekretion in Clostridien bekannt. Da die Proteinsekretion ein wichtiger Teil des pathogenen Phänotyps ist - schließlich sind viele Virulenzfaktoren Exoenzyme - soll an dieser Stelle der Versuch unternommen werden, die Genomsequenz und -annotation dahingehend $\mathrm{zu}$ durchsuchen, welche sekretorischen Systeme C. tetani benutzen kann. Hintergrund dieser Suche ist unter anderem, dass bisher nicht verstanden ist, ob und wie das Tetanus-Toxin in den extrazellulären Raum exportiert wird (MUKHERJEE et al., 2002).

Zuvor aber soll eine Identifikation und Klassifikation solcher C. tetani-Proteine unternommen werden, die über das Sec-System sekretiert werden, das unter den Prokaryoten am weitesten verbreitete System des Proteinexports (DRIESSEN et al., 1998). Proteine, die diesen sekretorischen Weg gehen, werden entweder in die Cytoplasmamembran inseriert oder aber ins Periplasma abgegeben. Zur Identifikation solcher Sec-abhängig exportierten Proteine wurde ausgenutzt, dass sie eine N-terminale Erkennungssequenz besitzen, das sogenannte Signalpeptid. Alle ORFs wurden auf das Vorhandensein einer typischen Signalpeptidsequenz mit einem Signalpeptid-Vorhersageprogramm überprüft (http://www.cbs.dtu.dk/services/ SignalP/). So konnten 419 Signalpeptid-tragende Proteine gefunden werden*. Unter den 419 Proteinen befinden sich mindestens 91 Transporter, darunter auch periplasmatische Substratbindeproteine. Weitere 107 sind entweder konservierte (64) oder hypothetische (52) Proteine unbekannter Funktion - die meisten davon ausgesprochen hydrophober Natur, was auf ihre Membranständigkeit hinweist. Dieser Befund verdeutlicht, dass allgemein viel weniger über membranständige als über cytoplasmatische Proteine bekannt ist. Des weiteren finden sich unter den 419 Proteinen über 28 S-Layer-Proteine, eine ganze Reihe von Virulenzfaktoren wie die Collagenase, Tetanolysin O oder die Fibronectin-Bindeproteine, 19 Zellzyklus- bzw. sporulationsrelevante Proteine, 17 extrazelluläre Peptidasen, 15 Chemotaxis-Proteine und mindestens 18 Sensor-Histidin-Kinasen. Auch einige metabolische Enzyme besitzen offenbar eine Signalpeptidsequenz, wie z. B. Fumarat-Reduktase, $\beta$ -

\footnotetext{
* Vermutlich sind mehr Proteine mit typischer Signalpeptidsequenz vorhanden. Oftmals war der exakte Startpunkt eines Gens nicht eindeutig vorherzusagen, was Auswirkungen auf die Ähnlichkeitsberechnung zur Identifikation von Signalpeptiden in N-Termini von Proteinen hatte. Andererseits sind auch Falschpositive denkbar.
} 
Hydroxybutyryl-CoA-Dehydrogenase, L-Lactat-Dehydrogenase und L-SerinDehydratase.

Aufgrund der erstaunlichen Anzahl gefundener Proteine mit Signalpeptiden scheint das Sec-System offensichtlich unter den sekretorischen Systemen in C. tetani eine dominante Rolle zu spielen. Es kommt in Gram-negativen wie in Gram-positivenBaktereien vor und ist hochkonserviert (DRIESSEN et al., 1998). In E. coli besteht es aus den Proteinen SecABDEFGY (Abb. 27).

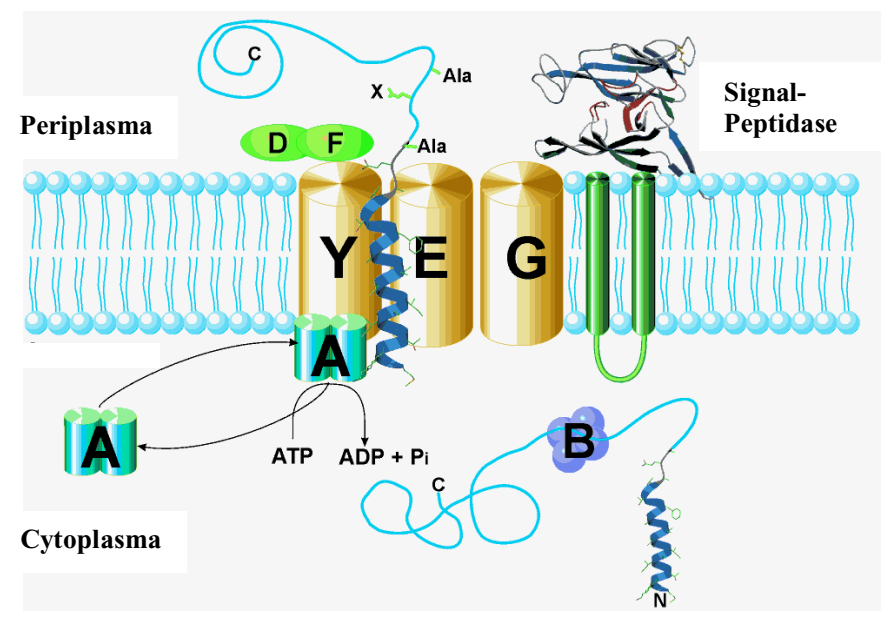

\section{Abb. 27: Das Sec-abhängige Protein-Sekretionssystem Gram-negativer Bakterien (Abbildung produziert von Fern Ness) (http://byron.biochem.ubc.ca/research2.sec2.htm)}

Auch im Genom von C. tetani lassen sich einige der bekannten Sec-Komponenten ausmachen: SecA (CTC327), ein hochkonserviertes Protein mit ATPase-Aktivität (75\% Proteinidentität über 830 As zu SecA aus C. acetobutylicum und $C$. perfringens), SecD (CTC2205), SecE (CTC2615), SecF (CTC2203) und SecY (CTC2584) konnten identifiziert werden. Das Chaperon SecB und SecG, welches normalerweise Teil des membranintegralen Komplexes SecYEG ist, scheinen aber in C. tetani sowie den anderen Clostridien zu fehlen. Auch in anderen Gram-positiven Bakterien wie B. subtilis wurde diese Beobachtung gemacht und über die Existenz eines modifizierten Sec-Systems spekuliert (KUNST et al., 1997). Vermutlich können andere Proteine die Funktionen von SecBG übernehmen. Ein Homologon zu YajC (CTC2208) konnte gefunden werden, welches einen membranintegralen Komplex zusammen mit SecD und SecF bilden kann (NOUWEN \& DRIESSEN, 
2002). Das entsprechende Gen liegt mit den Genen von SecD und SecF in einem Cluster. Ein Protein (CTC0096), dessen Gen in unmittelbarer Nähe zum Replikationsursprung liegt, zeigt Homologie zu YidC aus E. coli, welches einen Komplex mit SecDF+YajC eingehen kann (NOUWEN \& DRIESSEN, 2002). Des weiteren konnten zwei Proteine (CTC166 und CTC458) identifiziert werden, die ausschließlich in Clostridien vorkommen und Ähnlichkeiten zum C-Terminus von SecA zeigen.

Mindestens zwei Signal-Peptidasen konnten in der Genomsequenz gefunden werden (CTC1253, CTC1615). Eine der beiden ist in einem Gencluster kodiert, welches Gene für einen SRP(Signal Recognition Particle)-ähnlichen Weg der Proteinsekretion enthält, einem Proteintranslokationssystem, das vor allem in höheren Lebewesen vorkommt (LUTCKE, 1995; ZWIEB \& SAMUELSSON, 2000). Ob das SRP-System in C. tetani unabhängig arbeitet oder aber mit dem Sec-System zusammenarbeitet, wie für Gram-positive-Bakterien vermutet wird, bleibt offen (VAN WELY et al., 2001). Das SRP-System besteht in C. tetani - sowie allen anderen bisher sequenzierten Organismen der Bacillus/Clostridium-Gruppe - aus dem SRP54-Homologon Ffh (CTC1249) und einer kleinen cytoplasmatischen RNA (7SL RNA, stromaufwärts von CTC75), die wahrscheinlich zusammen den SRPKomplex bilden, welcher an die im Zuge der Translation am Ribosomen erscheinende Signalpeptidsequenz bindet. Der SRP-Rezeptor besteht u. a. aus der GTPase FtsY (CTC1246). Möglicherweise sind auch das Protein CTC1247 (,SRPassoziiertes Protein') und die GTPase CTC1254 beteiligt. Eine GTPase spielt auch im eukaryotischen Pendant eine entscheidende Rolle. Der SRP-Rezeptor übernimmt die Annahme des Komplexes aus sekretorischem Protein plus SRP an der Cytoplasmamembran und katalysiert unter GTP-Hydrolyse die Abspaltung des SRP vom Komplex. Im Genom von C. tetani sind die Gene des SRP-Systems mit Genen geclustert, die möglicheweise am SRP-System beteiligt sind: neben der bereits erwähnten Signal-Peptidase (CTC1253) lassen sich eine Ribonuklease (CTC1255), ein GTP-bindendes Protein (CTC1254), ein 16S rRNA prozessierendes Protein (CTC1250), zwei ribosomale Proteine (L19P und S16P), eine tRNA(Guanin-N1)Methyltransferase (CTC1251) und ein RNA-bindendes Protein ausmachen. 
Im folgenden wurde nach weiteren Proteintranslokationssystemen gesucht. Es zeigte sich, dass die Gene des Sec-unabhängigen TAT (Twin Arginine Translocation)Systems nicht in den betrachteten Clostridien-Genomen vorkommen.

Es konnten aber zwei Proteine (CTC1603, CTC1604 mit ATPase-Domäne) identifiziert werden, die sowohl Homologien zu den Gsp (General secretion pathway)-Proteinen E und F (synonym: EpsE und F), welche Teil eines bakteriellen Typ II-Sekretionssystems sind, als auch zu den Pilus-Assembly-Proteinen PilB und PilC zeigten. Das Typ II-Sekretionssystem kommt in vielen Gram-negativen Bakterien vor, wie in E. coli oder in $V$. cholerae (SANDKVIST, 2001). Interessant in diesem Zusammenhang ist, dass einige bakterielle Toxine, wie z. B. das CholeraToxin, mittels des Typ II-Sekretionssystems exportiert werden, das in $V$. cholerae aus 12 Untereinheiten besteht, deren Gene geclustert vorkommen (Abb. 28; SANDKVIST et al., 1997). Deshalb wurde die genetischen Umgebung von CTC1603 und CTC1604 genauer analysiert. Erst durch einen Psi-BLAST, der auch schwache Homologien aufdeckt, konnten weitere Komponenten des Typ IISekretionssystems in C. tetani identifiziert werden, welche zuvor als hypothetisch annotiert wurden (Abb. 28). Ein ORF (CTC1600) zeigte dabei Homologien zu einer Prepilin-Peptidase. Nun konnte in Legionella pneumophila gezeigt werden, dass die Prepilin-Peptidase für die Protein-Sekretion mittels des Typ II-Systems benötigt wird (LILES et al., 1998). Eine Inaktivierung des entsprechenden Gens in diesem Organismus hatte nicht nur zur Folge, dass weniger Proteine sekretiert wurden; darüber hinaus ging das Ausschalten dieses Gens mit der Reduktion seiner Pathogenität einher. Insbesondere wurde festgestellt, dass eine bestimmte ZinkMetalloprotease nicht mehr sekretiert werden konnte (LILES et al., 1999). Inwieweit solch ein Typ II-ähnliches Sekretionssystem in C. tetani funktionsfähig ist, könnte auch im Hinblick auf die Erforschung des Exports des Tetanus-Toxins von Interesse sein. 


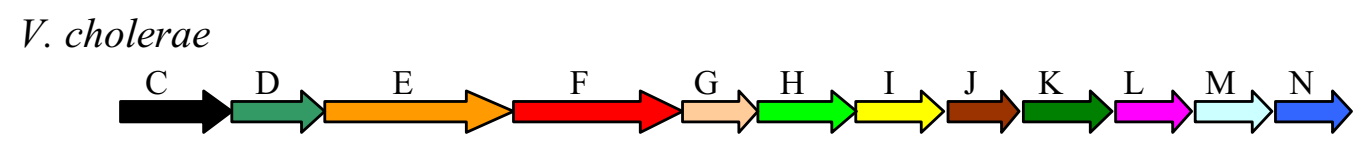

C. tetani

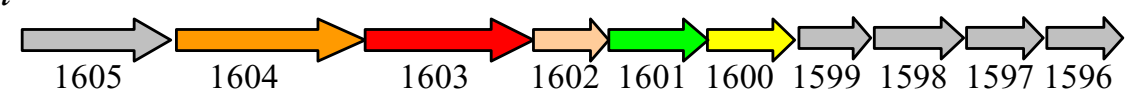

\begin{abstract}
Abb. 28: Vergleich des Genclusters für das Typ II-Sekretionssystem in $V$. cholerae mit einem ähnlichen Gencluster in $C$. tetani

Die Farben spiegeln die Homologien zwischen $C$. tetani und $V$. cholerae wider. In grau: Proteine mit unbekannter Funktion, die nur in $C$. tetani, $C$. acetobutylicum und $C$. botulinum gefunden wurden.
\end{abstract}

\title{
3.4.13 Regulatorische Funktionen
}

C. tetani kommt normalerweise als harmloses Bakterium im Boden vor. Der Eintritt des Organismus über Wundinfektionen in den Säugetierwirt kann mit der Ausprägung eines pathogenen Phänotyps einhergehen. Solche Änderungen des Phänotyps werden i. d. R. auf genetischer Ebene reguliert. Daher sollen in diesem Abschnitt mögliche, aus der Genomsequenz abgeleitete Elemente des regulatorischen Netzwerks vorgestellt werden.

\subsubsection{Transkriptionsregulatoren}

Im Genom von C. tetani können mindestens 127 Proteine identifiziert werden, die zu Transkriptionsregulatoren homolog sind und über eine DNA-bindende Domäne verfügen. Viele der Gene dieser Transkriptionsregulatoren lassen sich in unmittelbarer genetischer Nähe zu Transport-Systemen ausmachen (CTC163, CTC277, СТC483, СТC527, СТC533, СТC913, СТC1361, СТC1391, СТC1411, etc.). Andere Gene für Transkriptionsregulatoren befinden sich in unmittelbarer Nähe von Operonen, die z. B. für den Fettsäure-Abbau (CTC126), die Glykolyse (CTC377), den Butyrat-Weg (CTC707), einige S-Layer Proteine (CTC762), die Flagellum-Synthese (CTC1655), den Ethanolamin-Katabolismus (CTC2163), die Sec-System-Synthese (CTC2206), eine Citrat-Lyase (CTC2468), eine SulfitReduktase (CTC2488) oder für eine Glutamat-Mutase (CTC2569) kodieren. 


\subsubsection{Zwei-Komponenten-Systeme}

29 der DNA-bindenden Proteine sind als Response-Regulatoren Teil von ZweiKomponenten-Systemen, wobei die zwei Komponenten i. d. R. direkt benachbart kodiert sind. Ein typisches Zwei-Komponenten-System besteht neben dem Transkriptionsregulator noch aus einer Sensor-Histidin-Kinase, die meistens membranständig ist und i. d. R. ein Signal im Periplasma empfängt, was dann über eine Konformationsänderung zur Autophosphorylierung des Sensors führt. Oft ist noch ein periplasmatisches Bindeprotein zwischengeschaltet, das mit dem Signal interagiert und anschließend die Sensor-Histidin-Kinase aktiviert. In einem nächsten Schritt wird eine Phosphoryl-Gruppe des Sensors auf den Response-Regulator übertragen, der dadurch aktiviert wird und z. B. eine Bindung an bestimmte sequenzspezifische Bereiche der DNA eingehen kann. Diese liegen meistens in der Nähe von Promotoren, so dass eine Proteinbindung direkt die Aktivität der RNAPolymerase und damit den Expressionsspiegel des Gens oder des Operons beinflussen kann. Mit solchen Zwei-Komponentensystemen führen Bakterien eine adaptive Antwort auf Umweltsignale herbei. Als Beispiele sollen bakterielle Systeme wie Arc (aerobe/anaerobe Umschaltung), EnvZ/OmpR (Osmoregulation), Spo (Sporulation), Lyt (N-Acetylmuramoyl-L-Alanin-Amidase-Biosynthese), Nar (Nitrat-/Nitrit-Metabolismus), Pho (Phosphat-Regulation) und Vir (VirulenzAusbildnung) genannt werden.

Um erste Informationen darüber zu gewinnen, welche Gene oder Operone in $C$. tetani jeweils von diesen 29 Zwei-Komponenten-Systemen reguliert werden, wurden die gefundenen Homologien $\mathrm{zu}$ bereits untersuchten Systemen und die direkte genetische Nachbarschaft dieser Systeme betrachtet (Tabelle 13). Die zuletzt genannte Herangehensweise beruhte auf der empirischen Beobachtung, dass einige Zwei-Komponentensysteme direkt benachbarte Gene regulieren. Neben diesen Systemen gibt es aber auch solche, die mehrere im Genom verstreut liegende Gene regulieren, z. B. das VirR/VirS-System aus C. perfringens (BA-THEIN et al., 1996). 
Tabelle 13: Die in der Genomsequenz von $C$. tetani identifizierten Zwei-Komponentensysteme, ihre Homologien und ihre genetische Nachbarschaft (RR, Response-Regulator; SHK, Sensor-Histidin-Kinase)

\begin{tabular}{|c|c|c|}
\hline System & Homologie & benachbart-liegende Gene \\
\hline CTC189/191 & RR: ResD (respiratorische Kontrolle) & periplasmatische Endopeptidase \\
\hline СТC392/393 & $\begin{array}{l}\text { RR/SHK: BacR/BacS (Peptid-Antibiotika } \\
\text { (z. B. Bacitracin)-Synthese und -Resistenz) }\end{array}$ & $\begin{array}{l}\text { ABC-Transporter-System (Peptid- } \\
\text { oder Protein-Transporter) }\end{array}$ \\
\hline CTC411/412 & $\begin{array}{c}\text { RR/SHK: VirI/VirJ (Regulation der Toxin- } \\
\text { Synthese) }\end{array}$ & - \\
\hline CTC455/456 & RR ist rRNA-Methylase & - \\
\hline СТC597/598 & $\begin{array}{l}\text { RR: BacR (Peptid-Antibiotika (z. B. } \\
\text { Bacitracin)-Synthese und -Resistenz) }\end{array}$ & $\begin{array}{l}\text { konserviertes Protein; Glycerin- } \\
\text { Dehydrogenase }\end{array}$ \\
\hline СТC628/629 & $\begin{array}{l}\text { RR/SHK: SpaR/SpaK (Subtilin- } \\
\text { Biosynthese und -Resistenz) }\end{array}$ & $\begin{array}{l}\text { ABC-Transporter-System SpaEFG } \\
\text { (Subtilin-Export) }\end{array}$ \\
\hline СТC805/806 & $\begin{array}{c}\text { RR/SHK: VanR/VanS (Glycopeptid (z. B. } \\
\text { Vancomycin)-Resistenz) }\end{array}$ & Transport-Protein \\
\hline СТC848/849 & $\begin{array}{l}\text { RR/SHK: GtcR/GtcS (Peptid-Antibiotika- } \\
\text { Biosynthese und Resistenz) }\end{array}$ & $\begin{array}{l}\text { periplasmatische Protease } \\
\text { (Hitzeschock-Protein) }\end{array}$ \\
\hline СТC $872 / 873$ & $\begin{array}{c}\text { SHK: Arc (Regulation des Switches } \\
\text { zwischen aerober/anaerober Respiration) }\end{array}$ & Efflux-ATPase für Kupfer \\
\hline СТC924/925 & $\begin{array}{l}\text { RR: Regulation des Katabolismus von } \\
\text { Purinen; SHK ist Chemotaxis-Protein }\end{array}$ & Zink-abhängige Peptidase \\
\hline СТC934/935 & SHK: LytS (Regulation der Zell-Autolyse) & $\begin{array}{c}\text { Pyruvat-Formiat-Lyase; Parathion- } \\
\text { Hydrolase }\end{array}$ \\
\hline СТC949/950 & $\begin{array}{c}\text { RR/SHK: VirR/VirS (Regulation von } \\
\text { Virulenzfaktoren) }\end{array}$ & $\begin{array}{l}\text { Chemotaxis-Protein; } \\
\text { Transkriptionsaktivator }\end{array}$ \\
\hline CTC1130/1131 & $\begin{array}{c}\text { RR/SHK: PhoR/PhoP (Regulation des } \\
\text { Phosphat-Haushalts) }\end{array}$ & ABC-Transportsystem für Phosphat \\
\hline CTC1211/1212 & $\begin{array}{l}\text { RR: LytR (Regulation der Zell-Autolyse); } \\
\text { SHK ist Chemotaxis-Protein }\end{array}$ & anaerobe Sulfit-Reduktase \\
\hline CTC1420/1421 & $\begin{array}{c}\text { RR/SHK: YycF/YycG (Regulation der } \\
\text { Zellteilung) }\end{array}$ & $\begin{array}{l}\text { ABC-Transporter (Peptid- } \\
\text { Transporter) }\end{array}$ \\
\hline CTC1481/1482 & $\begin{array}{c}\text { RR/SHK: FeuP/FeuQ (Regulation der } \\
\text { Eisen-Aufnahme) }\end{array}$ & $\begin{array}{c}\text { konserviertes Protein mit }[4 \mathrm{Fe} 4 \mathrm{~S}]- \\
\text { Cluster mit } 4 \text { transmembranen } \\
\text { Helices }\end{array}$ \\
\hline CTC1490/1491 & - & $\begin{array}{l}\text { Hitzeschock-Protein HtpG } \\
\text { (Chaperon); Membranprotein }\end{array}$ \\
\hline CTC1523/1524 & $\begin{array}{l}\text { RR/SHK: DcuR/DcuS (C4-Dicarboxylat- } \\
\text { stimulierte Regulation der Gene für } \\
\text { anaerobe Fumarat-Respiration) }\end{array}$ & $\begin{array}{l}\text { lösliche Flavocytochrom c-Fumarat- } \\
\text { Reduktase }\end{array}$ \\
\hline
\end{tabular}




\begin{tabular}{|c|c|c|}
\hline CTC1804/1805 & $\begin{array}{l}\text { RR/SHK: BacR/BacS (Peptid-Antibiotika } \\
\text { (z. B. Bacitracin)-Synthese und -Resistenz) }\end{array}$ & $\begin{array}{l}\text { ABC-Transporter (Peptid- } \\
\text { Transporter) }\end{array}$ \\
\hline CTC1818/1819 & - & $\begin{array}{l}\text { ABC-Transporter; RNA } \\
\text { Polymerase-Sigmafaktor }\end{array}$ \\
\hline CTC1848/1849 & - & $\begin{array}{c}\text { lösliche Flavocytochrom c-Fumarat- } \\
\text { Reduktase }\end{array}$ \\
\hline CTC1857/1858 & $\begin{array}{l}\text { RR : SinR (Regulation des Eintritts in die } \\
\text { stationäre Phase; Antwort auf } \\
\text { Nährstoffmangel; Repressor des Spo0A- } \\
\text { Gens); SHK ist Chemotaxis-Protein }\end{array}$ & - \\
\hline CTC1905/1906 & $\begin{array}{l}\text { RR: BacR; VanR (Peptid-Antibiotika- } \\
\text { Synthese und -Resistenz) }\end{array}$ & $\begin{array}{c}\text { ABC-Transporter (Peptid- } \\
\text { Transporter) }\end{array}$ \\
\hline CTC1918/1919 & $\begin{array}{l}\text { RR: BacR; VanR (Peptid-Antibiotika- } \\
\text { Synthese und -Resistenz) }\end{array}$ & $\begin{array}{c}\text { ABC-Transporter (Peptid- } \\
\text { Transporter) }\end{array}$ \\
\hline CTC1951/1953 & $\begin{array}{l}\text { RR/SHK: PhoR/PhoP (Regulation des } \\
\text { Phosphat-Haushalts) }\end{array}$ & - \\
\hline CTC1978/1979 & $\begin{array}{l}\text { RR/SHK: LytR/LytS (Regulation der Zell- } \\
\text { Autolyse) }\end{array}$ & Carbon-Starvation Protein CstA \\
\hline CTC2155/2156 & $\begin{array}{l}\text { RR/SHK: VanR/VanS (Glycopeptid (z. B. } \\
\text { Vancomycin)-Resistenz) }\end{array}$ & DNA-Reparaturprotein HexA \\
\hline СТC2178/2179 & $\begin{array}{l}\text { RR/SHK: EutR/EutS (Regulation des } \\
\text { Abbaus von Ethanolamin) }\end{array}$ & $\begin{array}{c}\text { Ethanolamin-Katabolismus-Proteine } \\
\text { EutA/EutP }\end{array}$ \\
\hline CTC2322/2323 & $\begin{array}{l}\text { RR/SHK: AtoC/AtoS (Regulation des } \\
\text { Acetoacetat-Metabolismus) }\end{array}$ & $\begin{array}{l}\mathrm{Na}^{+} / \text {Glutamat-Symporter; V-Typ- } \\
\text { ATPase-Proteine }\end{array}$ \\
\hline
\end{tabular}

Die in Tabelle 13 aufgelisteten Befunde für die Zwei-Komponentensysteme in $C$. tetani offenbarten einige interessante Aspekte. So konnten zwei Systeme, CTC411/412 und CTC949/950, gefunden werden, die Homologien zu Systemen aus C. perfringens zeigten, welche die Synthese von Virulenzfaktoren regulieren. VirR/VirS stellt dabei das am besten untersuchte System dar: es reguliert u. a. die Expression von Virulenzfaktoren wie Phospholipase C, Perfringolysin O, Collagenase und eine Sialidase (CHEUNG \& ROOD, 2000). Dabei wird die Expression von Perfringolysin O direkt durch Bindung von VirR am entsprechenden Promotor reguliert, während die anderen Toxin-Gene wahrscheinlich durch eine VirR-regulierte RNA reguliert werden (SHIMIZU et al., 2002b). Das VirR/VirSähnliche System in C. tetani wird derzeit im Göttinger Institut für Mikrobiologie und Genetik durch Elke Raade untersucht. Über das VirI/VirJ-System liegen keine 
veröffentlichten Daten vor. Es wird allerdings als negativer Regulator von extrazellulären Toxinen angesehen (OHTANI et al., 1999).

Ein weiterer interessanter Aspekt ist, dass in einigen Fällen ein Zusammenhang zwischen den Funktionen der homologen Systeme und den Funktionen der benachbart-liegenden Gene hergestellt werden konnte. So konnten sechs Systeme (CTC392/393, CTC628/629, CTC805/806, CTC1804/1805, CTC1905/1906, CTC1918/1919) erkannt werden, die zur BacR/BacS- bzw. VanR/VanS-Familie zu rechnen sind, welche Gene zur Ausbildung einer Resistenz gegen Peptid-Antibiotika regulieren. Stromabwärts der Gene dieser Systeme befinden sich in C. tetani Gene für Peptid-ABC-Transporter, die möglicherweise als Peptid-Efflux-Systeme arbeiten können. Ein weiteres Beispiel ist das System CTC1523/1524, dessen Homologon DcuR/DcuS aus E. coli Gene für die anaerobe Fumarat-Atmung als adaptive Antwort auf das Vorhandensein von C4-Dicarbonsäuren im Medium reguliert (JANAUSCH, et al., 2002). In Bezug dazu findet man stromabwärts in C. tetani das Gen für die Flavocytochrom c-Fumarat-Reduktase. Weitere Beispiele sind das mögliche Phosphat-Regulationssystem CTC1130/1131 sowie das System CTC1481/1482, welches Gene für die Aufnahme von Eisen regulieren könnte.

\subsubsection{RNA-Polymerase-Sigmafaktoren}

Als nächstes wurde nach RNA-Polymerase-Sigmafaktoren gesucht, um zu ermitteln, welche alternativen Sigmafaktoren neben dem Standard-Sigmafaktor (RpoD, Sigma70) zur Verfügung stehen. Die Verwendung von alternativen Sigmafaktoren ermöglicht die einheitliche Regulation der Expression ganzer Gengruppen (Regulons). Es konnten im Genom von C. tetani 19 Sigmafaktoren identifiziert werden. Tabelle 14 zeigt die Ähnlichkeitsvergleiche dieser Faktoren zu Sigmafaktoren aus B. subtilis und anderen Organismen. Dadurch konnten erste Hinweise auf die Art der Regulons erhalten werden, welche von den verschiedenen Sigmafaktoren reguliert werden. 
Tabelle 14: Die Sigmafaktoren in C. tetani, deren Homologien und mögliche regulatorische Bedeutungen

\begin{tabular}{|c|c|c|}
\hline ORF-Name & $\begin{array}{c}\text { Homologie zu } B \text {. subtilis u. a. / } \\
\text { vorhandene Domänen }\end{array}$ & $\begin{array}{l}\text { mögliche regulatorische } \\
\text { Bedeutung }\end{array}$ \\
\hline СТC376 & RpoN (Sigma-54) & $\begin{array}{c}\text { primärer alternativer Faktor } \\
\text { (Fermentationsmetabolismus, } \\
\text { N-Metabolismus) }\end{array}$ \\
\hline СТC553, СТC665 & $\begin{array}{c}\text { SigW, ECF*-Familie (Sigma-70- } \\
\text { Faktor-Domäne) }\end{array}$ & unbekannt \\
\hline $\begin{array}{l}\text { CTC608, СТC618, } \\
\text { СТC688, СТC } 1790\end{array}$ & $\begin{array}{l}\text { SigV, ECF-Familie (Sigma-70- } \\
\text { Faktor-Domäne) }\end{array}$ & unbekannt \\
\hline СТC867, СТC2010 & RpoD (Sigma-70) & $\begin{array}{l}\text { Standard-Sigmafaktor } \\
\text { (Housekeeping-Gene) }\end{array}$ \\
\hline СТC1066 & Sigma-28 & Sporulation (Stadium IV) \\
\hline CTC1126 & Sigma-E & Sporulation (Stadium II) \\
\hline CTC 1128 & Sigma-G & Sporulation (Stadium III) \\
\hline $\begin{array}{l}\text { CTC1433, CTC1786, } \\
\text { CTC1788, CTC1817 }\end{array}$ & $\begin{array}{c}\text { ECF-Familie (Sigma-70-Faktor- } \\
\text { Domäne) }\end{array}$ & unbekannt \\
\hline CTC1653 & FliA & $\begin{array}{c}\text { Flagellum-Synthese / Motilität / } \\
\text { Chemotaxis }\end{array}$ \\
\hline СТC2246 & Sigma-F & Sporulation (Stadium II) \\
\hline CTC2617 & Sigma-H & $\begin{array}{c}\text { Einleitung in stationäre Phase / } \\
\text { Sporulation }\end{array}$ \\
\hline
\end{tabular}

*ECF: extracytoplasmatische Funktion

Die Anzahl der in C. tetani gefundenen Sigmafaktoren stimmt in etwa mit der in den Genomen von B. subtilis (18) und C. acetobutylicum (17) gefundenen Anzahl überein (KUNST et al., 1997; NÖLLING et al., 2001). Allgemein kann festgestellt werden, dass die Zahl der Sigmafaktoren in Genomen von Sporenbildnern weitaus größer ist als in anderen Genomen wie z. B. in dem von Staphylococcus aureus, in dem lediglich 2 Sigmafaktoren identifiziert werden können. Es ist bekannt, dass die Sporulation mittels einer Kaskade von alternativen Sigmafaktoren reguliert wird. An dieser Stelle sollte die Besonderheit erwähnt werden, dass der hier verwendete $C$. tetani Stamm E88 eine nicht-sporulierende Variante des Stammes Massachusetts ist. Anhand der Genomsequenz kann nicht geklärt werden, warum der Stamm E88 die Fähigkeit zur Sporulation eingebüßt hat, da auf genetischer Ebene ein ähnlicher Satz an Sporulationsfaktoren vorhanden ist wie in den sequenzierten Sporenbildnern $C$. acetobutylicum und C. perfringens. Kurz erwähnt sei hier auch die Beobachtung, dass sich der Satz an Sporulationsgenen zwischen B. subtilis und den drei 
sequenzierten Clostridien stark unterscheidet: die Clostridien besitzen viel weniger Sporulationsgene (NÖLLING et al., 2001). Es fehlen u. a. die SpoV-Gene sowie regulatorische Elemente wie das Zwei-Komponenten-System SpoOB/OF, die Histidin-Kinasen KinABCDE und sporulationsrelevante Phosphatasen der RapFamilie. Die genannten Elemente regulieren in B. subtilis erwiesenermaßen den Eintritt in die stationäre Phase und den Beginn der Sporulation.

Die Identifizierung weiterer von C. tetani verwendeter Regulationsmechanismen wie Antisense-RNAs oder posttranslationale Mechanismen ist nahezu unmöglich, wenn lediglich die Genomsequenz betrachtet wird. Andere Techniken wie etwa die Microarray-Technik oder Proteomanalysen mittels der 2D-Gelelektrophorese müssen hinzugezogen werden. Dass C. tetani auch andere Regulationsmechanismen benutzt, ist bei den Untersuchungen zum Tetanus-Toxin entdeckt worden: zur Aktivierung des Toxins muss es posttranslational modifiziert werden, was durch eine proteolytische Spaltung des $150 \mathrm{kDa}$ großen Toxins in zwei Proteinketten geschieht (s. 4.2.1.1).

\subsubsection{Mobile Elemente und Prophagen}

Im Genom von $C$. tetani lassen sich im Vergleich zu Genomen von Enterobakterien sehr wenig mobile DNA-Elemente ausmachen. So konnten 19 Genregionen identifiziert werden, die Transposase-ähnliche Proteine kodieren. 9 davon sind 100\%ige Kopien desselben Elements. Jede Kopie besteht dabei aus zwei ORFs: ORF A kodiert ein Protein mit der Integrase-Domäne RVE, während ORF B ein Transposase-Fragment zu sein scheint. Ähnliche Systeme gibt es auch in E. coli (IS150) und $V$. cholerae. Die höchsten Homologien treten allerdings zu Systemen aus Marinococcus halophilus und Oceanobacillus iheyensis auf (ERGO, interne Datenbank). Die Mehrzahl dieser Transposasegene ist wahrscheinlich nicht mehr funktionell, da der ORF durch eine Leserasterverschiebung, die von Insertionen, Deletionen und Punktmutationen herrühren könnte, unterbrochen ist.

Des weiteren fallen im Genom drei Bereiche auf, die auffallend viele Phagenrelevante Proteine kodieren, und wahrscheinlich cryptische Prophagen 
repräsentieren. Der erste Bereich umfasst etwa $47 \mathrm{~kb}$ und enthält 49 ORFs (CTC1067-CTC1116). Dieser potentielle Prophage existiert nicht in den Genomen von $C$. acetobuylicum und $C$. perfringens. Stattdessen zeigen die meisten Proteine Homologien zu hypothetischen oder Phagen-relevanten Proteinen aus C. botulinum. Die anderen zwei Bereiche von etwa 39 und $41 \mathrm{~kb}$ umfassen 35 (CTC1532CTC1567) bzw. 47 ORFs (CTC2105-CTC2152). Wiederum kodieren diese ORFs lediglich hypothetische oder Phagen-relevante Proteine. Die Inserierung dieser Phagen ins Genom von C. tetani könnte auch die in Abbildung 19 ersichtliche Beobachtung erklären, dass Replikationsursprung und -terminus nicht genau eine halbe Genomlänge voneinander entfernt sind. 


\section{Diskussion}

Im vorangegangenen Ergebnis-Teil dieser Arbeit wurde ein Einstieg in die Sequenzanalyse des Genoms von C. tetani versucht. Es wurden das genetische Potential des Organismus in Bereichen wie Virulenz, Stoffwechsel, Bioenergetik, Transport, Regulation und Proteinsekretion vorgestellt und bemerkenswerte Einzelheiten und Besonderheiten erläutert. Dabei ist oft auch der Versuch unternommen worden, einen Vergleich zwischen den in C. tetani gefundenen Daten und den Genomdaten anderer Clostridien herzustellen. So z. B. wurden das Vorkommen und die Zusammensetzung verschiedener Gencluster unter den Clostridien verglichen.

Hier soll nun ein genereller, genomweiter Vergleich zwischen verschiedenen Arten der Gattung Clostridium durchgeführt und die erhaltenen Ergebnisse diskutiert werden. Im letzten Teil der Diskussion wird dann das genetische Potential von $C$. tetani zusammengefasst.

\subsection{Vergleichende Sequenzanalyse der Genome von pathogenen und nicht-pathogenen Clostridien}

\subsubsection{Stand der Genomforschung von Organismen der Gattung Clostridium}

Zu Beginn der Arbeiten zur Sequenzierung des Genoms von C. tetani lag noch keine komplette Genomsequenz von einem Organismus der Gattung Clostridium vor. Erst im August 2001 wurde die Genomsequenz von C. acetobutylicum ATCC824 veröffentlich, einem nicht-pathogenen Organismus, der Lösungsmittel wie Aceton, Butanol und Ethanol produzieren kann (Genome Therapeutics Corporation (GTC)Sequencing Center; NÖLLING et al., 2001). Es folgte im Januar 2002 die Veröffentlichung der Genomsequenz von $C$. perfringens 13, einem pathogenen Organismus, der im Menschen Gasgangrän (clostridielle Myonekrose) und nekrotische Enteritis und Diarrhö verursachen kann (Institute of Basic Medical Sciences, University of Tsukuba, Japan; SHIMIZU et al., 2002). 
Als nächstes und bisher letztes konnte das Genom von C. tetani im Rahmen dieser Arbeit geschlossen werden, die entsprechende Sequenz ist in der NCBI-Datenbank abgelegt (BRÜGGEMANN et al., 2003). Daten über diese drei Genome sind in Tabelle 8 zusammengefasst (s. 3.4.1).

Zur Zeit werden noch weitere Genome clostridieller Organismen sequenziert. Das Sanger-Zentrum in Cambridge, England, sequenziert die Genome der pathogenen Organismen C. difficile Stamm 630 und C. botulinum A (ATCC3502).

C. difficile 630 ist einer der am weitesten verbreiteten nosocomialen Erreger, also solcher, die in erste Linie in Krankenhäusern auftreten. Der Organismus kann verschiedene Krankheiten wie Antibiotika-assoziierte Diarrhoe bis hin zu lebensbedrohlicher pseudomembranöser Kolitis verursachen. Das Genomprojekt befindet sich zur Zeit im letzten Stadium (2 verbliebende Sequenzlücken, Stand: 08.11.2002). Die vorläufige Gesamtgenomlänge beträgt 4,298 Mb.

C. botulinum Stamm A (ATCC3502) produziert das Botulinus-Toxin A, das mit dem Tetanus-Toxin in Sequenz, Struktur und Wirkungsweise eng verwandt ist. Das Botulinus-Toxin verursacht die folgenschwerste Lebensmittelvergiftung, den Botulismus, welcher $\mathrm{zu}$ einer tödlichen Atemlähmung führen kann. Das Genomprojekt befindet sich derzeit ebenfalls in der letzten Phase: 63114 Einzelsequenzen assemblieren $\mathrm{zu} \quad 20$ Contigs mit einer vorläufigen Gesamtgenomgröße von 3,951 Mb (Stand:08.11.2002). Der aktuelle Stand der Genomsequenzierung ist auf den Web-Seiten (http://www.sager.ac.uk) des SangerZentrums einsehbar. Zusätzlich hat die Öffentlichkeit unter ftp://ftp.sanger.ac.uk /pub/pathogens/cb/ freien Zugang zu vorläufigen C. botulinum-Sequenzdaten.

Ein weiterer pathogener $C$. perfringens-Stamm wird derzeit von TIGR (The Institute of Genomic Research, Rockville, USA) sequenziert. Dabei handelt es sich um $C$. perfringens ATCC13124. Es sind derzeit noch 9 Contigs vorhanden, die zusammen 3,266 Mb ergeben (Stand: 16.05.2002).

Der Vollständigkeit halber sei erwähnt, dass auch die Rohsequenzierung des Genoms von C. thermocellum ATCC27405 durchgeführt wurde, einem thermophilen, Cellulose-abbauenden Organismus (Joint Genome Institute (JGI), California, USA). Der Datensatz besteht aus 469 Contigs, die zusammen eine vorläufige Genomgröße von 3,654 Mb ergeben (Stand: 17.09.2002). 


\subsubsection{Verwandtschaft clostridieller Genome}

4.1.2.1 Phylogenetische Betrachtungen anhand von 16S rRNA-Sequenzen

Die Organismen der Gattung Clostridium sind als Gram-positive, anaerobe und Endosporen-bildende Bakterien charakterisiert, die nicht zur dissimilatorischen Sulfat-Reduktion befähigt sind (GOTTSCHALK et al., 1981). Die Auflistung der Genomprojekte im letzten Abschnitt deutete es aber bereits an: die Gattung Clostridium ist sehr heterogen. Die Genomgrößen unterscheiden sich z. T. erheblich. Während das Chromosom in C. tetani nur 2,799 $\mathrm{Mb}$ groß ist, besteht z. B. das Genom von C. difficile aus 4,298 Mb. Phylogenetische Studien mit 16S rRNASequenzen revidierten das bis dahin diffuse Wissen über die Verwandtschaftsbeziehungen der Clostridien (COLLINS et al., 1994). Es wurde eine extreme Heterogenität der Gattung festgestellt. So konnten 19 verschiedenen Cluster definiert werden. Viele Clostridien sind phylogenetisch gesehen mit Sporenbildenden und Nicht-Sporen-bildenden Organismen aus anderen Gattungen verwandt. Trotzdem geht man davon aus, dass die Arten der Gattung Clostridium von einem gemeinsamen Vorfahren abstammen, welcher sehr früh in der Evolution Gram-positiver Bakterien auftrat (STACKEBRANDT \& RAINEY, 1997). Die meisten pathogenen Arten, darunter C. tetani, C. perfringens und C. botulinum, aber auch der nicht-pathogene Organismus C. acetobutylicum sind im Cluster I eingeordnet, das in Abbildung 29 wiedergegeben ist. 


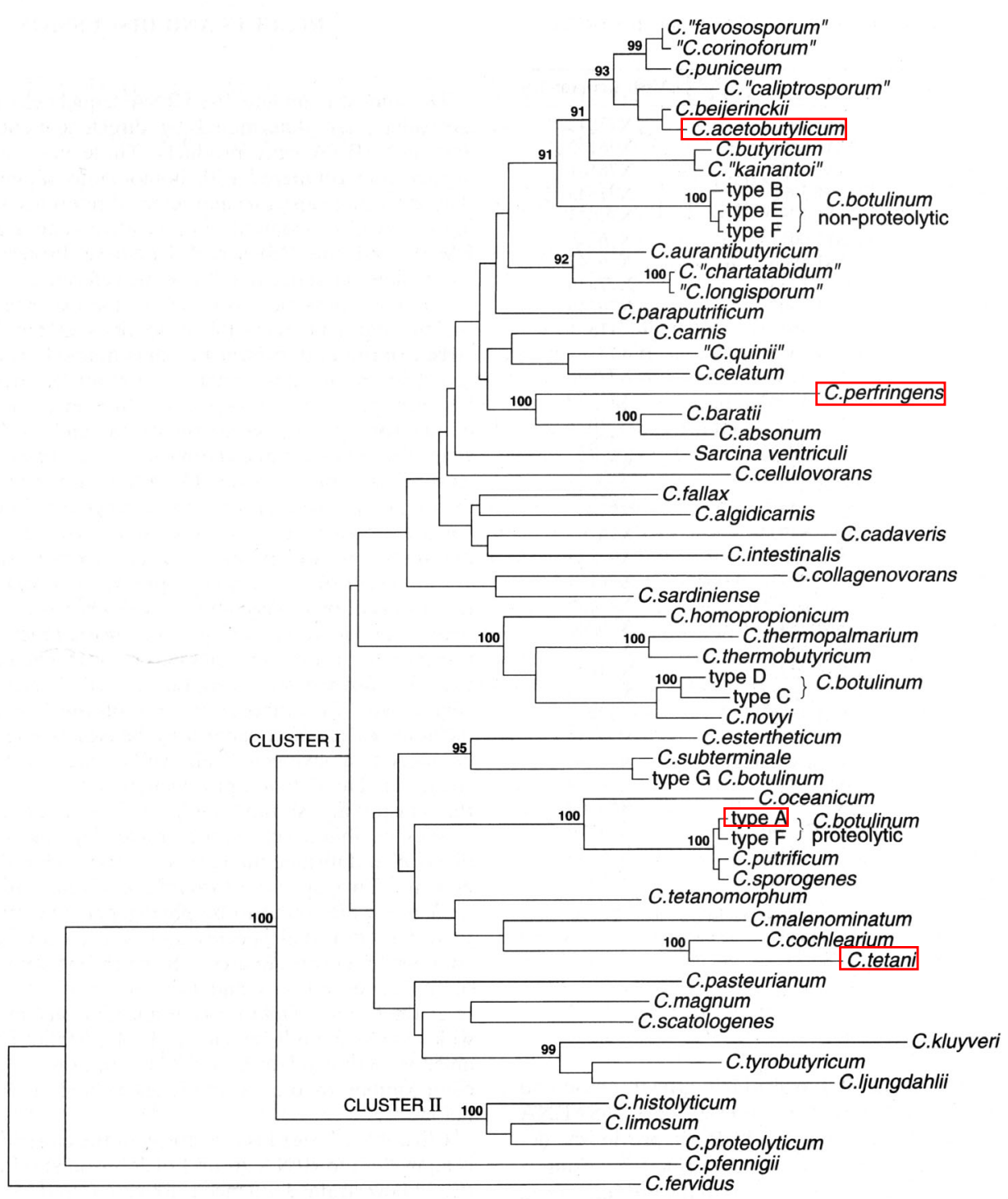

\section{Abb. 29: Dendogramm der Verwandtschaftsbeziehungen innerhalb der Organismen des Clostridien-Clusters I}

(Abbildung aus COLLINS et al., 1994)

4.1.2.2 Phylogenetische Betrachtungen anhand von TriosephosphatIsomerase- und Elongationsfaktor EF-Tu-Sequenzen

Nachfolgend sollen nun speziell die sequenzierten Clostridien und verwandte sequenzierte Organismen phylogenetisch anhand anderer Vergleichsmoleküle als der $16 \mathrm{~S}$ rRNA in Beziehung gesetzt werden. Als Vergleichskriterien wurden die Proteinsequenzen der Triosephosphat-Isomerase (Abb. 30) und des Elongationsfaktors EF-Tu (Abb. 31) gewählt, da diese Proteine sehr konserviert sind und in letzter Zeit des öfteren als Vergleichsmoleküle in phylogenetischen Studien 
benutzt wurden (CANBACK et al., 2002; DHALLUIN et al., 2002; JENKINS \& FUERST, 2001).

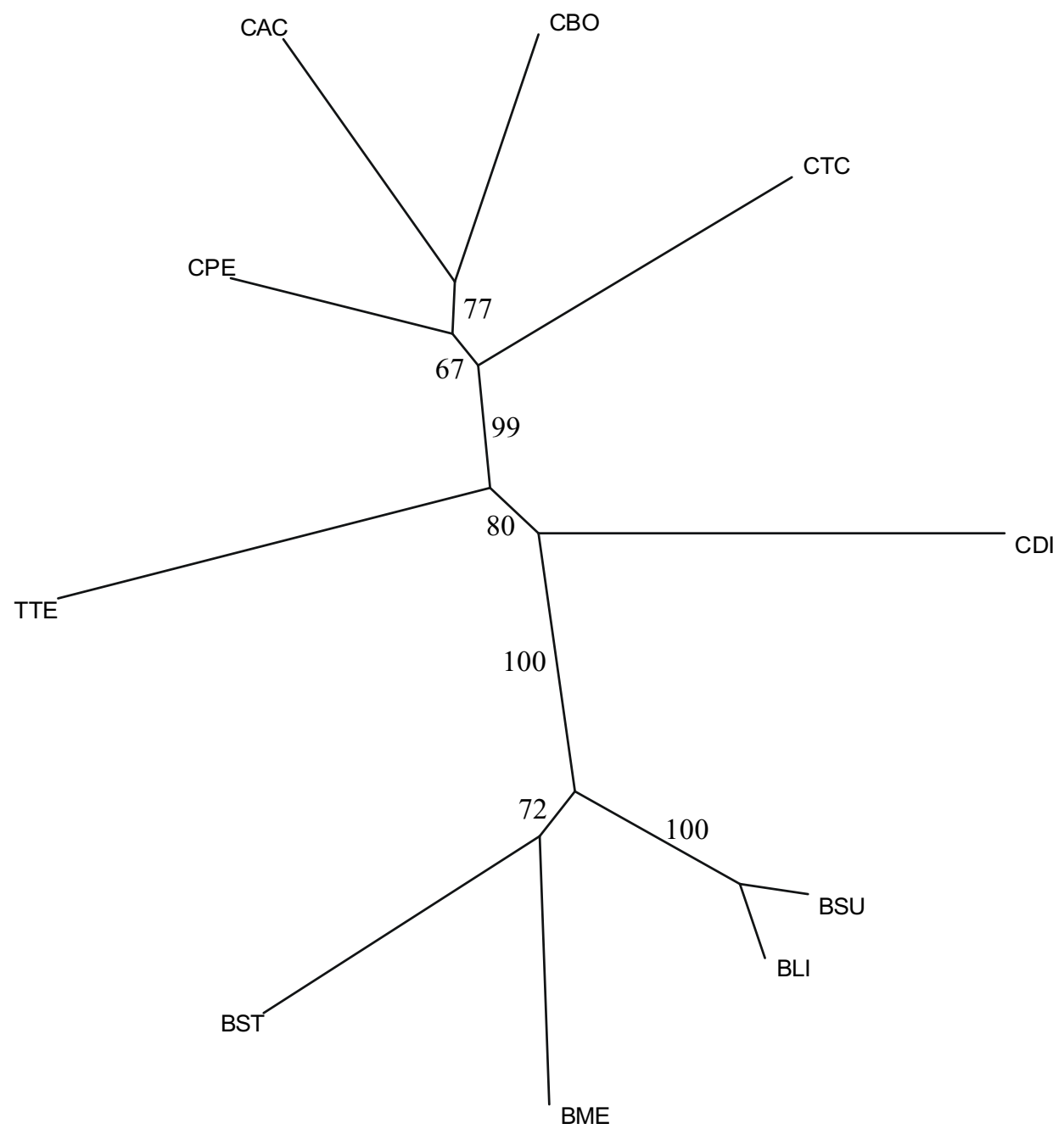

0.1

Abb. 30: Phylogenetische Beziehung zwischen $C$. tetani und verwandten Organismen anhand der Proteinsequenzen der Triosephosphat-Isomerase Ausgewählt wurden diejenigen 10 Organismen, die bezüglich der Triosephosphat-Isomerase die höchsten Sequenzähnlichkeiten zur Proteinsequenz aus C. tetani zeigten. Der Neighbour-joining (NJ)-Tree wurde wie in der Legende zur Abb. 9 (s. 3.2.6.2) erklärt berechnet. Die Nummern an den Gabelungen bedeuten in \% die Häufigkeit, mit der eine solche Gabelung unter 1000 berechneten NJ-Trees erhalten wurde. Abkürzungen: BLI, B. licheniformis; BME, B. megaterium; BST, $B$. stearothermophilus; BSU, B. subtilis; CAC, C. acetobutylicum; CBO, C. botulinum A; CDI, C. difficile; CPE, C. perfringens; CTC, C. tetani; TTE, Thermoanaerobacter tengcongensis. 




Abb. 31: Phylogenetische Beziehung zwischen $C$. tetani und verwandten Organismen anhand der Proteinsequenzen des Elongationsfaktors EF-Tu Ausgewählt wurden diejenigen 12 Organismen, die bezüglich des Elongationsfaktors EF-Tu die höchsten Sequenzähnlichkeiten zur Proteinsequenz aus C. tetani zeigten. Der Neighbour-joining-Tree wurde wie in der Legende zur Abb. 9 (s. 3.2.6.2) erklärt berechnet. Abkürzungen: siehe Legende Abb. 30; weitere Organismen: CTH, C. thermocellum; DHA, Desulfitobacterium halfniense; FNU, Fusobacterium nucleatum; NME, Neisseria meningitidis; TMA, Thermotoga maritima.

Ein interessanter Aspekt dieser phylogenetischen Studien ist, dass die Gruppe bestehend aus $C$. acetobutylicum, C. botulinum A, C. perfringens und C. tetani einen relativ großen Abstand vom Rest der Sequenzen zeigt (bei 1000 Replicons 99\%ige bzw. 100\%ige Separation). Innerhalb dieser Gruppe sind C. botulinum A und $C$. acetobutylicum am engsten verwandt, was der von COLLINS et al. (1994) festgelegten Verwandtschaft widerspricht (Abb. 29). Auffallend ist der relativ große phylogenetische Abstand von $C$. difficile zu den anderen betrachteten Clostridien. Bei der relativen Nähe von C. tetani zu C. botulinum A ist die Frage interessant, 
welche zusätzlichen Funktionen $C$. botulinum A auszeichnet, der ein um mehr als $1000 \mathrm{~kb}$ größeres Genom als C. tetani besitzt. Die Ergebnisse der phylogenetischen Betrachtungen basierend auf multiplen Sequenzalignments der TriosephosphatIsomerase und des Elongationsfaktors EF-Tu sind kohärent mit den im Laufe der Annotation des C. tetani-Genoms beobachteten Ähnlichkeiten. Es wurde dabei deutlich, dass die meisten Proteine die höchste Ähnlichkeit zu Proteinen aus folgenden Organismen hatten - und zwar häufig gemäß der genannten Reihenfolge: C. botulinum - C. perfringens - C. acetobutylicum, Thermoanaerobacter tengcongensis, C. difficile, B. anthracis, B. cereus, Fusobacterium nucleatum, B. licheniformis, B. halodurans, B. subtilis, Xyella fastidosa, L. monocytogenes, Enterococcus faecium und andere.

Überraschend ist die nahe Verwandtschaft zum Gram-negativen und thermophilen Organismus Thermoanaerobacter tengcongensis, die auch schon von COLLINS et al. (1994) beobachtet wurde. Der Organismus ist vor kurzem vollständig sequenziert worden (BAO et al., 2002). Thermoanaerobacter tengcongensis ist obligat anaerob und bildet keine Sporen. Die optimale Wachstumstemperatur dieses primär saccharolytisch lebenden Bakteriums liegt bei $75^{\circ} \mathrm{C}$.

\subsubsection{Genomweiter Vergleich von $C$. acetobutylicum und $C$. perfringens mit C. tetani}

4.1.3.1 Vergleich der Genome auf Proteinebene

Die zur Verfügung stehenden veröffentlichten Genomsequenzen von $C$. acetobutylicum, C. perfringens und $C$. tetani sollen nun genomweit verglichen werden. Die noch nicht geschlossenen Genome von C. difficile und C. botulinum wurden aufgrund der noch vorhandenen Sequenzlücken und der nicht gesicherten Sequenzqualität an dieser Stelle nicht betrachtet. Der Vergleich wurde auf Proteinebene vollzogen, in dem alle Proteinsequenzen aus $C$. tetani mit denjenigen aus $C$. acetobutylicum und $C$. perfringens abgeglichen wurden. Abbildung 32 gibt nun genomweit die Homologien unter den ORFs der drei Clostridien wieder. Es lassen sich sieben Gruppen von ORFs differenzieren. 


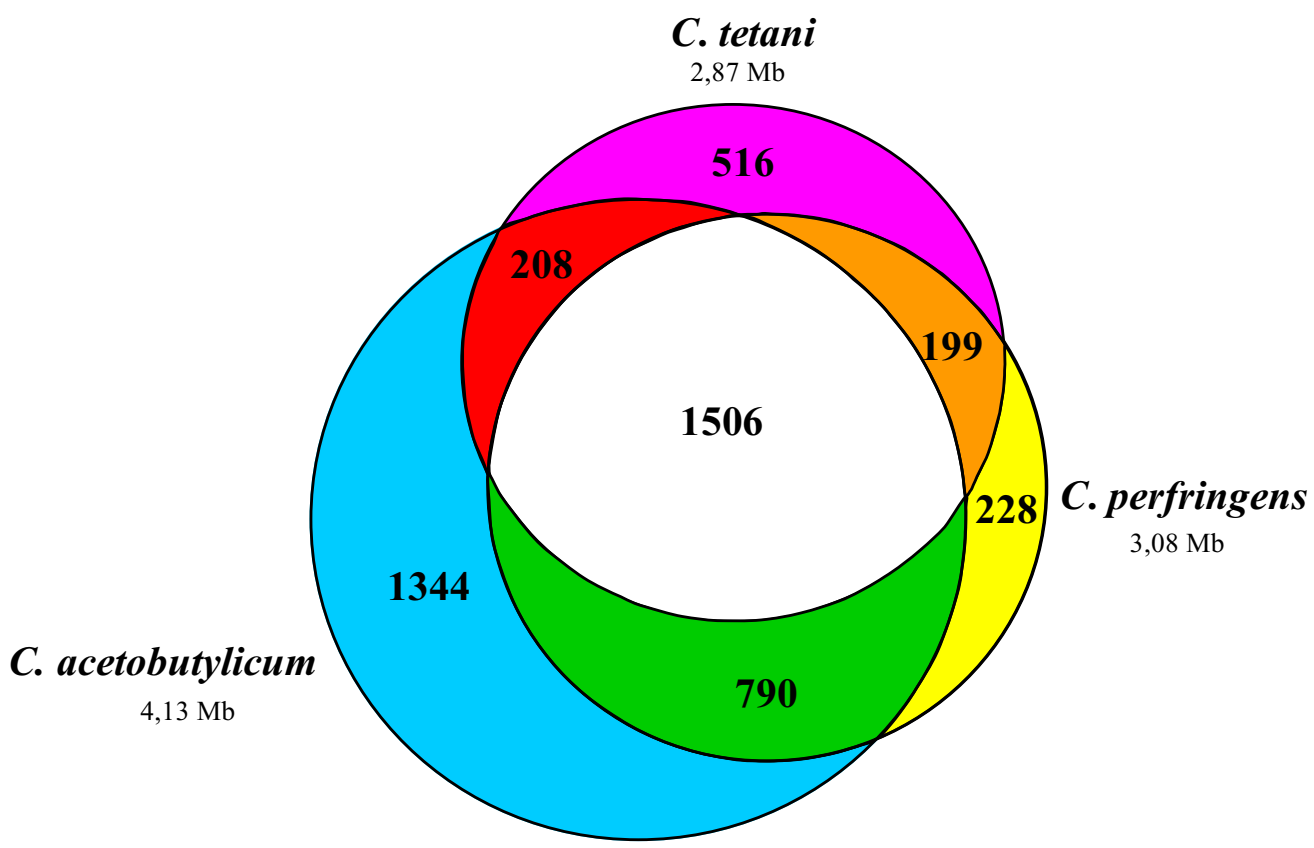

Abb. 32: Auftreten homologer ORFs in C.tetani, C. perfringens und C. acetobutylicum

Farbkodierung der vier $C$. tetani-ORF-Gruppen: orange: $C$. tetani-ORFs, die Homologons im Genom von $C$. perfringens, aber nicht in dem von $C$. acetobutylicum haben; pink: $C$. tetani-ORFs, die nicht in den beiden anderen Clostridien-Genomen vorkommen; rot: ORFs, die $C$. tetani und $C$. acetobutylicum gemein haben; weiß: ORFs, die in allen drei Clostridien vorkommen (clostridieller "backbone"). Die Größe der drei Kreise ist proportional zur Anzahl der ORFs der Genome. Als signifikante Homologie zwischen zwei Proteinen wurde ein BLAST-Erwartungswert (e-Wert) von kleiner als $10^{-5}$ angesehen.

Bezüglich C. tetani können vier Gruppen von ORFs unterschieden werden; zwei davon sollen in den nächsten Abschnitten genauer betrachtet und diskutiert werden. Die 516 ORFs, welche nur in C. tetani vorkommen, stellen womöglich Gene dar, deren Proteine an der Ausprägung des C. tetani-spezifischen Phänotyps beteiligt sind (s. 4.1.3.3). Darunter könnten also auch solche sein, die bei der Ausbildung der Tetanus-Krankheit von Bedeutung sind. Die zweite hier näher betrachtete Gruppe umfasst die 199 ORFs, die nur in den pathogenen Bakterien $C$. tetani und $C$. perfringens vorkommen und für die Ausbildung einer pathogenen Lebensweise der Clostridien eine Rolle spielen könnten (s. 4.1.3.2).

Die hohe Anzahl homologer ORFs unter den Clostridien, vor allem bei $C$. perfringens und C. tetani, veranlasste eine weitere Untersuchung mit dem Ziel, 
Informationen über den Konservierungsgrad der Genordnung zwischen den verschiedenen Genomen zu erlangen. Zuerst wurde genomweit die DNA-Sequenz von $C$. tetani und $C$. perfringens verglichen. Es konnte aber auf DNA-Basis keine Konservierung zwischen diesen Genomen festgestellt werden (Daten nicht gezeigt). Anschließend wurden die Proteinsequenzen aller ORFs beider Organismen abhängig von der Position der entsprechenden Gene auf den Genomen gegeneinander abgeglichen. Das Ergebnis ist in Abbildung 33 wiedergegeben; es zeigt, dass zwar einzelne homologe Operone und Gencluster zwischen C. tetani und C. perfringens existieren, eine genomweite Konservierung der Genordnung aber nicht festgestellt werden kann.

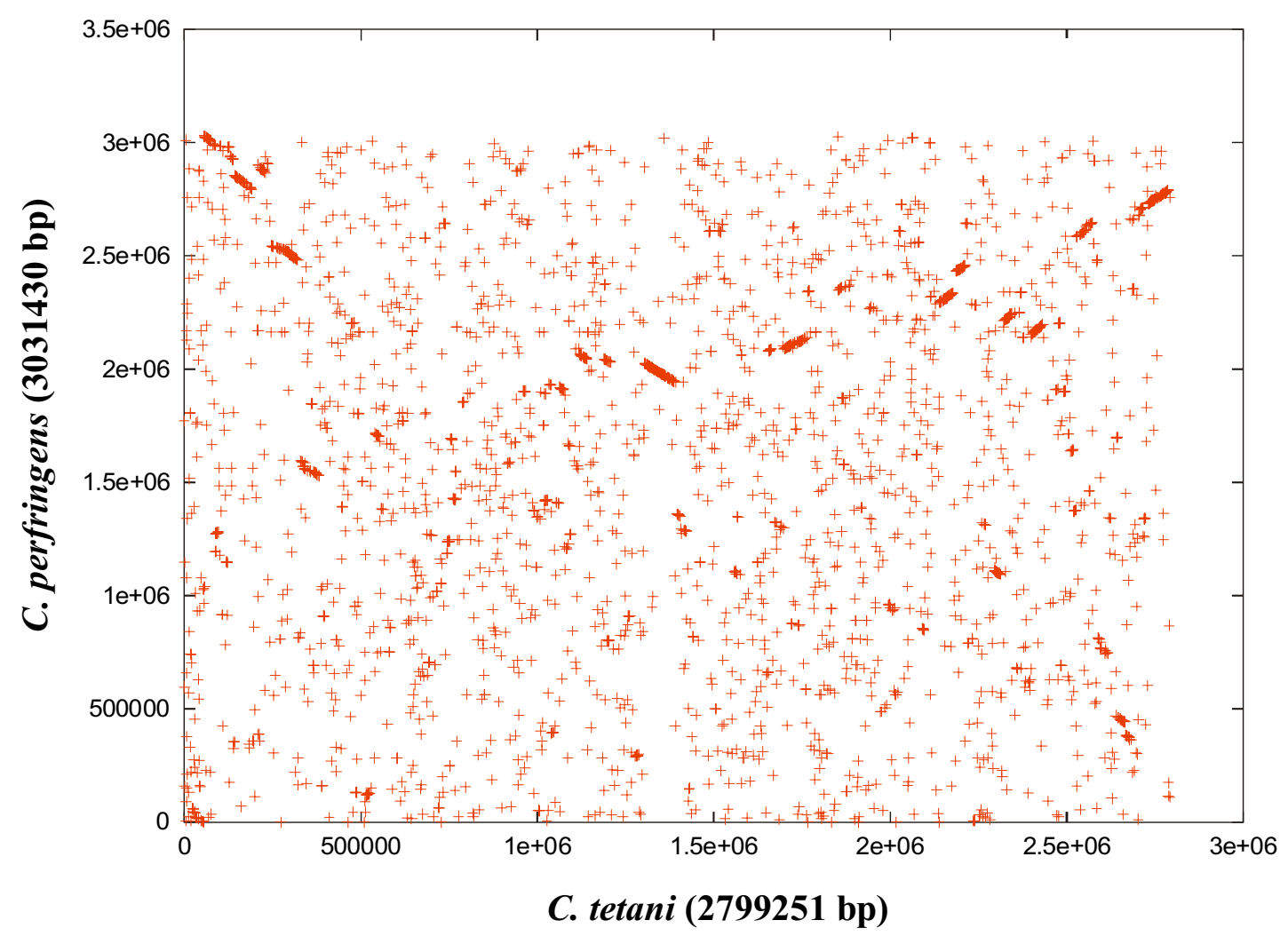

Abb. 33: Abgleich der Genome von $C$. tetani gegen $C$. perfringens

Gezeigt ist der BLAST-Abgleich (dargestellt als Dot-Blot) der Proteinsequenzen aller ORFs beider Organismen abhängig von der Position der entsprechenden Gene auf den Genomen. Ein rotes Kreuz bedeutet, dass die homologen Proteine der beiden Organismen einen BLASTErwartungswert kleiner als $10^{-5}$ aufwiesen. Rote Diagonalen, die aus der Überlagerung vieler roten Kreuze entstanden sind, weisen auf eine konservierte Genordnung in diesem Genombereich hin. 
Im Gegensatz dazu zeigen Enterobakterien z. B. der Gattungen Salmonella oder Escherichia aber auch Vertreter der Gattung Bacillus wie B. subtilis und B. licheniformis eine deutlich höhere Konservierung der Genordnung (PARKHILL et al., 2001).

4.1.3.2 Kandidaten-Gene für eine pathogene Lebensweise clostridieller Organismen

Zunächst sollen die 199 ORFs betrachtet werden, die in den pathogenen Bakterien $C$. tetani und $C$. perfringens vorkommen, nicht aber in dem nicht-pathogenen Organismus C. acetobutylicum. Diese könnten bei der Etablierung oder der Aufrechterhaltung einer pathogenen Lebensweise in virulenten Clostridien eine Rolle spielen. Tabelle 15 klassifiziert diese ORFs nach ihrer Funktion.

Taballe 15: ORFs von $C$. tetani mit Homologons in $C$. perfringens, aber nicht in C. acetobutylicum

\begin{tabular}{|c|c|c|}
\hline $\begin{array}{c}\text { Funktionelle } \\
\text { Kategorie }\end{array}$ & $\begin{array}{l}\text { An- } \\
\text { zahl }\end{array}$ & Produkt \\
\hline Virulenz & 6 & $\begin{array}{l}\text { Collagenase, Tetanolysin O, } 2 \text { Fibronectin-Bindeproteine, } \\
\text { Myosin-crossreaktives Antigen, Clostripain-Homologon }\end{array}$ \\
\hline Peptidasen & 11 & $\begin{array}{l}\text { Kreatininase, Cyanophycinase, Di- und Oligopeptidasen } \\
\text { mit unbekannter Spezifität, mehrere N-Acetylmuramoyl- } \\
\text { L-Alanin-Amidasen }\end{array}$ \\
\hline Transport & 48 & $\begin{array}{l}\text { periplasmatische Eisen(III)-Bindeproteine, Ionen- } \\
\text { Aufnahme-Systeme für Zink, Kalium und Chrom, } \\
\text { Aminosäure/Na }- \text { Symporter für Alanin, Glutamat, Glycin, } \\
\text { Prolin, Serin, Threonin, Tryptophan und Tyrosin; } \\
\mathrm{Na}^{+} / \mathrm{Myo} \text {-Inositol-Symporter, } \mathrm{Na}^{+} / \text {Pantothenat-Symporter, } \\
\mathrm{Na}^{+} / \mathrm{H}^{+} \text {-Antiporter, Transporter (Permeasen) für Ribose, } \\
\text { Ethanolamin, Galactosid, Nucleosid, Häm, u. a. }\end{array}$ \\
\hline $\begin{array}{l}\text { Ethanolamin- } \\
\text { Katabolismus }\end{array}$ & 21 & $\begin{array}{c}\text { homolog zu den eut-Genen der pathogenen Bakterien der } \\
\text { Gattungen Salmonella und Listeria }\end{array}$ \\
\hline Regulation & 9 & in erster Linie DNA-bindende Transkriptionsregulatoren \\
\hline $\begin{array}{l}\text { Elektronen- } \\
\text { transport }\end{array}$ & 6 & Proteine des $\mathrm{Na}^{+}$-translozierenden $\mathrm{Nqr} / \mathrm{Rnf}-$ Systems \\
\hline ATPase & 12 & V-Typ-ATPase $\left(\mathrm{Na}^{+}\right.$-translozierend $)$ \\
\hline
\end{tabular}




\begin{tabular}{ccc}
\hline $\begin{array}{c}\text { Aminosäure- } \\
\text { Metabolismus }\end{array}$ & 5 & $\begin{array}{c}\text { Threonin-Dehydratase, Glutaminase, Aspartat- } \\
\text { Ammonium Ligase, Histidin-Decarboxylase, Glutamin- } \\
\text { Synthetase }\end{array}$ \\
\hline $\begin{array}{c}\text { DNA- oder } \\
\text { Nukleotid- } \\
\text { modifizierende } \\
\text { Enzyme }\end{array}$ & 6 & $\begin{array}{c}\text { Desoxyguanosintriphosphat-Triphosphohydrolase, } \\
\text { Inosin/Uridin-Nucleosid-Hydrolase, Purin-Nucleosid- } \\
\text { Phosphorylase, Endonuclease, Uridin-Kinase, Cytosin- } \\
\text { Deaminase }\end{array}$ \\
\hline $\begin{array}{c}\text { konservierte } \\
\text { oder } \\
\text { hypothetische } \\
\text { Proteine }\end{array}$ & 62 & $\begin{array}{c}18 \text { davon mit Signalpeptid-Sequenz, 13 sind homolog zu } \\
\text { Membranproteinen aus L. monocytogens }\end{array}$ \\
\hline sonstige & 20 & $\begin{array}{c}\text { Myo-Inositol-Katabolismus, Lipase, Polyglutamat- } \\
\text { Synthase, Citrat-Lyase-Komplex (6), Häm-Oxygenase, } \\
\text { etc. }\end{array}$ \\
\hline
\end{tabular}

Auffällig ist die hohe Anzahl an Transport-Proteinen. Hierbei ist bemerkenswert, dass darunter viele $\mathrm{Na}^{+}$-abhängige Symporter - vor allem für Aminosäuren - zu finden sind. Auch andere $\mathrm{Na}^{+}$-abhängige Systeme sind in Tabelle 15 aufgeführt, wie die V-Typ-ATPase und das Nqr/Rnf-System. Eine detaillierte Wiedergabe $\mathrm{Na}^{+}-$ abhängiger Prozesse in C. tetani ist in Kapitel 4.1.4 zu finden.

Des weiteren gibt es in $C$. tetani und $C$. perfringens mehrere homologe Eisen(III)Aufnahmesysteme sowie ein ABC-Transportersystem (CTC959-CTC962), das wahrscheinlich Häm transportieren kann. Die Akquirierung von Eisen ist für die erfolgreiche Kolonisierung und Proliferation des Bakteriums im infizierten Wirt von besonderer Bedeutung, da Eisen im Wirt i. d. R. nur in gebundener und damit schwer zugänglicher Form vorliegt (Ferritin, Hämosiderin, Eisentransferrin). So muss das Bakterium Aufnahmesysteme (Siderophore) mit einer sehr hohen Eisen-Affinität bilden (CLARKE et al., 2001). In diesem Zusammenhang ist auch die Anwesenheit einer Häm-Oxygenase in $C$. tetani und $C$. perfringens interessant, welche die Öffnung des Häm-Ringes katalysieren kann, was zur Freisetzung des Eisen-Ions führt (s. 3.4.10.2). Unter den Transportproteinen, die in C. tetani und C. perfringens vorkommen, befindet sich auch ein Zink-Aufnahmesystem. Das ist deshalb von Interesse, weil Zink das Schlüssel-Ion in der Funktionalität von Zink-abhängigen Toxinen wie das Tetanus-Toxin und die Collagenase darstellt. Daneben gibt es im Genom 11 weitere Peptidasen, die das Zink-Bindemotiv HEXXH tragen, und somit wahrscheinlich auch Zink-abhängig sind.

Tabelle 15 listet ebenfalls Peptidasen auf, darunter sowohl cytoplasmatische wie auch periplasmatische Proteine. Lediglich zwei davon zeigen Homologien zu 
bekannten Peptidasen: die aufgeführte Kreatininase katalysiert die Hydrolyse von Kreatinin zu Kreatin und die Cyanophycinase, eine Exopeptidase, katalysiert die hydrolytische Spaltung von Cyanophycin, einem Wasser-unlöslichen Speicherpolymer (OBST et al., 2002).

Des weiteren sind die 21 Gene aufgeführt, die für den Cobalamin-abhängigen Katabolismus von Ethanolamin kodieren (KOFOID et al., 1999). Ethanolamin fällt z. B. beim Abbau bestimmter Phospholipide an, welcher durch Lipasen katalysiert wird, von denen 5 verschiedene im Genom von C. tetani vorkommen (s. 3.4.6.4).

\subsubsection{Kandidaten-Gene für Tetanus-spezifische Funktionen}

Nun sollen die 516 ORFs betrachtet werden, die in C. tetani nicht aber in den anderen beiden Clostridien-Genomen vorkommen. Diese ORFs kodieren also Funktionen, die für $C$. tetani spezifisch sind. Somit könnten sie möglicherweise in einem Zusammenhang mit der Ausbildung der Tetanus-Krankheit stehen. Allerdings ist aufgrund der kleinen Vergleichsmenge von lediglich drei Genomen das Vergleichsresultat mit Vorsicht zu genießen. Tabelle 16 fasst die Funktionen der ORFs zusammen.

Tabelle 16: ORFs von $C$. tetani ohne Homologons in $C$. perfringens und C. acetobutylicum

\begin{tabular}{|c|c|c|}
\hline $\begin{array}{c}\text { (Funktionelle) } \\
\text { Kategorie }\end{array}$ & $\begin{array}{l}\text { An- } \\
\text { zahl }\end{array}$ & Produkt \\
\hline Plasmid pE88 & 31 & $\begin{array}{c}25 \text { hypothetische, } 6 \text { konservierte Proteine; } 2 \\
\text { Replikationsproteine; Tetanus-Toxin }\end{array}$ \\
\hline Phagen & $\begin{array}{l}38 \\
19 \\
27\end{array}$ & $\begin{array}{c}3 \text { Prophagen der Größen } 47 \mathrm{~kb}, 39 \mathrm{~kb} \text { und } 41 \mathrm{~kb} \text {; } \\
\text { hypothetische oder Phagen-spezifische Funktionen, N- } \\
\text { Acetylmuramoyl-L-Alanin-Amidasen, Stress- } \\
\text { Protein 20U, RecT }\end{array}$ \\
\hline $\begin{array}{l}\text { Natrium- } \\
\text { abhängige } \\
\text { Prozesse }\end{array}$ & 17 & $\begin{array}{c}\text { Mrp-System }\left(\mathrm{Na}^{+} / \mathrm{H}^{+} \text {-Antiporter-Komplex }\right), 2 \text { weitere } \\
\mathrm{Na}^{+} / \mathrm{H}^{+} \text {-Antiporter, } \mathrm{Na}^{+} / \text {Glucose/Galactose- } \\
\text { Cotransporter, } \mathrm{Na}^{+} / \text {Glutamat-Symporter, } \mathrm{Na}^{+} / \text {Histidin- } \\
\text { Symporter, einige Untereinheiten der alternativen V- } \\
\text { Typ-ATPase }\end{array}$ \\
\hline Virulenz & 14 & $\begin{array}{l}\text { 11 S-Layer-Proteine, mögliche Thrombocyten- } \\
\text { aktivierender Faktor (PAF)-Acetylhydrolase, } \\
\text { periplasmatisches immunogenes Protein }\end{array}$ \\
\hline
\end{tabular}




\begin{tabular}{|c|c|c|}
\hline $\begin{array}{l}\text { Peptidasen/ } \\
\text { Amidasen }\end{array}$ & 16 & $\begin{array}{c}4 \text { Zink-abhängige Enzyme: CTC401, CTC445, } \\
\text { CTC519, CTC612; Cystein-Protease, Protease HtpX } \\
\text { (Hitzeschock-Protein); einige N-Acetylmuramoyl-L- } \\
\text { Alanin-Amidasen }\end{array}$ \\
\hline Transporter & 15 & $\begin{array}{l}\text { Subtilin-Transportsystem SpaEFG; Cobalt-Transporter; } \\
\text { Small-Multidrug-Exportproteine; } \\
\text { Homoserin/Homoserinlacton-Effluxprotein; Eisen- } \\
\text { Transportsystem }\end{array}$ \\
\hline $\begin{array}{c}\text { Genereller } \\
\text { Metabolismus }\end{array}$ & 8 & $\begin{array}{c}\text { Glucose-6-Phosphat-1-Dehydrogenase, 6- } \\
\text { Phosphogluconat-Dehydrogenase (Pentose-Phosphat- } \\
\text { Weg); 4-Hydroxybutyrat-CoA-Transferase (4- } \\
\text { Aminobutyrat- oder Succinat-Abbau); } \\
\text { Phosphoenolpyruvat-Phosphomutase, } \\
\text { Phosphonopyruvat-Decarboxylase (Phosphonat- } \\
\text { Biosynthese); mögliche Molybdän-abhängige CO- } \\
\text { Dehydrogenase }\end{array}$ \\
\hline $\begin{array}{l}\text { Aminosäure- } \\
\text { Metabolismus }\end{array}$ & 19 & $\begin{array}{c}\text { Glutamat-Mutase, Tryptophanase, Urocanat-Hydratase, } \\
\text { Histidin-Ammonium-Lyase (Histidase), Tyrosin- } \\
\text { Phenol-Lyase, L-Lysin-2,3-Aminomutase, L-allo- } \\
\text { Threonin-Aldolase, Glutamat- und Aspartat-Racemasen, } \\
\text { Ornithin-Synthase, Chorismat-Mutase, Glutamat- } \\
\text { Formiminotransferase, N-Carbamoyl-L-Aminosäure- } \\
\text { Amidohydrolase }\end{array}$ \\
\hline Fett-Abbau & 7 & $\begin{array}{c}\text { (Phospho-)Lipasen, Phosphatidylinositol-4-phosphat-5- } \\
\text { Kinase, Lipoat-Protein-Ligase A, Cholin/Ethanolamin- } \\
\text { Kinase, Dihydrolipoamidacyl-Transferase }\end{array}$ \\
\hline sonstige & 61 & $\begin{array}{l}\text { V-Typ H+-Pyrophosphatase, Fumarat-Reduktasen (4), } \\
\text { Pyrazinamidase, Thymidylat-Kinase, Metallo-beta- } \\
\text { Lactamase, Ferredoxin, mögliche Acyl-CoA:6- } \\
\text { Aminopenicillanic-Acid-Acyltransferase, ATP- } \\
\text { abhängige RNA-Helicase, S-Adenosylmethionin- } \\
\text { Decarboxylase, L-2,4-Diaminobutyrat-Decarboxylase } \\
\text { (Diaminobutyrat } \rightarrow \text { 1,3-Diaminopropan), u. a. }\end{array}$ \\
\hline $\begin{array}{l}\text { konservierte/ } \\
\text { hypothetische } \\
\text { ORFs }\end{array}$ & 242 & $\begin{array}{l}111 \text { ORFs ausschließlich in } C \text {. tetani vorkommend; } \\
94 \text { ORFs auch in C. botulinum oder/und C. difficile } \\
\text { vorkommend }\end{array}$ \\
\hline
\end{tabular}

Mehrere Aspekte sollen hier hervorgehoben werden:

1. Viele der ORFs des Plasmids und der drei im Chromosom integrierten Prophagen sind nicht in C. perfringens und C. acetobutylicum vorhanden. Den meisten konnte keine Funktion zugeordnet werden.

2. Wie schon im letzten Kapitel festgestellt, scheint C. tetani eine ausgeprägte $\mathrm{Na}^{+}-$ Bioenergetik $\mathrm{zu}$ betreiben. Das Bakterium besitzt dabei erheblich mehr $\mathrm{Na}^{+}-$ abhängige Systeme als C. perfringens (s. 4.1.4). 
3. Einige Proteine des Pentosephosphat-Weges sowie interessante membrangebundene oder -assoziierte Systeme wie das Mrp-System, vier FumaratReduktasen, eine V-Typ- $\mathrm{H}^{+}$-Pyrophosphatase, eine alternative V-Typ-ATPase und eine CO-Dehydrogenase konnten in C. tetani aber nicht in anderen Vertretern der Gattung Clostridium identifiziert werden (s. auch 3.4.9).

4. C. tetani besitzt eine 4-Hydroxybutyrat-CoA-Transferase, ein Enzym, welches für die Umsetzung von 4-Hydroxybutyrat zu Butyrat benötigt wird (s. auch 4.2.2). 4Hydroxybutyrat fällt als Abbauprodukt von 4-Aminobutyrat, das z. B. durch $C$. aminobutyricum fermentiert werden kann (GERHARDT et al., 2000), oder von Succinat an, welches z. B. durch C. kluyveri verwertet wird (SÖHLING \& GOTTSCHALK, 1996). Succinat kann mittels der in C. tetani vorhandenen FumaratReduktase gebildet werden. 4-Aminobutyrat entsteht bei der Decarboxylierung von Glutamat*. Es liegt aber auch in Vertebraten als Neurotransmitter GABA $(\gamma-$ Aminobutyrat) vor, dessen Freisetzung von den Synapsen durch das Tetanus-Toxin verhindert wird (s. 4.2.1.1).

5. C. tetani besitzt weit mehr Enzyme zur Vergärung von Aminosäuren als $C$. perfingens (s. auch 3.4.6.3 und Abb. 34). Auch gibt es offensichtlich ein Repertoire an Enzymen zum Abbau von Lipiden (s. 3.4.6.4). Diese beiden Feststellungen machen hinsichtlich des Infektionsortes Sinn: C. tetani kolonisiert anaerobe Zonen in Wunden des Säugetier-Wirts. Als Nahrungsquelle stehen somit verschiedenste Peptide und Fette zur Verfügung.

6. In C. tetani wurden 111 ORFs gefunden, die bisher in keinem anderen Genom identifiziert werden konnten. Interessant hinsichtlich ihrer möglichen Virulenzunterstützenden Funktionen sind auch die 94 ORFs, die außer in $C$. tetani nur noch in C. botulinum und/oder C. difficile vorkommen.

\subsubsection{Natrium-abhängige Prozesse in C. tetani}

In vorangegangenen Kapiteln wurde mehrmals über die Existenz von $\mathrm{Na}^{+}-$ abhängigen Systemen in C. tetani berichtet. Auch wurde in der vorliegenden Arbeit an mehreren Stellen die erhebliche Anzahl an Enzymen erwähnt, die an der Vergärung von Aminosäuren beteiligt sind. Hier sollen nun diese Daten gebündelt

\footnotetext{
* In C. tetani konnte allerdings keine Glutamat-Decarboxylase identifiziert werden.
} 
und in einen Zusammenhang gestellt werden. Abbildung 34 zeigt, dass die $\mathrm{Na}^{+}$Abhängigkeit von C. tetani offenbar in direktem oder indirektem Zusammenhang mit seiner Fähigkeit steht, eine erhebliche Anzahl von Aminosäuren vergären zu können. Eine Vielzahl von Exoenzymen katalysiert den Abbau von wirtsspezifischem Gewebe. Peptide und Aminosäuren sowie andere Degradationsprodukte können dann über Transportsysteme aufgenommen werden. Dabei geschieht die Aufnahme von Aminosäuren aus dem extrazellulären Raum mittels einer Vielzahl Membranpotential-getriebener Symporter, die größtenteils $\mathrm{Na}^{+}$-abhängig sind. Die Frage ist nun, wie die nachfolgend ablaufende Fermentation von Aminosäuren zur Entstehung eines $\mathrm{Na}^{+}$-Membranpotentials genutzt werden kann.

\subsubsection{Mögliche Beteiligung des Nqr/Rnf-Systems an der $\mathrm{Na}^{+}$-Bioenergetik}

Ein Abbauprodukt bei der Vergärung der meisten Aminosäuren ist Pyruvat. Dieses kann unter ATP-Synthese zu Acetat oder Butyrat umgesetzt werden (s. 3.4.7). Nun könnte das entstandene ATP mittels der V-Typ-ATPase zur $\mathrm{Na}^{+}$-Ionen-Translokation eingesetzt werden. Das wäre allerdings für die Zelle ein sehr kostspieliger Prozess. Es wird angenommen, dass $\mathrm{Na}^{+}$-abhängige ATPasen nur in extremen Situationen zur $\mathrm{Na}^{+}$-Translokation benutzt werden (IKEGAMI et al., 1999; HÄSE et al., 2001). Das ATP wird dringend auch für andere zelluläre Prozesse wie z. B. für die Fortbewegung gebraucht.

Die Genomsequenz offenbarte nun eine energetisch gesehen sinnvollere Alternative, die es $C$. tetani erlaubt, einen membrangebundenen Elektronentransportprozess durchzuführen, der mit einer $\mathrm{Na}^{+}$-Ionen-Translokation gekoppelt ist. Gemeint ist das in Kapitel 3.4.9.1 vorgestellte Nqr/Rnf-System. Wie kann nun dieses System in den Aminosäure-fermentierenden Metabolismus von C. tetani eingebunden sein, und zwar unter Berücksichtigung der Feststellung, dass das System eine $\mathrm{NAD}^{+}-$ Bindestelle sowie eine Polyferredoxin-Untereinheit besitzt ? Es ist anzunehmen, dass das im Laufe der Fermentation von Aminosäuren anfallende Pyruvat mittels der Pyruvat:Ferredoxin-Oxidoreduktase zu Acetyl-CoA umgesetzt wird. Damit einher geht die Reduktion von Ferredoxin. Dieses wird gewöhnlich durch eine Hydrogenase reoxidiert, wobei molekularer Wasserstoff gebildet wird; die Reduktionsäquivalente gehen hierbei also verloren. Das reduzierte Ferredoxin $\left(E_{0}{ }^{\prime}=-420 \mathrm{mV}\right)$ könnte aber 
alternativ zur Reduktion von $\operatorname{NAD}^{+}\left(E_{0}{ }^{\prime}=-320 \mathrm{mV}\right)$ genutzt werden. Diese Reduktion wäre energetisch machbar und könnte durch das $\mathrm{Na}^{+}$-Ionen-translozierende $\mathrm{Nqr} / \mathrm{Rnf}$ System katalysiert werden (Abb. 34). Ein weiterer Hinweis zur Unterstützung diese Hypothese ist die Beobachtung, dass eine hohe NADH-Dehydrogenase-Aktivität in gewaschenen Membranen von C. tetanomorphum, einem zu C. tetani sehr nah verwandten Organismus, detektiert werden konnte (BUCKEL, persönliche Mitteilung). Die nächste daraus resultierende Frage adressiert den Nutzen des reduzierten $\mathrm{NAD}^{+}$für $C$. tetani. Bei der Vergärung vieler Aminosäuren entsteht im Gegensatz zur Vergärung von Glucose kein $\mathrm{NADH}+\mathrm{H}^{+}$. Dieses wird aber für die Reduktion von Acetyl-CoA zu Butyrat in den Reaktionen benötigt, welche durch die Butyryl-CoA-Dehydrogenase und die $\beta$-Hydroxybutyryl-CoA-Dehydrogenase katalysiert werden. In diesem Zusammenhang sind die Gencluster dieser Enzyme interessant (s. 3.4.7.2). Sie enthalten die Elektronentransfer-Flavoproteine EtfA und B. Bisher ist bekannt, dass EtfA und EtfB die für die Reduktion von Crotonyl-CoA benötigten Elektronen bereitstellen (BOYNTON et al., 1996). Somit wäre es auch denkbar, dass das Nqr/Rnf-System nicht $\mathrm{NAD}^{+}$sondern eines der ElektronentransferFlavoproteine reduziert. Zur genaueren Analyse dieser Hypothese wurde die mögliche NADH-Bindestelle in NqrF betrachtet. Aus NADH-bindenden Proteinen, wie z. B. NuoF im Komplex 1 oder $\mathrm{NAD}^{+}$-reduzierende Hydrogenasen, wurde von WEIDNER et al. (1993) eine Consensus-Sequenz für ein mögliches Bindemotiv postuliert: $\mathrm{NADE}^{\mathrm{M}} /{ }_{\mathrm{G}} \mathrm{EPGT}$. An der entsprechenden Stelle im multiplen Sequenzalignment zeigt NqrF aus $C$. tetani folgende Sequenz: NAAECEPYL. Das Bindemotiv entspricht also nur zu etwa 55\% dem Consensus. Letztendlich können nur experimentelle Versuche die Spezifitäten des Nqr/Rnf-Komplexes in C. tetani klären. 


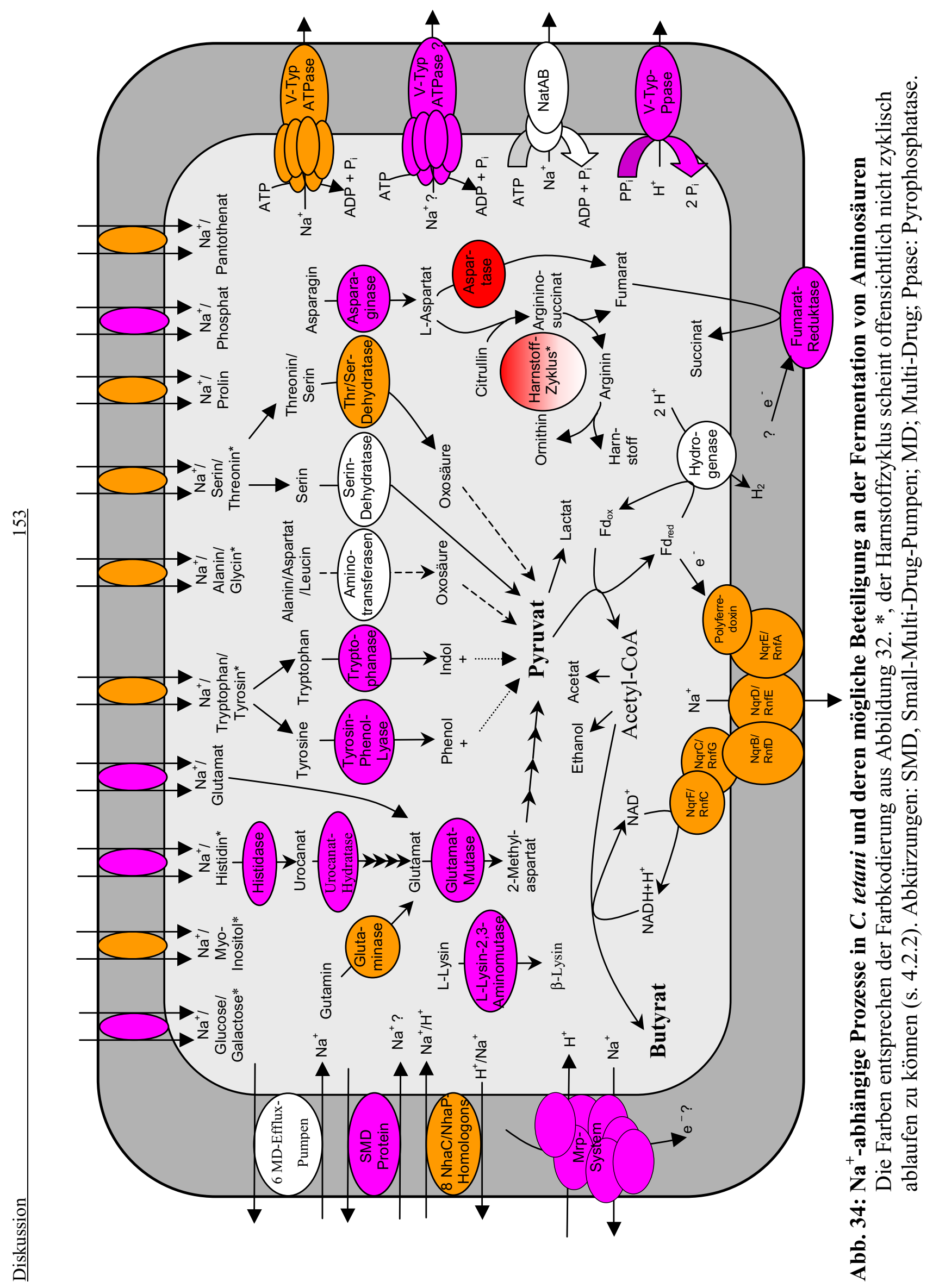




\subsubsection{2 $\quad \mathrm{Na}^{+}$-Bioenergetik und Virulenz}

Die meisten Bakterien generieren mittels primärer Pumpen ein Protonenpotential über der Membran und nutzen diesen zur ATP-Synthese und für zelluläre Prozesse wie z. B. die Substrataufnahme oder die Fortbewegung. Nun ist aber seit längerem auch bekannt, dass einige extremophile, vor allem alkalophile und thermophile Bakterien $\mathrm{Na}^{+}$-Ionen zur Generierung eines transmembranen elektrochemischen Gradienten nutzen (DIMROTH, 1994; SKULACHEV, 1989). Auch in marinen Bakterien wurde solch eine $\mathrm{Na}^{+}$-Abhängigkeit beobachtet (KOGURE, 1998). Analog zu Bakterien, die einen $\mathrm{H}^{+}$-Zyklus betreiben, gibt es eine Vielzahl $\mathrm{Na}^{+}$-abhängiger Prozesse in solchen Zellen. Dieser $\mathrm{Na}^{+}$-Zyklus kann den $\mathrm{H}^{+}$-Zyklus sowohl ersetzen aber auch ergänzen. Es wurden mehrere primäre $\mathrm{Na}^{+}$-Pumpen in solchen Bakterien gefunden wie z. B. $\mathrm{Na}^{+}$-translozierende Decarboxylasen (u. a. Oxalacetat-Decarboxlyase und Methylmalonyl-CoA-Decarboxlyase in Propionigenium modestum, Glutaconyl-CoA-Decarboxylase in Acidaminococcus fermentans), $\mathrm{Na}^{+}$-translozierende ATPasen (z. B. in Enterococcus hirae, C. fervidus), $\mathrm{Na}^{+}$-translozierende Methyltransferasen (z. B. Methyltetrahydromethanopterin:CoM-Methyltransferase in methanogenen Archaeen) und das oben erwähnte $\mathrm{Na}^{+}$-translozierende $\mathrm{Nqr} / \mathrm{Rnf}$ System, das in aeroben Bakterien als NADH-Dehydrogenase fungiert (BOTT et al., 1997; BRAUNE et al., 1999; DEPPENMEIER et al., 1999; STEUBER, 2001; DIMROTH, 1997). Der durch solche primären $\mathrm{Na}^{+}$-Pumpen generierte $\mathrm{Na}^{+}$-Gradient kann für viele zelluläre Prozesse genutzt werden, wie z. B. zur ATP-Synthese $\left(\mathrm{F}_{0} \mathrm{~F}_{1}\right.$ Typ-ATPase von Propionigenium modestum und $V$. alginolyticus), zum Substratimport (sekundäre Symporter), zum Antibiotika- und Schwermetall-Export (Multidrug-Efflux-Pumpen) oder zur $\mathrm{Na}^{+}$-abhängigen Fortbewegung durch einen $\mathrm{Na}^{+}$-abhängigen Flagellenmotor z. B. in $V$. parahaemolyticus und $V$. alginolyticus (ASAI et al., 1999; HEYNE et al., 1991; DIMROTH, 1994). Es gibt auch Vermutungen darüber, dass der Export bestimmter Toxine (z. B. Phospholipase YplA in $Y$. enterocolitica) mittels des Flagellen-Exportapparates $\Delta_{\mathrm{Na}^{+-}}$getrieben ablaufen könnte (YOUNG et al., 1999).

Ein genereller Genomvergleich der meisten der bisher vollständig sequenzierten Bakteriengenome offenbarte, dass viele der genannten $\mathrm{Na}^{+}$-abhängigen Prozesse vor allem in pathogenen Bakterien wie Chlamydia pneumoniae, Haemophilus influenzae, $N$. gonorrhoeae, N. meningitidis, Sa. enterica, $V$. cholerae oder $Y$. pestis zu finden 
sind (HÄSE et al., 2001). Diese Beobachtung konnte nun auch durch die Sequenzierung des Genoms von C. tetani bestätigt werden. C. acetobutylicum dagegen - obwohl nahe verwandt - besitzt kaum $\mathrm{Na}^{+}$-abhängige Systeme; nur die Gene für $\mathrm{Na}^{+}$-abhängige Multi-Drug-Effluxpumpen konnten in diesem Genom ausgemacht werden.

Damit kann also festgestellt werden, das viele pathogene Organismen eine $\mathrm{Na}^{+}-$ abhängige Bioenergetik betreiben, wobei die meisten davon auch $\mathrm{H}^{+}$-abhängige Systeme besitzen. Diese Koexistenz beider Systeme konnte auch in C. tetani gefunden werden. Eine Reihe von $\mathrm{H}^{+} / \mathrm{Na}^{+}$-Antiportern garantiert die Austauschbarkeit dieser beiden Membranpotentiale.

Welche Gründe könnten die pathogenen Bakterien für die Ausbildung zweier bioenergetischer Zyklen haben ? Zum einen ist denkbar, dass dadurch zusätzliche Fähigkeiten gewonnen werden, z. B. bezüglich der Substrataufnahme oder des Exports. Eine gesteigerte ATP-Synthese könnte beim Eintritt in den Wirt den entscheidenden Ausschlag zum Überleben gegen wirtsspezifische Abwehrmaßnahmen und zur erfolgreichen Kolonisierung geben. Eine weitere Erklärung hängt mit der im Vergleich zur $\mathrm{H}^{+}$-Konzentration $10^{6}$-fach höheren $\mathrm{Na}^{+}$Konzentration in den meisten natürlichen Standorten zusammen. Damit könnte die Generierung einer Natriumionen-motorischen Kraft stabiler und verlässlicher durchzuführen sein als die einer Protonen-motorischen Kraft. Auch ist denkbar, das aufgrund des ähnlichen Salzgehaltes des Meerwassers und des Blutes ein evolutionärer Druck zugunsten der Entwicklung ähnlicher bioenergetischer Systeme in marinen wie in humanpathogenen Bakterien herrschte; oder aber die entsprechenden Gene wurden über horizontalen Gentransfer ausgetauscht.

Zum Abschluss dieses Abschnitts soll erwähnt werden, dass man sich die Existenz $\mathrm{Na}^{+}$-abhängiger Systeme in vielen pathogenen Bakterien zur Herstellung von Breitbandspektrum-Impfstoffen zunutze machen könnte. So wäre z. B. NqrA als Impfstoff-Kandidat denkbar, da dieses eine immunogene Antwort in infizierten Schweinen hervorruft (CRUZ et al., 1996). Somit könnte eine Immunisierung gegen einer ganzen Reihe humanpathogener Organismen auf einen Schlag erfolgen. 


\subsection{Aspekte des genetischen Potentials von $C$. tetani}

\subsubsection{Pathogenitätsfaktoren}

Aufgrund der dominierenden Bedeutung der Toxine und anderer Virulenzfaktoren für die Pathogenität eines Organismus sollen hier einige Pathogenitätsfaktoren von C. tetani detailliert vorgestellt werden. Neben dem sehr gut untersuchten TetanusToxin sollen clostridielle Collagenasen und Cytolysine charakterisiert und im Zusammenhang mit den in C. tetani gefundenen homologen Toxinen diskutiert werden. Abschließend sollen Zelloberflächenproteine von C. tetani als weitere mögliche Virulenzfaktoren vorgestellt werden.

\subsubsection{Tetanus-Toxin}

Die Tetanus-Krankheit manifestiert sich bei betroffenen Menschen meistens als eine spastische Paralyse, d. h. eine krampfhafte Starre bzw. Lähmung der Muskeln, beginnend i. d. R. im Kieferbereich und schließlich den gesamten Körper erfassend. Diese Muskelstarre wird durch das neurotoxisch wirkende Tetanus-Toxin verursacht, welches durch $C$. tetani-Zellen produziert wird, die sich in anaeroben Zonen von Wunden ansiedeln konnten (BIZZINI, 1979; ARNON, 1997). Das Toxin bindet zuerst an Nervenzellen der neuromuskulären Verbindungen (motorische Endplatten) und wird anschließend internalisiert. Dann gelangt es durch einen retrograden Transport innerhalb der Axone zum eigentlichen Wirkungsort, den Synapsen von inhibitorischen Interneuronen des Knochenmarks und des Stammhirns (SCHIAVO \& MONTECUCCO, 1997). Dort blockiert es die Freisetzung der Neurotransmitter Glycin und $\gamma$-Aminobutyrat (GABA) von der präsynaptischen Membran, wodurch die Entspannung der mit den Neuronen vernetzten Muskeln nicht mehr möglich ist. Der molekulare Mechanismus dieses Prozesses besteht darin, dass das Toxin die Hydrolyse des synaptischen Vesikelproteins Synaptobrevin-II katalysiert, welches auch als VAMP, Vesikel-assoziiertes Membranprotein, bezeichnet wird (Abb. 35; SCHIAVO et al., 1992). Synaptobrevin-II ist mit zwei weiteren Proteinen im sogenannten SNARE-Komplex vereinigt, welcher die Fusion der Neurotransmitterenthaltenden Vesikeln mit der präsynaptischen Membran vermittelt (SUTTON et al., 1998). Durch die Spaltung von Synaptobrevin-II wird eine Fusion unmöglich 
gemacht; die Neurotransmitter verbleiben in den Vesikeln und können nicht in den synaptischen Spalt abgegeben werden, wodurch das Signal (Aktionspotential) nicht zum benachbarten Axon weitergetragen werden kann.

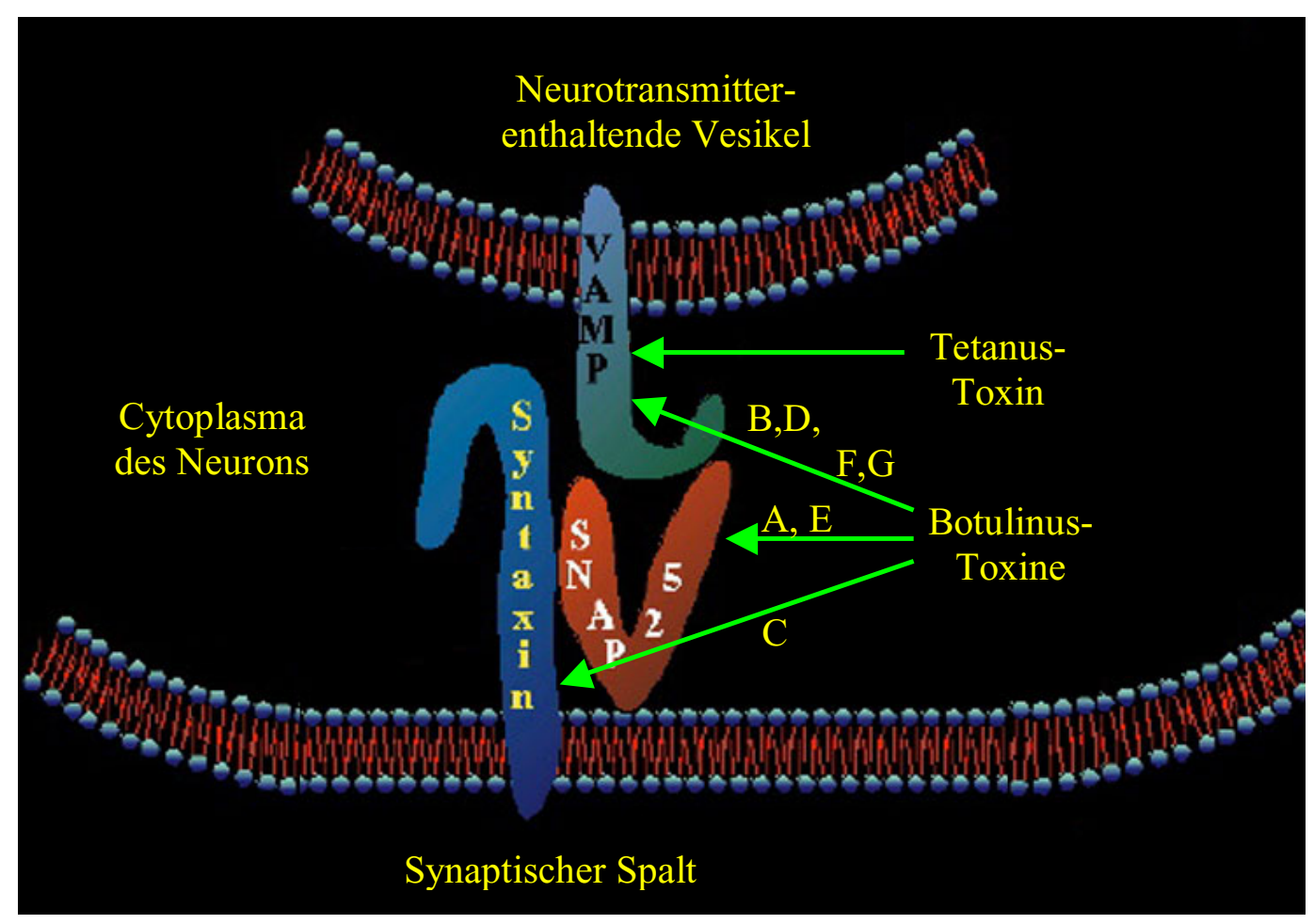

Abb. 35: Wirkort und Spezifitäten des Tetanus-Toxins und der Botulinus-Toxine

Die Proteine Synaptobrevin-II (VAMP), Syntaxin und SNAP-25 bilden den sogenannten SNARE-Komplex. Während das Tetanus-Toxin Synaptobrevin-II spaltet, haben die sieben Botulinus-Toxine unterschiedliche Spezifitäten. Zu bemerken ist, dass die Botulinus-Toxine an anderen Neuronen als das Tetanus-Toxin angreifen, und zwar an solchen der motorischen Endplatten, was die Freisetzung des Neurotransmitters Acetylcholin blockiert; dadurch sind Muskelkontraktionen nicht mehr möglich.

Genauere funktionelle und strukturelle Analysen des Tetanus-Toxins und der sieben homologen Botulinus-Toxine (BoNTs) zeigten, dass die Aktivierung der ca. $150 \mathrm{kDa}$ großen Toxine posttranslational durch proteolytische Spaltung in zwei Polypeptidketten stattfindet (SCHIAVO \& MONTECUCCO, 1997). Es entstehen eine schwere (H-Kette, $100 \mathrm{kDa}$ ) und eine leichte Kette (L-Kette, $50 \mathrm{kDa})$, welche über eine Disulfid-Brücke verbunden bleiben. Eine schematische Darstellung des Domänen-Aufbaus ist in Abbildung 36 gezeigt. Die N-terminale L-Kette stellt die katalytische Domäne dar, eine Zink-abhängige Endopeptidase. Die schwere Kette 
besteht aus einer Domäne $\left(\mathrm{H}_{\mathrm{C}}\right)$, die die Bindung an Gangliosiden (z. B. GT1b) vermittelt, welche in neuronalen Membranen zu finden sind, und einer Domäne $\left(\mathrm{H}_{\mathrm{N}}\right)$, die in der Translokation des Toxins über die neuronale Membran und eventuell auch im retrograden axonalen Transport involviert ist (EMSLEY et al., 2000).
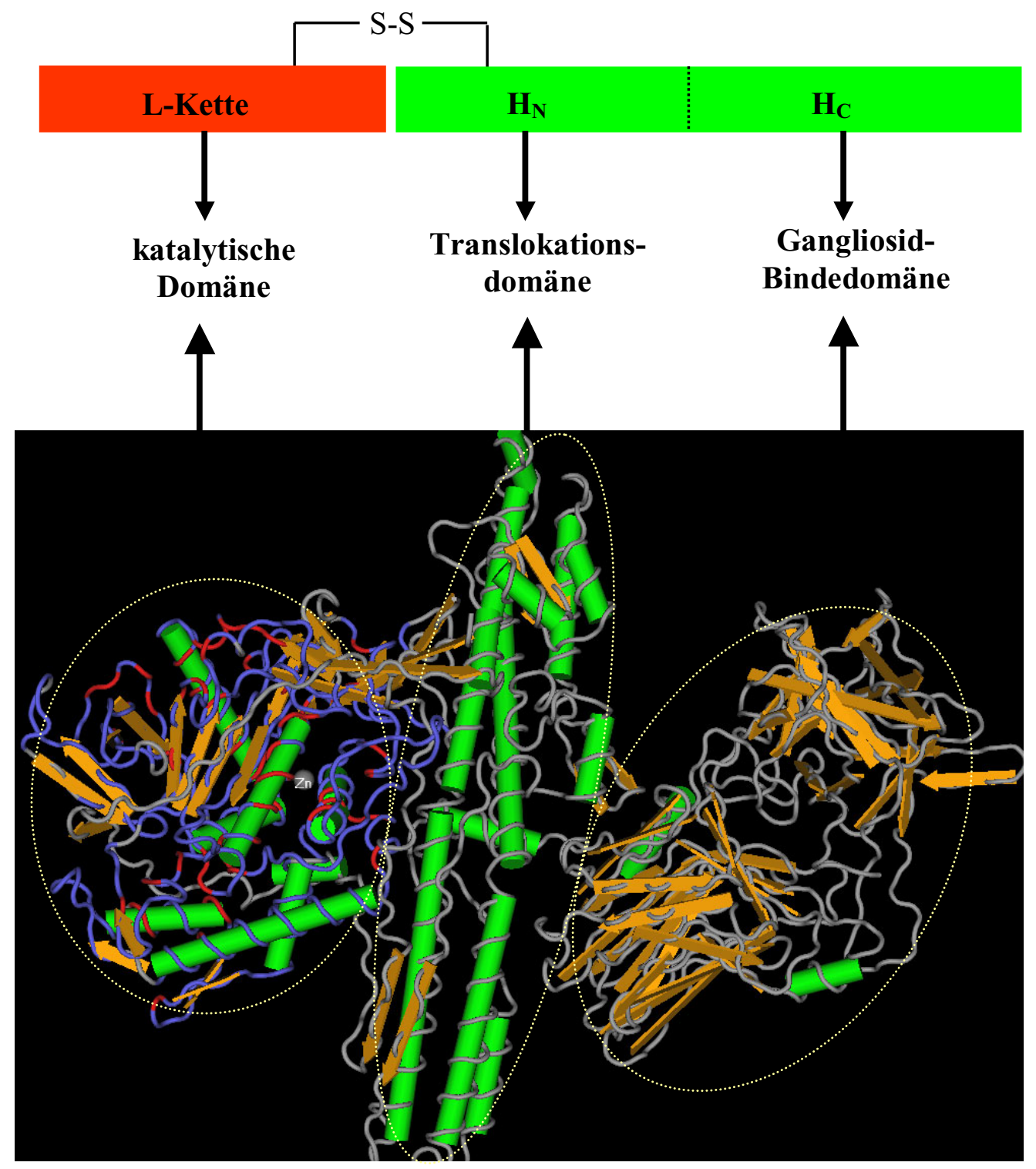

Abb. 36: Schematischer Domänenaufbau des Tetanus-Toxins bzw. der Botulinus-Toxine sowie die Strukturen dieser Domänen Gezeigt ist die Proteinstruktur des Botulinus-Toxins B (SWAMINATHAN \& ESWARAMOORTHY, 2000), welches das zum Tetanus-Toxin ähnlichste Protein ist. In Grün sind $\alpha$-helikale Regionen, in orange $\beta$ Faltblätter gekennzeichnet. In der katalytischen Domäne befindet sich ein Zink-Ion $\left(\mathrm{Zn}^{2+}\right)$, welches über die zwei Histidin-Reste des ZinkBindemotivs HELIH sowie über ein Glutamat-Rest koordiniert wird. 
Neurotoxine mit Spezifitäten für synaptische Proteine werden ausschließlich durch C. tetani und $C$. botulinum sowie durch toxigene Stämme von $C$. barati, $C$. argentinense und C. butyricum gebildet. Das 1315 Aminosäuren umfassende Tetanus-Toxin des im Rahmen dieser Arbeit sequenzierten C. tetani-Stammes E88 zeigt die höchsten Ähnlichkeiten zu BoNT B und G (beide 40 \% Proteinidentität über 1315 As). Dabei besitzt unter den Botulinus-Toxinen lediglich das BoNT B eine mit dem Tetanus-Toxin identische Substratspezifität: die Spaltung der GlutaminPhenylalanin-Bindung an Position 67 im Synaptobrevin-II (SCHIAVO et al., 1992).

Die meisten clostridiellen Neurotoxine sind auf extrachromosomalen Elementen kodiert. Neben dem Tetanus-Toxin ist auch das BoNT G plasmid-kodiert. Es befindet sich auf einem etwa $114 \mathrm{~kb}$ großen Plasmid, das bisher nicht sequenziert wurde (ZHOU et al., 1995). Die Toxine BoNT C und BoNT D sind auf den Genomen von lysogenen Bakteriophagen lokalisiert, die nicht ins Bakterienchromosom integrieren (EKLUND et al., 1972). Auch diese Bakteriophagen-Genome sind bisher nicht sequenziert. Für BoNT E wird angenommen, dass es sich auf einem ins Chromosom integrierten Prophagen befindet. Die restlichen Botulinus-Toxine scheinen chromosomal-kodiert vorzuliegen, wobei allerdings darüber spekuliert wird, ob die Gene der Toxine in einer Transposon-ähnlichen Sequenzumgebung liegen (HENDERSON et al., 1996).

\subsubsection{Collagenase}

Die Sequenzanalyse des Plasmids pE88 ergab, dass neben dem Tetanus-Toxin ein weiteres Toxin, eine Collagenase - hier ColT genannt - kodiert vorlag.

Bakterielle Collagenasen wurden bisher in einer Reihe von pathogenen Organismen identifiziert und charakterisiert, u. a. auch in den Clostridien C. perfringens (ColA; MATSUSHITA et al., 1994) und C. histolyticum (ColG und ColH; MATSUSHITA et al., 1999). Collagenasen katalysieren die Spaltung des Proteins Collagen, welches ubiquitär im Säugetierreich vorkommt; im Menschen z. B. macht das Collagen 1/4 des Gesamtproteins aus. Collagen besteht aus einer vernetzten dreifachen Helix, welche durch drei Proteinketten gebildet wird, wobei jede Kette aus der wiederholten Abfolge dreier Aminosäuren aufgebaut ist. Es wird angenommen, dass Collagenasen eine wichtigen Beitrag zur Pathogenität invasiver Organismen leisten, da die 
Spaltung des Collagens - im Bereich der helikalen Region - zum Verlust der Integrität des Gewebes im infizierten Wirt beitragen könnte (HARRINGTON, 1996). Bisher charakterisierte bakterielle Collagenasen bestehen aus drei unterschiedlichen Segmenten (s. Abb. 37). Das Segment 1 ist die katalytische Domäne, wie beim Tetanus-Toxin eine Metalloprotease, welche in ihrer Aminosäurensequenz das Consensus-Motiv für Zink-Proteasen, HEXXH, trägt. Die Funktion des Segments 2 ist bisher nicht verstanden. Es trägt die sogenannte PKD-Domäne. Der Name bezieht sich auf das im Menschen gefundene PKD(Polycystic Kidney Disease)1-Protein, welches die Domäne in mehreren Kopien trägt (THE INTERNATIONAL POLYCYSTIC KIDNEY DISEASE CONSORTIUM, 1995). Für Segment 3, welches oftmals dupliziert vorliegt, wird angenommen, dass es die Collagenbindende Domäne darstellt (MATSUSHITA et al., 2001).

Beim Abgleich der ColT-Sequenz aus pE88 mit allen verfügbaren Datenbanken wurde eine weitere, bisher unerkannte Collagenase gefunden: das vom SangerInstitut (Cambridge, England) sequenzierte Genom von $C$. botulinum A kodiert ebenfalls für eine Collagenase, welche hier nachfolgend ColB genannt werden soll. Zusätzlich wurde eine Collagenase in B. anthracis gefunden, hier ColBA genannt (READ et al., 2002). Mit den Aminosäuresequenzen der aus den Clostridien und aus B. anthracis stammenden Collagenasen wurde nun ein multiples Sequenzalignment (MSA) gemacht. Eine schematische Repräsentation dieses Alignments ist in Abbildung 37 wiedergegeben. Dadurch konnte gezeigt werden, dass sich ColT von allen bisher identifizierten Collagenasen unterscheidet: das Segment 2, welches die PKD-Domäne enthält, fehlt in ColT. Dies hat wahrscheinlich keine Auswirkungen auf die katalytische Aktivität der Collagenase: MATSUSHITA et al. (2001) haben zeigen können, dass die katalytische Aktivität lediglich von Segment 1 abhängt. Des weiteren vermuteten sie, dass das Segment 2 nicht für die Bindung des Collagens benötigt wird. Vielmehr kann aufgrund der Ähnlichkeit zur PKD-Domäne aus PKD1 - ein integrales Membranprotein, das in Zell-Matrix-Interaktionen involviert ist angenommen werden, dass mittels Segment 2 weitere Substrate gebunden werden können. 


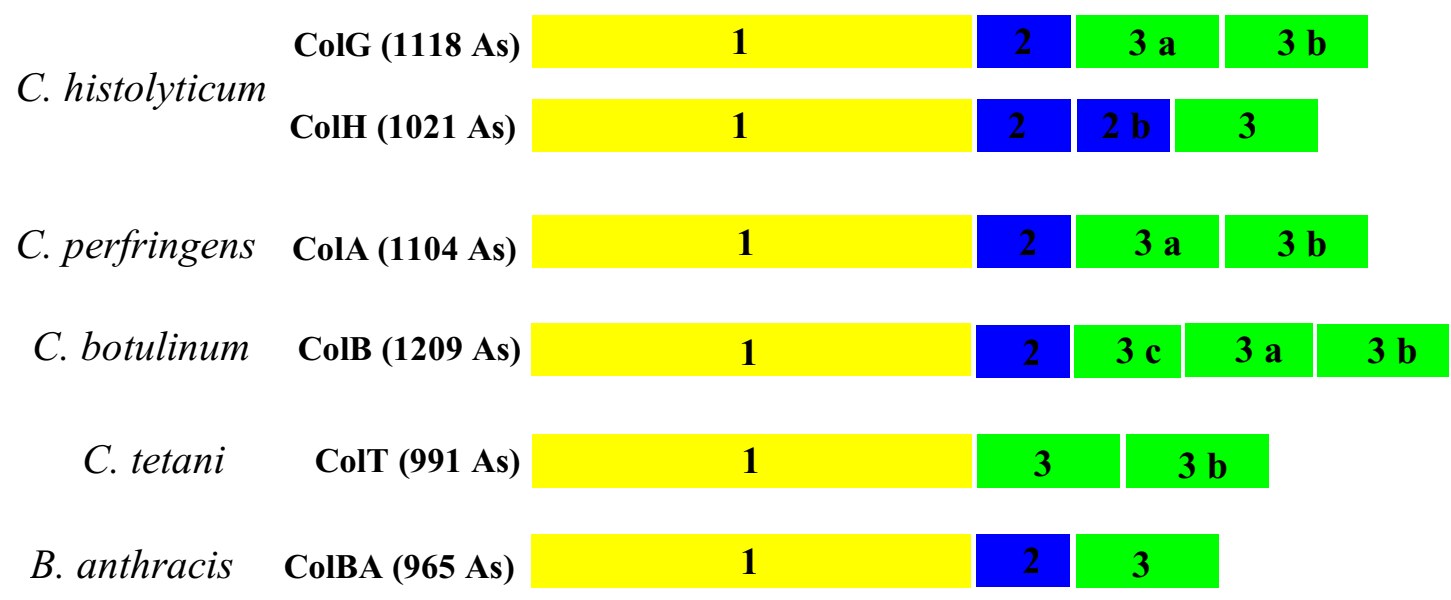

\section{Abb. 37: Schematische Darstellung und Vergleich der Struktur von} Collagenasen aus Clostridien und $B$. anthracis

Erklärungen zu den einzelnen Segmenten sind im Text gegeben.

ColT ist als bisher einzige Collagenase Plasmid-kodiert. Darum lohnt sich ein Blick in ihre phylogenetische Abstammung. Um diese $\mathrm{zu}$ untersuchen, wurde der Neighbour-joining-Algorithmus auf das MSA der Proteinsequenzen der in Abbildung 37 aufgeführten Collagenasen angewandt. Die so berechnete phylogenetische Distanz der Collagenasen zeigt Abbildung 38. Hier wird die enge Verwandtschaft der Enzyme aus $C$. tetani und $C$. botulinum deutlich. Über das Segment 1 weisen diese Collagenasen eine Proteinidentität von $79 \%$ auf. Im Gegensatz dazu zeigen die anderen clostridiellen Collagenasen keine klare Clusterung. 


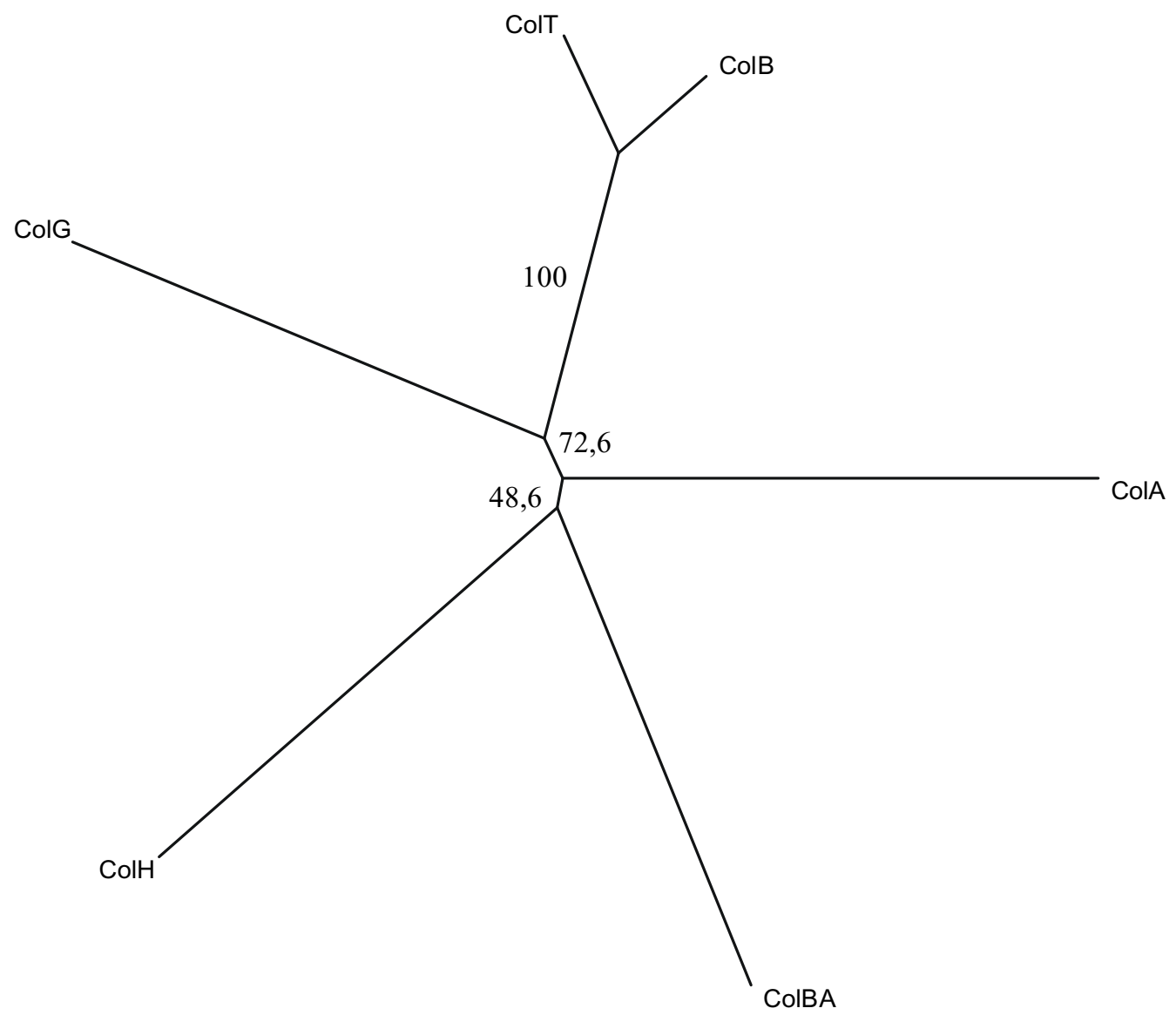

\section{Abb. 38: Phylogenetische Beziehung der Collagenasen einiger pathogener Clostridien und $B$. anthracis}

Gezeigt ist ein die Collagenasen verbindender Neighbour-joining(NJ)-Tree. Der NJ-Algorithmus wurde auf genetische Distanzen zwischen Paaren von CollagenaseProteinsequenzen angewandt (1000 bootstrap-Iterationen; SAITOU \& NEI, 1987). Die Herkunft der aufgeführten Collagenasen wird aus Abbildung 37 deutlich.

\subsubsection{Tetanolysin $\mathrm{O}$}

Das Chromosom von C. tetani kodiert für ein Cytolysin, das Tetanolysin O, das eine starke Ähnlichkeit zum gut charakterisierten Perfringolysin O, dem sogenannten $\theta$ Toxin aus $C$. perfringens zeigt (ROOD, 1998). Tabelle 17 gibt den Ähnlichkeitsvergleich des Tetanolysin O aus C. tetani E88 zu homologen Proteinen wieder, welche alle aus pathogenen Gram-positiven Organismen stammen. Diese Klasse von Toxinen wurde bislang als Thiol (Sulfhydryl)-aktivierte CytolysinFamilie bezeichnet, was auf die reversible Inaktivierung durch Sauerstoff anspielt. 
Diese Sauerstoff-Labilität ist aber nur bei wenigen Cytolysinen dieses Typs feststellbar, so dass die alternative Klassen-Bezeichnung Cholesterol-abhängige Cytolysine (CDC) vorgeschlagen wurde (TWETEN, 1997).

Tabelle 17: Ähnlichkeit des Tetanolysin O aus C. tetani E88 zu Cholesterolabhängigen Cytolysinen Gram-positiver Bakterien

\begin{tabular}{c|c} 
Cytolysin & $\begin{array}{c}\text { Proteinidentität (Ähnlichkeit) zu } \\
\text { Tetanolysin O (E88) in \% }\end{array}$ \\
\hline $\begin{array}{c}\text { Tetanolysin O (C. tetani } \\
\text { Stamm Spanien)* }\end{array}$ & $67(78)$ über 471 As \\
\hline $\begin{array}{c}\text { Perfringolysin O }(C . \\
\text { perfringens })\end{array}$ & $55(72)$ über 465 As \\
\hline Alveolysin O (B. alvei) & $54(70)$ über 484 As \\
\hline NC_003995 (B. anthracis) & $53(72)$ über 464 As \\
\hline Novyilysin $(C$. novyi) & $54(71)$ über 465 As \\
\hline Septicolysin $(C$. septicum $)$ & $53(69)$ über 465 As \\
\hline Streptolysin O $($ S. pyogenes $)$ & $50(68)$ über 477 As \\
\hline $\begin{array}{c}\text { Listeriolysin O } \\
(\text { L. monocytogenes })\end{array}$ & $44(66)$ über 475 As \\
\hline * Der C. tetani-Stamm ist nicht näher charakterisiert worden (CERRATO et al. 2000).
\end{tabular}

* Der C. tetani-Stamm ist nicht näher charakterisiert worden (CERRATO et al., 2000).

CDCs sind in der Lage, Löcher in eukaryotischen Cholesterol-haltigen Zellmembranen entstehen zu lassen. Das geschieht durch die Oligomerisierung von bis zu 50 Cytolysin-Momomeren, welche eine transmembrane $\beta$-Barrel-Pore bilden, die einen Durchmesser von bis zu $30 \mathrm{~nm}$ haben kann, wodurch nicht nur Ionen sondern auch Makromoleküle hindurchgelangen können, was i. d. R. die Integrität der Wirtszelle zerstört (SHATURSKY et al., 1999). Das in vielen eukaryotischen Zellmembranen enthaltene Cholesterol (z. B. in Erythrocyten-Membranen) fungiert dabei sowohl als Cytolysin-Rezeptor als auch als Initiationspunkt der Oligomerisierung der Cytolysin-Monomere sowie als Stabilisator der Pore (HOTZE et al., 2002).

Strukturelle und funktionelle Studien sind in erster Linie mit Perfringolysin O aus $C$. perfringens gemacht worden (ROSSJOHN et al., 1997; RAMACHANDRAN et al., 2002). Man fand, dass der bei allen bisher bekannten Cholesterol-abhängigen 
Cytolysinen konservierte C-terminale Sequenzabschnitt ,ECTGLAWEWWR' eine essentielle Funktion hat. Vor allem der Cystein-Rest (sowie die drei TryptophanReste) wurden intensiv untersucht. Eine Modifikation des Cysteins mit Sulfhydrylspezifischen Agenzien eliminierte die Aktivität des Toxins. Erstaunlicherweise hatte aber eine Substitution des Cysteins durch ein Alanin keine Auswirkungen auf die cytolytische Aktivität (PINKNEY et al., 1989). Durch die Analyse der Struktur des Perfringolysin O konnte festgestellt werden, dass sich der erwähnte C-terminale Sequenzabschnitt in einer $\beta$-Faltblatt-reichen Domäne (D4) befindet, welche wahrscheinlich in der Bindung des Cholesterols involviert ist (ROSSJOHN et al., 1997). Die Struktur des Perfringolysin O ist in Abbildung 39 gezeigt.

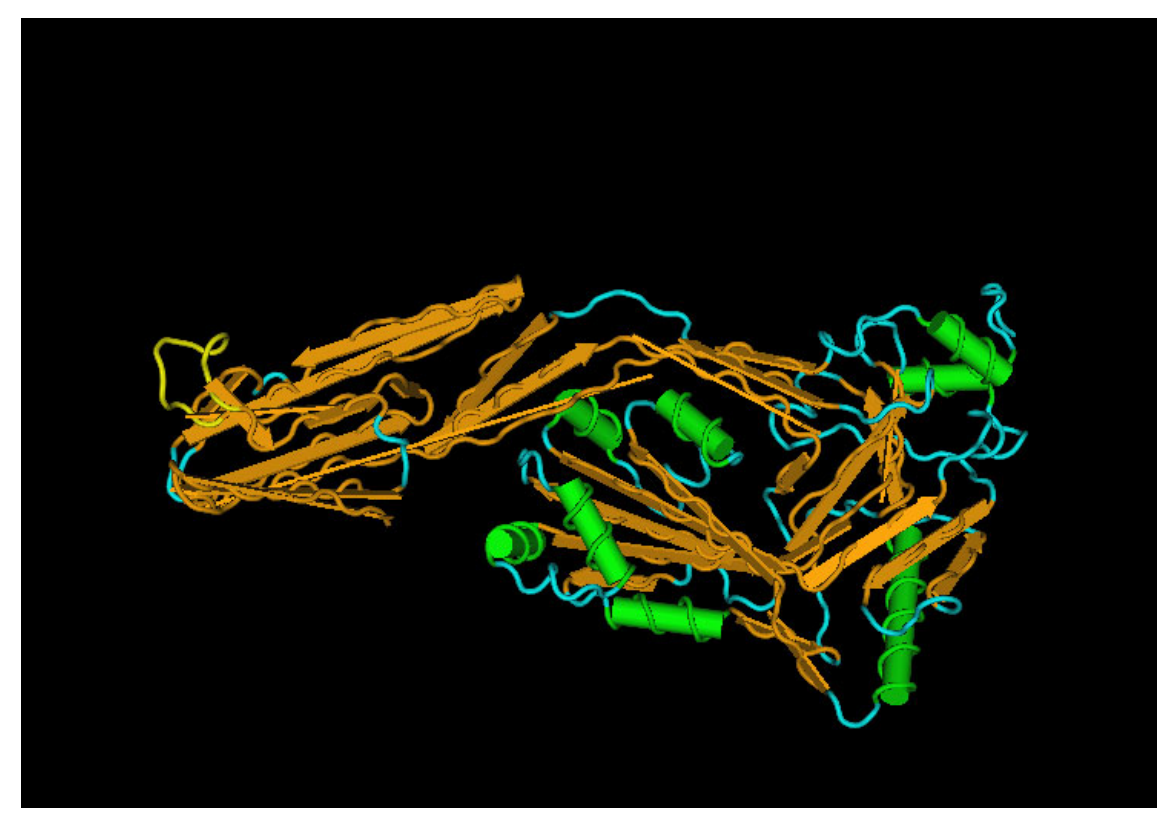

Abb. 39: Struktur des Perfringolysin $O$ aus $C$. perfringens, einem Homologon von Tetanolysin $O$ aus $C$. tetani (ROSSJOHN et al., 1997)

Die $\beta$-Faltblatt-reiche Region stellt den C-Terminus dar. Der für die Proteinaktivität essentielle konservierte Sequenzabschnitt ,ECTGLAW EWWR' ist gelb markiert.

Der Vergleich der Cytolysine aus Tabelle 17 in einem multiplen Sequenzalignment zeigt eine im C-Terminus der Proteine sehr stark ausgeprägte Konservierung. Allerdings unterscheiden sich die bisher kaum untersuchten N-Termini; während sich die von Perfringolysin O, Septicolysin O und Novyilysin O nahezu gleichen, zeigte der N-Terminus von Tetanolysin O des Stammes E88 eine erhebliche Abweichung; die ersten 60 Aminosäurereste wiesen kaum Ähnlichkeit zu den N-Termini der 
andern Cytolysine auf, einschließlich des Tetanolysin $\mathrm{O}$ eines nicht näher charakterisierten $C$. tetani-Stammes (CERRATO et al., 2000). Zur besseren Visualisierung der Verwandtschaftsverhältnisse unter den CDCs wurden die phylogenetischen Distanzen mit der Neighbour-Joining-Methode berechnet (Abb. 40).

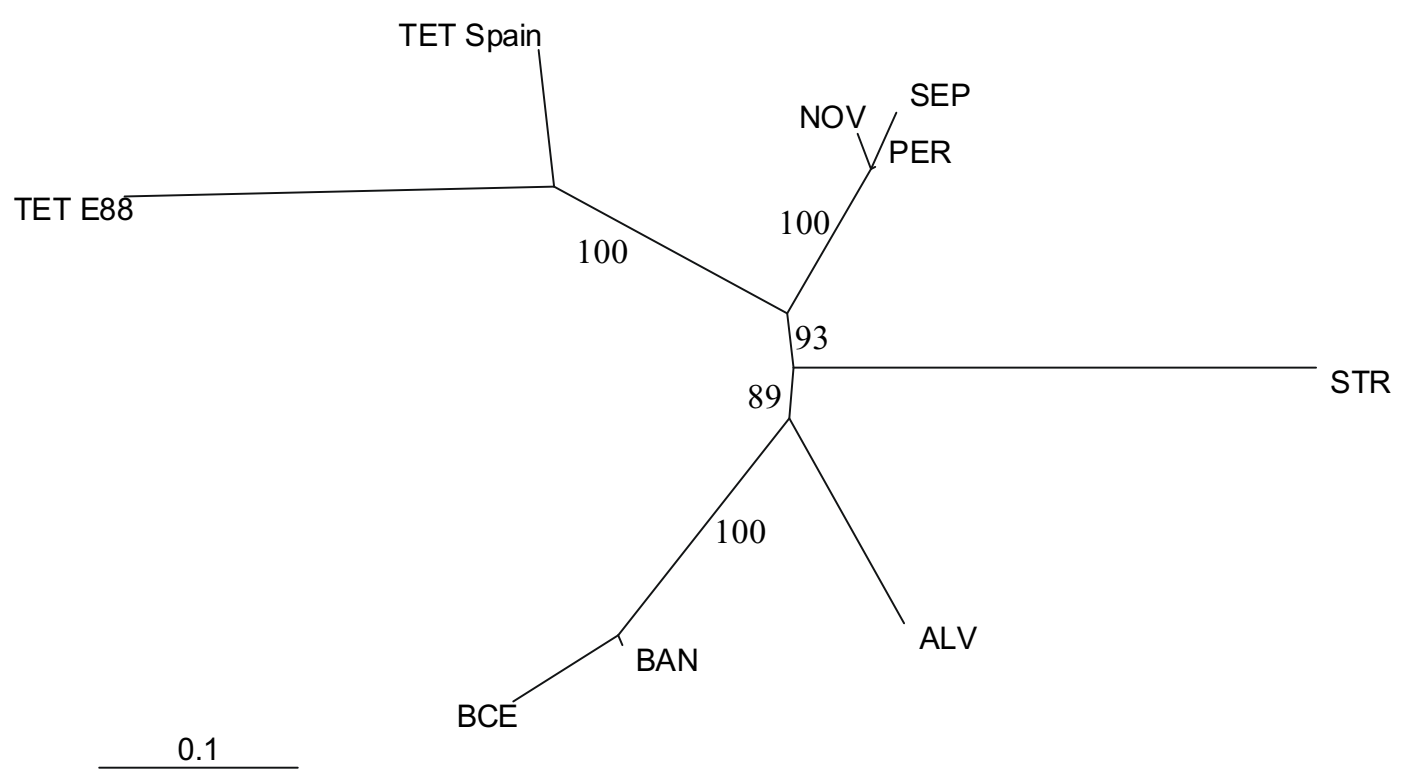

\section{Abb. 40: Phylogenetische Beziehungen homologer Cholesterol-abhängiger} Cytolysine pathogener Gram-positiver Organismen

Die Heterogenität der N-Termini hatte keine Auswirkungen auf die Struktur des Baumes. Abkürzungen: TET, Tetanolysin $\mathrm{O}$ aus C. tetani; NOV, Novyilysin $\mathrm{O}$ aus $C$. novyi; SEP, Septicolysin $\mathrm{O}$ aus $C$. septicum; PER, Perfringolysin $\mathrm{O}$ aus $C$. perfringens; STR, Streptolysin $\mathrm{O}$ aus $S$. pyogenes; ALV, Alveolysin $\mathrm{O}$ aus $B$. alvei; BAN, Cytolysin aus $B$. anthracis; BCE, Hämolysin aus B. cereus.

Es sind drei Cluster erkennbar: das erste Cluster besteht aus den nahezu identischen Cytolysinen von C. novyi, C. septicum und $C$. perfringens. Das zweite Cluster umfasst Cytolysine aus Organismen der Gattung Bacillus (B. cereus, B. anthracis, B. alvei). Überraschend ist die relativ große Distanz der Tetanolysine aus den zwei verschiedenen $C$. tetani-Stämmen, die ebenfalls ein Cluster bilden, obwohl sich die N-Termini dieser beiden Proteine erheblich voneinander unterscheiden. Es bleibt zu klären, warum solche divergierenden N-Termini bestehen und ob diese Divergenz Spezifitäten für unterschiedliche Membrantypen zu Folge hat. 


\subsubsection{S-Layer-Proteine als möglicher Virulenzfaktoren}

S (Surface)-Layer-Proteine, auch SLPs genannt, bilden eine einschichtige Hülle um die Bakterienzelle. Diese wurde mit Hilfe der Elektronenmikroskopie bei verschiedenen Organismen entdeckt (SARA \& SLEYTR, 2000). Die Genomsequenz von C. tetani offenbarte nun mindestens 32 verschiedene Zelloberflächenproteine (s. Tabelle 10 in 3.4.5.2). Es ist anzunehmen, dass einige dieser Proteine an der Ausbildung einer S-Layer-Schicht in $C$. tetani beteiligt sind; andere wiederum könnten Zelloberflächen-assoziiert vorliegen und ganz bestimmte Funktionen ausüben, die für die Pathogenität des Organismus von Bedeutung sind. Es wird seit längerem vermutet, dass Zelloberflächenproteine, die Teil der S-Layer oder mit ihr assoziiert sind, als Pathogenitätsfaktoren fungieren, da sie in der Lage sind, die Anheftung der Bakterienzelle an das Gewebe des infizierten Wirts zu vermitteln, welche der Kolonisierung und der Proliferation vorausgeht (BEVERIDGE et al., 1997). Alternativ oder zusätzlich wird ihnen auch die Fähigkeit der Interaktion mit dem Immunsystem des infizierten Wirts zugesprochen.

Daher sollen die 32 in $C$. tetani gefundenen Zelloberflächenproteine genauer analysiert und mit bereits charakterisierten Proteinen verglichen werden. Erst kürzlich wurde die S-Layer des virulenten Stammes C253 sowie anderer Stämme von $C$. difficile analysiert (KARJALAINEN et al., 2001; CALABI et al., 2001). Man identifizierte zwei Protein-Komponenten der S-Layer: das sogenannte low- $M W$-SLP (S-Layer-Protein mit niedrigem Molekulargewicht) und das high-MW-SLP (S-LayerProtein mit höherem Molekulargewicht). Das low-MW-SLP ist das am häufigsten gefundene Antigen in Patienten mit einer C. difficile-Infektion (CERQUETTI et al., 1992). Des weiteren wurde entdeckt, dass sich das low-MW-SLP bei verschiedenen C. difficile-Stämmen erheblich unterscheidet (CALABI \& FAIRWEATHER, 2002). Beide Komponenten, low-MW-SLP und high-MW-SLP, werden in C. difficile C253 von demselben Gen kodiert, slpA. Das SlpA-Protein wird also posttranslational prozessiert. SlpA weist Ähnlichkeiten zu den charakterisierten Zellwand-gebundenen Proteinen N-Acetylmuramoyl-L-Alanin-Amidase (= Autolysin CwlB/LytC) und seinem Verstärker (CwbA/LytB) aus B. subtilis auf. Nun konnten im Genom von $C$. difficile 28 weitere ORFs gefunden werden, die eine hohe Homologie zum SlpA zeigten (CALABI \& FAIRWEATHER, 2002). Bisher ist lediglich eines der 28 
paralogen SlpA-Proteine aus $C$. difficile näher untersucht worden: das Zellwand- und Adhäsionsprotein Cwp66 (WALIGORA et al., 2001).

In C. tetani konnten nun 19 zum SlpA bzw. zum Cwp66 homologe Proteine gefunden werden, die alle über eine typische Signalpeptidsequenz verfügen. Eine Analyse der Domänen-Struktur der Proteine aus C. tetani und der homologen Proteine SlpA und Cwp66 aus C. difficile ist in Abbildung 41 gezeigt.



\section{Abb. 41: Domänenaufbau von 19 Zelloberflächenproteinen aus $C$. tetani sowie homologen Proteinen aus $C$. difficile und $B$. subtilis}

SlpA und Cwp66 stammen aus $C$. difficile; CwlB und CwbA stammen aus B. subtilis. In Grün sind jeweils die Zellwand-Bindedomänen (PF04122), gekennzeichnet. In rot, Amidase-Domäne PF01520; in blau, Metallo- $\beta$ Lactamase-Domäne PF00753; in orange, LRR (Leucin-reiche Wiederholungen)-Domäne PF00560; in violett, BIG (bakterielle Immunglobulin-ähnliche)-Domäne PF02368. Die Größenverhältnisse der Proteine (zwischen 353 und 1080 As) wurden nicht berücksichtigt. 
Die Homologie der aufgeführten Proteine basiert auf dem Vorhandensein einer putativen Zellwand-bindenden Domäne (PF04122), die i. d. R. im N-Terminus in mehreren Kopien vorkommt. Die C-Termini der C. tetani-Proteine unterscheiden sich z. T. erheblich, was in Zusammenhang mit dem Befund von Interesse ist, dass die C-terminale Domäne von Cwp66 auf der Zelloberfläche exponiert ist (WALIGORA et al., 2001). Es wird angenommen, dass sie für die eigentliche Adhäsion an Gewebezellen des Wirts verantwortlich ist (CALABI et al., 2002). Bezüglich des C-Terminus ließen sich lediglich in drei Proteinen bekannte Domänen identifizieren: CTC1364 besitzt C-terminal eine Zink-abhängige $\beta$-LactamaseDomäne, die wahrscheinlich in den extrazellulären Raum ragt. Diese Domäne wurde z. B. in der Zink-abhängigen $\beta$-Lactamase von B. cereus gefunden, welche die Hydrolyse von fast allen bekannten $\beta$-Lactamen katalysiert (CARFI et al., 1995). CTC2092 enthält C-terminal eine Amidase-Domäne und ähnelt damit im Domänenaufbau dem Autolysin CwlB aus B. subtilis, die dominante ZellwandHydrolase dieses Organismus (KURODA \& SEKIGUCHI, 1991). Interessant ist auch CTC520, welches C-terminal 9 Kopien einer LRR (Leucin-reiche Wiederholungen)-Domäne enthält. Diese kommt auch in Internalinen aus $L$. monocytogenes und in zwei weiteren C. tetani-Proteinen vor und wird im folgenden Abschnitt im Detail besprochen.

Zwei Proteine aus C. tetani, CTC494 und CTC495, die eine N-terminale Signalpeptidsequenz haben, zeigen Ähnlichkeiten zu Internalin A und anderen Internalinen des invasiven Organismus Listeria monocytogenes. Die C. tetaniProteine enthalten wie die Internaline multiple Leucin-reiche Sequenzwiederholungen (LRR-Domäne). Diese sind in den Internalinen in ProteinProtein-Interaktionen involviert. Internaline sind verantwortlich für die Herstellung des Zellkontaktes zu bestimmten Epithelzellen des Säugetierwirts (MENGAUD et al., 1996). Internalin A z. B. bindet an das Epithelzelloberflächenprotein E-Cadherin. Nach Herstellung eines solchen Kontaktes kann die Listeria-Zelle ins Epithel eindringen (CABANES et al., 2002).

Die zwei C. tetani-Proteine enthalten im Vergleich zum Internalin A mehr Kopien der LRR-Domäne, die über die ganze Proteinsequenz verteilt auftreten (Abb. 42). 


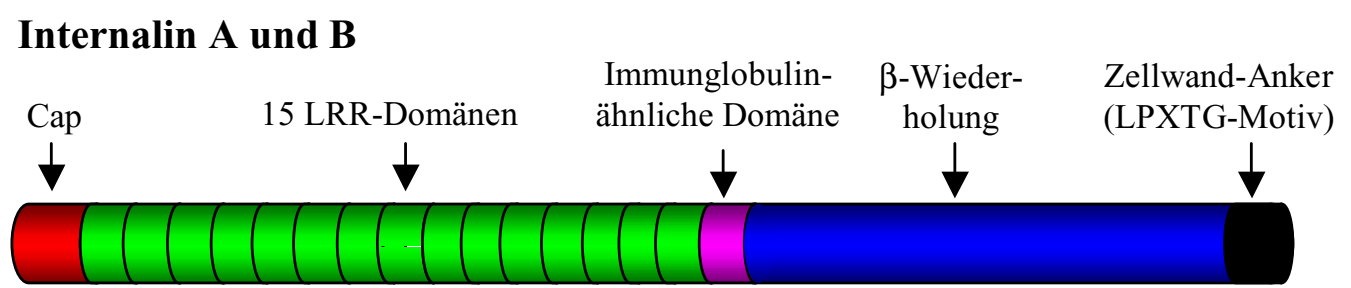

\section{CTC494, CTC495}

Abb. 42: Vergleich der Domänenstruktur von Internalin A aus L. monocytogenes mit den C. tetani-Proteinen CTC494, CTC495

Zwischen CTC494 und CTC495 besteht bezüglich der Domänenstruktur kein Unterschied. Beide Proteine enthalten eine 79 As große Region (in gelb), die keine Leucin-reichen Sequenzwiederholungen (LRR-Domäne) beinhaltet.

Im Gegensatz zu den Internalinen, die über eine Zellwand-Anker-Domäne verfügen, ist keine bekannte Zellwand-bindende Domäne in den Proteinen CTC494 und CTC495 auszumachen. Im übrigen konnte das in L. monocytogenes und anderen Gram-positiven Bakterien wie Staphylococcus aureus vorkommende ZellwandAnker-Motiv ,LPXTG', worüber die Oberflächenproteine kovalent mit der Zellwand verbunden werden (NOVICK, 2000), im Genom von C. tetani nicht gefunden werden.

Zur näheren Betrachtung der 23 LRR-Domänen in CTC494 und CTC495 wurden sie untereinander ausgerichtet (Abb. 43). Jede Domäne besteht aus exakt 22 Aminosäuren. Für das Motiv kann der Consensus XXNX ${ }^{\mathrm{I}} /{ }_{\mathrm{V}}$ XXLXXLXXLXXLXX LXL gebildet werden. Er unterscheidet sich nicht von der Consensus-Sequenz der LRR-Domänen des Internalins A. 


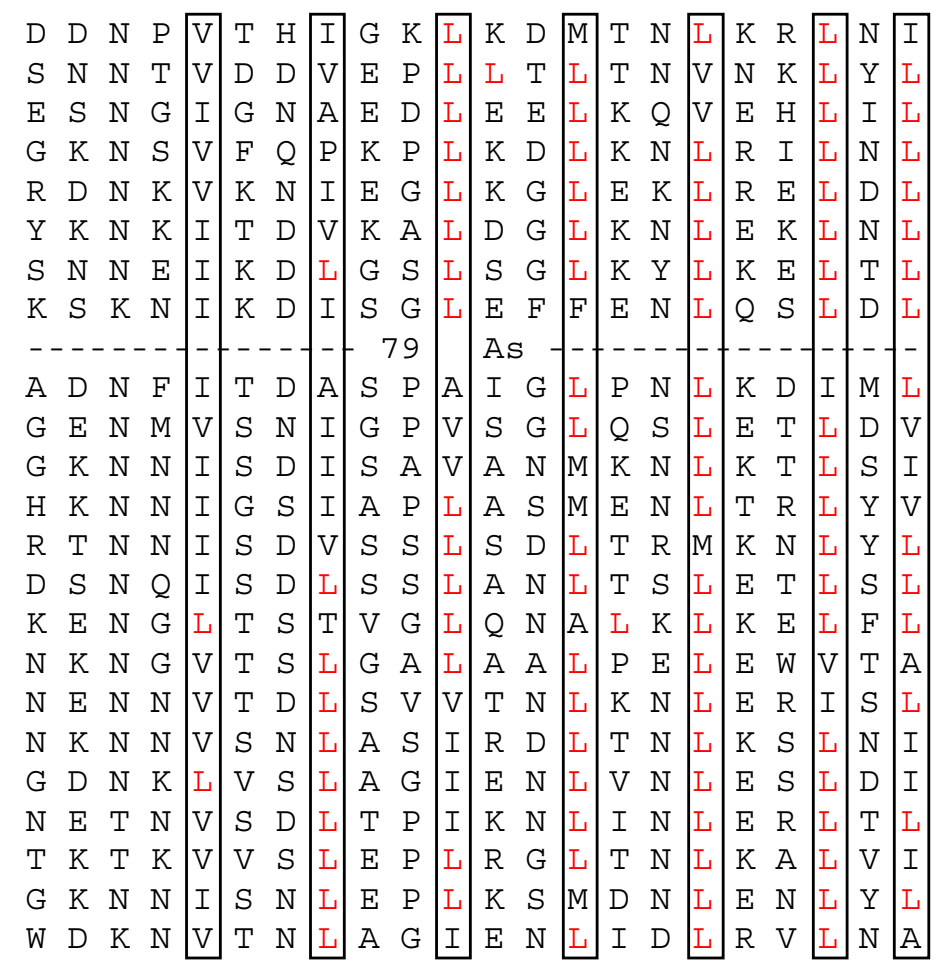

\section{Abb. 43: Die 23 LRR-Domänen des Proteins CTC495}

Die Domänen schließen - bis auf eine 79 As große Lücke - unmittelbar aneinander an. In rot sind alle Leucin-Reste hervorgehoben. Gekästelt sind alle Leucin-reichen Positionen dieser Domäne. Leucin wird des öfteren von den ähnlichen Aminosäuren Isoleucin und Valin ersetzt.

Mittlerweile sind die ersten Strukturdaten von Proteinen mit Leucin-reichen Wiederholungen ermittelt worden. Abbildung 44 zeigt die Struktur des N-Terminus von Internalin B, welches dem Internalin A sehr ähnlich ist. Der N-Terminus mit den multiplen LRR-Domänen stellt die funktionelle Region dieses Proteins dar und stellt den Kontakt zu Epithelzelloberflächenproteinen her (MARINO et al., 1999). Auch andere LRR-enthaltende Proteine sind kristallographisch analysiert worden wie das YopM-Effector-Protein aus Y. pestis (Abb. 44; EVDOKIMOV et al., 2001), ein essentieller Virulenzfaktor des Pest-Erregers, welcher den Blutgerinnungsfaktor Thrombin binden kann. 

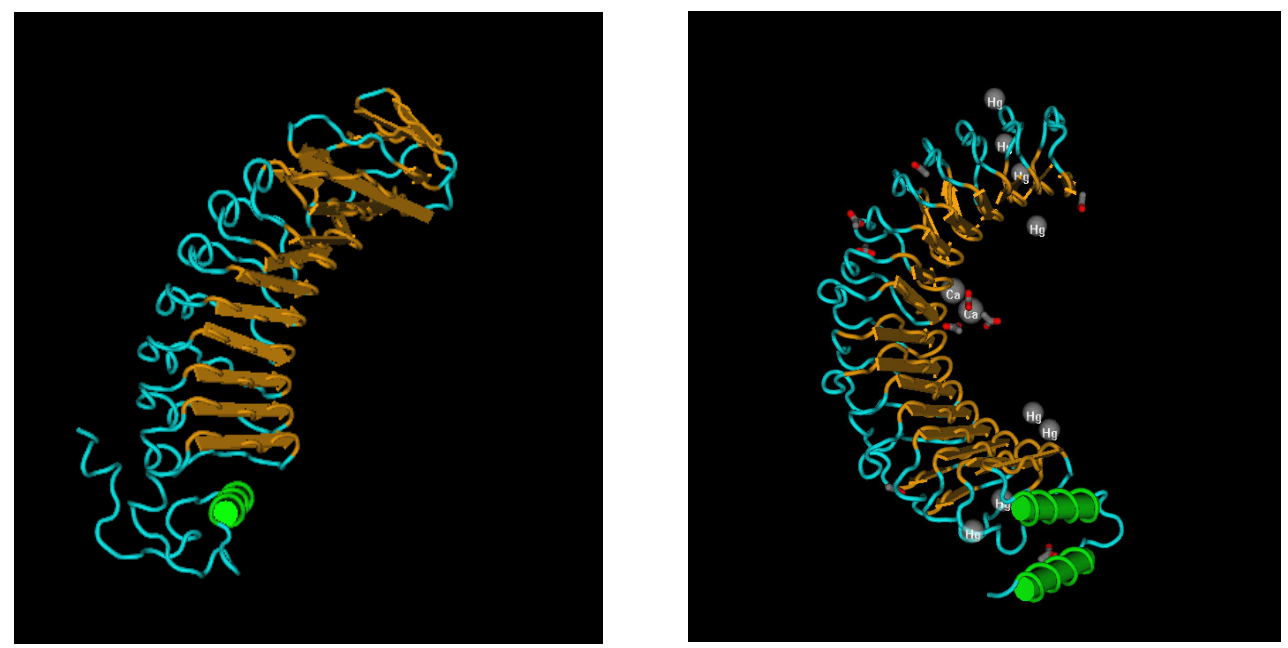

Abb. 44: Strukturen des N-Terminus von Internalin B aus L. monocytogenes und des YopM-Effektorproteins aus $Y$. pestis (MARINO et al., 1999; EVDOKIMOV et al., 2001)

Deutlich zu erkennen sind die in beiden Proteinen vorhandenen multiplen LRR-Domänen, die jeweils ein $\beta$-Faltblatt und ein Loop umfassen.

Die dritte Gruppe von Zelloberflächenproteine in C. tetani beinhaltet 10 Proteine mit typischer N-terminaler Signalpeptidsequenz, die einige Zelloberflächen-Domänen aufweisen, ansonsten aber keine signifikanten Ähnlichkeiten zu Proteinen aus Datenbanken zeigen. Die Proteine CTC747, CTC749, CTC750, CTC770, CTC771, CTC772 und CTC777 besitzen 1-4 Kopien der BIG (bakterielle Immunglobulinähnliche)-Domänen PF02368 und PF02369, welche auch in Hüllproteinen von Phagen und bakteriellen Oberflächenproteinen wie Intimin und Invasine vorkommen. Intimine sind Adhäsionsproteine, die vor allem in pathogenen E. coli-Stämmen gut charakterisiert sind. Sie bewirken die Anheftung der E. coli-Zelle an Zellen des Intestinaltrakts (FRANKEL et al., 2001). Zusätzlich lassen sich in einigen Proteinen noch weitere bekannte Domänen identifizieren: In CTC767, CTC769 und CTC776 findet man 1-3 Kopien der Prenyltransferase- und Squalen-Oxidase-Domäne PF00432. Diese kommt z. B in Farnesyltransferasen vor und ist in diesem Enzym wahrscheinlich an der Bindung von Peptiden beteiligt. In CTC777 lassen sich neben drei Kopien der BIG-Domäne 5 Kelch-Motive entdecken. Das Kelch-Motiv bildet ein $\beta$-Faltblatt; mehrere dieser Motive bilden eine $\beta$-Superbarrel-Struktur. Das Motiv findet sich - stets in multiplen Kopien - vor allem in eukaryotischen und viralen 
Proteinen wie z. B. in Scruinen, welche Aktin quervernetzen können, oder in Neuraminidasen, die Sialinsäurereste von Glykoproteinen abspalten können.

Der Fülle verschiedener Zelloberflächenproteine in C. tetani ist erstaunlich. Neben solchen, die auch in anderen Organismen gefunden wurden, gibt es eine ganze Reihe neuartiger Proteine unbekannter Funktion. Die Analyse der Domänenstruktur zeigte, dass die meisten Zelloberflächenproteine aus $C$. tetani wahrscheinlich an der Herstellung des Kontaktes zu Faktoren der Außenwelt über adhäsive Mechanismen beteiligt sind. Die C. tetani-Zelle scheint also in der Lage zu sein, mit Faktoren des Wirts wie z. B. Gewebeoberflächen zu interagieren. Die Analyse der Genomsequenz hat also neue Erkenntnisse über die Interaktion von $C$. tetani mit seinem Wirt ergeben.

\subsection{2 Übersicht über die metabolischen Fähigkeiten sowie andere zelluläre Funktionen}

Abschließend sollen die aus der Genomsequenz abgeleiteten wichtigsten metabolischen Wege und weitere zelluläre Funktionen von $C$. tetani in einem Schema zusammengefasst werden (Abb. 45). Das Hauptaugenmerk wird dabei auf metabolische Merkmale des Bakteriums gelegt. So sind alle in Kapitel 3.4 erwähnten Systeme enthalten. Weitere Systeme wurden hinzugefügt, wie etwa der offensichtlich nicht vollständig vorhandene Harnstoffzyklus; es konnten zwar die ORFs für Argininosuccinat-Synthetase (CTC561), Argininosuccinat-Lyase (CTC562) und Arginase (CTC1763), aber keine Ornithin-Transcarbamoylase gefunden werden - in C. perfringens fehlt dagegen die Arginase. Die Nutzung eines Harnstoffzyklus würde hinsichtlich der metabolischen Präferenzen von C. tetani - die Vergärung von Aminosäuren - Sinn machen. Damit könnte sich C. tetani der beim Abbau von Aminosäuren anfallenden Mengen von Ammonium in Form von Harnstoff entledigen. Zusätzlich könnte der Harnstoffzyklus für C. tetani möglicherweise noch eine zweite vielleicht wichtigere Funktion haben: die Produktion von Fumarat. Das könnte das Vorhandensein der vier verschiedenen Kopien der Fumarat-Reduktase erklären. Das durch die Vergärung von Aminosäuren im Harnstoffzyklus anfallende Fumarat könnte im Rahmen einer Fumarat-Atmung als terminaler 
Elektronenakzeptor genutzt werden, was möglicherweise mit einem Energiegewinn einhergehen würde. Zudem könnte das in der Fumarat-Reduktase-Reaktion gewonnene Succinat zu Butyrat umgesetzt werden. Dazu sind die Gene der Enzyme Succinat-CoA-Transferae, Succinat-Semialdehyd-Dehydrogenase und 4Hydroxybutyrat-CoA-Transferase vorhanden. Eine typische 4-HydroxybutyratDehydrogenase wie z. B. aus C. kluyveri konnte nicht ausgemacht werden. Deren Funktion kann aber möglicherweise von vorhandenen Enoyl-CoA-Hydratasen übernommen werden (HENNE et al., 1999). Es bleibt zu klären, ob diese beschriebenen metabolischen Wege in vivo begangen werden.

Weitere zelluläre Funktionen wie die Flagellensynthese oder Chemotaxis sind in Abbildung 45 eingefügt. Auch sind die 65 gefundenen sporulationsrelevanten Proteine vermerkt, obwohl der sequenzierte $C$. tetani-Stamm E88 eine nicht sporulierende Variante darstellt. Womöglich ist der Verlust der Sporulationsfähigkeit auf den Defekt eines Gens zurückzuführen, dessen Protein regulatorische Funktion hinsichtlich der Weichenstellung zur Sporulation besitzt.

Abschließend sei bemerkt, dass das Genom für viele weitere Funktionen kodiert, die hier nicht näher erläutert werden konnten, wie z. B. Systeme der Proteinbiosynthese, der DNA-Replikation und -Modifikation; diese sagen wenig über die Besonderheiten von $C$. tetani aus, da sie im wesentlichen in allen bakteriellen Organismen vorkommen.

\section{(nächste Seite)}

\section{Abb. 45: Übersicht über wichtige zelluläre Funktionen von $C$. tetani}

Gezeigt sind in erster Linie metabolische Wege, Transportfunktionen und membranständige Systeme mit möglicher bioenergetischer Relevanz. In rot sind die ORF-Nummern der involvierten Proteine aufgeführt. Durchgezogene Pfeile deuten eine direkte Umsetzungsreaktion an, gestrichelte Linien weisen auf eine Umsetzung in mehreren Schritten oder auf sonstige Interaktionen hin. Abkürzungen: SLP, S-Layer-Protein; ABC, ATP-bindende Kassette; PTS, Phosphotransferasesystem; MDR, MultiDrug-Resistenz; SRP, Signal recognition particle; V-Typ, Vacuolärer-Typ; ZKS, Zwei-Komponenten-Systeme. 


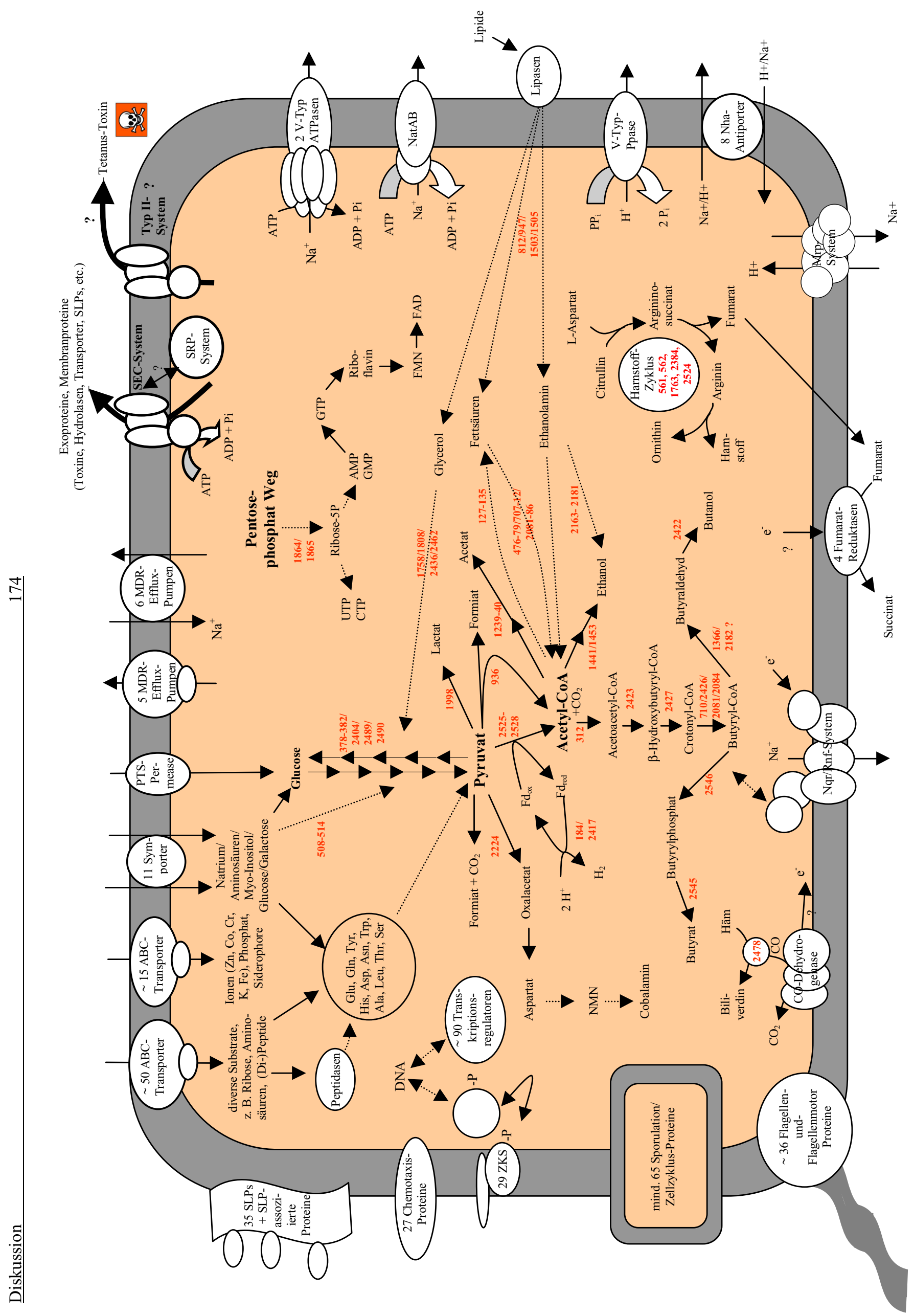




\subsection{Ausblick}

Die im Rahmen der vorliegenden Arbeit ermittelte Genomsequenz stellt das Fundament zur Erforschung des Potentials von C. tetani dar. Zum ersten Mal ist es nun möglich, die gesamten stoffwechselphysiologischen und bioenergetischen Möglichkeiten des Organismus zu studieren. Darüber hinaus bildet die Genomsequenz die Grundlage zur Erforschung des pathogenen Potentials von $C$. tetani. Neben der Identifizierung sämtlicher Virulenzfaktoren können nun auch die regulatorischen Netzwerke analysiert werden, welche die Pathogenitätsausprägung kontrollieren. Ein nächster Schritt wäre eine detaillierte Transkriptionsanalyse z. B. mittels der Mircorarray-Technik, die darüber Auskunft geben könnte, welche Gene des Genoms unter welchen Bedingungen tatsächlich transkribiert werden. Zur Analyse des Expressionsprofils - also aller unter den gewählten Bedingungen tatsächlich gebildeten Proteinen - böten sich Techniken wie die 2DGelelektrophorese an.

Die Ermittlung der Genomsequenz bietet aber auch mögliche praktische Anwendungsbezüge von - zumindest potentiell - industrieller Bedeutung. Trotz der Verfügbarkeit eines guten Impfstoffes gegen eine Tetanus-Erkrankung, des TetanusToxoids, ist dessen Herstellung ein kostspieliger und aufwendiger Prozess, der gewisse Risiken mit sich bringt, da mit Wildtyp-Stämmen von C. tetani gearbeitet wird. Die Genomsequenz von C. tetani und ihr Vergleich mit den Genomen anderer pathogener Organismen bietet nun die Möglichkeit, neue Impfstoffkandidaten zu finden, die billiger herzustellen und leichter handhabbar sind. Denkbar ist auch die Entwicklung eines Impfstoffes mit erweitertem Wirkungsspektrum - auf der Grundlage eines Proteins, das nicht nur in $C$. tetani sondern darüber hinaus in eine Reihe weiterer (clostridieller) Erreger vorkommt. Die Entwicklung solcher Impfstoffe kann in Zukunft angesichts der Erkenntnis, dass sich AntibiotikaResistenzen unter pathogenen Bakterien rasch verbreiten können, eine wichtige Strategie zur Abwehr humanpathogener Erreger sein. 


\section{Zusammenfassung}

1. Im Rahmen dieser Arbeit wurde das Genom des Tetanus-Erregers Clostridium tetani E88 vollständig sequenziert. Es besteht aus einem 74.082 bp (Basenpaare) großen Plasmid, genannt pE88, und einem 2.799.251 bp großen Chromosom. Die Consensus-Sequenz des Genoms lag nach Abschluss der Arbeiten in durchschnittlich 9,5facher Abdeckung vor.

2. Die Sequenz des Plasmids pE88 enthält 61 offene Leserahmen (ORFs) darunter das Gen des Tetanus-Toxins, tet $X$. Die kodierende Sequenz auf pE88 beträgt insgesamt 67,1\% der Gesamtsequenz. Auffällig war der niedrige G+C-Gehalt $(24,5 \%)$ der pE88-Sequenz, wobei der durchschnittliche $\mathrm{G}+\mathrm{C}-$-Gehalt der dritten Base eines Codons innerhalb der kodierenden Sequenz bei lediglich 15\% lag.

3. Das Plasmid kodiert für ein weiteres Toxin, eine Collagenase, genannt ColT, welche die Spaltung des Bindegewebeproteins Collagen katalysiert. Der Vergleich der Proteinsequenz von ColT mit allen bisher bekannten clostridiellen Collagenasen offenbarte, dass nur in ColT die PKD-Domäne fehlt. Über die Funktion dieser Proteindomäne ist bisher nichts bekannt.

4. Zusätzlich zum bereits charakterisierten Transkriptionsregulator des TetanusToxins, TetR, kodiert das Plasmid für weitere regulatorische Proteine mit unbekannten Spezifitäten. So ließen sich die Gene für ein Zwei-Komponentensystem, für zwei Sigmafaktor-ähnliche Proteine sowie für zwei weitere regulatorische Proteine ausfindig machen. Einige dieser möglichen Regulatoren zeigten signifikante Ähnlichkeiten zu den Toxin-Synthese-Regulatoren TxeR aus C. difficile, BotR aus $C$. botulinum und dem UviA/B-System aus $C$. perfringens.

5. Das Plasmid kodiert des weiteren für fünf verschiedene ABC-Transporter, wobei diese Systeme jeweils aus einer ATP-hydrolysierenden Untereinheit und einer oder mehrerer transmembraner Untereinheiten bestehen. Ein Datenbank-Abgleich ergab Ähnlichkeiten einiger dieser Systeme zu Peptid-transportierenden ABCTransportern. 
6. Das Chromosom von C. tetani enthält mindestens 2373 ORFs; die kodierende Sequenz macht dabei $86 \%$ der Gesamtsequenz aus. Es zeigte sich, dass das Chromosom bezüglich des kodierenden Stranges eine starke Codirektionalität von Replikation und Transkription aufweist: so werden 81,1\% der 2373 ORFs in der gleichen Richtung transkribiert, in der auch die Replikation verläuft. Dadurch und mittels der GC-Skew-Analyse konnte der Replikationsursprung des Chromosoms lokalisiert werden. Die Region des ori umfasst die Gene einer Vielzahl hoch konservierter Replikationsproteine.

7. Das Genom von C. tetani enthält im Gegensatz zu den Genomen vieler Enterobakterien verhältnismäßig wenig mobile Elemente wie z. B. Transposasen. Darüber hinaus lassen sich genomweit signifikante Abweichungen vom durchschnittlichen $\mathrm{G}+\mathrm{C}$ - Gehalt $(28,6 \%)$ lediglich in rDNA-Sequenzregionen feststellen. Somit scheint eine Akquirierung von Genen anderer Organismen durch lateralen Gentransfer kaum stattgefunden zu haben, oder aber solche Insertionsereignisse ereigneten sich schon vor langer Zeit.

8. Neben dem bereits bekannten Tetanolysin O konnte eine Reihe weiterer auf dem Chromosom kodierte Virulenzfaktoren wie Hämolysine, FibronectinBindeproteine und eine wahrscheinlich für den Thrombocyten-aktivierenden Faktor spezifische Acetyl-Hydrolase identifiziert werden. Des weiteren konnten viele Exoenzyme wie Lipasen und verschiedenste Peptidasen gefunden werden, die z. T. das Zink-Bindemotiv tragen.

9. Zusätzlich konnten 32 ORFs ausgemacht werden, die möglicherweise an der Virulenzausbildung beteiligt sind. Es handelt sich dabei um Zelloberflächenproteine, die N-terminal ein Signalpeptid tragen. Drei Proteinklassen konnten unterschieden werden: 19 dieser Proteine zeigen Homologien zu charakterisierten Adhäsionsund S-Layer-Proteinen aus $C$. difficile; zwei Proteine besitzen wie die Internaline aus Listeria monocytogenes multiple Leucin-reiche Sequenzwiederholungen (LRR-Domänen), die wahrscheinlich an Protein-Protein-Interaktionen beteiligt sind. 11 weitere ORFs weisen keine signifikanten Homologien zu bekannten Proteinen auf; sie besitzen allerdings charakterisierte Zelloberflächen-domänen. 
10. Der Vergleich des Genoms von $C$. tetani mit den Genomen von $C$. perfringens und C. acetobutylicum zeigte, dass die Organismen 1506 ORFs gemein haben. Eine genomweite Konservierung der Genanordnung konnte allerdings nur in einigen Genclustern festgestellt werden. C. tetani besitzt 516 ORFs, die keine Homologons in C. perfringens und C. acetobutylicum haben. Zusätzlich ließen sich 199 ORFs identifizieren, die nur in den pathogenen Clostridien $C$. tetani und $C$. perfringens, nicht aber in C. acetobutylicum zu finden waren.

11. Viele der Gene von C. tetani, die in C. acetobutylicum nicht vorhanden sind, kodieren für Aminosäure-abbauende Proteine. Offenbar hat sich C. tetani auf die Degradation von Proteinen bzw. Aminosäuren spezialisiert. Im Gegensatz dazu finden sich wenige Zucker-abbauende Systeme in C. tetani; diese sind aber zahlreich in C. acetobutylicum und C. perfringens vorhanden.

12. Ein weiterer großer Unterschied zu C. acetobutylicum ist die offensichtliche Entwicklung einer ausgeprägten Natriumionen $\left(\mathrm{Na}^{+}\right)$-Bioenergetik in C. tetani. Es konnte eine Vielzahl $\mathrm{Na}^{+}$-abhängiger Substrat-Symporter detektiert werden. C. tetani besitzt zudem eine $\mathrm{Na}^{+}$-abhängige $\mathrm{V}$-Typ-ATPase, aber keine $\mathrm{F}_{0} \mathrm{~F}_{1}$-TypATPase, welche in C. acetobutylicum und C. perfringens vorliegt. Zusätzlich existiert in $C$. tetani ein membrangebundenes Elektronentransportsystem, das Nqr/Rnf-System, welches wahrscheinlich als primäre $\mathrm{Na}^{+}$-Pumpe dient.

13. Es konnte eine Reihe weiterer membrangebundener oder -assoziierter Systeme in C. tetani identifiziert werden, die nicht in den beiden anderen Clostridien zu finden waren, wie z. B. vier Kopien einer Fumarat-Reduktase, die die anaerobe Atmung mit Fumarat erlauben, einen $\mathrm{Na}^{+} / \mathrm{H}^{+}$-Antiporterkomplex, eine V-Typ- $\mathrm{H}^{+}$Pyrophosphatase und ein CO-Dehydrogenase-System.

14. C. tetani besitzt 419 Proteine, die ein Signalpeptid tragen und somit über das SecSystem exportiert werden; dazu gehören die meisten der 167 im Genom kodierten Transportproteine. Neben dem Sec-Proteinsekretionssystem lassen sich das SRP (Signal Recognition Particle)-System sowie ein Typ II-ähnliches Sekretionssystem finden, das spezifisch für einige Arten der Gattung Clostridium zu sein scheint. 
15. Durch die Sequenzierung des Genoms von C. tetani und die eingehende Analyse der erhaltenen Daten erscheint dieses Bakterium in einem neuen Licht. So wird der Umfang der vorhandenen Virulenzfaktoren ebenso deutlich wie die Bedeutung von Natriumionengradienten für die Bioenergetik. Zusätzlich konnte eine Reihe von Genen für regulatorische Proteine wie z. B. 29 Zwei-KomponentenSysteme und 98 DNA-bindende Proteine identifiziert werden. Die Ergebnisse der vorliegenden Arbeit bilden die Grundlage für Untersuchungen, durch die so wichtige Fragen beantworten werden können, wie die nach dem regulatorischen Netzwerk, welches die Bildung des Tetanus-Toxins kontrolliert, und nach den Umweltsignalen, die diese Kontrolle beeinflussen. 
Ajdic, D., McShan, W. M., McLaughlin, R. E., Savic, G., Chang, J., Carson, M. B., Primeaux, C., Tian, R., Kenton, S., Jia, H., Lin, S., Qian, Y., Li, S., Zhu, H., Najar, F., Lai, H., White, J., Roe, B. A., Ferretti, J. J., 2002: Genome sequence of Streptococcus mutans UA159, a cariogenic dental pathogen. Proc. Natl. Acad. Sci. U S A 99, 14434-14439.

Altschul, S. F., Gish, W., Miller, W., Myers, E. W., Lipman, D. J., 1990: Basic local alignment search tool. J. Mol. Biol. 215, 403-410.

Arnon, S. S., 1997: Human tetanus and human botulism. In Rood, J. I., McClane, B. A., Songer, J. G., Titball, R. W. (Hrsg.). The clostridia; molecular biology and pathogenesis, 95-115. Academic press, San Diego.

Asai, Y., Kawagishi, I., Sockett, R. E., Homma, M., 1999: Hybrid motor with $\mathrm{H}(+)$ - and $\mathrm{Na}(+)$-driven components can rotate Vibrio polar flagella by using sodium ions. J. Bacteriol. 181, 6332-6338.

Baida, G. E. \& Kuzmin, N. P., 1995: Cloning and primary structure of a new hemolysin gene from Bacillus cereus. Biochim. Biophys. Acta 1264, 151-154.

Bao, Q., Tian, Y., Li, W., Xu, Z., Xuan, Z., Hu, S., Dong, W., Yang, J., Chen, Y., Xue, Y., Xu, Y., Lai, X., Huang, L., Dong, X., Ma, Y., Ling, L., Tan, H., Chen, R., Wang, J., Yu, J., Yang, H., 2002: A complete sequence of the Thermoanaerobacter tengcongensis genome. Genome Res. 12, 689-700.

Barquera, B., Hellwig, P., Zhou, W., Morgan, J. E., Häse, C. C., Gosink, K. K., Nilges, M., Bruesehoff, P. J., Roth, A., Lancaster, C. R., Gennis, R. B., 2002: Purification and characterization of the recombinant $\mathrm{Na}(+)$-translocating NADH:quinone oxidoreductase from Vibrio cholerae. Biochemistry 41, 3781-3789. 
Ba-Thein, W., Lyristis, M., Ohtani, K., Nisbet, I. T., Hayashi, H., Rood, J. I., Shimizu, T., 1996: The virR/virS locus regulates the transcription of genes encoding extracellular toxin production in Clostridium perfringens. J. Bacteriol. 178, 25142520 .

Bergey, D. H., Harrison, F. C., Breed, R., Hammer, B. W., Huntoon, F. M. (Hrsg.), 1923: Bergey's manual of determinative bacteriology, $1^{\text {st }}$ Ed. The Williams \& Wilkins Co., Baltimore.

Beveridge, T. J., Pouwels, P. H., Sara, M., Kotiranta, A., Lounatmaa, K., Kari, K., Kerosuo, E., Haapasalo, M., Egelseer, E. M., Schocher, I., Sleytr, U. B., Morelli, L., Callegari, M. L., Nomellini, J. F., Bingle, W. H., Smit, J., Leibovitz, E., Lemaire, M., Miras, I., Salamitou, S., Beguin, P., Ohayon, H., Gounon, P., Matuschek, M., Koval, S. F., 1997: Functions of S-layers. FEMS Microbiol. Rev. 20, 99-149.

Bizzini, B., 1979: Tetanus toxin. Microbiol. Rev. 43, 224-240.

Blum, H., Beier, H., Gross, H. J., 1987: Improved silver staining of plant proteins, RNA and DNA in polyacrylamide gels. Electrophoresis 8, 93-99.

Bonfield, J. K., Smith, K., Staden, R., 1995: A new DNA sequence assembly program. Nucleic Acids Res. 24, 4992-4999.

Bonfield, J. K. \& Staden, R., 1996: Experiment files and their application during large-scale sequencing projects. DNA Sequence 6, 109-117.

Bott, M., Pfister, K., Burda, P., Kalbermatter, O., Woehlke, G., Dimroth, P., 1997: Methylmalonyl-CoA decarboxylase from Propionigenium modestum-cloning and sequencing of the structural genes and purification of the enzyme complex. Eur. J. Biochem. 250, 590-599. 
Boynton, Z. L., Bennet, G. N., Rudolph, F. B., 1996: Cloning, sequencing, and expression of clustered genes encoding beta-hydroxybutyryl-coenzyme A (CoA) dehydrogenase, crotonase, and butyryl-CoA dehydrogenase from Clostridium acetobutylicum ATCC 824. J. Bacteriol. 178, 3015-3024.

Bradford, M. M., 1976: A rapid and sensitive method for quantitation of microgram quantities of protein utilizing the principle of protein dye-binding. Anal. Biochem. 72, 248-254.

Braune, A., Bendrat, K., Rospert, S., Buckel, W., 1999: The sodium ion translocating glutaconyl-CoA decarboxylase from Acidaminococcus fermentans: cloning and function of the genes forming a second operon. Mol. Microbiol. 31, 473487.

Brüggemann, H., Bäumer, S., Fricke, W. F., Wiezer, A., Liesegang, H., Decker, I., Herzberg, C., Martínez-Arias, R., Merkl, R., Henne, A., Gottschalk, G., 2003: The genome sequence of Clostridium tetani, the causative agent of tetanus disease. Proc. Natl. Acad. Sci. U S A, in press.

Brumm, P. J., Fried, J., Friedmann, H. C., 1983: Bactobilin: blue bile pigment isolated from Clostridium tetanomorphum. Proc. Natl. Acad. Sci. U S A 80, 39433947.

Bryant, M. P., 1972 : Commentary on the hungate technique for cultur of anaerobic bacteria. AM. J. Clin. Nutr. 25, 1324-1328.

Cabanes, D., Dehoux, P., Dussurget, O., Frangeul, L., Cossart, P., 2002: Surface proteins and the pathogenic potential of Listeria monocytogenes. Trends Microbiol. 10, 238-245.

Calabi, E., Ward, S., Wren, B., Paxton, T., Panico, M., Morris, H., Dell, A., Dougan, G., Fairweather, N., 2001: Molecular characterization of the surface layer proteins from Clostridium difficile. Mol. Microbiol. 40, 1187-1199. 
Calabi, E. \& Fairweather, N., 2002: Patterns of sequence conservation in the SLayer proteins and related sequences in Clostridium difficile. J. Bacteriol. 184, 38863897.

Calabi, E., Calabi, F., Phillips, A. D., Fairweather, N. F., 2002: Binding of Clostridium difficile surface layer proteins to gastrointestinal tissues. Infect. Immun. 70, 5770-5778.

Canback, B., Andersson, S. G., Kurland, C. G., 2002: The global phylogeny of glycolytic enzymes. Proc. Natl. Acad. Sci. U S A 99, 6097-6102.

Carfi, A., Pares, S., Duee, E., Galleni, M., Duez, C., Frere, J. M., Dideberg, O., 1995: The 3-D structure of a zinc metallo-beta-lactamase from Bacillus cereus reveals a new type of protein fold. EMBO J. 14, 4914-4921.

Cerquetti, M., Pantosti, A., Stefanelli, P., Mastrantonio, P., 1992: Purification and characterization of an immunodominant $36 \mathrm{kDa}$ antigen present on the cell surface of Clostridium difficile. Microb. Pathog. 13, 271-279.

Cerrato, R., Valle, J., Gonzalez-Zorn, B., Vazquez-Bolabd, J., 2000: tly gene for tetanolysin. In GenBank abgelegte Nukleotidsequenz mit der Erkennungsnummer AJ276621.

Chen, C. H. \& Friedmann, H. C., 1993: Anaerobic breakdown of uroporphyrins I and III to bile pigments by extracts of Clostridium tetanomorphum. FEMS Microbiol. Lett. 110, 77-83.

Cheng, J., Guffanti, A. A., Krulwich, T. A., 1997: A two-gene ABC-type transport system that extrudes $\mathrm{Na}+$ in Bacillus subtilis is induced by ethanol or protonophore. Mol. Microbiol. 23, 1107-1120.

Chester, N. \& Marshak, D. R., 1993: Dimethyl sulfoxid-mediated primer $T_{m}$ reduction: a method for analyzing the role of renaturation temperature in the polymerase chain reaction. Anal. Biochem. 209, 284-290. 
Cheung, J. K. \& Rood, J. I., 2000: The VirR response regulator from Clostridium perfringens binds independently to two imperfect direct repeats located upstream of the pfoA promoter. J. Bacteriol. 182, 57-66.

Chu, G. C., Tomita, T., Sonnichsen, F. D., Yoshida, T., Ikeda-Saito, M., 1999: The heme complex of $\mathrm{Hmu} \mathrm{O}$, a bacterial heme degradation enzyme from Corynebacterium diphtheriae. Structure of the catalytic site. J. Biol. Chem. 274, 24490-24496.

Clarke, T. E., Tari, L. W., Vogel, H. J., 2001: Structural biology of bacterial iron uptake systems. Curr. Top. Med. Chem. 1, 7-30.

Collins, M. D., Lawson, P. A., Willems, A., Cordoba, J. J., FernandezGarayzabal, J., Garcia, P., Cai, J., Hippe, H., Farrow, J. A., 1994: The phylogeny of the genus Clostridium: proposal of five new genera and eleven new species combinations. Int. J. Syst. Bacteriol. 44, 812-826.

Costilow, R. N., 1981: Biophysical factors in growth. In Gerhardt, P., Murray, G. E., Costilow, R. N., Nester, E. W., Wood, W. A., Krieg, R., Philips, G. B. (Hrsg.). Manual of methods for general bacteriology, 66-78. ASM, Washington D. C.

Cruz, W. T., Nedialkov, Y. A., Thacker, B. J., Mulks, M. H., 1996: Molecular characterization of a common 48-kilodalton outer membrane protein of Actinobacillus pleuropneumoniae. Infect. Immun. 64, 83-90.

Dargatz, H., Diefenthal, T., Witte, V., Reipen, G., von Wettstein, D., 1993: The heterodimeric protease clostripain from Clostridium histolyticum is encoded by a single gene. Mol. Gen. Genet. 240, 140-145.

Dassa, E., Hofnung, M., Paulsen, I. T., Saier, M. H., 1999: The Escherichia coli ABC transporters: an update. Mol. Microbiol. 32, 887-889.

Davidson, A. L., 2002: Mechanism of coupling of transport to hydrolysis in bacterial ATP-binding cassette transporters. J. Bacteriol. 184, 1225-1233. 
Delcher, A. L., Harmon, D., Kasif, S., White, O., Salzberg, S. L., 1999: Improved microbial gene identification with GLIMMER. Nucleic Acids Res. 27, 4636-4641.

Deppenmeier, U., Lienard, T., Gottschalk, G., 1999: Novel reactions involved in energy conservation by methanogenic archaea. FEBS Lett. 457, 291-297.

Deppenmeier, U., Johann, A., Hartsch, T., Merkl, R., Schmitz, R., MartinezArias, R., Henne, A., Wiezer, A., Bäumer, S., Jacobi, C., Brüggemann, H., Lienard, T., Christmann, A., Bömeke, M., Steckel, S., Bhattacharyya, A., Lykidis, A., Overbeek, R., Klenk, H. P., Gunsalus, R. P., Fritz, H. J., Gottschalk, G., 2002: The genome of Methanosarcina mazei: evidence for lateral gene transfer between bacteria and archaea. J. Mol. Microbiol. Biotechnol. 4, 453-461.

Dhalluin, A., Lemee, L., Pestel-Caron, M., Mory, F., Lemeland, J.-F., Pons, J.L., 2002: Genotypic differentiation of twelve Clostridium species by polymorphism analysis of the gene tpi encoding triosephosphate isomerase. Poster on Congress 'The World of Microbes' by IUMS, $27^{\text {th }}$ July $-1^{\text {st }}$ August, Paris.

Dimroth, P., 1994: Bacterial sodium ion-coupled energetics. Antonie Van Leeuwenhoek 65, 381-395.

Dimroth, P., 1997: Primary sodium ion translocating enzymes. Biochim. Biophys. Acta 1318, 11-51.

Dobbek, H., Gremer, L., Meyer, O., Huber, R., 1999: Crystal structure and mechanism of CO dehydrogenase, a molybdo iron-sulfur flavoprotein containing Sselanylcysteine. Proc. Natl. Acad. Sci. U S A 96, 8884-8889.

Dorn, M., Andreesen, J. R., Gottschalk, G., 1978: Fumarate reductase of Clostridium formicoaceticum. A peripheral membrane protein. Arch. Microbiol. 119, $7-11$.

Driessen, A. J., Fekkes, P. \& van der Wolk, J. P., 1998: The Sec system. Curr. Opin. Microbiol. 1, 216-222. 
Eisel, U., Jarausch, W., Goretzki, K., Henschen, A., Engels, J., Weller, U., Hudel, M., Habermann, E., Niemann, H., 1986: Tetanus toxin: primary structure, expression in E. coli, and homology with botulinum toxins. EMBO J. 5, 2495-2502.

Eklund, M. W., Poysky, F. T., Reed, S. M., 1972: Bacteriophage and the toxigenicity of Clostridium botulinum type D. Nat. New Biol. 235, 16-17.

Emsley, P., Fotinou, C., Black, I., Fairweather, N. F., Charles, I. G., Watts, C., Hewitt, E., Isaacs, N. W., 2000: The structures of the H(C) fragment of tetanus toxin with carbohydrate subunit complexes provide insight into ganglioside binding. J. Biol. Chem. 275, 8889-8894.

Evans, G. A., Lewis, K., Rothenberg, B. E., 1989: High efficiency vectors for cosmid microcloning and genomic analysis. Gene 79, 9-20.

Evdokimov, A. G., Anderson, D. E., Routzahn, K. M., Waugh, D. S., 2001: Unusual molecular architecture of the Yersinia pestis cytotoxin YopM: a leucine-rich repeat protein with the shortest repeating unit. J. Mol. Biol. 312, 807-821.

Ewing, B., Hillier, L., Wendl, M. C., Green, P., 1998: Base-calling automated sequencer traces using phred. I. Accuracy assessment. Genome Res.8, 175-185.

Fairweather, N. F. \& Lyness, V. A., 1986: The complete nucleotide sequence of tetanus toxin. Nucleic Acids Res. 14, 7809-7812.

Fiedler, S. \& Wirth, R., 1988: Transformation of bacteria with plasmid DNA by electroporation. Anal. Biochem. 170, 38-44.

Finn, C. W., Silver R. P., Habig, W. H., Hardegree, M. C., 1984: The structural gene for tetanus toxin is on a plasmid. Science 224, 881-884.

Frankel, G., Phillips, A. D., Trabulsi, L. R., Knutton, S., Dougan, G., Matthews, S., 2001: Intimin and the host cell-is it bound to end in Tir(s)? Trends Microbiol. 9, 214- 218 . 
Garnier, T., \& Cole, S. T., 1988a: Studies of UV-inducible promoters from Clostridium perfringens in vivo and in vitro. Mol. Microbiol. 2, 607-614.

Garnier, T. \& Cole, S. T., 1988b: Identification and molecular genetic analysis of replication functions of the bacteriocinogenic plasmid pIP404 from Clostridium perfringens. Plasmid 19, 151-60.

Gerhardt, A., Cinkaya, I., Linder, D., Huisman, G., Buckel, W., 2000: Fermentation of 4-aminobutyrate by Clostridium aminobutyricum: cloning of two genes involved in the formation and dehydration of 4-hydroxybutyryl-CoA. Arch. Microbiol. 174, 189-199.

Gill, D. M., 1982: Bacterial toxins: table of lethal amounts. Microbiol. Rev. 46, 8694.

Gilot, P., Jossin, Y., Content, J., 2000: Cloning, sequencing and characterisation of a Listeria monocytogenes gene encoding a fibronectin-binding protein. J. Med. Microbiol. 49, 887-896.

Gordon, E. H., Pealing, S. L., Chapman, S. K., Ward, F. B., Reid, G. A., 1998: Physiological function and regulation of flavocytochrome $\mathrm{c} 3$, the soluble fumarate reductase from Shewanella putrefaciens NCIMB 400. Microbiology 144, 937-945.

Gottschalk, G., Andreesen, J. R., Hippe, H., 1981: The genus Clostridium. In Starr, M. P., Stolp, H., Trüper, H. G., Balows, A., Schlegel, H. G. (Hrsg.). The prokaryotes, 1767-1803. Springer-Verlag, Berlin.

Grigoriev, A., 1998: Analyzing genomes with cumulative skew diagrams. Nucleic Acids Res. 26, 2286-2290.

Gustafsson, C. \& Persson, B. C., 1998: Identification of the rrmA gene encoding the 23S rRNA m1G745 methyltransferase in Escherichia coli and characterization of an m1G745-deficient mutant. J. Bacteriol. 180, 359-365. 
Hanahan, D., 1983: Studies on transformation of Escherichia coli with plasmids. J. Mol. Biol. 166, 557-580.

Harrington, D. J., 1996: Bacterial collagenases and collagen-degrading enzymes and their potential role in human disease. Infect. Immun. 64, 1885-1891.

Häse, C. C., Fedorova, N. D., Galperin, M. Y., Dibrov, P. A., 2001: Sodium ion cycle in bacterial pathogens: evidence from cross-genome comparisons. Microbiol. Mol. Biol. Rev. 65, 353-370.

Hatada, Y., Ito, S., 1999: A novel plasmid isolated from an alkaline Bacillus strain. EMBL/GenBank/DDBJ-Veröffentlichungsnummer: Q93RK7.

Hayashi, M., Nakayama, Y., Unemoto, T., 1996: Existence of Na+-translocating NADH-quinone reductase in Haemophilus influenzae. FEBS Lett. 381, 174-176.

Henderson, I., Whelan, S. M., Davis, T. O., Minton, N. P., 1996: Genetic characterisation of the botulinum toxin complex of Clostridium botulinum strain NCTC 2916. FEMS Microbiol. Lett. 140, 151-158.

Henne, A., Daniel, R., Schmitz, R. A., Gottschalk, G., 1999: Construction of environmental DNA libraries in Escherichia coli and screening for the presence of genes conferring utilization of 4-hydroxybutyrate. Appl. Environ. Microbiol. 65, 3901-3907.

Heyne, R. I., de Vrij, W., Crielaard, W., Konings, W. N., 1991: Sodium iondependent amino acid transport in membrane vesicles of Bacillus stearothermophilus. J. Bacteriol. 173, 791-800.

Hiramatsu, T., Kodama, K., Kuroda, T., Mizushima, T., Tsuchiya, T., 1998: A putative multisubunit $\mathrm{Na}+/ \mathrm{H}+$ antiporter from Staphylococcus aureus. J. Bacteriol. 180, 6642-6648. 
Höner zu Bentrup, K., Ubbink-Kok, T., Lolkema, J. S., Konings, W. N., 1997: An Na+-pumping V1V0-ATPase complex in the thermophilic bacterium Clostridium fervidus. J. Bacteriol. 179, 1274-1279.

Horowitz, J. P., Chua, J., Curby, R. J., Thomson, M. A., Da Rooge, M. A., Fischer, B. E., Mauricio, J., Klundt, I., 1964: Substrates for cytochemical demonstration of enzyme activity. I. Some substituted 3-indoyl- $\beta, D-$ glycopyranosides. J. Med. Chem. 7, 547-548.

Hoskins, J., Alborn, W. E., Arnold, J., Blaszczak, L. C., Burgett, S., DeHoff, B. S., Estrem, S. T., Fritz, L., Fu, D. J., Fuller, W., Geringer, C., Gilmour, R., Glass, J. S., Khoja, H., Kraft, A. R., Lagace, R. E., LeBlanc, D. J., Lee, L. N., Lefkowitz, E. J., Lu, J., Matsushima, P., McAhren, S. M., McHenney, M., McLeaster, K., Mundy, C. W., Nicas, T. I., Norris, F. H., O'Gara, M., Peery, R. B., Robertson, G. T., Rockey, P., Sun, P. M., Winkler, M. E., Yang, Y., YoungBellido, M., Zhao, G., Zook, C. A., Baltz, R. H., Jaskunas, S. R., Rosteck, P. R., Skatrud, P. L., Glass, J. I., 2001: Genome of the bacterium Streptococcus pneumoniae strain R6. J. Bacteriol. 183, 5709-5717.

Hotze, E. M., Heuck, A. P., Czajkowsky, D. M., Shao, Z., Johnson, A. E., Tweten, R. K., 2002: Monomer-monomer interactions drive the prepore to pore conversion of a beta-barrel-forming cholesterol-dependent cytolysin. J. Biol. Chem. 277, 11597-11605.

Hungate, R. E., 1969: A roll tube for cultivation of strict anaerobes. In Norris, J. R., Ribbons, D. W. (Hrsg.). Methods in Microbiology 3, 117-132. Academic Press, London.

Ikegami, M., Kawano, M., Takase, K., Yamato, I., Igarashi, K., Kakinuma, Y., 1999: Enterococcus hirae vacuolar ATPase is expressed in response to $\mathrm{pH}$ as well as sodium. FEBS Lett. 454, 67-70. 
Ishikawa, J. \& Hotta, K., 1999: FramePlot: a new implementation of the frame analysis for predicting protein-coding regions in bacterial DNA with a high $\mathrm{G}+\mathrm{C}$ content. FEMS Microbiol. Lett. 174, 251-253.

Ito, M., Guffanti, A. A., Oudega, B., Krulwich, T. A., 1999: Mrp, a multigene, multifunctional locus in Bacillus subtilis with roles in resistance to cholate and to $\mathrm{Na}+$ and in pH homeostasis. J. Bacteriol. 181, 2394-2402.

Ito, M., Guffanti, A. A., Krulwich, T. A., 2001: Mrp-dependent $\mathrm{Na}(+) / \mathrm{H}(+)$ antiporters of Bacillus exhibit characteristics that are unanticipated for completely secondary active transporters. FEBS Lett. 496, 117-120.

Janausch, I. G., Garcia-Moreno, I., Unden, G., 2002: Function of DcuS from Escherichia coli as a fumarate-stimulated histidine protein kinase in vitro. J. Biol. Chem. 277, 39809-39814.

Jenkins, C. \& Fuerst, J. A., 2001: Phylogenetic analysis of evolutionary relationships of the planctomycete division of the domain bacteria based on amino acid sequences of elongation factor Tu. J. Mol. Evol. 52, 405-418.

Jouanneau, Y., Jeong, H. S., Hugo, N., Meyer, C., Willison, J. C., 1998: Overexpression in Escherichia coli of the rnf genes from Rhodobacter capsulatuscharacterization of two membrane-bound iron-sulfur proteins. Eur. J. Biochem. 251, 54-64.

Karasawa, K., Yato, M., Setaka, M., Nojima, S., 1994: Purification and characterization of platelet-activating factor acetylhydrolase from peritoneal fluid obtained from guinea pigs after endotoxin shock. J. Biochem. 116, 374-379.

Karjalainen, T., Waligora-Dupriet, A. J., Cerquetti, M., Spigaglia, P., Maggioni, A., Mauri, P., Mastrantonio, P., 2001: Molecular and genomic analysis of genes encoding surface-anchored proteins from Clostridium difficile. Infect. Immun. 69, $3442-3446$. 
Karjalainen, T., Saumier, N., Barc, M. C., Delmee, M., Collignon, A., 2002: Clostridium difficile genotyping based on slpA variable region in S-layer gene sequence: an alternative to serotyping. J. Clin. Microbiol. 40, 2452-2458.

Kleerebezem, M., Quadri, L. E., Kuipers, O. P., de Vos, W. M., 1997: Quorum sensing by peptide pheromones and two-component signal-transduction systems in Gram-positive bacteria. Mol. Microbiol. 24, 895-904.

Klein, C. \& Entian, K. D., 1994: Genes involved in self-protection against the lantibiotic subtilin produced by Bacillus subtilis ATCC 6633. Appl. Environ. Microbiol. 60, 2793-2801.

Knipppers, R., 1995: Molekulare Genetik. Georg-Thieme-Verlag, Stuttgart \& New York.

Kofoid, E., Rappleye, C., Stojiljkovic, I., Roth, J., 1999: The 17-gene ethanolamine (eut) operon of Salmonella typhimurium encodes five homologues of carboxysome shell proteins. J. Bacteriol. 181, 5317-5329.

Kogure, K., 1998: Bioenergetics of marine bacteria. Curr. Opin. Biotechnol. 9, 278282.

Koretke, K. K., Lupas, A. N., Warren, P. V., Rosenberg, M., Brown, J. R., 2000: Evolution of two-component signal transduction. Mol. Biol. Evol. 17, 1956-1970.

Kunst, F., Ogasawara, N., Moszer, I., Albertini, A. M., Alloni, G., Azevedo, V., Bertero, M. G., Bessieres, P., Bolotin, A., Borchert S., Borriss, R., Boursier, L., Brans, A., Braun, M., Brignell, S. C., Bron, S., Brouillet, S., Bruschi, C. V., Caldwell, B., Capuano, V., Carter, N. M., Choi, S. K., Codani, J. J., Connerton, I. F., Danchin, A., und 126 weitere Autoren, 1997: The complete genome sequence of the Gram-positive bacterium Bacillus subtilis. Nature 390, 249-256.

Kuroda, A. \& Sekiguchi, J., 1991: Molecular cloning and sequencing of a major Bacillus subtilis autolysin gene. J. Bacteriol. 173, 7304-7312. 
Lander, E. S. \& Waterman, M. S., 1988: Genomic mapping by fingerprinting random clones: a mathematical analysis. Genomics 2, 231-239.

Lehman, T. C. \& Thorpe, C., 1992: A new form of mammalian electrontransferring flavoprotein. Arch. Biochem. Biophys. 292, 594-599.

Lemon, K. P., Kurtser, I., Wu, J., Grossman, A. D., 2000: Control of initiation of sporulation by replication initiation genes in Bacillus subtilis. J. Bacteriol. 182, 29892991.

Leutbecher, U., Bocher, R., Linder, D., Buckel, W., 1992: Glutamate mutase from Clostridium cochlearium: Purification, cobamide content and stereospecific inhibitors. Eur. J. Biochem. 205, 759-765.

Leys, D., Tsapin, A. S., Nealson, K. H., Meyer, T. E., Cusanovich, M. A., Van Beeumen, J. J., 1999: Structure and mechanism of the flavocytochrome c fumarate reductase of Shewanella putrefaciens MR-1. Nat. Struct. Biol. 6, 1113-1117.

Liles, M. R., Viswanathan, V. K., Cianciotto, N. P., 1998: Identification and temperature regulation of Legionella pneumophila genes involved in type IV pilus biogenesis and type II protein secretion. Infect. Immun. 66, 1776-1782.

Liles, M. R., Edelstein, P. H., Cianciotto, N. P., 1999: The prepilin peptidase is required for protein secretion by and the virulence of the intracellular pathogen Legionella pneumophila. Mol. Microbiol. 31, 959-970.

Lindler, L. E., Hadfield, T. L., Tall, B. D., Snellings, N. J., Rubin, F. A., Van De Verg, L. L., Hoover, D., Warren, R. L., 1996: Cloning of a Brucella melitensis group 3 antigen gene encoding Omp28, a protein recognized by the humoral immune response during human brucellosis. Infect. Immun. 64, 2490-2499.

Lobry, J. R., 1996: Asymmetric substitution patterns in the two DNA strands of bacteria. Mol. Biol. Evol. 13, 660-665. 
Lowe, T. M. \& Eddy, S. R., 1997: tRNAscan-SE: A program for improved detection of transfer RNA genes in genomic sequence. Nucleic Acids Res. 25, 955 964.

Lutcke, H., 1995: Signal recognition particle (SRP), a ubiquitous initiator of protein translocation. Eur. J. Biochem. 228, 531-550.

Mani, N. \& Dupuy, B., 2001: Regulation of toxin synthesis in Clostridium difficile by an alternative RNA polymerase sigma factor. Proc. Natl. Acad. Sci. USA 98, 5844-5849.

Marino, M., Braun, L., Cossart, P., Ghosh, P., 1999: Structure of the lnlB leucinerich repeats, a domain that triggers host cell invasion by the bacterial pathogen $L$. monocytogenes. Mol. Cell. 4, 1063-1072.

Marmur, J., 1961: A procedure for the isolation of desoxyribonucleic acid from microorganisms. J. Mol. Biol. 3, 208-218.

Marvaud, J-C., Eisel, U., Binz, T., Niemann, H., Popoff, M. R., 1998a: TetR is a positive regulator of the tetanus toxin gene in Clostridium tetani and is homologous to BotR. Infect. Immun. 66, 5698-5702.

Marvaud, J.-C., Gibert, M., Inoue, K., Fujinaga, Y., Oguma, K., Popoff, M. R., 1998b: botR/A is a positive regulator of botulinum neurotoxin and associated nontoxin protein genes in Clostridium botulinum A. Mol. Microbiol. 29, 1009-1018.

Marvaud, J.-C., Raffestin, S., Gibert, M., Popoff, M. R., 2000: Regulation of the toxinogenesis in Clostridium botulinum and Clostridium tetani. Biol. Cell. 92, 455457.

Matsushita, O., Yoshihara, K., Katayama, S.-I., Minami, J., Okabe, A., 1994: Purification and characterization of a Clostridium perfringens 120-kilodalton collagenase and nucleotide sequence of the corresponding gene. J. Bacteriol. 176, 149-156. 
Matsushita, O., Jung, C.-M., Katayama, S., Minami, J., Takahashi, Y., Okabe, A., 1999: Gene duplication and multiplicity of collagenases in Clostridium histolyticum. J. Bacteriol. 181, 923-933.

Matsushita, O., Koide, T., Kobayashi, R., Nagata, K., Okabe, A., 2001: Substrate recognition by the collagen-binding domain of Clostridium histolyticum class I collagenase. J. Biol. Chem. 276, 8761-8770.

McGuire, M., Huang, K., Kapadia, G., Herzberg, O., Dunaway-Mariano, D., 1998: Location of the phosphate binding site within Clostridium symbiosum pyruvate phosphate dikinase. Biochemistry 37, 13463-13474.

McLean, M. J., Wolfe, K. H., Devine, K. M., 1998: Base composition skews, replication orientation, and gene orientation in 12 prokaryote genomes. J. Mol. Evol. 47, 691-696.

Mengaud, J., Ohayon, H., Gounon, P., Mege, R.-M., Cossart, P., 1996: Ecadherin is the receptor for internalin, a surface protein required for entry of $L$. monocytogenes into epithelial cells. Cell 84, 923-932.

Moore, P., 1995: Handbook of botulinum toxin treatment. Blackwell Science, Oxford.

Mukherjee, K., Karlsson, S., Burman, L. G., Akerlund, T., 2002: Proteins released during high toxin production in Clostridium difficile. Microbiology 148, $2245-2253$.

Murata, T., Takase, K., Yamato, I., Igarashi, K., Kakinuma, Y., 1997: Purification and reconstitution of $\mathrm{Na}$-translocating vacuolar ATPase from Enterococcus hirae. J. Biol. Chem. 272, 24885-24890. 
Nölling, J., Breton, G., Omelchenko, M. V., Makarova, K. S., Zeng, Q., Gibson, R., Lee, H. M., Dubois, J., Qiu, D., Hitti, J., Wolf, Y. I., Tatusov, R. L., Sabathe, F., Doucette-Stamm, L., Soucaille, P., Daly, M. J., Bennett, G. N., Koonin, E. V., Smith, D. R., 2001: Genome sequence and comparative analysis of the solventproducing bacterium Clostridium acetobutylicum. J. Bacteriol. 183, 4823-4838.

Nouwen, N. \& Driessen, A. J., 2002: SecDFyajC forms a heterotetrameric complex with YidC. Mol. Microbiol. 44, 1397-1405.

Novick, R. P., 2000: Sortase: the surface protein anchoring transpeptidase and the LPXTG motif. Trends Microbiol. 8, 148-151.

Obst, M., Oppermann-Sanio, F. B., Luftmann, H., Steinbüchel, A., 2002: Isolation of cyanophycin-degrading bacteria, cloning and characterization of an extracellular cyanophycinase gene (cphE) from Pseudomonas anguilliseptica strain BI. The cphE gene from $P$. anguilliseptica $\mathrm{BI}$ encodes a cyanophycinhydrolyzing enzyme. J. Biol. Chem. 277, 25096-25105.

Ohtani, K., Swe, T., Hayashi, H., Shimizu, T., 1999: A novel two-component regulatory system involved in the shutdown of extracellular toxin production in Clostridium perfringens. In GenBank abgelegte Nukleotidsequenz mit der Erkennungsnummer AB028738.

Overbeek, R., Larsen, N., Pusch, G. D., D'Souza, M., Selkov, E. Jr., Kyrpides, N., Fonstein, M., Maltsev, N., Selkov, E., 2000: WIT: integrated system for highthroughput genome sequence analysis and metabolic reconstruction. Nucleic Acids Res. 28, 123-125. 
Parkhill, J., Dougan, G., James, K. D., Thomson, N. R., Pickard, D., Wain, J., Churcher, C., Mungall, K. L., Bentley, S. D., Holden, M. T., Sebaihia, M., Baker, S., Basham, D., Brooks, K., Chillingworth, T., Connerton, P., Cronin, A., Davis, P., Davies, R. M., Dowd, L., White, N., Farrar, J., Feltwell, T., Hamlin, N., Haque, A., Hien, T. T., Holroyd, S., Jagels, K., Krogh, A., Larsen, T. S., Leather, S., Moule, S., O'Gaora, P., Parry, C., Quail, M., Rutherford, K., Simmonds, M., Skelton, J., Stevens, K., Whitehead, S., Barrell, B. G., 2001: Complete genome sequence of a multiple drug resistant Salmonella enterica serovar Typhi CT18. Nature 413, 848-852.

Pealing, S. L., Black, A. C., Manson, F. D., Ward, F. B., Chapman, S. K., Reid, G. A., 1992: Sequence of the gene encoding flavocytochrome c from Shewanella putrefaciens: a tetraheme flavoenzyme that is a soluble fumarate reductase related to the membrane-bound enzymes from other bacteria. Biochemistry 31, 12132-12140.

Pinkney, M., Beachey, E., Kehoe, M., 1989: The thiol-activated toxin streptolysin $\mathrm{O}$ does not require a thiol group for cytolytic activity. Infect. Immun. 57, 2553-2558.

Ramachandran, R., Heuck, A. P., Tweten, R. K., Johnson, A. E., 2002: Structural insights into the membrane-anchoring mechanism of a cholesterol-dependent cytolysin. Nat. Struct. Biol. 9, 823-827.

Ratliff, M., Zhu, W., Deshmukh, R., Wilks, A., Stojiljkovic, I., 2001: Homologues of neisserial heme oxygenase in gram-negative bacteria: degradation of heme by the product of the pigA gene of Pseudomonas aeruginosa. J. Bacteriol. 183, 6394-6403.

Read, T. D., Salzberg, S. L., Pop, M., Shumway, M., Umayam, L., Jiang, L., Holtzapple, E., Busch, J. D., Smith, K. L., Schupp, J. M., Solomon, D., Keim, P., Fraser, C. M., 2002: Comparative genome sequencing for discovery of novel polymorphisms in Bacillus anthracis. Science 296, 2028-2033.

Richaud, C. \& Zabulon, G., 1997: The heme oxygenase gene ( $p b s A)$ in the red alga Rhodella violacea is discontinuous and transcriptionally activated during iron limitation. Proc. Natl. Acad. Sci. U S A 94, 11736-11741. 
Riggs, M. G. \& McLachlan, A., 1986: A simplified screening procedure for large numbers of plasmid minipreparation. Bio Techniques 4, 310-311.

Rood, J. I., 1998: Virulence genes of Clostridium perfringens. Annu. Rev. Microbiol. 52, 333-360.

Rossjohn, J., Feil, S. C., McKinstry, W. J., Tweten, R. K., Parker, M. W., 1997: Structure of a cholesterol-binding, thiol-activated cytolysin and a model of its membrane form. Cell 89, 685-692.

Saier, M. H., 1999: Classification of transmembrane transport systems in living organisms. In Van Winkle, L. (Hrsg.). Biomembrane transport, 265-276. Academic Press, San Diego.

Saitou, N. \& Nei, M., 1987: The neighbour-joining method: a new method for reconstructing phylogenetic trees. Mol. Biol. Evol. 4, 406-425.

Sambrook, J., Fritsch, E. F., Maniatis, T., 1989: Molecular cloning: a laboratory manual. Cold Spring Harbor, New York.

Sandkvist, M., Michel, L. O., Hough, L. P., Morales, V. M., Bagdasarian, M., Koomey, M., DiRita, V. J., Bagdasarian, M., 1997: General secretion pathway (eps) genes required for toxin secretion and outer membrane biogenesis in Vibrio cholerae. J. Bacteriol. 179, 6994-7003.

Sandkvist, M., 2001: Biology of type II secretion. Mol. Microbiol. 40, 271-283.

Sanger, F. S., Nicklen, S., Coulson, A. R., 1977: DNA sequencing with chain terminating inhibitors. Proc. Nat. Acad. Sci. U S A 74, 5463-5467.

Sanger, F. S., Coulson, A. R., Hong, G. F., Hill, D. F., Petersen, G. B., 1982: Nucleotide sequence of bacteriophage Lambda-DNA. J. Mol. Biol. 162, 729-773. 
Sara, M. \& Sleytr, U. B., 2000: S-Layer proteins. J. Bacteriol. 182, 859-868.

Schiavo, G., Benfenati, F., Poulain, B., Rossetto, O., Polverino de Laureto, P., DasGupta, B. R., Montecucco, C., 1992: Tetanus and botulinum-B neurotoxins block neurotransmitter release by proteolytic cleavage of synaptobrevin. Nature 359, 832-835.

Schiavo, G. \& Montecucco, C., 1997: The structure and mode of action of botulinum and tetanus toxin. In Rood, J. I., McClane, B. A., Songer, J. G., Titball, R. W. (Hrsg.). The clostridia; molecular biology and pathogenesis, 295-322. Academic press, San Diego.

Schmehl, M., Jahn, A., Meyer zu Vilsendorf, A., Hennecke, S., Masepohl, B., Schuppler, M., Marxer, M., Oelze, J., Klipp, W., 1993: Identification of a new class of nitrogen fixation genes in Rhodobacter capsulatus: a putative membrane complex involved in electron transport to nitrogenase. Mol. Gen. Genet. 241, 602615.

Schubel, U., Kraut, M., Morsdorf, G., Meyer, O., 1995: Molecular characterization of the gene cluster coxMSL encoding the molybdenum-containing carbon monoxide dehydrogenase of Oligotropha carboxidovorans. J. Bacteriol. 177, 2197-2203.

Schwalb, C., Chapman, S. K., Reid, G. A., 2002: The membrane-bound tetrahaem c-type cytochrome CymA interacts directly with the soluble fumarate reductase in Shewanella. Biochem. Soc. Trans. 30, 658-662.

Shatursky, O., Heuck, A. P., Shepard, L. A., Rossjohn, J., Parker, M. W., Johnson, A. E., Tweten, R. K., 1999: The mechanism of membrane insertion for a cholesterol-dependent cytolysin: a novel paradigm for pore-forming toxins. Cell 99, 293-299. 
Shimizu, T., Ohtani, K., Hirakawa, H., Ohshima, K., Yamashita, A., Shiba, T., Ogasawara, N., Hattori, M., Kuhara, S., Hayashi, H., 2002a: Complete genome sequence of Clostridium perfringens, an anaerobic flesh-eater. Proc. Natl. Acad. Sci. U S A 99, 996-1001.

Shimizu, T., Yaguchi, H., Ohtani, K., Banu, S., Hayashi, H., 2002b: Clostridial VirR/VirS regulon involves a regulatory RNA molecule for expression of toxins. Mol. Microbiol. 43, 257-265.

Shumin, Z. \& Dianliang, L., 2001: Cloning and sequence analysis of tetanus toxin gene. GenBank-Veröffentlichungsnummer: AF389424.

Skulachev, V. P., 1989: The sodium cycle: a novel type of bacterial energetics. J. Bioenerg. Biomembr. 21, 635-647.

Sloan, J., Warner, T. A., Scott, P. T., Bannam, T. L., Berryman, D. I., Rood, J. I., 1992: Construction of a sequenced Clostridium perfringens-Escherichia coli shuttle plasmid. Plasmid 27, 207-219.

Söhling, B. \& Gottschalk, G., 1996: Molecular analysis of the anaerobic succinate degradation pathway in Clostridium kluyveri. J. Bacteriol. 178, 871-880.

Stackebrandt, E. \& Rainey, F. A., 1997: Phylogenetic relationships. In Rood, J. I., McClane, B. A., Songer, J. G., Titball, R. W. (Hrsg.). The clostridia; molecular biology and pathogenesis, 3-19. Academic press, San Diego.

Staden, R., Beal, K. F., Bonfield, J. K., 2000: The Staden package, 1998. Methods Mol. Biol. 132, 115-130.

Steuber, J., 2001: $\mathrm{Na}(+)$ translocation by bacterial NADH:quinone oxidoreductases: an extension to the complex-I family of primary redox pumps. Biochim. Biophys. Acta 1505, 45-56. 
Studier, F. W. \& Moffatt, B. A., 1986: Use of bacteriophage T7 RNA polymerase to direct selective high-level expression of cloned genes. J. Mol. Biol. 189, 113-130.

Sutton, R. B., Fasshauer, D., Jahn, R., Brunger, A. T., 1998: Crystal structure of a SNARE complex involved in synaptic exocytosis at 2.4 A resolution. Nature 395 , 347-353.

Swaminathan, S. \& Eswaramoorthy, S., 2000: Structural analysis of the catalytic and binding sites of Clostridium botulinum neurotoxin B. Nat. Struct. Biol. 7, 693699.

Takami, H., Nakasone, K., Takaki, Y., Maeno, G., Sasaki, R., Masui, N., Fuji, F., Hirama, C., Nakamura, Y., Ogasawara, N., Kuhara, S., Horikoshi, K., 2000: Complete genome sequence of the alkaliphilic bacterium Bacillus halodurans and genomic sequence comparison with Bacillus subtilis. Nucleic Acids Res. 28, 43174331 .

The international polycystic kidney disease consortium, 1995: Polycystic kidney disease: the complete structure of the PKD1 gene and its protein. Cell 81, 289-298.

Tillier, E. R. M., Collins, R. A., 2000: Replication orientation affects the rate and direction of bacterial gene evolution. J. Mol. Evol. 51, 459-463.

Tizzoni, G \& Cattani, G., 1890: Untersuchungen über das Tetanusgift. Arch. exp. Pathol. Pharmakol. 27, 432-450.

Tsuda, H., Yamashita, Y., Shibata, Y., Nakano, Y., Koga, T., 2002: Genes involved in bacitracin resistance in Streptococcus mutans. Antimicrob. Agents Chemother. 46, 3756-3764.

Turner, D. C. \& Stadtman, T. C., 1973: Purification of protein components of the clostridial glycine reductase system and characterization of protein $\mathrm{A}$ as a selenoprotein. Arch. Biochem. Biophys. 154, 366-381. 
Tweten, R. K., 1997: The thiol-activated clostridial toxins. In Rood, J. I., McClane, B. A., Songer, J. G., Titball, R. W. (Hrsg.). The clostridia; molecular biology and pathogenesis, 211-221. Academic press, San Diego.

van Wely, K. H., Swaving, J., Freudl, R. \& Driessen, A. J., 2001: Translocation of proteins across the cell envelope of Gram-positive bacteria. FEMS Microbiol. Rev. 25, 437-454.

Waligora, A. J., Hennequin, C., Mullany, P., Bourlioux, P., Collignon, A., Karjalainen, T., 2001: Characterization of a cell surface protein of Clostridium difficile with adhesive properties. Infect. Immun. 69, 2144-2153.

Wassilak, S. G. F. , Orenstein, W. A., Sutter, R. W., 1999: Tetanus toxoid. In Plotkin, S., Orenstein, W. (Hrsg). Vaccines, 441-474. W. B. Saunders Company, Philadelphia.

Waterman, M. S., 1984 : Efficient sequence alignment algorithms. J. Theor. Biol. 108, 333-337.

Weidner, U., Geier, S., Ptock, A., Friedrich, T., Leif, H., Weiss, H., 1993: The gene locus of the proton-translocating NADH: ubiquinone oxidoreductase in Escherichia coli. Organization of the 14 genes and relationship between the derived proteins and subunits of mitochondrial complex I. J. Mol. Biol. 233, 109-122.

Wenzel, R. \& Herrmann, R., 1996: Cosmid cloning with small genomes. In Birren, B. \& Lai, E. (Hrsg.). Nonmammalian genomic analysis: a practical guide. Academic Press Inc.

WHO (World Health Organisation), 2000: Maternal and neonatal tetanus elimination by 2005. Strategies for achieving and maintaining elimination (http://www.who.int/vaccines/en/tetanus.shtml). Annual Report 2000. 
Wilde, E., Hippe, H., Tosunoglu, N., Schallehn, G., Herwig, K., Gottschalk, G., 1989: Clostridium tetanomorphum sp. nov., nom. rev. Int. J. Syst. Bacteriol. 39, 127134.

Young, G. M., Schmiel, D. H., Miller, V. L., 1999: A new pathway for the secretion of virulence factors by bacteria: the flagellar export apparatus functions as a protein-secretion system. Proc. Natl. Acad. Sci. U S A 96, 6456-6461.

Youngleson, J. S., Jones, D. T., Woods, D. R., 1989: Homology between hydroxybutyryl and hydroxyacyl coenzyme A dehydrogenase enzymes from Clostridium acetobutylicum fermentation and vertebrate fatty-acid $\beta$-oxidation pathways. J. Bacteriol. 171, 6800-6807.

Zhou, Y., Sugiyama, H., Nakano, H., Johnson, E. A., 1995: The genes for the Clostridium botulinum type G toxin complex are on a plasmid. Infect. Immun. 63, 2087-2091.

Zwieb, C. \& Samuelsson, T., 2000 : SRPDB (signal recognition particle database). Nucleic Acids Res. 28, 171-172. 


\section{Danksagungen}

Mein besonderer Dank gilt Herrn Prof. Dr. G. Gottschalk für die Überlassung des Themas, die Ermöglichung zum selbständigen wissenschaftlichen Arbeiten, seine in vielfältiger Weise gewährte Unterstützung und dafür, dass ich an nationalen wie internationalen Tagungen teilnehmen durfte. Insbesondere möchte ich ihm für sein großes Interesse und Engagement für das Clostridium tetani-Genomprojekt danken.

Den ehemaligen und jetzigen Mitgliedern des Göttinger Genomlabors möchte ich für die gute Zusammenarbeit (beim Puzzeln mit Genomsequenzen) danken; vor allem sei dem Sequenzierteam für die hervorragende Arbeit gedankt: Anke Henne (Dankeschön auch für die Korrekturarbeit), Armin Wiezer, Axel Strittmatter, Birgit Veith, Carsten Raasch, Christina (,Kombiniere') Herzberg, Elke Raade, Elzbieta Brzuszkiewicz, Heiko (,ERGO') Liesegang, Iwona Decker (dzi kuje !), Jarek Sobkowiak, Kirsten (,pragmatische Problemlöserin') Hahne, Mechthild Bömecke, Monika Grzywa, Olaf Waase, Olivia Gohl, Rainer Merkl, Ralf Westermann, Rosa Martínez-Arias, Rosalie Bauer, Sebastian Bäumer, Silke Denker, Silke Schlenzeck, Silke Steckel und Thomas Jeffke. Ein besonderes Dankeschön an Florian (,Annotator') Fricke für sein Durchhaltevermögen. Ein großes Dankeschön auch an meine Lehrmeister Andre Johann und Thomas Hartsch, die mich in die Welt der Genomsequenzierung eingearbeitet haben.

Allen weiteren Mitgliedern des Instituts, die mir mit Rat und Tat zur Seite standen und zum Gelingen dieser Arbeit beigetragen haben, sei an dieser Stelle gedankt.

De corazón agradezco a Rosa sus consejos (no solamente phylogenéticos), su simpatía y su apoyo en los días oscuros.

Ein herzliches Dankeschön an die ,Welt da draußen' für viele schöne Erlebnisse und gemeinsame Erkenntnisse; insbesondere an Holger (,Ich-Du-Holongi'), Andrea (,Düsenberg'), Tom und Anne sowie an meine Brüder Jürgen, Andreas und Ingo.

Herzlich danke ich meinem Vater für die in vielerlei Hinsicht geleistete Unterstützung. 


\section{Lebenslauf}

26.12.1972

1979-1985

1985-1992

Mai 1992

September 1992

bis Oktober 1993

Oktober 1993

Oktober 1995

September 1996

bis Juni 1997

März 1998

bis Juni1998

Oktober 1998

Dezember 1998

bis Dezember 1999

März 2000
Geburt in Neuenhaus

Besuch der Grundschule und Orientierungsstufe Neuenhaus

Besuch der KGS Neuenhaus - Schulzweig Gymnasium

Abitur

Zivildienst im Altenwohnzentrum der AWO in Nordhorn

Immatrikulation an der Georg August-Universität zu Göttingen für das Studienfach Biologie (Diplom)

Diplomvorprüfung in den Fächern Mikrobiologie, Zoologie, Chemie und Physikalische Chemie

Erasmus / Sokrates-Studienjahr an der 'School of Biological Sciences' der University of Birmingham, UK. Prüfungsfächer: Bacterial Genetics, Virology, Immunology, Molecular Cell Biology, Environmental Microbiology.

Viermonatiges Industriepraktikum in der Pharmatechnik-Abteilung Mikrobiologie der Bayer AG, Wuppertal; Projekt ,Optimierung der Fermentation und Biotransformation von Gluconobacter oxydans zur Oxidation von Zuckerderivaten im Rahmen der Produktion des Antidiabetikums Miglitol ${ }^{\circledR}$, unter Anleitung von Dr. Schedel

Diplomprüfung in den Fächern Mikrobiologie, Immunologie und Chemie

Experimentelle Diplomarbeit unter Anleitung von Prof. Dr. G. Gottschalk mit dem Titel: ,Vergleichende molekularbiologische Untersuchungen zur $\mathrm{F}_{420} \mathrm{H}_{2}$-Dehydrogenase aus Archaeoglobus fulgidus und Methanosarcina mazei Gö1'

Beginn der Arbeiten zur vorliegenden Dissertation 